\title{
(ब(I)
}

AUTARQUIA ASSOCIADA À UNIVERSIDADE DE SÃO PAULO

\section{AVALIAÇÃO DE PROPRIEDADES MECÂNICAS E CARACTERIZAÇÃO MICROESTRUTURAL DE CONSOLIDADOS DE COBALTO-CROMO-MOLIBDÊNIO OBTIDOS POR FUSÃO SELETIVA A LASER E FUNDIIÇ̃̃O DE PRECISÃO}

MARCELLO VERTAMATTI MERGULHÃO

Dissertação apresentada como parte dos requisitos para obtenção do Grau de Mestre em Ciências na Área de Tecnologia Nuclear - Materiais

Orientador:

Prof. Dr. Maurício David Martins das Neves 
INSTITUTO DE PESQUISAS ENERGÉTICAS E NUCLEARES

Autarquia associada à Universidade de São Paulo

\section{AVALIAÇÃO DE PROPRIEDADES MECÂNICAS E CARACTERIZAÇÃO MICROESTRUTURAL DE CONSOLIDADOS DE COBALTO-CROMO-MOLIBDÊNIO OBTIDOS POR FUSÃO SELETIVA A LASER E FUNDIÇÃO DE PRECISÃO}

MARCELLO VERTAMATTI MERGULHÃO

Dissertação apresentada como parte dos requisitos para obtenção do Grau de Mestre em Ciências na Área de Tecnologia Nuclear - Materiais

Orientador:

Prof. Dr. Maurício David Martins das Neves 
Dedico esta obra à minha noiva, que me mostrou o quão forte podemos ser naquilo que desejamos. 


\section{AGRADECIMENTOS}

Ao maior idealizador e incentivador deste trabalho e de meu desenvolvimento acadêmico, o Prof. Dr. Maurício David Martins das Neves, que me orientou neste caminho da pesquisa científica, com grande dedicação, paciência e energia.

Ao Engo . Eduardo Carlos Podestá e a Leonaia Maria Podestá da empresa HighBond, pelo grande desprendimento, suporte e colaboração envolvidos neste trabalho e na formação de um promissor grupo de pesquisa.

Agradeço também aos Prof. Dr. Waldemar Alfredo Monteiro, Profa. Dra. Dolores Ribeiro Ricci Lazar, Prof. Dr. Walter Ussui, que sempre me deram a maior atenção quando havia alguma dúvida ou discussão a ser feita durante esse projeto.

Agradeço ao Centro de Ciência e Tecnologia de Materiais (CCTM) e ao Laboratório de Metalurgia do Pó do Instituto de Pesquisas Energéticas e Nucleares (IPEN/CNEN-SP) pelo espaço cedido para o desenvolvimento deste projeto. Em especial ao técnico M. Sc. Luis Carlos Elias da Silva, pela assistência, orientação e conversas durante a vivência no laboratório.

Aos Prof. Dr. Marcílio Alves, responsável pelo Grupo de Mecânica dos Sólidos e Impacto em Estruturas (GMSIE) do Departamento de Engenharia Mecatrônica e Mecânica da Escola Politécnica da USP, e aos técnicos Henrique Ramos e Vinícius Moreira Cruz pela disponibilidade e suporte na condução dos ensaios mecânicos realizados neste estudo.

Agradeço em especial, a Profa. Dra. Ana Helena de Almeida Bressiani e o Bolsista Márcio Mendes do Laboratório de Cerâmicas Estruturais e Biomateriais, pelo uso e auxilio na utilização do durômetro Vickers. A Profa. Dra. Marilene Morelli Serna pelas diversas análises de fluorescência de raios $\mathrm{X}$ e ensinamentos de microdureza desenvolvidos neste trabalho. Em especial aos técnicos Mariano Castagnet do Laboratório de Comportamento Mecânico, Olandir V. Correa do Laboratório de Corrosão, Glauson A. Ferreira e Flávia R. O. Silva do Laboratório de Microscopia e Microanálise por toda assistência, ensinamentos e conversas durante esse longo período de trabalho.

Agradeço ao Prof. Dr. Michelangelo Durazzo pelo acesso ao laboratório de caracterização térmica do Centro de Combustível Nuclear (CCN/IPEN). Especialmente aos técnicos Jorge Clementino dos Santos e Felipe Bonito Jaldi Ferrufino pelo suporte, orientação e realização dos ensaios realizados. 
Agradeço ao Amed Belaid e a SLM Solutions pelo auxílio e fornecimento das amostras consolidadas por SLM.

Agradeço a parceria e amizades de mestrado, Igor Martins, Bruno Pizzol e Eurico Pieretti das diversas conversas e discussões de caracterizações e análises de materiais.

Ao Conselho Nacional de Desenvolvimento Científico e Tecnológico (CNPq), pela bolsa de estudos concedida.

À Fundação de Amparo à Pesquisa do Estado de São Paulo (FAPESP) pelo financiamento do projeto envolvido neste mestrado.

A minha família, em especial aos meus irmãos e principalmente a minha mãe, que nunca pouparam tempo, energia e paciência para acompanhar meu desenvolvimento pessoal e acadêmico durante essa longa empreitada.

Em especial à minha noiva Juliana Haruko, pelas diversas vivências que passamos juntos! Por ser essa pessoa maravilhosa, nunca deixando de acreditar, incentivar e motivar o crescimento pessoal, psicológico e emocional. Sua parceria, amizade e amor sempre serão fundamentais em meu crescimento. E pela compreensão em todos os momentos de: "só uma horinha ou no máximo duas". 
"Há momentos em que a maior sabedoria é parecer não saber nada" Sun Tzu 


\section{AVALIAÇÃO DE PROPRIEDADES MECÂNICAS E CARACTERIZAÇÃO MICROESTRUTURAL DE CONSOLIDADOS DE COBALTO-CROMO- MOLIBDÊNIO OBTIDOS POR FUSÃO SELETIVA A LASER E FUNDIÇÃO DE PRECISÃO}

\section{Marcello Vertamatti Mergulhão}

\section{RESUMO}

Este trabalho tem por objetivo estudar as propriedades mecânicas e a caracterização microestrutural de espécimes da liga de Co-Cr-Mo obtidos por manufatura aditiva - fusão seletiva a laser (do inglês Selective Laser Melting - "SLM") e por fundição de precisão, visando a confecção de próteses odontológicas. A partir de pós de Co-Cr-Mo atomizados a gás foram realizadas as seguintes etapas: 1) investigação das propriedades físicas, químicas e térmicas dos pós atomizados em diferentes faixas granulométricas (denominadas: D1 < $15 \mu \mathrm{m}$, D2 de 20-50 $\mu \mathrm{m}$ e D3 > $75 \mu \mathrm{m}$ ); 2) confecção de espécimes, em dimensões padronizadas, por meio das técnicas de consolidação; 3) caracterização dos consolidados por análise de: citotoxicidade, porosidade, difração de raios X e dilatometria; 4) caracterização mecânica de tração, flexão em três pontos, dureza (macro e micro Vickers) e caracterização microestrutural (microscopia óptica e eletrônica de varredura). De modo geral, os resultados obtidos foram: a granulometria D2 $(20-50 \mu \mathrm{m})$ é a que melhor se enquadra nas análises de empacotamento para a consolidação por meio de SLM; a biocompatibilidade das amostras obteve resultado positivo para ambas técnicas de processamento; a avaliação mecânica dos espécimes evidencia que a técnica de fusão seletiva a laser propicia propriedades mecânicas (tensão de escoamento, tensão de ruptura, tensão máxima, alongamento e dureza) superiores as obtidas pela técnica de fundição de precisão; a microestrutura obtida pelo processo SLM é composta por grãos ultrafinos e de elevada homogeneidade química. Conclui-se que, o desenvolvimento do presente estudo evidenciou que na fabricação de componentes odontológicos customizados (coroas) a técnica SLM apresenta qualidade superior quando comparada a fundição de precisão.

Palavras-chave: Biomateriais, Liga de Co-Cr-Mo, Manufatura Aditiva, Fusão Seletiva a Laser, Fundição de Precisão. 


\title{
EVALUATION OF MECHANICAL PROPERTIES AND MICROSTRUCTURAL CHARACTERIZATION OF CONSOLIDATED COBALT-CHROMIUM- MOL YBDENUM OBTAINED BY SELECTIVE LASER MELTING AND PRECISION CASTING
}

\section{Marcello Vertamatti Mergulhão}

\begin{abstract}
The objective of this work was to study the mechanical properties and microstructural characterization of specimens of the Co-Cr-Mo alloy obtained by additive manufacturing selective laser melting (SLM) and precision casting aiming at the manufacture of dental prostheses. The following steps were carried out on Co-Cr-Mo gas-atomized powders: 1) investigation of the physical, chemical and thermal properties of atomized powders in different grain sizes (denominated: D1 $<15 \mu \mathrm{m}$, D2 20-50 $\mu \mathrm{m}$ and D3 $>75 \mu \mathrm{m}$ ); 2) the consolidation of standard specimens via consolidation techniques; 3) characterization of consolidated by analysis of: cytotoxicity, porosity, X ray diffraction and dilatometry; 4) mechanical characterization of tensile, 3 point bending, hardness (macro and micro Vickers) tests and microstructural characterization (optical and scanning electron microscopy). In general, the results observed were: the grain size D2 $(20-50 \mu \mathrm{m})$ is the one that best fits in the analysis of packaging, for the consolidation by SLM; the biocompatibility of the samples obtained a positive result for both processing techniques; the mechanical evaluation of the specimens shows that the SLM technique provides superior mechanical properties (yield stress, rupture stress, maximum stress, elongation and hardness), compared to those obtained by the precision casting technique; the microstructure obtained by the SLM process results in an ultrafine grains with high chemical homogeneity, differentiated by the gross dendritic microstructure in the casting process. In this way, the development of the present study evidenced superior quality in manufacturing customized dental components (copings) by SLM technique compared to precision casting.
\end{abstract}

Keywords: Biomaterials, Co-Cr-Mo alloy, Additive Manufacturing, Selective Laser Melting, Precision Casting. 
1. INTRODUÇÃO..............................................................................................................

2. OBJETIVO......................................................................................................................... 23

2.1. Objetivo geral ............................................................................................................ 23

2.2. Objetivos secundários..............................................................................................23

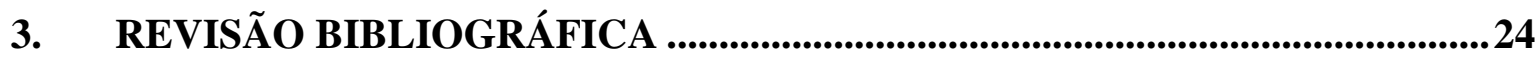

3.1. BIOMATERIAIS METÁLICOS........................................................................25

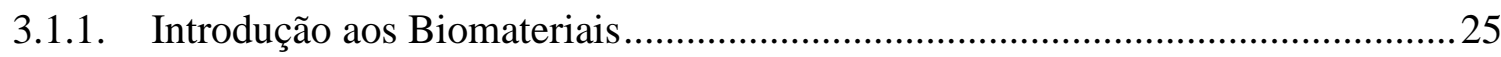

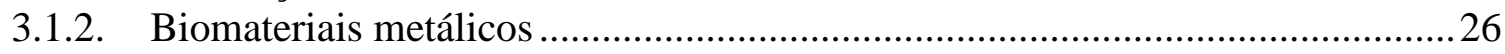

3.2. LIGAS À BASE DE COBALTO ........................................................................28

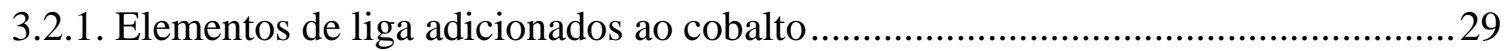

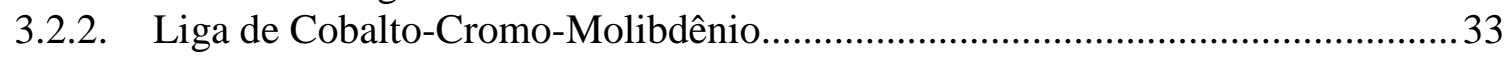

3.2.3. Produção de pós metálicos - atomização ……................................................. 37

3.3. PRÓTESES DENTÁRIAS ............................................................................40

3.3.1. Introdução à confecção de próteses......................................................................40

3.3.2. Componentes dentários .................................................................................. 42

3.3.3. Confecção de próteses dentárias ………………………………………………...4

3.3.3.1. Técnica de fundição de precisão ………………………………………….... 45

3.4. TECNOLOGIA DE MANUFATURA ADITIVA......................................................46

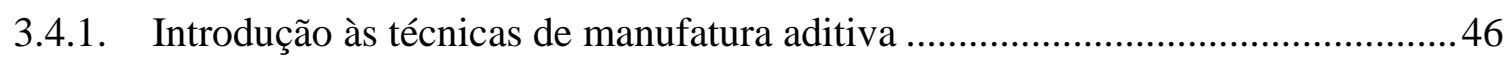

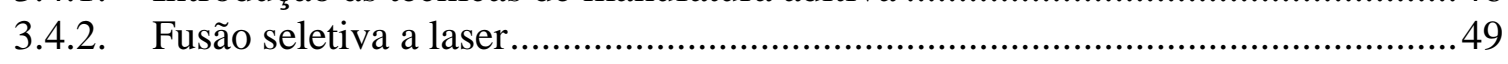

3.4.3. Fusão seletiva a laser e fundição de precisão em ligas de $\mathrm{Co}-\mathrm{Cr}$...........................54

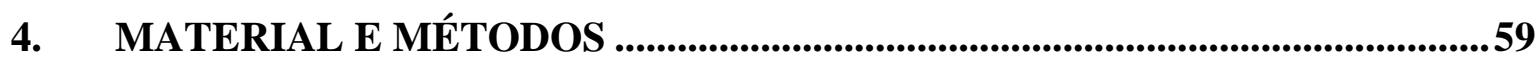

4.1. FLUXOGRAMA ..........................................................................................................59

4.2. MATERIAL UTILIZADO...........................................................................................61

4.3. CARACTERIZAÇÃo FÍSICA E QUÍMICA DOS PÓS.........................................61

4.3.1. Distribuição granulométrica dos pós ..................................................................62

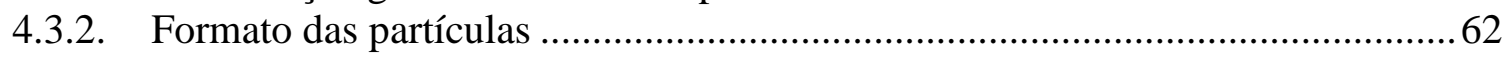

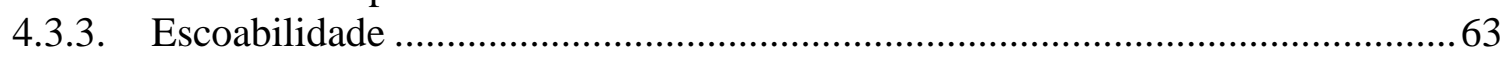

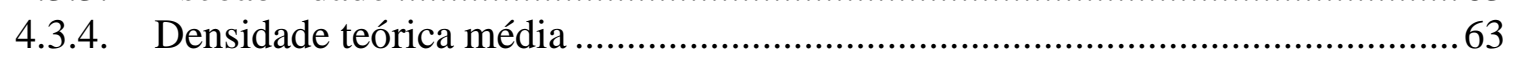

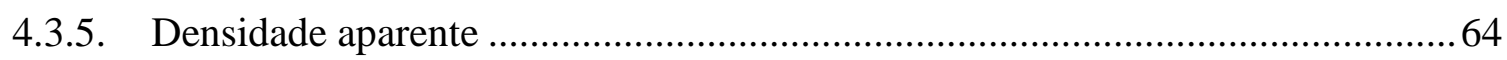

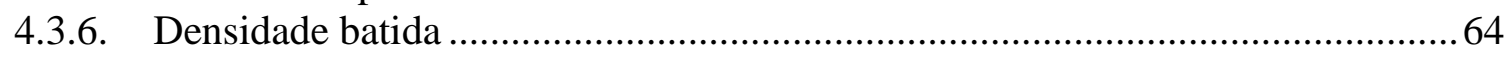

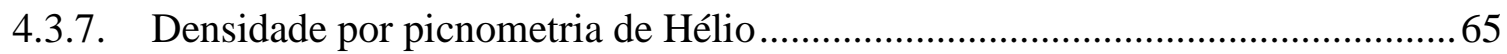

4.3.8. Análise de Calorimetria Exploratória Diferencial (DSC) ......................................65 
4.4. CONSOLIDAÇÃ̃ DAS AMOSTRAS........................................................................66

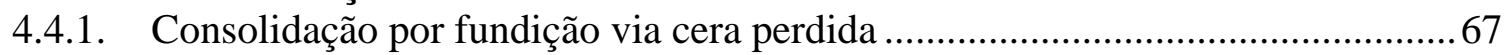

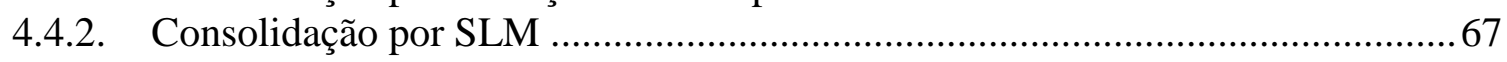

4.5. AVALIAÇÃO DA BIOCOMPATIBILIDADE................................................69

4.6. CARACTERIZAÇÃO MECÂNICA ….....................................................................70

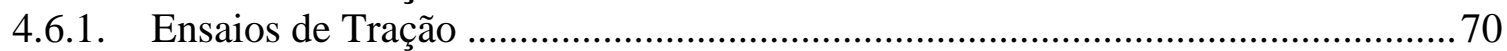

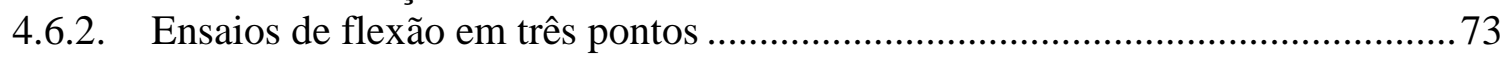

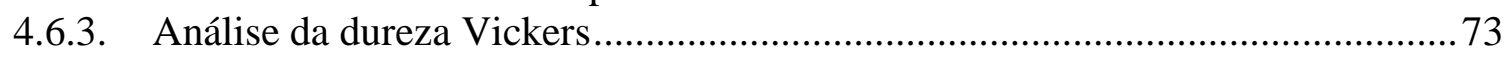

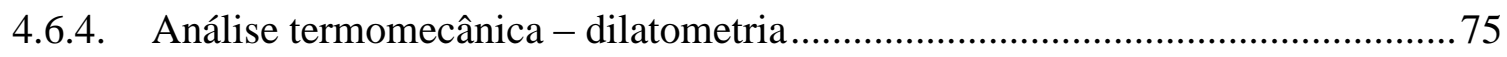

4.7. CARACTERIZAÇÃO MICROESTRUTURAL .................................................76

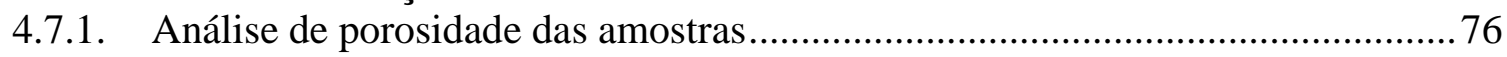

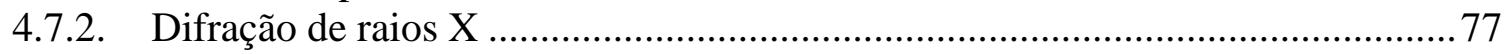

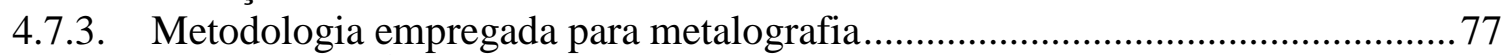

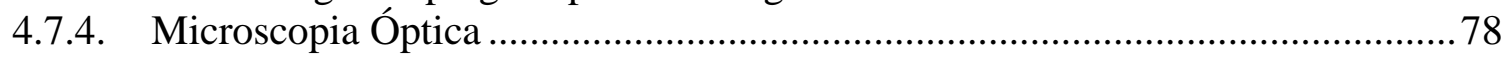

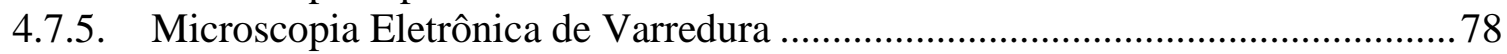

5. RESULTADOS E DISCUSSÃO

5.1. CARACTERIZAÇÃO DO MATERIAL ...............................................................80

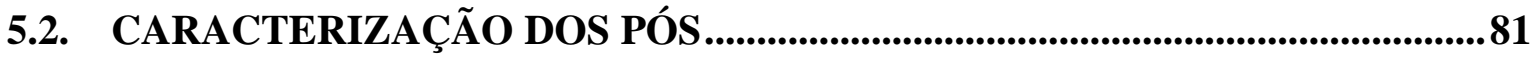

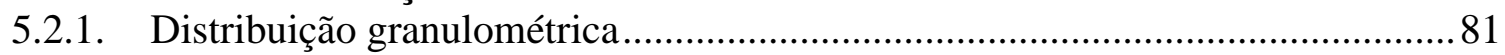

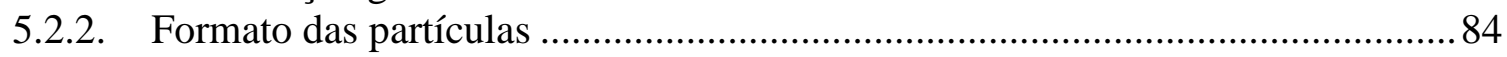

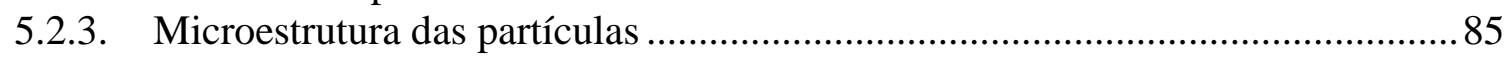

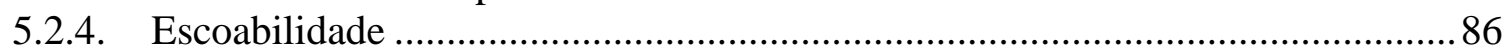

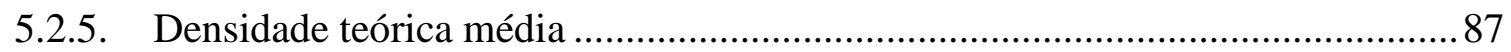

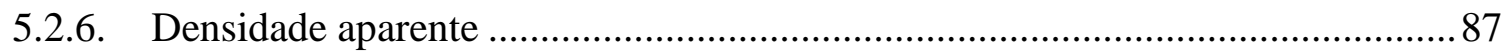

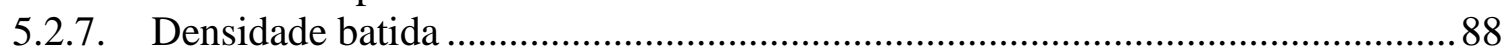

5.2.8. Densidade por picnometria de Hélio ............................................................. 89

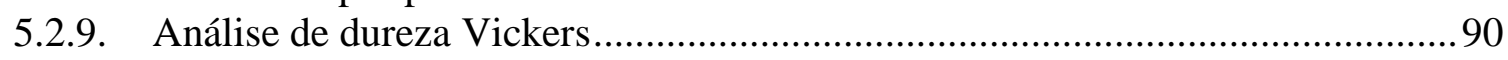

5.2.10. Análise de calorimetria exploratória diferencial (DSC) ................................. 91

5.3. AVALIAÇÃO DA BIOCOMPATIBILIDADE......................................................99

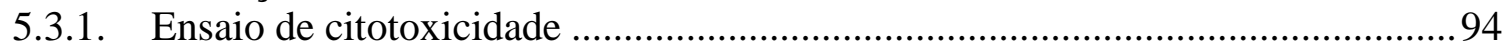

5.4. PROPRIEDADES MECÂNICAS ...........................................................................95

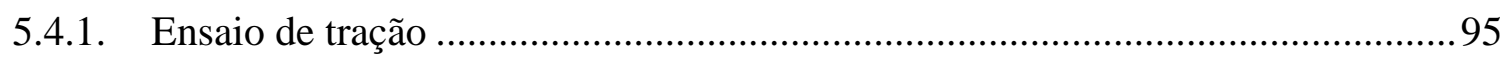

5.4.2. Ensaios de flexão em três pontos ................................................................. 97

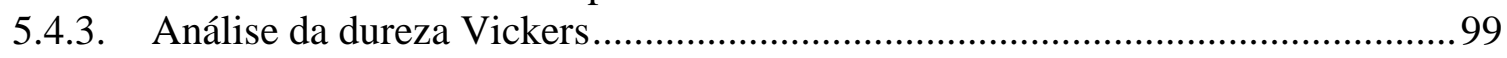

5.4.4. Análise Termomecânica (TMA) - Dilatometria ............................................. 102

5.5. CARACTERIZAÇÃO MICROESTRUTURAL ...........................................106

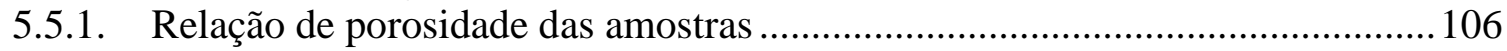

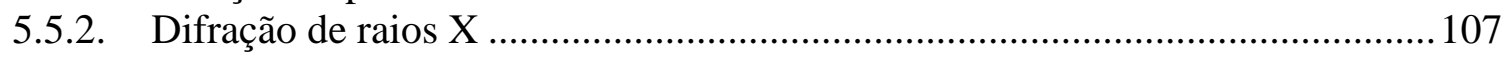

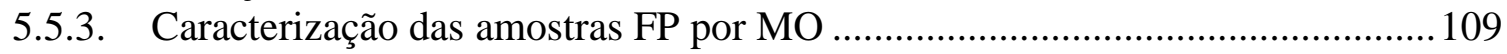

5.5.4. Caracterização das amostras FP por MEV ….................................................. 112

5.5.4.1 Microscopia versus microdureza Vickers da amostra FP.................................. 114

5.5.5. Caracterização das amostras SLM por MO ................................................. 118 
5.5.6. Caracterização das amostras SLM por MEV

5.5.7. Análise de fratura ................................................................................... 124

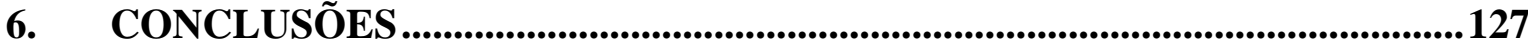

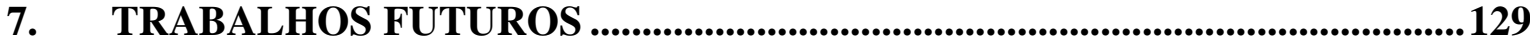

REFERÊNCIAS BIBLIOGRÁFICAS..............................................................................130 


\section{LISTA DE TABELAS}

Tabela 1 - Propriedades mecânicas relevantes para os biomateriais metálicos 26

Tabela 2 - Relação dos materiais metálicos aplicados em implantes e próteses médicas... 27

Tabela 3 - Efeito de adição de elementos de liga em liga a base de cobalto. 30

Tabela 4 - Propriedades mecânicas de ligas Co-Cr utilizadas em implantes cirúrgicos.......32

Tabela 5 - Resultados das propriedades mecânicas obtidas de literatura em ligas de Co-Cr-

Mo consolidada por fundição (F) e SLM.

Tabela 6 - Caracterização dos pós de Co-Cr-Mo em relação a faixa granulométrica recebida.

Tabela 7 - Principais parâmetros do sistema de operação da máquina SLM ${ }^{\circledR} 280^{\mathrm{HL}}$ (SLM Solutions $\left.{ }^{\circledR}\right)$. 68

Tabela 8 - Propriedades mecânicas mínimas requeridas para liga de Co-Cr-Mo consolidada por fundição e materiais metálicos utilizados em próteses odontológicas.

Tabela 9 - Composição química (\% em peso) dos elementos de liga das amostras (pós, FP e SLM) da liga de Co-Cr-Mo por meio de FRX.

Tabela 10 - Composição química (\% em peso) dos elementos residuais das amostras (pós, FP e SLM) da liga de Co-Cr-Mo por meio de LECO®.

Tabela 11 - Resultado da distribuição granulométrica dos pós de Co-Cr-Mo por difração a laser.

Tabela 12 - Resultado das medições do diâmetro médio das partículas de pó D3 por imagens ópticas.

Tabela 13 - Resultado da escoabilidade dos pós de Co-Cr-Mo. 87

Tabela 14 - Representação dos cálculos para obter a densidade teórica média da liga de Co-Cr-Mo com base na composição mássica. .87

Tabela 15 - Resultado da densidade aparente dos pós de Co-Cr-Mo. 87

Tabela 16 - Resultado da densidade batida dos pós de Co-Cr-Mo. 88

Tabela 17 - Resultado da densidade por picnometria de He dos pós da liga Co-Cr-Mo. ... 89

Tabela 18 - Resultado geral das propriedades físicas dos pós de Co-Cr-Mo obtidas

Tabela 19 - Resultados de microdureza Vickers HV 0.1N/10s dos pós de Co-Cr-Mo após polimento de amostras embutidas.

Tabela 20 - Resultados das temperaturas correspondentes aos eventos ocorridos na curva de aquecimento durante a análise DSC para o pó D1 de Co-Cr-Mo. 92 
Tabela 21 - Resultados (valores médios e desvio padrão) das propriedades mecânicas obtidas nas amostras FP e SLM do pó D2 da liga de Co-Cr-Mo, em relação as propriedades mecânicas mínimas requeridas segundo as normas ISO 22674 e ASTM F75.

Tabela 22 - Resultados do ensaio de flexão em três pontos das amostras consolidadas por SLM e FP de Co-Cr-Mo. 98

Tabela 23 - Resultados de dureza Vickers das amostras SLM e FP. 99

Tabela 24 - Resultados das propriedades mecânicas obtidas da liga de Co-Cr-Mo consolidada por FP e SLM, em comparação com os resultados de literaturas. 101

Tabela 25 - Relação do coeficiente de dilatação e dos picos dos eventos nas curvas de aquecimento de TMA das amostras consolidadas por SLM e fundição da liga de CoCr-Mo 103

Tabela 26 - Relação do coeficiente de dilatação e dos picos dos eventos nas curvas de resfriamento de TMA das amostras consolidadas por SLM e fundição da liga de CoCr-Mo 104

Tabela 27 - Resultado da amostragem de densidades média teórica, por picnometria de $\mathrm{He}$ e volumétrica das amostras consolidadas por FP e SLM 107

Tabela 28 - Resultados da microdureza Vickers 100 mN/10s (HV 0.1N/10s) nas fases presentes na amostra fundida. 115 


\section{LISTA DE FIGURAS}

Figura 1 - Organograma da revisão bibliográfica realizada.

Figura 2 - Dureza do Cobalto em função da temperatura. Fonte: Adaptado de (ASM INTERNACIONAL, 2000).

Figura 3 - Microestrutura da liga de Co-Cr-Mo em relação aos processos de fabricação, em

a) fundição de precisão apresentando tamanho de grãos grosseiros e carbonetos largos, b) forjado apresentando grãos finos e c) prensagem isostática a quente apresentando grãos finos e reforços por carbonetos. Fonte: Adaptado de (ASM INTERNATIONAL, 2000).

Figura 4 - Diagrama de equilíbrio do binário Co-Cr. Fonte: Adaptado de (MASSALSKI et al., 1990). 34

Figura 5 - Diagrama de equilíbrio do binário Co-Mo. Fonte: Adaptado de (MASSALSKI et al., 1990). 35

Figura 6 - Diagrama de equilíbrio do binário Cr-Mo. Fonte: Adaptado de (MASSALSKI et al., 1990).

Figura 7 - a) Isoterma à $1300^{\circ} \mathrm{C}$ do sistema ternário de Co-Cr-Mo e b) fases presentes no sistema de uma liga de Co-Cr-Mo. Fonte: Adaptado de (GUPTA, 2005) .36

Figura 8 - Curvas de experimento de DSC e TMA (taxa de aquecimento de $20^{\circ} \mathrm{C} / \mathrm{min}$ ) em liga ASTM F75 produzida por fusão por feixe de elétrons (EBM). Fonte: Adaptado de (FACCHINI, 2010).

Figura 9 - Efeito da taxa de solidificação na distância entre braços dendríticos em liga de alumínio. Fonte: Adaptado de (GESSINGER, 1984). 38

Figura 10 - Esquema do processo de fabricação de pós por atomização a gás, respectivamente por bocais em ângulo (a) e tangencial (b). Fonte: Adaptado de (GESSINGER, 1984).

Figura 11 - a) Formação de braços dendríticos primários e secundários durante a solidificação da partícula e b) estruturas celulares formadas durante a solidificação. 40 Figura 12 - a) Representação da anatomia do dente e seus principais constituintes (NEUPE UFPR, 2016), b) elemento dentário metálico sob revestimento cerâmico (EOS GMBH, 2014) e c) representação dos componentes metálicos de um implante completo de dente (THEMES, 2017). 
Figura 13 - a) Modelo em resina de coroas e pontes dentária confeccionada por MA, para posterior fundição por cera perdida e b) Coroas fabricadas via técnica de fusão seletiva a laser. Fonte: Adaptado de (CRAIG, 2012).

Figura 14 - Etapas envolvidas no processo de fundição pela técnica de precisão via cera perdida. Fonte: Adaptado de (ASM INTERNACIONAL, 2008). 46

Figura 15 - Processo de manufatura orientada por camadas. Fonte: (VOLPATO, 2007)...48

Figura 16 - Esquema básico dos componentes presentes em uma máquina de fusão seletiva a laser. Fonte: Adaptado de (KURZYNOWSKI et al., 2012). 50

Figura 17 - Representação esquemática e variáveis do processo de consolidação da técnica SLM. Fonte: Adaptado de (MEINERS, 2012). 52

Figura 18 - Esquema de deposição de pós em formato esférico e formato irregular. Fonte: (KURZYNOWSKI et al., 2012). 52

Figura 19 - Exemplos de diferentes estratégias de escaneamento para consolidação de amostras, escaneamento em: a) ilha, b) linha e c) linha a $45^{\circ}$. Fonte: Adaptado de (CHENG; SHRESTHA; CHOU, 2016). 53

Figura 20 - a) Representação das amostras SLM orientadas em $0^{\circ}, 45^{\circ}$ e $90^{\circ}$ em relação a plataforma de consolidação e b) representação das orientações de consolidação de amostras por MA. Fonte: Adaptado respectivamente de DADBAKHSH et al., 2016 e ASTM F2971. 54

Figura 21 - Microestrutura típica de amostras fabricadas por fundição de precisão (a) e fusão seletiva a laser (b) de liga de Co-Cr após ataque químico. Fonte: Adaptado de (HAAN et al., 2015).

Figura 22 - Fluxograma da etapa I de caracterização química, física e microestrutural dos pós de Co-Cr-Mo.

Figura 23 - Fluxograma da etapa II de consolidação das amostras por fusão seletiva a laser (SLM) e por fundição de precisão (FP).

Figura 24 - Fluxograma da etapa III de caracterização mecânica e avaliação microestrutural das amostras consolidadas.

Figura 25 - a) Funil de Hall utilizado para medida de densidade aparente e b) recipiente de densidade. Fonte: Adaptado de (ASTM INTERNATIONAL, 2013b).

Figura 26 - a) Exemplo do equipamento de densidade batida e b) tubo graduado utilizado para realização da medida de densidade batida dos pós. Fonte: Adaptado de (ASTM INTERNATIONAL, 2014). 65 
Figura 27 - a) Modelos em cera usinados nas dimensões padronizadas dos corpos de prova de tração e flexão e b) corpos de provas fabricados por FP da liga Co-Cr-Mo.

Figura 28 - a) Esquema de orientação da consolidação SLM das amostras, b) corpos de prova de tração e c) corpos de prova de flexão em três pontos.

Figura 29 - a) e b) Arranjo experimental para ensaio de tração no laboratório GMSIE.....71 Figura 30 - a) Dimensões otimizadas (em milímetros) do corpo de prova de tração FP, com base na norma ISO22674-06 (2006) e b) arranjo do ensaio de tração utilizando dispositivo extensômetro. 72

Figura 31 - a) Arranjo experimental para ensaios de flexão em três pontos no laboratório

GMSIE e b) dispositivo de flexão em três pontos. 73

Figura 32 - Durômetros Vickers, a) Durômetro Buehler série 5100 e b) Microdurômetro

Fischerscope HM2000. 75

Figura 33 - a) Arranjo do sistema de análise de TMA e b) esquema de corte da amostra SLM para análise de TMA .76

Figura 34 - a) Seções de corte da amostra de tração para preparação metalográfica, b) amostras SLM e FP seccionadas e c) amostra final de metalografia. 78

Figura 35 - Imagens de MO da análise de imagens realizadas no pó D3, em a) pó D3 e b) medições realizadas de diâmetro médio das partículas de pó. Aumentos de 200x. .... 82 Figura 36 - Histogramas da distribuição granulométrica das amostras dos pós, em a) pó D1 (diâmetro médio de 12,76 $\mu \mathrm{m}$ ) e b) pó D2 (diâmetro médio de 32,36 $\mu \mathrm{m}$ ). 83

Figura 37 - Imagens de MEV dos pós de Co-Cr-Mo (setas destacam os satélites) em a) pó D1, b) pó D2, c) pó D3. Aumentos de: 250x, 1000x e 4000x. 84

Figura 38 - Imagem do espectrograma por EDS dos pós da liga Co-Cr-Mo 85

Figura 39 - Imagens obtidas por MEV das partículas de pó D2, em a) e b) aumento de 1000x, c) e d) aumento de 2000x. Ataque químico: $\mathrm{HCl}$ e $\mathrm{H}_{2} \mathrm{O}_{2}$ sob temperatura de $40-60^{\circ} \mathrm{C}$. 86

Figura 40 - Partículas dos pós de Co-Cr-Mo, respectivamente D2 e D3 com identação do penetrador Vickers (destacadas pelas setas em branco). Aumentos de 1000x. 90

Figura 41 - Curvas de aquecimento da análise de DSC da amostra de pó D1 de Co-Cr-Mo (taxa de aquecimento: 10, 20 e $30^{\circ} \mathrm{C} / \mathrm{min}$. Atmosfera: argônio). 92

Figura 42 - Curvas de resfriamento da análise de DSC da amostra de pó D1 de Co-Cr-Mo

(taxa de resfriamento: 10, 20 e $30^{\circ} \mathrm{C} / \mathrm{min}$. Atmosfera: argônio). 93

Figura 43 - Gráfico de viabilidade de crescimento celular das amostras consolidadas por FP e SLM da liga de Co-Cr-Mo. 94 
Figura 44 - Curvas de tensão versus deformação de engenharia da liga Co-Cr-Mo consolidada por SLM (Cp SLM) e por fundição de precisão (Cp FP).

Figura 45 - Resultados das propriedades mecânicas da liga de Co-Cr-Mo consolidada por FP e SLM, em a) tensão de limite de escoamento, b) alongamento total, c) módulo de elasticidade, d) tensão limite de resistência e f) tensão limite de ruptura. 96

Figura 46 - Gráfico do resultado de TRS dos ensaios de flexão em três pontos da liga CoCr-Mo consolidada por SLM e FP. 97

Figura 47 - a) Ensaio de flexão em três pontos da amostra FP interrompido devido a escora (apontado pelas setas em vermelho) da amostra com o dispositivo, b) corpo de prova FP após ensaio de TRS interrompido (marcas de escora destacadas pelas setas em vermelho) e c) corpo de prova SLM após fratura. 98

Figura 48 - Gráfico do resultado de dureza Vickers (HV0.5). 99

Figura 49 - Curvas de aquecimento da análise de TMA das amostras consolidadas por fusão seletiva a laser (SLM, em direções distintas de fabricação SLM 1 - na vertical e SLM 2 - na horizontal) e fundição de precisão (FP) (taxa de aquecimento: $10^{\circ} \mathrm{C} / \mathrm{min}$. Atmosfera: argônio). 103

Figura 50 - Curva de resfriamento da análise de TMA das amostras consolidadas por fusão seletiva a laser (SLM, em direções distintas de fabricação SLM 1 - na vertical e SLM 2 - na horizontal) e fundição de precisão (FP) (taxa de resfriamento: $20^{\circ} \mathrm{C} / \mathrm{min}$. Atmosfera: argônio). 104

Figura 51 - Curvas de aquecimento das análises de DSC - amostra de pó D1 e TMA amostras SLM 1, SLM 2 e F (taxa de aquecimento: $10^{\circ} \mathrm{C} / \mathrm{min}$. Atmosfera: argônio). 105

Figura 52 - Diagrama do sistema binário de Co-Cr. Fonte: Adaptado de (SANTOS, 2012). 106

Figura 53 - Difratogramas de raios X das amostras consolidadas por fundição de precisão e fusão seletiva a laser (SLM). 108

Figura 54 - a) Difratograma de raios X da amostra SLM (setas apontam os possíveis picos característicos de carbonetos) e b) difratograma obtido por (BARUCCA et al., 2015), em composição química similar à de estudo (com adição de $4 \%$ tungstênio).

Figura 55 - Imagens de MO da amostra fundida após polimento químico final, a) e b) seção horizontal da amostra, c) e d) seção vertical da amostra. Polimento químico final: 90\% sílica coloidal e 10\% $\mathrm{HCl}$. Aumentos de respectivamente: 50x e 100x. 110 
Figura 56 - Imagens de MO da amostra fundida após ataque químico, a) e b) seção horizontal da amostra, c) e d) seção vertical da amostra. Aumentos de respectivamente: 50x e 100x. Ataque químico: $\mathrm{HCl}$ e $\mathrm{H}_{2} \mathrm{O}_{2}$.

Figura 57 - Imagens de MO da amostra fundida após ataque químico, a) evidenciando a fase clara e fase escura (aumento de 100x), b) evidenciado em branco as regiões de fases intermediárias e c) evidenciando em branco a região da fase escura (aumentos de 1000x). Ataque químico: $\mathrm{HCl}$ e $\mathrm{H}_{2} \mathrm{O}_{2}$ 112

Figura 58 - Imagens de MEV por elétrons retroespalhados da amostra fundida: a) espécime sem ataque químico (setas indicam porosidade), b) espécime sem ataque químico (retângulos indicam a presença de fases distintas), c) e d) espécime com ataque químico (o círculo indica a formação de pitting e os retângulos indicam a presença de fases distintas - carboneto e matriz). Ataque químico: $\mathrm{HCl} \mathrm{e} \mathrm{H}_{2} \mathrm{O}_{2}$. 113

Figura 59 - Espectrogramas da amostra fundida das regiões selecionadas (as cores representam as áreas de análise) em a) espécime sem ataque químico (aumento de 1000x) e b) espécime com ataque químico (aumento de 1000x). 114

Figura 60 - Imagem das identações de microdureza na amostra FP (seção horizontal), respectivamente nas regiões a) fase clara, b) fase intermediária - carboneto e c) fase escura. Aumentos de 1000x. Ataque químico: $\mathrm{HCl}$ e $\mathrm{H}_{2} \mathrm{O}_{2}$.

Figura 61 - Representação da microdureza média das regiões da amostra FP. 116

Figura 62 - Imagens de MEV por BSE e respectivos espectrogramas, em a) análise da região da fase 1 - fase clara e b) análise da região da fase 3 - fase escura. Aumentos de 3000x. Ataque químico: $\mathrm{HCl}$ e $\mathrm{H}_{2} \mathrm{O}_{2}$.

Figura 63 - Imagens de MEV por BSE das análises realizadas na região da fase 2 - fase intermediária e respectivos espectrogramas, a) análise pontual e b) análise em linha. Aumentos de 3000x. Ataque químico: $\mathrm{HCl} \mathrm{e} \mathrm{H}_{2} \mathrm{O}_{2}$.

Figura 64 - Imagens de MO da amostra SLM após polimento químico final, a) e b) seção horizontal da amostra (aumentos de respectivamente 50x e 100x), c) e d) seção vertical da amostra (aumentos de respectivamente 50x e 100x). Polimento químico final: $90 \%$ sílica coloidal e $10 \% \mathrm{HCl}$

Figura 65 - Imagens de MO da amostra SLM após ataque químico, a) e b) seção horizontal (aumentos de respectivamente 100x e 200x), c) e d) seção vertical - sentido de consolidação destacado pela seta preta (aumentos de respectivamente 100x e 200x). Ataque químico: $\mathrm{HCl}$ e $\mathrm{H}_{2} \mathrm{O}_{2}$. 
Figura 66 - Análise das imagens de MO da amostra SLM, em a) seção horizontal e b) seção vertical. Aumentos de respectivamente 200x e 500x. Ataque químico: $\mathrm{HCl}$ e $\mathrm{H}_{2} \mathrm{O}_{2}$

Figura 67 - Imagens de MEV da amostra SLM após ataque químico, a) e b) imagens por elétrons secundários (SE) da seção horizontal (aumentos de respectivamente 1000x e 4000x), c) e d) imagens por elétrons retroespalhados (BSE) da seção vertical - seta preta no sentido de consolidação (aumentos de respectivamente 1000x e 4000x). Ataque químico: $\mathrm{HCl}$ e $\mathrm{H}_{2} \mathrm{O}_{2}$ 121

Figura 68 - Espectrogramas da amostra SLM em a) ponto claro e b) ponto escuro 122

Figura 69 - Imagens obtidas por meio do MEV-FEG das amostras SLM, em a) seção horizontal a partir de elétrons retroespalhados e b) a partir de elétrons secundários, c) e d) seção vertical a partir de elétrons retroespalhados (seta preta indica o sentido de consolidação). Ataque químico: $\mathrm{HCl}$ e $\mathrm{H}_{2} \mathrm{O}_{2}$ 123

Figura 70 - Representação da fratura das amostras consolidadas, em a) amostra FP e b) amostra SLM

Figura 71 - Imagens de MEV das fraturas dos corpos de prova de tração, em a) e b) regiões da fratura da amostra FP, c) e d) regiões da fratura da amostra SLM. Aumentos de 500x.

Figura 72 - Imagens de MEV das fraturas dos corpos de prova de tração, em a) e b) regiões da fratura da amostra FP (aumentos de 2000x), c) e d) regiões da fratura da amostra SLM (aumentos de respectivamente 2000x e 4000x) 126 


\section{LISTA DE ABREVIATURAS E SIGLAS}

\section{ANVISA Agência Nacional de Vigilância Sanitária}

ASTM Sociedade Americana de Ensaios de Materiais (do inglês American Society for Testing and Materials)

BSE Detector de elétrons retroespalhados (do inglês backscattering electron)

CAD Desenho assistido por computador (do inglês computer-aided design)

CAM Manufatura assistida por computador (do inglês computer-aided manufacturing)

CET Coeficiente de expansão térmico

CFC Cúbica de face centrada

CNC Comando numérico computadorizado (do inglês computer numeric control)

DSC Calorimetria exploratória diferencial (do inglês differential scanning calorimetry)

DRX Difração por raios $\mathrm{X}$

EDS Espectroscopia de raios X por energia dispersiva (do inglês energy dispersive spectroscopy)

FP Fundição de precisão

HC Hexagonal compacta

ISO Organização Internacional de Normalização (do inglês International Organization for Standardization)

MA Manufatura aditiva

MEV Microscopia eletrônica de varredura

MO Microscopia óptica

PR Prototipagem rápida

RPD Próteses parciais removíveis (do inglês Removable partial dentures)

SE Detector de elétrons secundários (do inglês secondary electron)

SLM Fusão seletiva a laser (do inglês Selective Laser Melting - SLM)

TMA Análise termomecânica (do inglês thermomechanical analysis)

3D Três dimensões (do inglês three-dimension) 


\section{LISTA DE SÍMBOLOS}

\section{Simbologia latina}

$\begin{array}{lll}\text { A }_{t} & \text { Alongamento total } & \text { adimensional } \\ \mathrm{P} & \text { Carga aplicada } & \mathrm{N} \\ L & \text { Distância entre apoios } & \mathrm{m} \\ t & \text { Espessura do corpo de prova } & \mathrm{m} \\ w & \text { Largura do corpo de prova } & \mathrm{m} \\ \mathrm{E} & \text { Módulo de elasticidade ou módulo de Young } & \mathrm{Pa} \\ \mathrm{V} & \text { Volume } & \mathrm{m}^{3} \\ \mathrm{RA} & \text { Redução de área } & \text { adimensional } \\ \text { TRS } & \text { Resistência à ruptura transversal (do inglês Transverse } & \mathrm{Pa}\end{array}$

Simbologia grega

$\begin{array}{lll}\varepsilon & \text { Deformação mecânica de engenharia } & \text { adimensional } \\ \rho & \text { Densidade } & \mathrm{kg} / \mathrm{m}^{3} \\ \sigma & \text { Tensão normal de engenharia } & \mathrm{Pa} \\ \sigma_{\mathrm{LE}} & \text { Tensão limite de escoamento } & \mathrm{Pa} \\ \sigma_{\mathrm{f}} & \text { Tensão limite de ruptura } & \mathrm{Pa} \\ \sigma_{\mathrm{LR}} & \text { Tensão limite de resistência } & \mathrm{Pa} \\ \alpha & \text { Coeficiente de dilatação ou coeficiente de expansão térmica } & \mathrm{K}^{-1}\end{array}$




\section{INTRODUÇÃ̃O}

O estudo de biomateriais representa um campo vasto, fértil e em constante transformação. O desenvolvimento na área de biomateriais auxilia na aplicação de tecnologias, materiais e processamentos que ampliam a vida útil dos componentes e a qualidade de vida dos seres humanos. O uso de implantes e próteses tem aumentado, não só em quantidade, mas, principalmente em qualidade, priorizando características como: durabilidade (maior tempo de uso sem a necessidade de troca ou outros tipos de procedimentos cirúrgicos) e adaptação ao uso (diminuindo o risco de rejeições, por exemplo), essenciais no desenvolvimento de tecnologias utilizadas na medicina em seres humanos.

A liga de Cobalto-Cromo (Stellite) começou a ser utilizada nos setores da indústria automobilística, aeronáutica e aeroespacial por suas propriedades mecânicas, relacionadas à alta resistência ao desgaste e a adequada resistência à corrosão. Em 1930, em razão de suas propriedades mecânicas e principalmente da biocompatibilidade, iniciouse a utilização de ligas de $\mathrm{Co}-\mathrm{Cr}$ na fabricação de próteses e implantes médicos e odontológicas (NIINOMI; NARUSHIMA; NAKAI, 2015; NARUSHIMA et al., 2013).

Avanços vêm ocorrendo na área de processamento utilizando as técnicas de metalurgia do pó, tornando estas tecnologias competitivas em relação aos processos tradicionais de fabricação, notadamente na área da saúde. Dentre as diversas técnicas convencionais utilizadas na confecção de próteses dentárias, o método mais utilizado, é o de fundição de precisão (cera perdida). O desenvolvimento de técnicas de manufatura aditiva (MA) têm se destacado quando comparadas aos métodos convencionais (fundição, conformação e usinagem por exemplo) (MISCH, 2015; NIINOMI; NARUSHIMA; NAKAI, 2015; VAN NOORT, 2012).

Neste contexto, as tecnologias de MA, comumente citadas pelo termo “impressão 3D" (do inglês 3DP - Three Dimension Printing) se destacam entre as técnicas de fabricação em metais, cerâmicas e polímeros. Estas tecnologias utilizam sistemas de criação de imagem digital por meio de sistemas CAD (do inglês Computer Aided-Design), promovendo desde o design até a confecção de protótipos (ou mesmo componentes de geometria final customizada) (CRAIG, 2012; VAN NOORT, 2012). O desenvolvimento de novas tecnologias na produção por MA de componentes metálicos utilizando feixe laser de 
alta potência é conhecida pelo termo em inglês SLM - Selective Laser Melting. Segundo Van Noort (2012), a tecnologia SLM é promissora, pois possibilita a confecção de componentes finais customizados e de elevadas propriedades mecânicas quando comparados as técnicas convencionais de fabricação.

As análises do desempenho dos componentes fabricados por técnicas de MA são de fundamental importância, pois se relacionam com aspectos de qualidades de: obtenção de matéria prima de maior qualidade, redução de desperdício, maior rendimento produtivo e maior aproveitamento da matéria prima em relação as técnicas convencionais (por exemplo a fundição de precisão). Representando um assunto de grande relevância nas áreas científica e industrial, sendo necessários estudos para avaliar seu desempenho e a viabilidade de fabricação.

Tendo em vista esse importante campo em expansão, o presente trabalho vem compor este cenário com enfoque no setor médico/odontológico, especificamente na produção de próteses dentárias - coroas (copings). Para tanto, a partir de pós metálicos (atomizados a gás) da liga Co-Cr-Mo foram consolidados espécimes padronizados por meio das técnicas de fusão seletiva a laser (SLM) e pela técnica convencional de fundição de precisão (FP). O estudo viabiliza o conhecimento desta tecnologia inovadora, por meio da avaliação das propriedades mecânicas e caracterização microestrutural da liga de CoCr-Mo, relacionando com as características específicas de desempenho da área da saúde. 


\section{OBJETIVO}

\subsection{Objetivo geral}

O objetivo geral deste trabalho é estudar as propriedades mecânicas e avaliar a microestrutura de amostras consolidadas pela técnica de fusão seletiva a laser, a partir de pós da liga de Co-Cr-Mo. E comparar com as propriedades mecânicas e microestruturais obtidas em amostras confeccionadas por fundição de precisão.

\subsection{Objetivos secundários}

- Caracterizar a matéria prima (pó atomizado a gás de Co-Cr-Mo) recebido em três faixas granulométricas, em relação à: composição química, física e microestrutura.

- Consolidar espécimes em SLM utilizando a granulometria de pó mais adequado ao processo, em termos de escoabilidade e empacotamento.

- Avaliar os processos de fabricação, por meio de espécimes padronizados, em relação à: composição química, biocompatibilidade, mecânicas (testes de tração, flexão em três pontos, dureza macro e micro Vickers e dilatometria) e caracterização microestrutural (análise de porosidade, DRX, MO e MEV).

- Avaliar a utilização da tecnologia SLM na fabricação de próteses dentárias. 


\section{REVISÃO BIBLIOGRÁFICA}

Neste capítulo é apresentada a revisão bibliográfica cujo organograma está apresentado na Figura 1. A revisão está dividida em quatro seções principais: biomateriais metálicos, ligas à base de cobalto, próteses dentárias e tecnologia de manufatura aditiva.

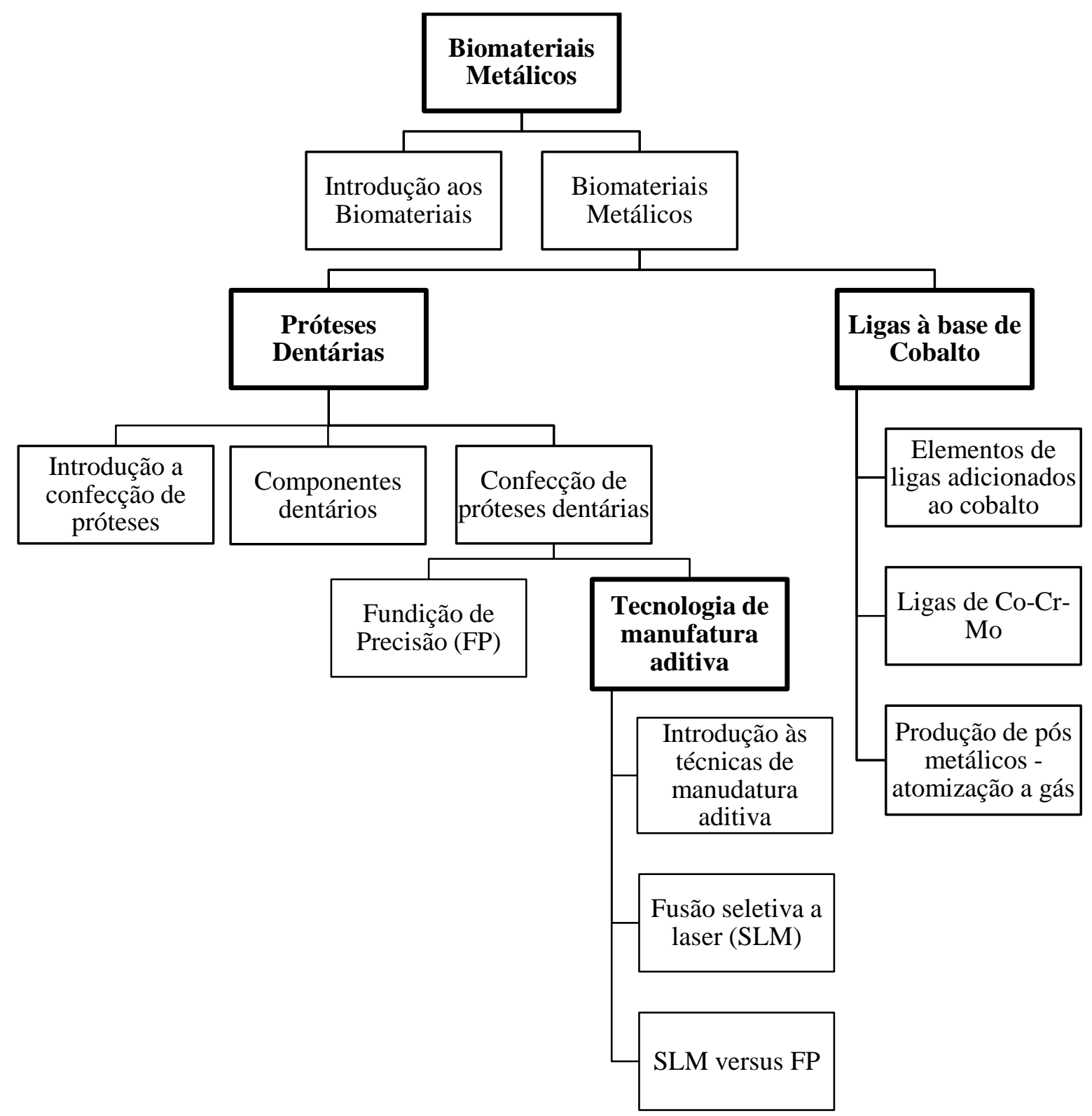

Figura 1 - Organograma da revisão bibliográfica realizada. 


\subsection{BIOMATERIAIS METÁLICOS}

\subsubsection{Introdução aos Biomateriais}

O uso de biomateriais aplicados em implantes visando a substituição ou reparação de componentes ósseos do corpo humano cresce de 5 a $15 \%$ a cada ano. Segundo Oréfice et al. (2006) apenas nos Estados Unidos o uso de pinos, placas e parafusos para fixação de fraturas atingiu 1,5 milhão de casos clínicos, evidenciando um campo de estudos fértil e em crescente expansão.

Segundo dados reportados por Kurtz (2007) é estimado que até o final de 2030, o número de próteses voltada a substituições totais do quadril deve aumentar em $174 \%$ (572.000 procedimentos) e para artoplastias total de joelho é projetado crescer em $673 \%$ a partir da taxa atual (3,48 milhões de procedimentos).

Na década de 1960, o termo biocompatibilidade começou a ser usado para designar um biomaterial que estivesse em contato ou em interação com os tecidos e fluidos do corpo humano (VAN NOORT, 2012). Desde então, a ciência dos materiais representa um tema de destaque na área médica. De acordo com a norma ISO10993-1 de 1997, o termo biomaterial é definido como um “...material sintético, natural ou natural modificado, destinado a estar em contato e interagir com o sistema biológico.”. Segundo Williams (2008) definições mais precisas do termo biocompatibilidade, incluem que o material não seja: tóxico, alérgico, carcinogênico, mutagênico e influente na fertilidade de um dado paciente.

Para que um material possa ser caracterizado como biocompatível, sua interação não pode ser afetada, tanto em relação ao meio biológico contra o material, quanto em relação ao material contra o meio biológico (IVANOVA; BAZAKA; CRAWFORD, 2014; VAN NOORT, 2012).

A necessidade de caracterizações e avaliações biológicas, físico-químicas e mecânicas são requisitos básicos para o desenvolvimento de novos biomateriais aplicados em dispositivos médicos. De modo geral, os biomateriais devem apresentar eficácia na aplicação clínica final (denominada biofuncionalidade) e biocompatibilidade (BORELLI, 2011; WILLIAMS, 2008). 


\subsubsection{Biomateriais metálicos}

Os biomateriais metálicos são amplamente utilizados na área da saúde, e em diferentes tipos de aplicações, em razão das principais características ligadas a biocompatibilidade, como: resistência a corrosão, ao desgaste e propriedades mecânicas (fadiga). É de grande importância que estes componentes de materiais metálicos (implantes) tenham características físicas similares aos componentes de substituição, como os tecidos ósseos e articulações. Adicionalmente, também devem portar capacidade de facilitar a regeneração, crescimento e reparo de tecidos ósseos.

Os biomateriais metálicos comumente utilizados na fabricação de implantes e próteses médicas e odontológicas estão ramificados em três classes principais, as quais correspondem as ligas de: aços inoxidáveis, cobalto-cromo e titânio (Ti). As principais propriedades mecânicas das ligas utilizadas em biomateriais podem ser conferidas na Tabela 1 em relação as propriedades mecânicas do osso cortical.

Tabela 1 - Propriedades mecânicas relevantes para os biomateriais metálicos.

\begin{tabular}{cccc} 
Materiais & $\mathbf{E}(\mathbf{G P a})$ & $\boldsymbol{\sigma L E}(\mathbf{M P a})$ & $\boldsymbol{\sigma L R}(\mathbf{M P a})$ \\
\hline Aço inoxidável & 190 & $221-1213$ & $586-1351$ \\
\hline Ligas de Co-Cr & $210-253$ & $448-1606$ & $655-1896$ \\
\hline Titânio & 110 & 485 & 760 \\
\hline Ti-6Al-4V & 116 & $896-1034$ & $965-1103$ \\
\hline Osso cortical & $15-30$ & $30-70$ & $70-150$ \\
\hline
\end{tabular}

Fonte: Adaptado de (BARTOLO et al., 2012; RATNER et al., 2004).

As ligas de aços inoxidáveis, principalmente os austeníticos do tipo 316L (ASTM F138) são amplamente utilizadas em virtude de seu baixo custo. As ligas de Co-Cr usuais são Co-Cr-Mo, Co-Cr-W e Co-Ni-Cr-Mo (BARTOLO et al., 2012; ORÉFICE; PEREIRA; MANSUR, 2006; SINGH; RAMAKRISHNA; SINGH, 2017). Estas possuem melhores propriedades físicas em relação a liga 316L, devido à boa resistência ao desgaste, corrosão e fadiga.

As ligas de $\mathrm{Ti}$ e $\mathrm{Ti}$ puro representam o principal grupo de biomateriais metálicos, por apresentar: baixo módulo de elasticidade, alta resistência à corrosão e à fadiga, porém apresentam baixa resistência ao desgaste. Estudos apontam que os elementos de alumínio e vanádio apresentam certa toxicidade ao organismo, respectivamente podendo aumentar a incidência do mal de Alzheimer, e irritar o sistema respiratório, comprometendo seu funcionamento (ORÉFICE; PEREIRA; MANSUR, 2006). Tendo em 
vista esta característica, o desenvolvimento da liga de Ti substituiu o vanádio (V) pelo nióbio $(\mathrm{Nb})$ que é um metal inerte, resultando na liga Ti-6Al-7Nb. De forma alternativa utiliza-se ligas de Ti com fase $\beta$-metaestável, fase a qual o alumínio não está presente (BARTOLO et al., 2012; ORÉFICE; PEREIRA; MANSUR, 2006; SINGH; RAMAKRISHNA; SINGH, 2017).

O uso de biomateriais metálicos pode ser encontrado em uma ampla gama de utilizações, seja em componentes médicos e odontológicos. Algumas das principais aplicações dos biomateriais metálicos são apresentadas na Tabela 2.

Tabela 2 - Relação dos materiais metálicos aplicados em implantes e próteses médicas.

\begin{tabular}{|c|c|}
\hline Materiais & Aplicações \\
\hline Aço inoxidável & $\begin{array}{l}\text { Dispositivos temporários (placas de fratura, parafusos, } \\
\text { pregos de quadril e joelho) } \\
\text { Substituições total de quadril e joelho } \\
\text { Válvulas cardíacas e stents }\end{array}$ \\
\hline $\begin{array}{l}\text { Ligas à base de } \\
\text { Cobalto }\end{array}$ & $\begin{array}{l}\text { Substituições total de quadril e joelho (ligas forjadas) } \\
\text { Componentes e implantes dentários (fundidos) } \\
\text { Válvulas cardíacas e stents }\end{array}$ \\
\hline $\begin{array}{l}\text { Ligas à base de } \\
\text { Titânio }\end{array}$ & $\begin{array}{l}\text { Haste femoral e acetábulo (substituição total de quadril com } \\
\text { cabeça femorais de Co-Cr-Mo ou cerâmicas). } \\
\text { Outros dispositivos permanentes (parafusos, marca passos) } \\
\text { Implantes dentários para fixação de dentes }\end{array}$ \\
\hline
\end{tabular}

Fonte: Adaptado de (CHEN; THOUAS, 2015; RATNER et al., 2004)

Na utilização de implantes metálicos, a principal propriedade mecânica de interesse é o módulo de elasticidade "E". A consequência entre a elevada diferença da rigidez do implante e do tecido ósseo (indicada na Tabela 1) é o processo de descalcificação (também conhecido como "stress shielding”), que pode acarretar na soltura ou até mesmo a fratura do implante ou do osso.

Em algumas aplicações são usados biomateriais com maior módulo de elasticidade, como as ligas de Co-Cr utilizadas na fabricação de componentes na área da saúde, como: próteses de quadril, joelho, fixadores de ossos fraturados (placas, parafusos, grampos e pinos), estruturas de suporte de válvulas cardíacas e implantes dentários (ASM, 2000). Dependendo do tipo de aplicação do componente, o módulo de elasticidade deve apresentar determinado valor. Segundo a norma ISO 22674, no caso de aplicações de próteses dentárias fixas ou removíveis (coroas, pontes entre outros), o módulo de elasticidade mínimo é de $150 \mathrm{GPa}$ (ISO, 2006). Na literatura são abordadas aplicações da liga de Co-Cr-Mo com módulo de elasticidade acima de $200 \mathrm{GPa}$, em componentes que 
não são exclusivos da área odontológica (HEDBERG et al., 2014; KAJIMA et al., 2016; YOSHINARI; UZAWA; KOMIYAMA, 2016), como em endopróteses de joelho (LIVERANI et al., 2016).

Visto que as ligas metálicas apresentam alto módulo de elasticidade, dificultando o uso em casos a longo prazo, o desenvolvimento de novas ligas, processamentos de fabricação e pós-tratamentos (térmicos e superficiais) envolvidos na fabricação de implantes e próteses é de grande relevância (BARTOLO et al., 2012; SINGH; RAMAKRISHNA; SINGH, 2017).

\subsection{LIGAS À BASE DE COBALTO}

Em razão do sucesso da aplicação das ligas de cobalto, em virtude a elevada resistência à fluência em longos períodos, estabilidade em temperaturas elevadas combinadas com a sua excelente resistência à corrosão em ambientes agressivos durante o serviço foram nomeadas de superligas (ASM INTERNACIONAL, 2000; GEDDES; LEON; HUANG, 2010; GESSINGER, 1984).

As ligas à base de cobalto desempenharam grande importância no início do desenvolvimento das superligas, sendo que estas apresentavam algumas vantagens em relação as superligas à base de níquel. A grande vantagem é possuir resistência a corrosão e boa estabilidade estrutural em elevadas temperaturas. Esta característica mecânica é associada pela matriz do cobalto possuir uma estabilidade estrutural inferior comparada com a do níquel, a qual é introduzida pela presença de estabilidade por parte do precipitado coerente $\gamma^{\prime}$ (GESSINGER, 1984).

O cobalto é um material que apresenta uma transformação alotrópica do seu estado estável de estrutura cristalina hexagonal compacta (cobalto $\mathcal{E}$ - HC) para a estrutura cúbica de face centrada (cobalto $\alpha-\mathrm{CFC}$ ), à temperatura de $422^{\circ} \mathrm{C}$, (ASM INTERNACIONAL, 2000; GESSINGER, 1984). Na Figura 2 é possível observar o comportamento da dureza do cobalto em relação à temperatura. A região em que o processo de difusão da transformação martensítica para a austenítica ocorre a aproximadamente na faixa de 388 a $431^{\circ} \mathrm{C}$. No entanto, verifica-se que a dureza do cobalto começa a decrescer em aproximadamente a temperatura de $350^{\circ} \mathrm{C}$ (ASM INTERNACIONAL, 2000; NISHIZAWA; ISHIDA, 1983). 
Segundo Nishizawa e Ishida (1983) a transformação alotrópica está associada com o relevo de superfície devido ao cisalhamento de transformação e a histerese de aproximadamente $40^{\circ} \mathrm{C}$ entre aquecimento e resfriamento, o que indica que a mudança de fase é martensítica. A temperatura de transformação e a histerese dependem do teor de impurezas, história térmica, tamanho de grão, número e tipos de imperfeições (NISHIZAWA; ISHIDA, 1983).

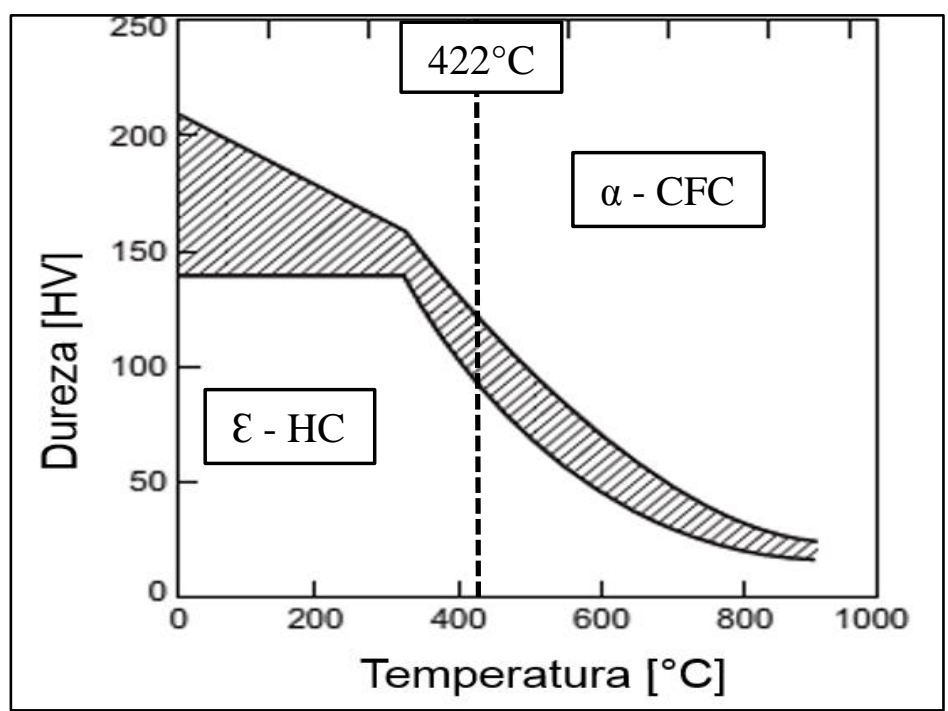

Figura 2 - Dureza do Cobalto em função da temperatura. Fonte: Adaptado de (ASM INTERNACIONAL, 2000).

\subsubsection{Elementos de liga adicionados ao cobalto}

Alguns elementos de liga, tais como, níquel, cromo, tungstênio, titânio, zircônio, nióbio, tântalo e carbono podem ser adicionados nas ligas à base de cobalto. Convencionalmente, essas ligas são formadas por três grupos, de acordo com concentração de carbono presente, que são as ligas de: alto-carbono (high-carbon) designadas a trabalho em desgaste; baixo-carbono (low-carbon) designadas a trabalho em altas temperaturas, e baixo-carbono designadas a trabalho em corrosão ou simultaneamente em desgaste e corrosão (ASM INTERNACIONAL, 2000; GESSINGER, 1984).

Em ligas à base de cobalto, este elemento é a matriz e os efeitos de solução sólida de reforço são provenientes dos elementos de liga de cromo $(\mathrm{Cr})$, tungstênio $(\mathrm{W})$ e molibdênio (Mo), os quais são responsáveis por formação de carbonetos metálicos, que incrementam a dureza, a tensão e a resistência a corrosão. A adição desses elementos de liga propicia a estabilização da estrutura hexagonal, porém como esta transformação é extremamente lenta, geralmente ligas à base de cobalto exibem uma estrutura metaestável 
CFC a temperatura ambiente (ASM INTERNACIONAL, 2000). Diagramas ternários derivados do sistema binário de Co-Cr, como Co-Cr-W e Co-Cr-Mo foram investigados primeiramente por Haynes em 1907, descobrindo-se que o aumento da tensão se dava pela a adição dos elementos de W e Mo na liga de Co-Cr, patenteando e nomeando as ligas de Stellite (do latim stella, cujo significado é estrela) (ASM INTERNATIONAL, 2000; ROACH, 2007).

O desenvolvimento das ligas de Co-Cr-Mo priorizou do controle das impurezas, como o carbono e o silício, bem como o controle dos elementos de liga de segunda fase. Neste caso os elementos de liga promovem aumento da resistência pela formação de carbonetos durante o processamento. A formação, o tamanho e o formato dos carbonetos (representados por MC, a letra M corresponde ao elemento de liga e C ao elemento de carbono) são influenciadas pela taxa de resfriamento e sutilmente por variações químicas. A influência dos elementos de liga adicionados ao cobalto modifica diretamente as propriedades mecânicas e químicas finais da liga, conforme pode ser observado na Tabela 3 (ASM INTERNATIONAL, 2000).

Tabela 3 - Efeito de adição de elementos de liga em liga a base de cobalto.

\begin{tabular}{cl}
\hline ELEMENTO & \multicolumn{1}{c}{ EFEITO } \\
\hline Cr & $\begin{array}{l}\text { Aumentar a resistência a oxidação e a corrosão, formadores de carbonetos }\left(\mathrm{M}_{7} \mathrm{C}_{3} \mathrm{e}\right. \\
\left.\mathrm{M}_{23} \mathrm{C}_{6}\right)\end{array}$ \\
\hline Mo e W & $\begin{array}{l}\text { Reforçador por solução sólida, formador de carboneto }\left(\mathrm{M}_{6} \mathrm{C}\right) \text {, composto } \\
\text { intermetálico }\left(\mathrm{Co}_{3} \mathrm{M}\right)\end{array}$ \\
\hline Ta e Nb & $\begin{array}{l}\text { Reforçador por solução sólida, formador de carbonetos }\left(\mathrm{MC} \text { e } \mathrm{M}_{6} \mathrm{C}\right) \text { e composto } \\
\text { intermetálico }\left(\mathrm{Co}_{3} \mathrm{M}\right)\end{array}$ \\
\hline $\mathbf{A l}$ & Resistência à oxidação e composto intermetálico $(\mathrm{CoAl})$ \\
\hline $\mathbf{T i}$ & $\begin{array}{l}\text { Formador de carboneto }(\mathrm{MC}) \text { e composto intermetálico }\left(\mathrm{Co}_{3} \mathrm{Ti} \text { e com níquel }\right. \\
\left.\text { suficiente Ni }{ }_{3} \mathrm{Ti}\right)\end{array}$ \\
\hline $\mathbf{N i}$ & Estabiliza forma de matriz CFC e composto intermetálico $\left(\mathrm{Ni}_{3} \mathrm{Ti}\right)$ \\
\hline $\mathbf{B o} \mathbf{Z r}$ & Aumentar a força de resistência à ruptura \\
\hline Y e La & Formação de carbonetos $\left(\mathrm{MC}, \mathrm{M}_{7} \mathrm{C}_{3}, \mathrm{M}_{6} \mathrm{C}, \mathrm{M}_{23} \mathrm{C}_{6}\right)$ \\
\hline Resistência à oxidação
\end{tabular}

Fonte: Adaptado de (ASM INTERNATIONAL, 2000).

O cromo, segundo componente químico de ligas à base de cobalto é muito encontrado em superligas. Este elemento possui duas funções que contribuem fortemente na formação de carbonetos (vide Tabela 3), a maior parte dos carbonetos são ricos em $\mathrm{Cr}$, proporcionando o aumento das propriedades mecânicas, bem como contribui na resistência a corrosão e oxidação. A resistência à oxidação de ligas que contenham $\mathrm{Cr}$ é proveniente da formação de óxidos $\left(\mathrm{Cr}_{2} \mathrm{O}_{3}\right)$ na superfície do material. $\mathrm{O}$ carboneto comumente encontrado em ligas Stellite é rico em cromo do tipo $\mathrm{M}_{7} \mathrm{C}_{3}$ e $\mathrm{M}_{23} \mathrm{C}_{6}$ estes são encontrados 
em grande porcentagem em ligas de baixo-carbono. Estes carbonetos "secundários" são formados gradualmente a altas temperaturas, provenientes de carbonetos primários $\mathrm{MC} \mathrm{e}$ MC 6 (ASM INTERNATIONAL, 2000; GEDDES; LEON; HUANG, 2010). Segundo Roach (2007), adições superiores a 30\% de Cr dificultam o processo de fundição da liga pela formação da fase $\sigma$ (sigma). Portanto, ligas utilizadas em aplicações odontológicas dificilmente contém proporções superiores de $29 \%$.

Os elementos de liga, tungstênio e molibdênio, nas ligas de cobalto possuem elevado diâmetro atômico, o que funciona como inibidor do fluxo de discordâncias quando associado ao átomo de soluto, e assim proporciona o aumento da tensão da matriz. Em alta concentração auxiliam a formação de carbonetos que durante a solidificação precipitam-se em $\mathrm{M}_{6} \mathrm{C}$. Os elementos de $\mathrm{W}$ e Mo proporcionam aumento da resistência a corrosão e são os principais elementos que justificam o sucesso comercial da liga Stellite. Porém diminui a área de formação de intermetálicos de $\mathrm{Cr}$. A presença de $\mathrm{Mo}$ em ligas de $\mathrm{Co}-\mathrm{Cr}$ proporciona a formação de carbonetos aumentando a resistência ao desgaste, corrosão e tensão. (ASM INTERNATIONAL, 2000; MISCH, 2015; ROACH, 2007).

Outros elementos, minoritários, como $\mathrm{Ni}, \mathrm{Si}, \mathrm{Mn}, \mathrm{C}$ e $\mathrm{Fe}$ podem ser encontrados em ligas à base de cobalto, influenciando as propriedades físicas e químicas. A adição de níquel aumenta a ductilidade e reduz a dureza da liga (melhorando o processo de forjamento). O Ni pode ser usado como estabilizador de matriz CFC, esta supressão da transformação da matriz CFC em relação a HC ocorre em porcentagens acima de $20 \%$ em massa de $\mathrm{Ni}$ (ou Fe). A adição de Ni decresce a solubilidade do carbono, propiciando uma maior precipitação do carbono (para um dado teor de carbono). No entanto, as ligas de Co apresentam baixa porcentagem de $\mathrm{Ni}$ (menor que 10\%), para evitar diminuição na resistência a ruptura da liga (GEDDES; LEON; HUANG, 2010).

O carbono em concentrações de aproximadamente 0,05 a 0,2\% em massa, se combina com elementos reativos e refratários como o titânio, tântalo e háfnio formando carbonetos primários MC. Em tratamentos térmicos ou serviços a altas temperaturas ocorre a transformação dos carbonetos primários para secundários $\mathrm{M}_{23} \mathrm{C}_{6}$ e $\mathrm{M}_{6} \mathrm{C}$, na região dos contornos de grão. Em concentrações acima de 0,15\% em massa, carbonetos também podem controlar o tamanho de grãos durante o processo de forjamento e tratamento térmico (GEDDES; LEON; HUANG, 2010).

Segundo Oréfice, Pereira e Mansur (2006) data-se de 1924 o uso de ligas à base de cobalto em implantes ortopédicos, e que teve primeiramente sua aplicação em cães. Somente em 1929 nos Laboratórios Austenal (York, Pennsylvania), desenvolveu-se a 
liga de Co-Cr-Mo e Co-Cr-W, para aplicações de materiais dentários fundidos. Segundo Roach (2007), em 1930 com o desenvolvimento de estudos e pesquisas em liga de Co-CrMo, sob os efeitos de resistência a fluidos corpóreos e ausência de efeitos em tecidos, comprovou-se a aplicação da liga em implantes. Posteriormente, em 1932 a liga de Co-CrMo teve seu nome consolidado como Vitallium e é utilizada até hoje na área da saúde (ASM INTERNATIONAL, 2000; ROACH, 2007).

A biocompatibilidade de ligas de Co-Cr é investigada em termos de processamentos aplicados em componentes. A constante avaliação em relação a minimização de efeitos tóxicos provenientes de solicitações mecânicas, em exemplo fadiga e desgaste, bem como efeitos sob corrosão é amplamente abordada por diversos autores (HEDBERG et al., 2014; KIM et al., 2016b; LUCCHETTI et al., 2015; MARTÍNEZ et al., 2013; MAS-AYU et al., 2013; SANTOS, 2012).

Grande parte das ligas de Co-Cr utilizadas em implantes cirúrgicos são normatizadas, as quais relacionam com a composição química e processamento de fabricação utilizado, os quais consequentemente alteram as propriedades mecânicas da liga, adequando-se ao tipo de aplicação, vide Tabela 4 (ASM INTERNATIONAL, 2000).

Tabela 4 - Propriedades mecânicas de ligas Co-Cr utilizadas em implantes cirúrgicos.

\begin{tabular}{|c|c|c|c|c|c|c|}
\hline ASTM & Liga & Condição & $\sigma \mathrm{LE}(\mathrm{MPa})$ & $\sigma \mathrm{LR}(\mathrm{MPa})$ & $E l(\%)$ & $E(\mathbf{G P a})$ \\
\hline F75 & Co-Cr-Mo & Fundido & 450 & 655 & 8 & 248 \\
\hline F799 & Co-Cr-Mo & $\begin{array}{c}\text { Processado } \\
\text { Termo-mecanicamente }\end{array}$ & 827 & 1172 & 12 & - \\
\hline F90 & Co-Cr-W-Ni & Forjado & 379 & 896 & - & 242 \\
\hline \multirow[b]{2}{*}{ F562 } & \multirow[b]{2}{*}{ Co-Ni-C } & Recozida & $241-448$ & 793-1000 & 50 & 228 \\
\hline & & $\begin{array}{c}\text { Trabalhada a frio e } \\
\text { envelhecida }\end{array}$ & 1586 & 1793 & 8 & - \\
\hline
\end{tabular}

Fonte: Adaptado de (ASM INTERNATIONAL, 2000).

De acordo com o tipo de aplicação do componente e do processo de fabricação, as ligas devem apresentar as propriedades de desempenho (tensão, alongamento e módulo de elasticidade) e alta resistência à fadiga, desgaste e corrosão, aliada a biocompatibilidade. $\mathrm{O}$ processo de fabricação está diretamente relacionado à microestrutura formada, conforme pode ser observado na Figura 3. A resistência à corrosão em ligas de Co-Cr implantáveis é proveniente e depende da formação do filme passivo de $\mathrm{Cr}_{2} \mathrm{O}_{3}$ (ASM INTERNATIONAL, 2000; ORÉFICE; PEREIRA; MANSUR, 2006). 


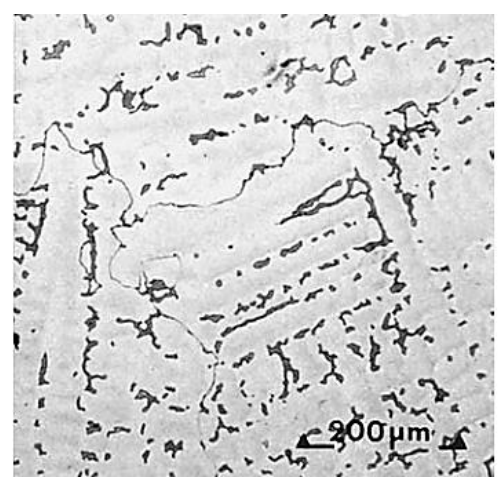

(a)

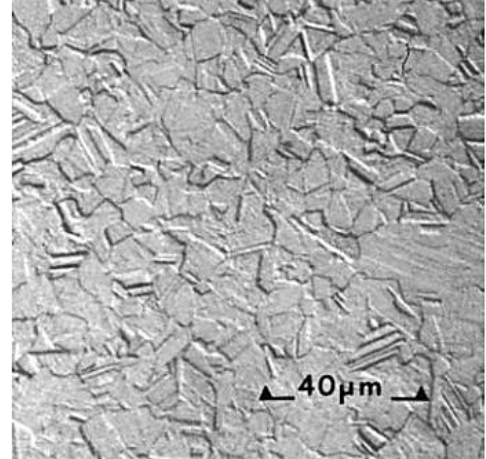

(b)

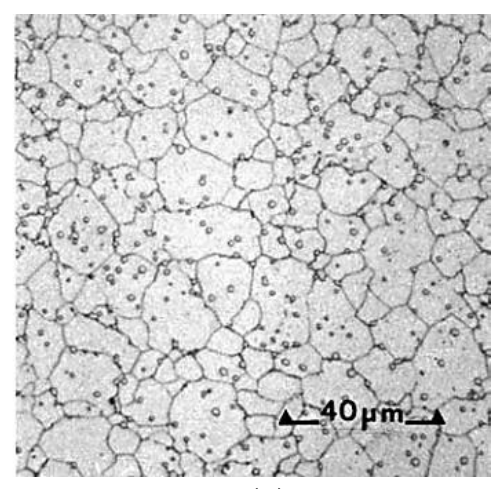

(c)

Figura 3 - Microestrutura da liga de Co-Cr-Mo em relação aos processos de fabricação, em a) fundição de precisão apresentando tamanho de grãos grosseiros e carbonetos largos, b) forjado apresentando grãos finos e c) prensagem isostática a quente apresentando grãos finos e reforços por carbonetos. Fonte: Adaptado de (ASM INTERNATIONAL, 2000).

\subsubsection{Liga de Cobalto-Cromo-Molibdênio}

O estudo da liga de Co-Cr-Mo vem ao encontro da necessidade de facilitar a avaliação da microestrutura presente e das propriedades mecânicas obtidas durante a fabricação da liga, nos processos de consolidação e nos parâmetros envolvidos. Portanto, os diagramas de equilíbrio dos principais elementos químicos da liga Co-Cr-Mo são investigados nesta seção, bem como os diagramas binários de Co-Cr, Co-Mo e Cr-Mo. A estequiometria da liga normatizada ASTM F75 é de Co-28Cr-6Mo.

No diagrama de equilíbrio binário de Co-Cr (vide Figura 4) observa-se o ponto de fusão para os elementos puros de $\alpha \mathrm{Co}$ e $\mathrm{Cr}$, respectivamente ocorrendo à temperatura de $1495^{\circ} \mathrm{C}$ e $1863^{\circ} \mathrm{C}$. Na temperatura de $1395^{\circ} \mathrm{C}(41,5 \% \mathrm{Cr})$ ocorre a reação eutética $\mathrm{L} \leftrightarrow$ $\alpha \mathrm{Co}+\mathrm{Cr}$. A qual L representa a fase liquidus, e as fases de soluções sólidas $\alpha \mathrm{Co}$ (estrutura cúbica de face centrada - CFC) e Cr (estrutura de corpo centrado cubico - CCC). Neste diagrama observam-se reações: eutetóide $(\mathrm{Cr} \leftrightarrow \alpha \mathrm{Co}+\sigma)$ à temperatura de $1275^{\circ} \mathrm{C}(41 \%$ $\mathrm{Cr})$; peritetóide $(\alpha \mathrm{Co}+\sigma \leftrightarrow \varepsilon)$ à temperatura de $967^{\circ} \mathrm{C}(38 \% \mathrm{Cr})$, onde $\varepsilon$ é uma solução sólida hexagonal compacta $(\mathrm{HC})$; congruente $(\mathrm{Cr} \leftrightarrow \sigma)$ à temperatura de $1306^{\circ} \mathrm{C}(63 \% \mathrm{Cr})$ (GUPTA, 2005; ISHIDA; NISHIZAWA, 1990).

Segundo Massalski et al. (1990), no diagrama binário de Co-Cr pode ocorrer a transformação alotrópica $(\alpha \mathrm{Co} \leftrightarrow \varepsilon \mathrm{Co})$ à temperatura de $422^{\circ} \mathrm{C}$, onde acontece a transformação de uma estrutura cristalina cúbica de face centrada $(\alpha \mathrm{Co})$ para uma estrutura cristalina hexagonal compacta ( $\varepsilon$ Co). Segundo Van Noort (2012), o limite de solubilidade de Cr no Co é de 30\%, formando uma solução sólida, e no caso da porcentagem de Cr ser superior a formação de uma segunda fase frágil. 


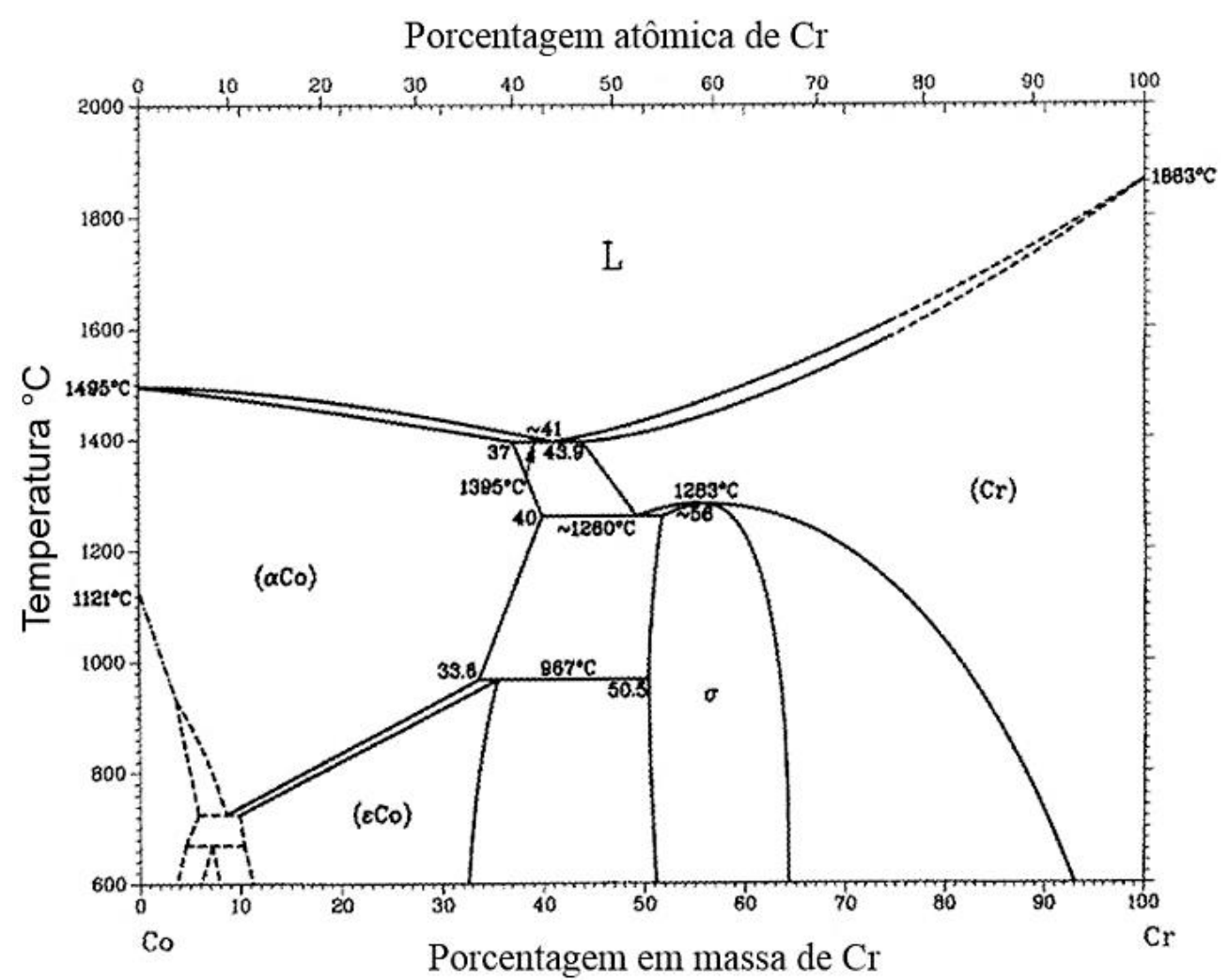

Figura 4 - Diagrama de equilíbrio do binário Co-Cr. Fonte: Adaptado de (MASSALSKI et al., 1990).

Segundo Gupta (2005), no sistema binário de Co-Mo (vide Figura 5) observase a presença de quatro fases intermediárias $\mathrm{Co}_{9} \mathrm{Mo}_{2}, \mathrm{Co}_{3} \mathrm{Mo}, \mathrm{Co}_{7} \mathrm{Mo}_{6}(\mu)$ e $\sigma$. Sendo que a fase $\mu$ e fase $\sigma$ são formadas a partir de uma reação peritética $L+\alpha \leftrightarrow \sigma$ à temperatura de $1620^{\circ} \mathrm{C}$, e $\mathrm{L}+\sigma \leftrightarrow \mu$ a temperatura de aproximadamente $1510^{\circ} \mathrm{C}$, onde $\alpha$ é uma solução sólida de corpo cubico centrado (CCC). A reação eutetóide, $\mathrm{L} \leftrightarrow \mu+\gamma$ ocorre à temperatura de $1355^{\circ} \mathrm{C}$. As três fases peritetóides, $\mu+\gamma \leftrightarrow \mathrm{Co}_{9} \mathrm{Mo}_{2}, \mathrm{Co}_{9} \mathrm{Mo}_{2}+\mu \leftrightarrow \mathrm{Co}_{3} \mathrm{Mo}$ e $\gamma+\mathrm{Co}_{3} \mathrm{Mo} \leftrightarrow \varepsilon$, ocorrem respectivamente nas temperaturas de 1200,1025 e $700^{\circ} \mathrm{C}$.

Segundo Gupta (2005), no diagrama binário Cr-Mo (vide Figura 6) apresenta um sistema de isomorfos (de mesma cristalinidade). O qual há uma ampla miscibilidade da fase $\alpha(\mathrm{CCC})$ de solução sólida $(\mathrm{Mo}, \mathrm{Cr})$ à temperatura inferior que $800^{\circ} \mathrm{C}$. 


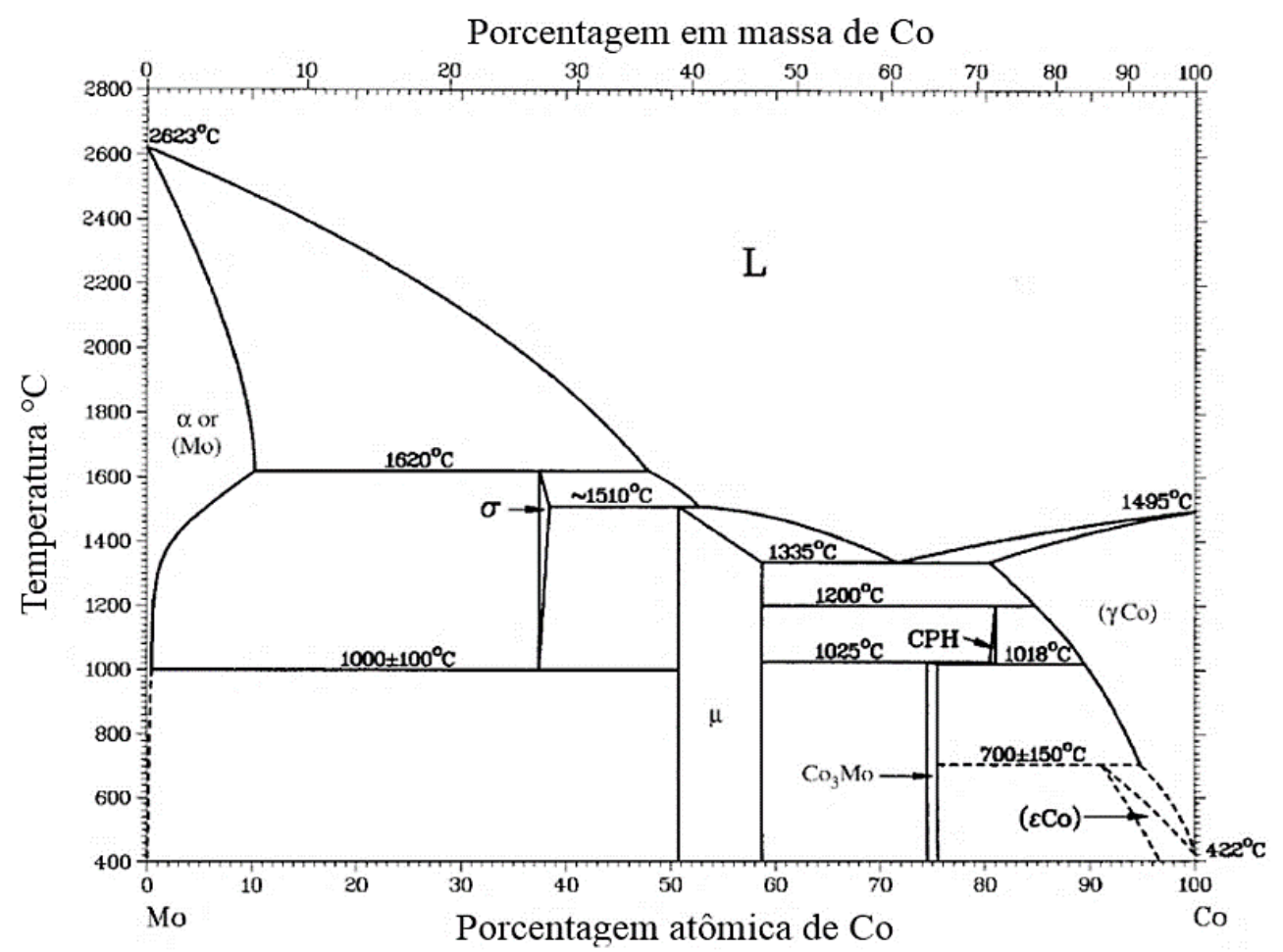

Figura 5 - Diagrama de equilíbrio do binário Co-Mo. Fonte: Adaptado de (MASSALSKI et al., 1990).

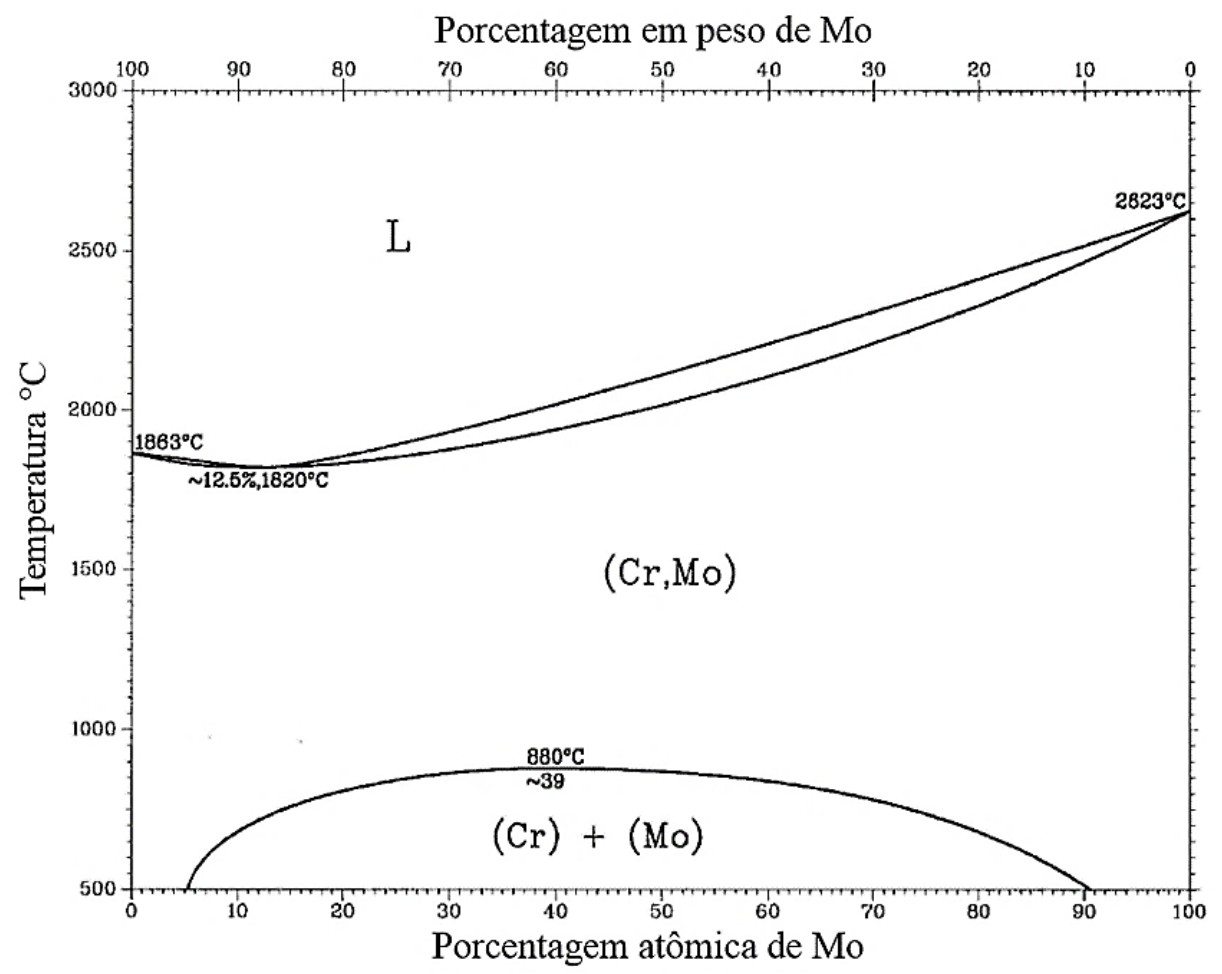

Figura 6 - Diagrama de equilíbrio do binário Cr-Mo. Fonte: Adaptado de (MASSALSKI et al., 1990).

O diagrama ternário proposto por Gupta (2005), à temperatura de $1300^{\circ} \mathrm{C}$ (vide Figura 7a), modifica a isoterma da fase $\sigma$ amplificando-a. Partindo-se do diagrama binário 
de Co-Cr â $1300^{\circ} \mathrm{C}$, a fase $\sigma$ é instável a uma temperatura de $1280^{\circ} \mathrm{C}$, sendo que a mesma deve apresentar três fases em equilíbrio $\left(\operatorname{com} \alpha\right.$ e $\gamma$ ) à $1300^{\circ} \mathrm{C}$. As fases e composições presentes de um sistema ternário de Co-Cr-Mo são apresentadas na Figura 7b.

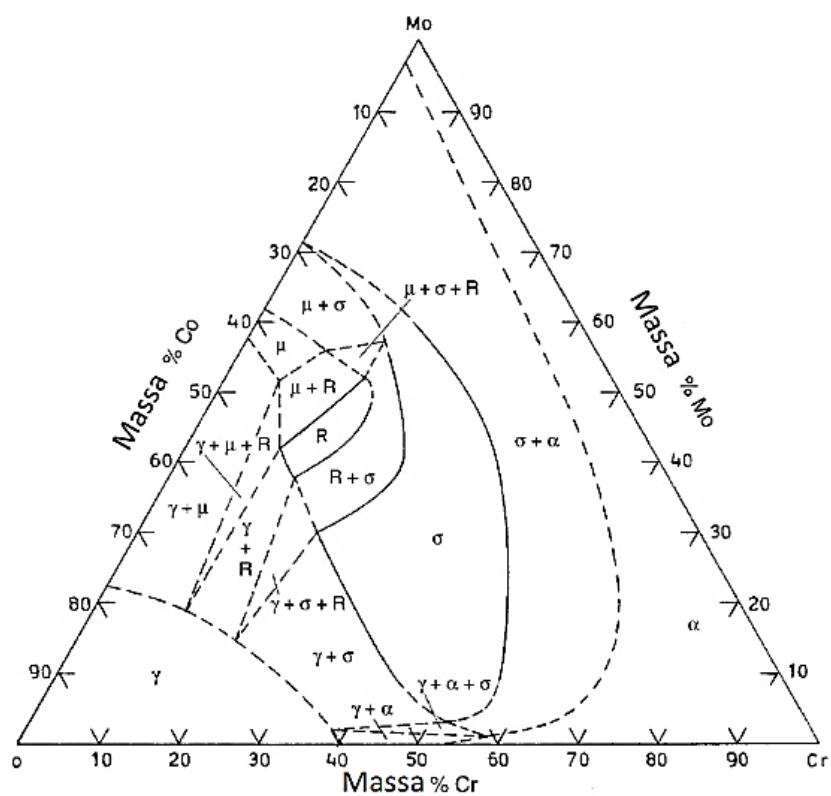

(a)

\begin{tabular}{|c|c|}
\hline Fase & Composição \\
\hline$\alpha$ & $(\mathrm{Cr}),(\mathrm{Mo}),(\mathrm{Cr}, \mathrm{Mo})$ \\
\hline$\gamma$ & $(\gamma \mathrm{Co})$ \\
\hline$\varepsilon$ & $(\varepsilon \mathrm{Co})$ \\
\hline \multirow{2}{*}{$\sigma$} & $\mathrm{Cr}_{8} \mathrm{Co}_{7}$ \\
\cline { 2 - 2 } & $\mathrm{Co}_{9} \mathrm{Mo}_{15}$ \\
\hline $\mathrm{Co}_{3} \mathrm{Cr}$ & $\mathrm{Co}_{3} \mathrm{Cr}$ \\
\hline $\mathrm{Co}_{2} \mathrm{Cr}$ & $\mathrm{Co}_{2} \mathrm{Cr}$ \\
\hline $\mathrm{Co}_{3} \mathrm{Cr}_{2}$ & $\mathrm{Co}_{3} \mathrm{Cr}_{2}$ \\
\hline$\pi$ & $\mathrm{Co}_{9} \mathrm{Mo}_{2}$ \\
\hline$\kappa$ & $\mathrm{Co}_{3} \mathrm{Mo}_{2}$ \\
\hline$\mu$ & $\mathrm{Co}_{7} \mathrm{Mo}_{6}$ \\
\hline$R$ & $\mathrm{Co}_{49} \mathrm{Cr}_{21} \mathrm{Mo}_{30}$ \\
\hline
\end{tabular}

(b)

Figura 7 - a) Isoterma à $1300^{\circ} \mathrm{C}$ do sistema ternário de Co-Cr-Mo e b) fases presentes no sistema de uma liga de Co-Cr-Mo. Fonte: Adaptado de (GUPTA, 2005).

Assim como o estudo dos diagramas (binários e ternário) da liga de Co-Cr-Mo tornasse necessário o entendimento do comportamento térmico da liga. Facchini (2010) evidencia a curva de análises térmicas (calorimetria exploratória diferencial - DSC e dilatometria - TMA, vide Figura 8) realizadas em liga de composição similar a ASTM F75 e processada por fusão por feixe de elétrons (EBM). Por meio das análises térmicas é possível observar os eventos térmicos, bem como associá-los aos diagramas de fase da liga de Co-Cr.

Na curva de DSC (vide Figura 8), os três eventos que ocorrem são interpretados, como sendo, respectivamente, o primeiro pico $\left(565-900^{\circ} \mathrm{C}\right)$ associado a transição da fase $\mathrm{CFC}(\alpha \mathrm{Co})$ para a fase $\mathrm{HC}(\varepsilon \mathrm{Co})$, o segundo pico $\left(900-1000^{\circ} \mathrm{C}\right) \mathrm{a}$ redução da fase $\mathrm{HC}(\varepsilon \mathrm{Co})$ e reaparecimento da fase $\mathrm{CFC}(\alpha \mathrm{Co})$. Ao associar a análise de TMA Facchini (2010) descreve que na região da temperatura entre 1000 e $1215^{\circ} \mathrm{C}$ ocorre a solubilização de carbonetos interdendríticos e intergranulares presentes na matriz. Esta evidência é confirmada a partir de análise microestrutural e de difração de raios X, em amostras submetidas a tratamentos térmico na faixa de temperatura de estudo. 


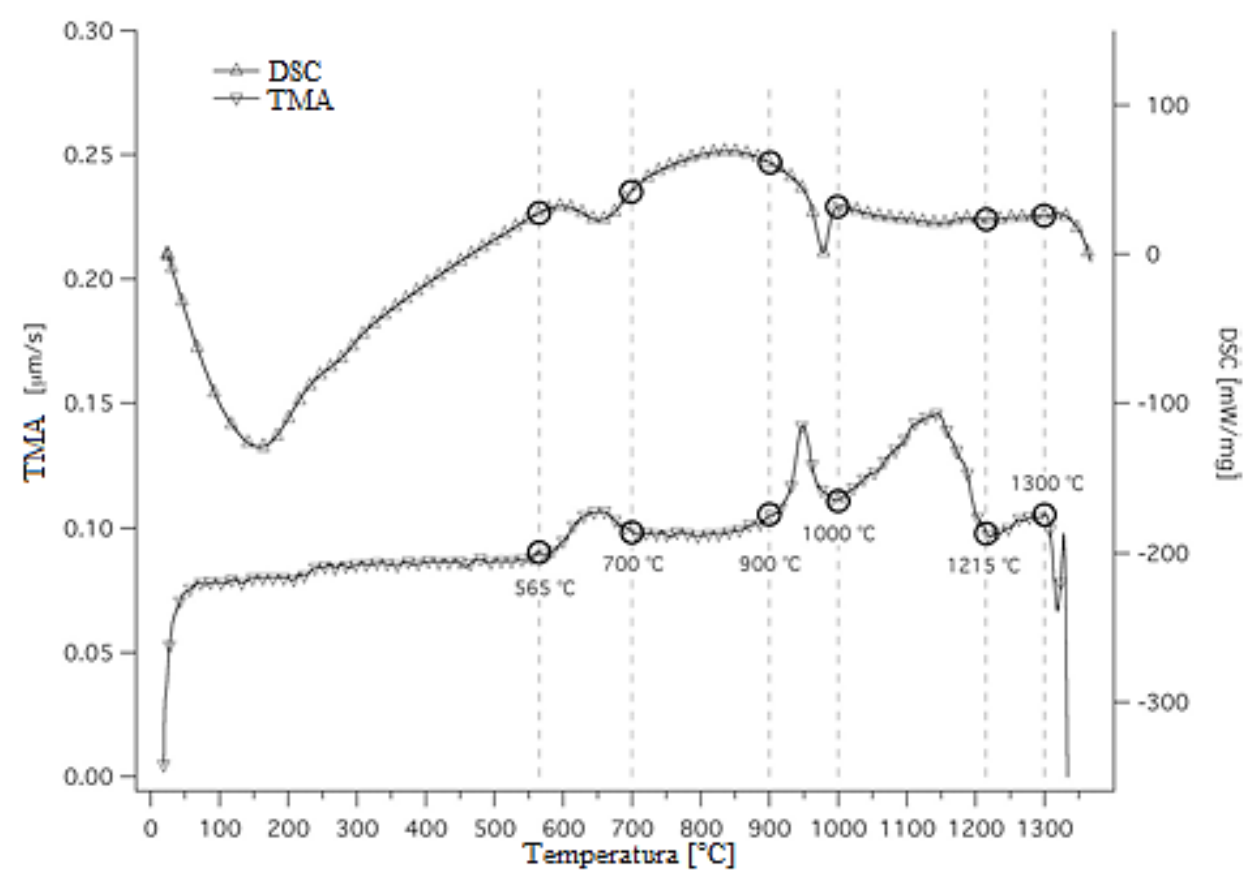

Figura 8 - Curvas de experimento de DSC e TMA (taxa de aquecimento de $20^{\circ} \mathrm{C} / \mathrm{min}$ ) em liga ASTM F75 produzida por fusão por feixe de elétrons (EBM). Fonte: Adaptado de (FACCHINI, 2010).

Estudos térmicos de ligas de Co-Cr-Mo são abordadas por diversos autores (CRAIG, 2012; KAISER et al., 2013; LIU et al., 2010; MCCABE; WALLS, 2008; RAMÍREZ-VIDAURRI et al., 2009; SANTOS, 2012) analisando outras propriedades térmicas de interesse, como por exemplo, a temperatura de solidificação (a qual ocorre na faixa de 1350 a $1390^{\circ} \mathrm{C}$ ) e o coeficiente de dilatação térmico (aproximadamente entre 14,0 a $\left.15,0.10^{-6 \circ} \mathrm{C}^{-1}\right)$.

\subsubsection{Produção de pós metálicos - atomização}

A metalurgia do pó é um processo de fabricação de elevada produtividade, baixo desperdício de matéria prima, permite diversas combinações de elementos químicos sem segregação e propicia custos muito competitivos em aplicações de peças de pequeno peso (até 1,5 kg) (CHIAVERINI, 2001; GESSINGER, 1984; NEVES, 2005).

A produção de pós metálicos é realizada por diversas formas de processamento, que influenciam nas características físicas dos pós obtidos em relação ao seu tamanho e a densidade. Os métodos de produção de materiais particulados podem ser obtidos por meio de: reações químicas e decomposição, atomização de metais fundidos, deposição eletrolítica e processamento mecânico de materiais sólidos. É possível ainda utilizar mais de um dos processos citados para obter pós metálicos (CHIAVERINI, 2001). 
A atomização é atualmente o processo de maior crescimento na fabricação de pós metálicos de superligas. A técnica de atomização é um processo antigo aplicado a produção de pós de ferro desde 1930. A grande motivação do uso desta técnica é a necessidade de se reduzir a segregação de elementos altamente ligados em superligas (CHIAVERINI, 2001).

O efeito da taxa de solidificação está diretamente relacionado com a microestrutura e a homogeneidade da partícula de pó. Como é possível verificar na Figura 9 relaciona-se o espaço entre os braços dendríticos formados na partícula pela taxa de solidificação (em diferentes métodos de fabricação de pós), destacando o processo de atomização a gás (ASM INTERNACIONAL, 1998; CHIAVERINI, 2001; GESSINGER, 1984).

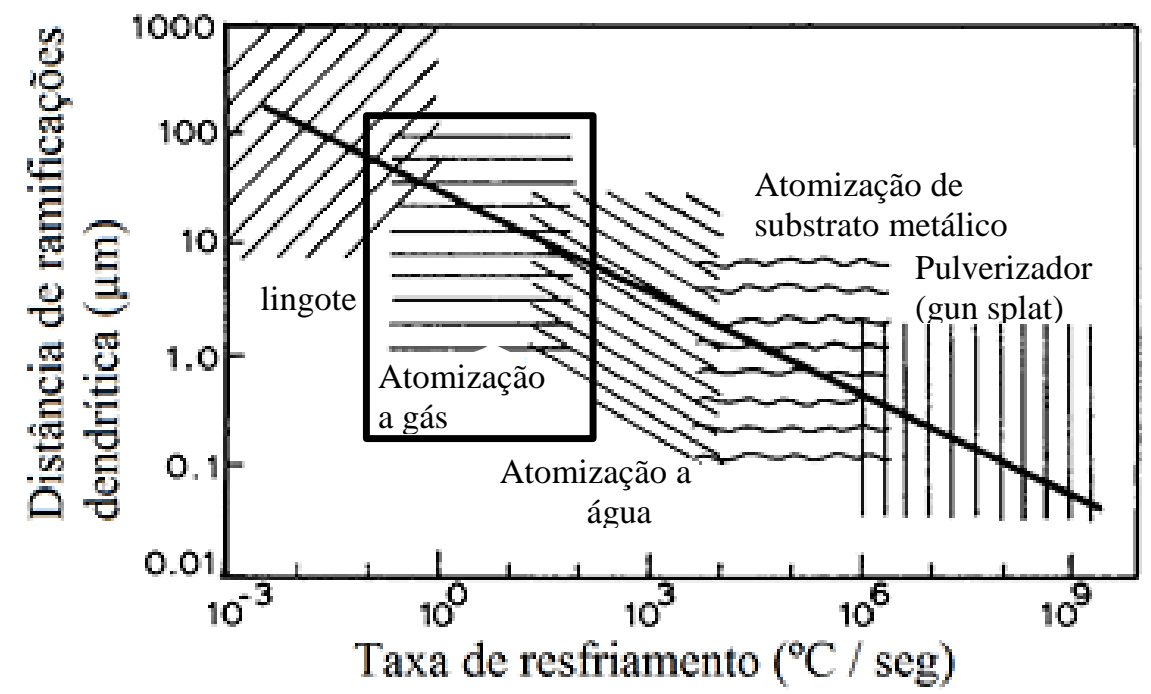

Figura 9 - Efeito da taxa de solidificação na distância entre braços dendríticos em liga de alumínio. Fonte: Adaptado de (GESSINGER, 1984).

A técnica de atomização a gás consiste na passagem de um fluído sob alta pressão (este pode ser o ar, argônio, hélio e outros gases inertes) através de um orifício do bocal, que incide em um filete de metal fundido. A rápida expansão do gás em contato com o fluxo de metal pulveriza o filete de metal em gotículas, que solidificam durante a queda na torre de atomização, vide Figura 10. 


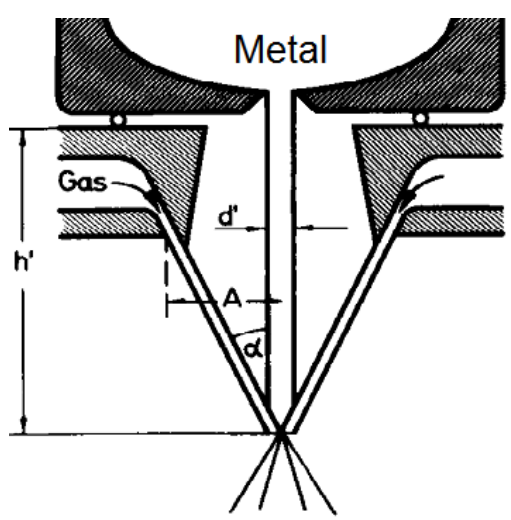

(a)

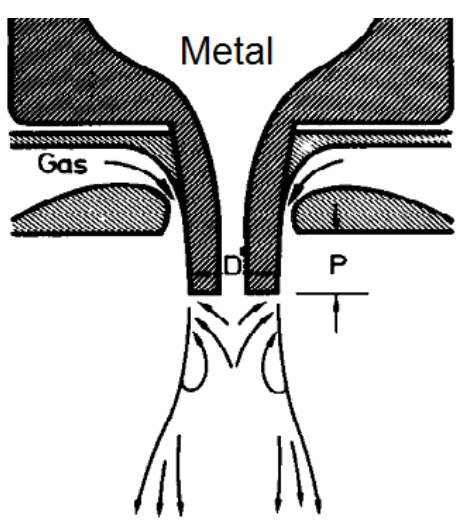

(b)

Figura 10 - Esquema do processo de fabricação de pós por atomização a gás, respectivamente por bocais em ângulo (a) e tangencial (b). Fonte: Adaptado de (GESSINGER, 1984).

O processo de atomização a gás possui diversos parâmetros de operação, incluindo: tipo de gás, atmosfera residual, temperatura de fundição e viscosidade, como também geometria do bocal, tipo de liga, taxa de alimentação do metal e pressão, velocidade e temperatura do gás. Estes parâmetros devem ser ajustados para manter o processo sob controle e manter as características do pó (GERMAN, 1998).

Segundo Chiaverini (2001), pós obtidos por este processo apresentam características microestruturais que variam de estrutura amorfa a microestrutura refinada e dendrítica. Estas características também podem ser encontradas em pós atomizados a água. A geometria esférica do pó metálico é favorecida pela atomização a gás em um formato esférico e apresenta uma ampla distribuição granulométrica, geralmente com tamanho inferior a $150 \mu \mathrm{m}$.

Segundo German (1994), quando elementos reativos são ligados com elementos de base, durante a atomização é possível ocorrer oxidação na superfície das partículas. Conforme descrito, em seu processo de solidificação, o decréscimo da temperatura ocorre inicialmente na superfície em direção ao núcleo. Deste modo, há formação de braços dendríticos, primários e secundários (vide Figura 11a), e em consequência do elevado gradiente de temperatura ocorre a formação de estruturas celulares (vide Figura 11b) (GESSINGER, 1984, 1984; YULE; DUNKLEY, 1994). 


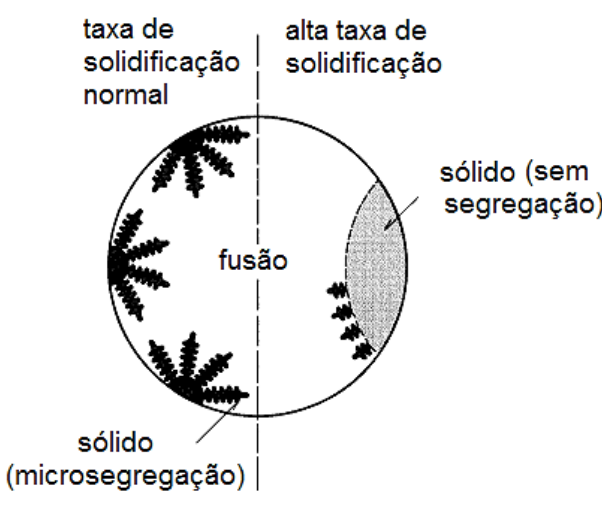

(a)

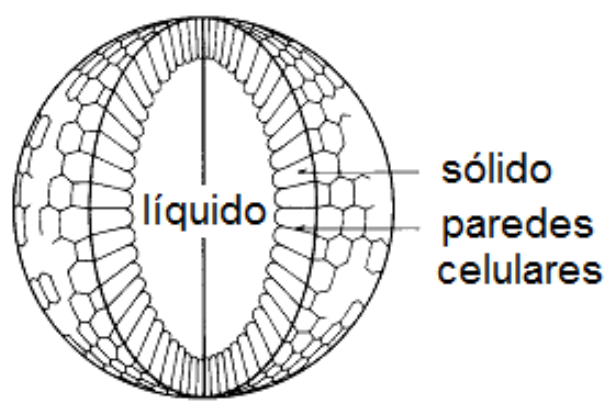

(b)

Figura 11 - a) Formação de braços dendríticos primários e secundários durante a solidificação da partícula e b) estruturas celulares formadas durante a solidificação. Fonte: Adaptado de (GESSINGER, 1984).

\subsection{PRÓTESES DENTÁRIAS}

\subsubsection{Introdução à confecção de próteses}

A dentição se relaciona a diversos campos humanos, como: cultural, social, saúde e estética. Existem diversas produções relacionadas às tentativas de aprimoramento de técnicas que substituíssem dentições perdidas, por motivações de: idade, patologia, trauma, estética, higiene, adaptabilidade e entre outras (CRAIG, 2012; MISCH, 2015).

Os primeiros modelos de dentaduras datam do final do século XVIII produzidas em marfim e dentes de cadáveres reforçadas com pequena quantidade de chumbo. Estas eram pesadas e de difícil adaptação, em razão do uso de técnicas rudimentares com a utilização de molas e ou dobradiças. Em meados do século XIX, por volta de 1800, James Gardette na Filadélfia esculpiu um conjunto de dentaduras de marfim e avaliou que o efeito do encaixe preciso nos contornos das estruturas bucais proporcionava a retenção das mesmas, sem o uso de molas (VAN NOORT, 2012).

Outros processos de fabricação e desenvolvimento de dentaduras surgiram como a substituição do marfim pelo ouro coesivo e moldado até se obter uma estrutura próxima ao modelo. Com o desenvolvimento de um material chamado vulcanite (borracha endurecida na presença de enxofre pelo processo de vulcanização) garantiu aos modelos de dentadura menores custos e um encaixe mais preciso (material maleável). Atualmente, a substituição do material vulcanite é realizada pelos polímeros sintéticos e resinas acrílicas, 
materiais que proporcionam a moldagem bucal ajustada e complexa (VAN NOORT, 2012). Novas metodologias de tratamentos foram incorporadas aos procedimentos odontológicos com o desenvolvimento de anestésicos e utensílios médicos (como as brocas). Com esses avanços houve uma redução de 53\% (entre 1938 a 1976) nos procedimentos odontológicos invasivos (VAN NOORT, 2012).

Com base nos dados do Projeto SB Brasil 2015, em relação a distribuição do grau de edentulismo (termo que avalia a necessidade de prótese dentária), destaca-se os números finais da necessidade de próteses (parcial e ou total) para as faixas etárias de 15 a 19; 35 a 44 e 65 a 74 anos. A necessidade de próteses em adolescentes é baixa, sendo $1,57 \%$ na arcada superior e 4,1\% na arcada inferior. Nos adultos, o uso de algum tipo de prótese é de $34,88 \%$ na arcada superior e 49,09\% na arcada inferior. Em idosos a necessidade de prótese total se destaca, sendo 41,10\% na arcada superior e 37,27\% na arcada inferior (MINISTÉRIO DA SAÚDE, 2016).

Em razão das estatísticas apontadas, compreende-se que a necessidade de prótese dentária é um nicho de mercado a ser investido. Estudos e desenvolvimentos na área de odontologia, abrangendo a necessidade de novos materiais, técnicas de fabricação e características biocompatíveis são apontadas na literatura (CRAIG, 2012; MCCABE; WALLS, 2008; MISCH, 2015; VAN NOORT, 2012).

As ligas de materiais metálicos utilizadas em próteses dentárias, segundo classificação da ANSI-ADA (American National Standards Institute - American Dental Association $\left.{ }^{\circledR}\right)$, são divididas em três grupos. O primeiro grupo consiste das ligas de alta nobreza contendo no mínimo $40 \%$ de ouro e no mínimo $60 \%$ de metais preciosos (tais como, platina, paládio e prata). O segundo grupo são ligas que contém no mínimo $25 \%$ de metais nobres e a presença de ouro não é especificada. O terceiro grupo é formado predominantemente de ligas e metais básicos contento menos de $25 \%$ de metais preciosos. Entre as ligas que contém metais preciosos, os elementos majoritários são os elementos de: ouro, platina, paládio e prata. Em ligas de metais básicos a matriz pode ser formada por: cobalto (com adição de cromo, molibdênio), titânio puro ou ligas de titânio (com adição de alumínio, vanádio, nióbio e tântalo), níquel (com adição de cromo, molibdênio e nióbio) e ferro (com adição de cromo, molibdênio e nióbio) (CRAIG, 2012; MCCABE; WALLS, 2008; MISCH, 2015; VAN NOORT, 2012).

Os materiais utilizados na confecção de próteses dentárias devem ser capazes de assegurar o desempenho de sua função. Estes devem apresentar propriedades que suportem, a curto ou a longo prazo, as forças geradas tanto na mastigação quanto na 
oclusão e do conjunto de eventos associados ao ambiente bucal. Os grupos de materiais que abrange esta área em específico são: o titânio e suas ligas, ligas de Co-Cr, aços austeníticos (Fe-Cr-Ni-Mo), tântalo, ligas de nióbio e de zircônia, materiais preciosos, cerâmicas e materiais poliméricos (MISCH, 2015).

No campo das ligas de metais básicos, as ligas de $\mathrm{Co}-\mathrm{Cr}$ e $\mathrm{Ni}-\mathrm{Cr}$ são comumente utilizadas na fabricação de componentes dentários sob revestimento cerâmico. No entanto, em virtude da elevada parcela de pacientes alérgicos ao níquel, as ligas de CoCr são as mais recomendadas (CRAIG, 2012; KANE et al., 2015; KIM et al., 2016a).

As propriedades mecânicas, físicas e eletroquímicas da liga de Co-Cr-Mo para implantes dentários foram avaliadas para determinação dos parâmetros de produção em sinterizados, com o intuito de melhorar as restaurações e implantes (FAZIRA et al., 2013; HENRIQUES; SOARES; SILVA, 2012; ÖRTORP et al., 2011). Outros autores (DONI et al., 2013; QIN et al., 2013; YAN et al., 2006) pesquisaram diversos aspectos para aumentar a durabilidade de implantes utilizando ligas de $\mathrm{Co}-\mathrm{Cr}$.

\subsubsection{Componentes dentários}

A necessidade de realizar procedimentos cirúrgicos para implantar componentes dentários pode estar associada a: perda parcial ou total de dentes (em decorrência a doenças, por exemplo a cárie), aos diversos tipos de ambiente (ácido, temperatura ou bactericida), esforços de mastigação (podendo agir associados ou não) e traumatismos faciais (CRAIG, 2012; MISCH, 2015). Neste tópico exemplifica-se as funções das próteses dentárias e dos componentes (restaurações, pontes dentárias e coroas) que as substituem (VAN NOORT, 2012).

A principal função dos dentes é a mastigação e de forma complementar a fonação e estética. Os dentes podem ser compreendidos por duas estruturas principais, a parte externa (coroa) e a parte interna a gengiva (raiz), como pode ser observado na Figura 12a. A função da coroa (corte, rasgo e mastigação dos alimentos) é influenciada pelo seu formato. A função da raiz é a fixação do dente ao osso maxilar (CRAIG, 2012; MISCH, 2015).

As coroas dentárias são próteses (conhecidas pelo termo em inglês de “copings" ou "crown”) confeccionadas em material metálico biocompatível e revestidas por material cerâmico (vide Figura 12b) (VAN NOORT, 2012). De modo geral, a coroa é fixada por um conjunto de componentes implantados ao osso maxilar. O conjunto de 
componentes é composto por 4 elementos (vide Figura 12c): coroa, parafuso de fixação, pilar e implante. A coroa pode ser fixada por diferentes métodos, por meio de: parafuso, deformação ou cimentado (KALE; METKAR; HIWASE, 2017; MCCABE; WALLS, 2008; ÖZCAN; HÄMMERLE, 2012).

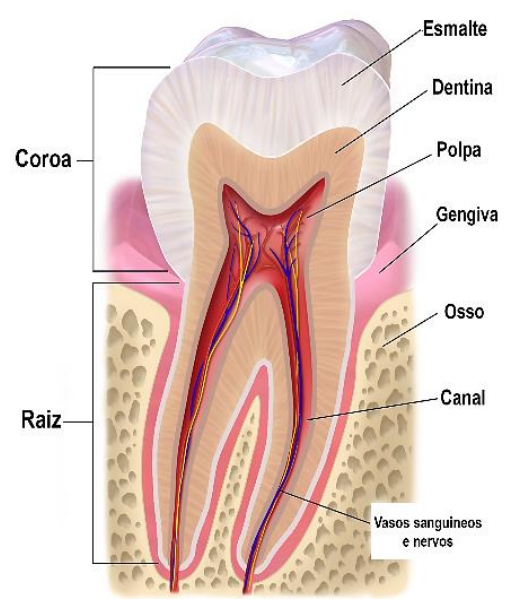

(a)

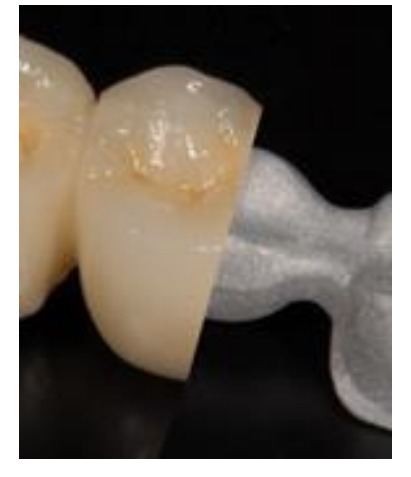

(b)

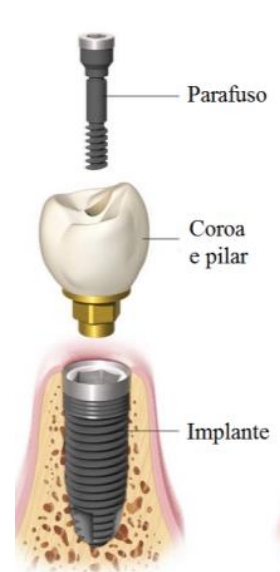

(c)

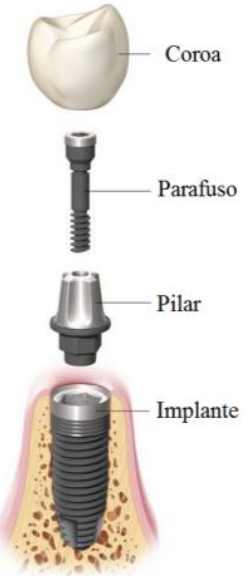

Figura 12 - a) Representação da anatomia do dente e seus principais constituintes (NEUPE UFPR, 2016), b) elemento dentário metálico sob revestimento cerâmico (EOS GMBH, 2014) e c) representação dos componentes metálicos de um implante completo de dente (THEMES, 2017).

Kale et al. (2017) analisaram diversos parâmetros em simulação de elementos finitos na fabricação de coroas dentárias utilizando biomateriais como: aço inoxidável, Ti6Al-4V, liga de Co-Cr, zircônia e titânio puro. Para tanto o estudo avaliou diversas espessuras de parede na construção de coroas. Os resultados apontaram que os melhores parâmetros de tensão e deformação foram obtidos com zircônia e liga de Co-Cr. No entanto, em relação à viabilidade econômica, o uso da liga de $\mathrm{Co}-\mathrm{Cr}$ mostrou-se mais vantajoso (o custo de fabricação de uma coroa de zircônia é de aproximadamente o dobro do custo de uma coroa de Co-Cr).

\subsubsection{Confecção de próteses dentárias}

A evolução dos métodos de fabricação de próteses dentárias é contínua e as principais técnicas de fabricação são: fundição de precisão (método de cera perdida); compactação direta de ouro (seja em folha, pó ou obtido por precipitação eletrolítica); condensação direta do amálgama (liga de mercúrio, prata, estanho e cobre); adaptação de folhas metálicas laminadas (aplicadas sobre modelo e o posterior tratamento térmico); 
usinagem (através de fresadoras controladas por sistemas de comando numérico computadorizado - CNC); e por erosão pelo método de faísca elétrica (em meio de alta condutividade elétrica) (CRAIG, 2012).

Atualmente, o método de fundição de precisão (conhecido por cera perdida ou microfundição) é o mais utilizado. Novas tecnologias de MA estão substituindo as técnicas convencionais (fundição, conformação e usinagem) usando sistemas de criação e design de imagem digital por sistemas CAD/ CAM, e a confecção de protótipos ou produtos em geometria final, por meio de máquinas CNC e métodos de fabricação de MA (por exemplo a estereolitografia) (CRAIG, 2012).

Segundo Van Noort (2012), o desenvolvimento das tecnologias de MA possibilitam a confecção de implantes customizados. Na Figura 13 apresenta-se os processos de produção utilizando as técnicas de MA - estereolitografia e SLM implementadas na manufatura de componentes dentários (coroas e pontes). A produção inicial de modelos em resina utilizando a técnica de estereolitografia é uma das etapas para se obter os componentes finais por meio de um segundo processo de fabricação (fundição de precisão). Na técnica de fusão seletiva a laser (SLM) é possível obter a confecção de componentes dentários em sua geometria final sem a necessidade de outros processos de fabricação. E também permite obter componentes finais customizados de elevadas propriedades mecânicas quando comparados a outras técnicas convencionais (REN et al., 2016; CRAIG, 2012; VAN NOORT, 2012; UTELA et al., 2008).

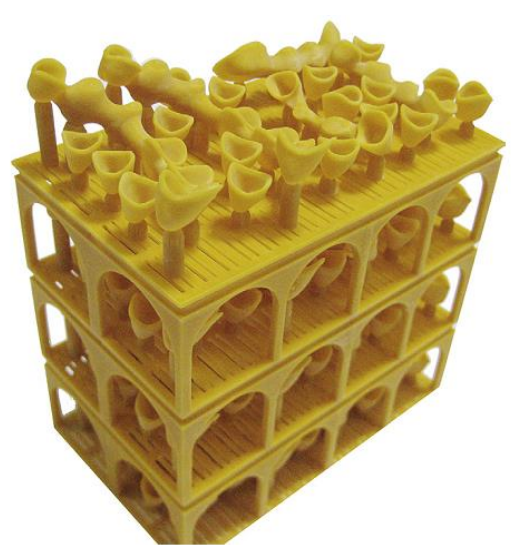

(a)

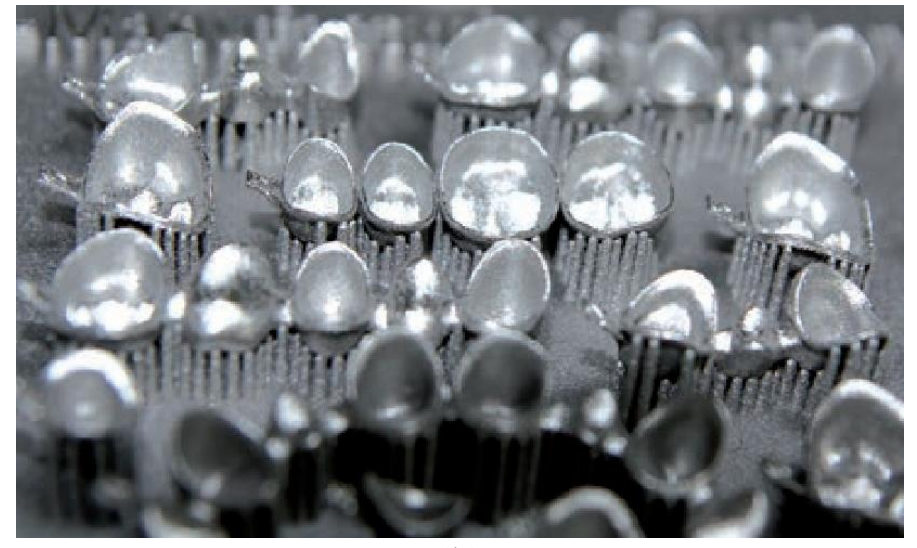

(b)

Figura 13 - a) Modelo em resina de coroas e pontes dentária confeccionada por MA, para posterior fundição por cera perdida e b) Coroas fabricadas via técnica de fusão seletiva a laser. Fonte: Adaptado de (CRAIG, 2012).

Bammani et al. (2012) realizaram um estudo comparativo entre as técnicas de fundição de precisão (convencional) e a estereolitografia (MA) na fabricação de coroas 
dentárias. Os resultados evidenciaram que as técnicas de MA proporcionaram componentes dentários com maior controle de tolerâncias e maior economia de tempo e custo de fabricação (50 a 80 componentes de alta qualidade em 56 minutos de operação).

Segundo Kale et al. (2017) a fabricação de componentes dentários (coroas e implantes mandibulares) é possível em quaisquer materiais biocompatíveis, usando novas tecnologias de impressão 3D. Para o correto design do componente, a manufatura deve ser avaliada por softwares de simulação dos esforços e tensões presentes no local de aplicação. Atualmente, a vida útil de coroas dentárias é de 10 a 15 anos (KALE; METKAR; HIWASE, 2017), mas com o desenvolvimento da fabricação de componentes dentários, a perspectiva é que a vida útil seja prolongada com a performance da análise de fadiga em relação aos métodos de consolidação.

\subsubsection{Técnica de fundição de precisão}

A técnica de fundição é um processo de fabricação versátil por apresentar: obtenção de geometrias complexas, tamanhos diferenciados e viabilidade econômica. Quando comparado aos outros processos de fabricação existentes o uso da técnica de fundição é mais vantajoso com relação ao custo, processamento e produtividade de componentes (ASM INTERNACIONAL, 2008).

Uma ampla gama de técnicas de fundição é empregada e, dependendo de sua aplicação, apresentam vantagens e desvantagens. Entre as técnicas mais utilizadas destacam-se a fundição: em molde de areia, com matriz, de revestimento (precisão), em modelo consumível e contínua (ASM INTERNACIONAL, 2008; CALLISTER; RETHWISCH, 2010).

A técnica de fundição de revestimento ou de precisão está representada de forma esquemática na Figura 14. Esta técnica baseia-se na fabricação de um modelo feito por cera (ou polímeros) com baixa temperatura de fusão. O modelo é revestido por uma lama, que se solidifica envolvendo a superfície do modelo. A etapa seguinte consiste em aquecer e fundir o modelo de cera (etapa de desceragem), produzindo uma cavidade de alta precisão dimensional com excelente acabamento (reprodução de detalhes do modelo). Após a queima do revestimento de lama, o modelo adquire certa resistência mecânica e consequentemente há o vazamento do metal líquido na cavidade do molde (formado pela cera). Por fim, ao solidificar o metal, o conjunto é desmoldado dando sequência as etapas finais de acabamento (ASM INTERNACIONAL, 2008). 


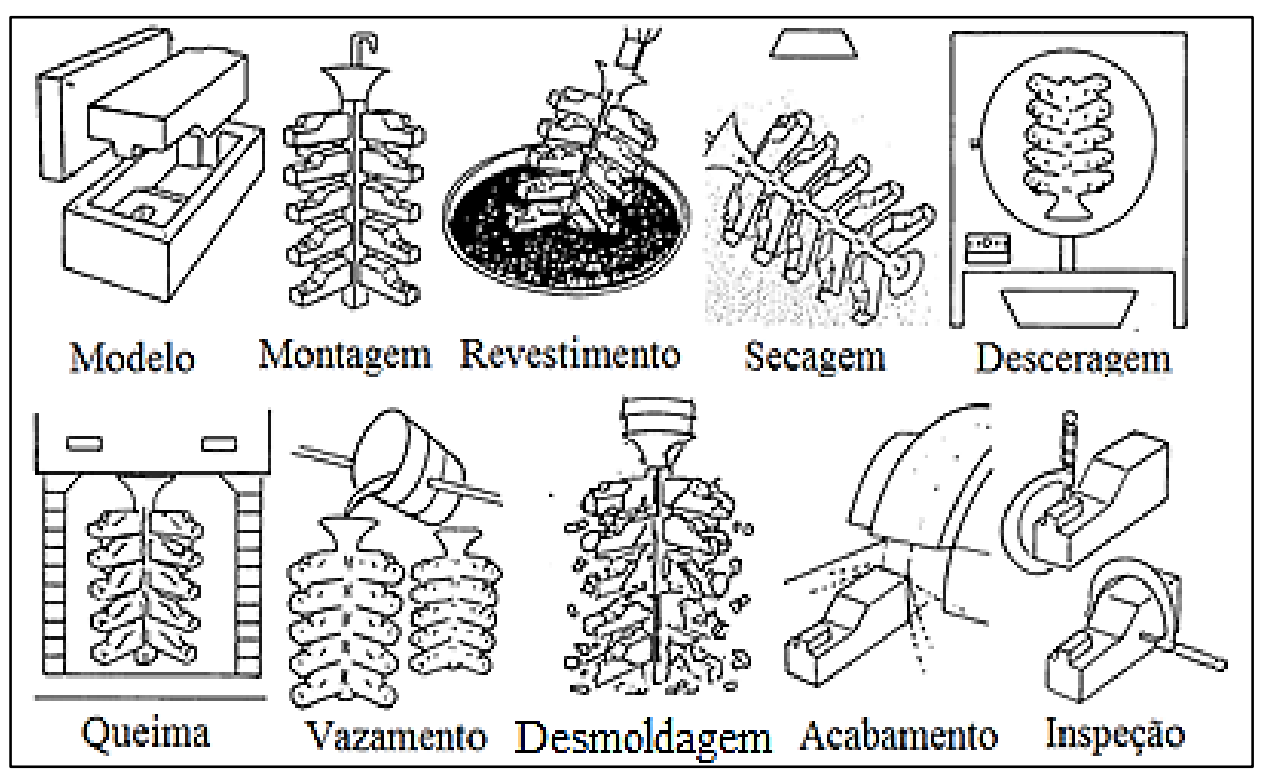

Figura 14 - Etapas envolvidas no processo de fundição pela técnica de precisão via cera perdida. Fonte: Adaptado de (ASM INTERNACIONAL, 2008).

O metal como fundido pode apresentar três zonas distintas de estrutura de grãos, que consistem em: uma zona de refrigeração de cristais muito pequenos produzidos por uma taxa rápida na superfície; uma zona de comprimento colunar de cristais finos ao longo da direção do fluxo de calor na região de resfriamento inicial; e uma região de cristais equiaxiais aproximadamente esférica no centro da peça fundida. É possível que estas zonas de estruturas se formem ou não (ASM INTERNACIONAL, 2008).

$\mathrm{Na}$ ausência de zonas equiaxiais, o fundido se apresenta inteiramente colunar. Os grãos equiaxiais crescem frente a dendrita colunar, e a transição de colunar para equiaxial ocorre quando os grãos equiaxiais são suficientes em tamanho e número para impedir o avanço da frente colunar. A formação da zona equiaxial requer a presença de núcleos em grande quantidade e condições que promovam o seu crescimento em relação a dendrita colunar (ASM INTERNACIONAL, 2008).

\subsection{TECNOLOGIA DE MANUFATURA ADITIVA}

\subsubsection{Introdução às técnicas de manufatura aditiva}

Nas últimas décadas as tecnologias de prototipagem rápida (PR) tiveram grande expansão em diversos campos de aplicação. Historicamente, a PR foi a primeira 
aplicação comercialmente significativa para a MA e, por isso, tem sido comumente utilizada como um termo geral para este tipo de tecnologia. A rapidez do processo está associada com a possibilidade de obter o protótipo em seu formato final (do inglês near-net shape) ou muito próximo de seu formato final, a partir de geometrias virtuais (FACCHINI, 2010; CANCIGLIERI; SELHORST; IAROZINSKI, 2007). A MA por definição da ISO / ASTM representa "O processo de unir materiais para fazer objetos a partir modelos de dados 3D, usualmente camada por camada, em oposição a tecnologias de manufaturas subtrativas. " (ISO / ASTM52900, 2015).

No final da década de 80, nos Estados Unidos surge a primeira técnica de MA, comercialmente disponibilizada (modelo SLA-1) pela empresa 3D System. O princípio de manufatura (Estereolitografia, do inglês "Stereolithography - SL") do objeto se baseia pela fotopolimerização do material (polímero líquido - fotossensível) acondicionado em um tanque. A exposição de radiação ultravioleta consolida de camada em camada o objeto tridimensional (GIBSON, 2005; MELCHELS; FEIJEN; GRIJPMA, 2010). Sucessivamente, o aprimoramento e desenvolvimento de tecnologias trouxeram ao mercado as técnicas de: modelagem por fusão e deposição, manufatura de objetos laminados e entre outros a sinterização seletiva a laser.

As técnicas de MA viabilizam notáveis desenvolvimentos em diversos setores (aeronáutica, aeroespacial, automotiva, área da saúde, arquitetura, design e joalheria), em razão de sua aplicabilidade em uma ampla gama de materiais (cerâmicos, poliméricos e metálicos), eficiência de utilização da matéria prima, fabricação de peças com relevante tolerância dimensional, eficiência no projeto e na produção de peças de menor peso (MANÇANARES, 2016).

A norma ISSO/ASTM 52900 classifica as técnicas de MA de acordo com o processo de consolidação, sendo: 1) injeção de aglutinante - um agente de ligação líquido é depositado seletivamente para juntar materiais em pó; 2) deposição direta de energia - a energia térmica focalizada (por exemplo, laser, feixe de elétrons ou arco de plasma) é usada para fundir materiais à medida que eles estão sendo depositados; 3) extrusão de material - o material é distribuído seletivamente através de um bocal ou orifício; 4) injeção de material - gotículas de material (fotopolímero e cera) são depositadas seletivamente; 5) fusão de camada em pó - a energia térmica liga seletivamente as regiões de um leito de pó; 6) laminação de folhas - folhas de material são ligadas para formar uma peça; 7) fotopolimerização em cuba - o fotopolímero líquido numa cuba é curado seletivamente por polimerização ativada por luz (ISO / ASTM52900, 2015). 
As etapas do processo de manufatura se baseiam na: 1) criação do modelo geométrico virtual (modelo em 3D) por meio de sistema CAD; 2) conversão do modelo em 3D em um formato STL (formato de arquivo que descreve a geometria de superfície de um objeto, usado para comunicar geometrias 3D a máquinas para construir partes físicas); 3) processamento/ fatiamento do modelo em 3D (arquivo STL) pela máquina; 4) consolidação do modelo pela adição de camada; 5) acabamento do modelo físico (GIBSON, 2005; GOUVEIA, 2009; MELCHELS; FEIJEN; GRIJPMA, 2010; VAN NOORT, 2012).

Novas técnicas para se obter modelos geométricos virtuais têm sido abordados. Este processo reverso de obtenção do modelo virtual é conhecido como engenharia reversa, por meio de técnicas de escaneamento (digitalização, tomografia computadorizada ou ressonância magnética) e programas específicos de importação da peça para o sistema CAD se obtém o modelo em 3D. Na Figura 15 observa-se de maneira simplificada as etapas do processo de fabricação por manufatura orientada por camadas, que abrange as técnicas de MA (VOLPATO, 2007).

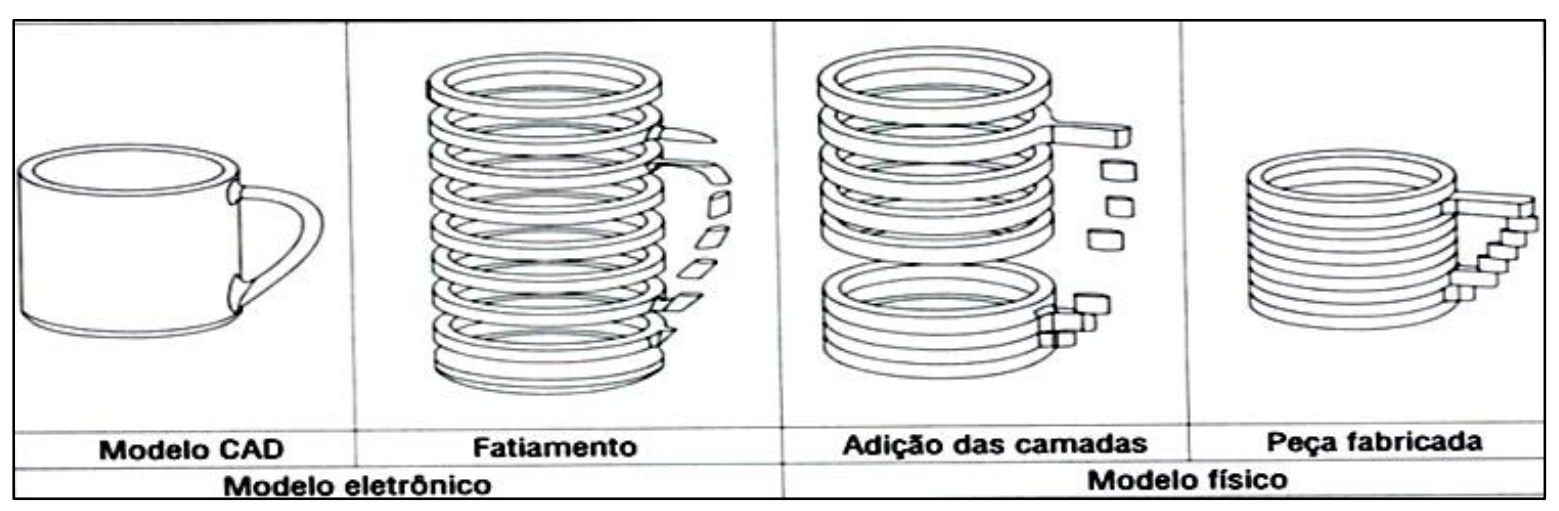

Figura 15 - Processo de manufatura orientada por camadas. Fonte: (VOLPATO, 2007).

A aplicação de processos de MA na área médica ganha destaque na construção de modelos anatômicos e pré-operatórios que permitem à equipe médica uma avaliação crítica de cada caso, proporcionando a otimização do planejamento de cirurgias complexas. Bem como, na fabricação personalizada de implantes para reconstrução de falhas de crânio e face (ASSIS et al., 2010; SHAH; RACASAN; BILLS, 2016).

Com a popularização das técnicas de MA, o termo "impressão 3D" (do inglês “3D Printing”) é frequentemente utilizado como um sinônimo (em um contexto não técnico), pela mídia não especializada no assunto (HARRIS, 2012; VAN NOORT, 2012). No âmbito das técnicas de MA de componentes metálicos o termo impressão 3D em metais 
(de utilização incorreta), pode compreender as técnicas de fusão por feixe laser (SLM) e por feixe de elétrons (do inglês "Electron Beam Melting - EBM"). Estas técnicas encontram-se em expansão principalmente na área da saúde em razão a perspectiva de se produzir componentes customizados, atendendo a necessidade de cada paciente.

Nestas tecnologias é possível obter diversos aspectos positivos, tais como: redução de desperdício, características microestruturais uniformes, propriedades mecânicas homogêneas, elevada precisão dimensional e rapidez de fabricação com características

específicas. É descrito pelos autores a possibilidade de se obter componentes próximos de 100\% da densidade total (CALIGNANO et al., 2017; YAP et al., 2015).

A escolha da matéria-prima, ou material de partida a ser utilizado nos processos de MA influencia no resultado final da fabricação de componentes. Nas técnicas de fusão de camada de pó (do inglês "powder bed melting"), por exemplo nos processos SLM e EBM, o material metálico, em formato particulado, deve apresentar características de: distribuição granulométrica, tamanho, formato, fluidez e empacotamento para um melhor rendimento (TANG et al., 2015; SLOTWINSKI et al., 2014). No processo SLM destaca-se o uso de pós atomizados a gás, por apresentarem propriedades físicas superiores aos pós atomizados a água (SUN; YANG; WANG, 2013; ASM INTERNACIONAL, 1998; GESSINGER, 1984).

Além disso, a capacidade de reutilização do material de alimentação em processos de MA é importante na promoção de processos que otimizem: economia, redução de matéria-prima e proteção ambiental (TANG et al., 2015; SIMCHI; POHL, 2003). Os efeitos e influência do reuso do pó em peças fabricadas é assunto de grande relevância (TANG et al., 2015; SLOTWINSKI et al., 2014; GAYTAN et al., 2009). Tang et al. (2015) avaliaram a reutilização de pós de Ti-6Al-4V no processo EBM. O estudo apresentou o aumento do teor de oxigênio, partículas menos esféricas e com menor presença de satélites. Em relação à amostras consolidadas com o material de reuso não houve alteração significante nas propriedades mecânicas avaliadas em ensaio de tração (TANG et al., 2015).

\subsubsection{Fusão seletiva a laser}

A tecnologia SLM é um processo que se baseia na fusão de camada em pó (descrito pela ISO/ASTM52900-15) e surgiu após o desenvolvimento do processo de sinterização seletiva a laser (Selective Laser Sintering - SLS) em meados da década de 
1980 (YAP et al., 2015; BREMEN; MEINERS; DIATLOV, 2012).

Nesta técnica a matéria prima está em formato de pó metálico e a energia térmica necessária para a completa fusão da camada de pó provém de um feixe laser, que utiliza uma fonte de fibra de Ytérbio (Yb). A potência máxima do laser em máquinas SLM é de aproximadamente $400 \mathrm{~W}$ e o foco do laser possui um diâmetro de aproximadamente $100 \mu \mathrm{m}$. Por sua vez, o feixe laser é comandado por uma interface que o transmite para o conjunto óptico, que, seletivamente, direciona (plano x e y) o feixe laser e proporciona a fusão dos pós.

O pó metálico é armazenado em um container, este pode ou não ser o distribuidor do pó (depositado pela gravidade), que por sua vez uniformiza a camada (entre 20 a $100 \mu \mathrm{m})$ sobre uma plataforma de consolidação do objeto. A cada camada consolidada a plataforma se move no eixo z (de acordo com sobreposição das camadas) até a completa consolidação do componente (YAP et al., 2015; GU et al., 2012; BREMEN; MEINERS; DIATLOV, 2012; MEINERS, 2012; GERMANOVIX, 2011). Na Figura 16 observa-se o esquema básico dos componentes presentes no processo.

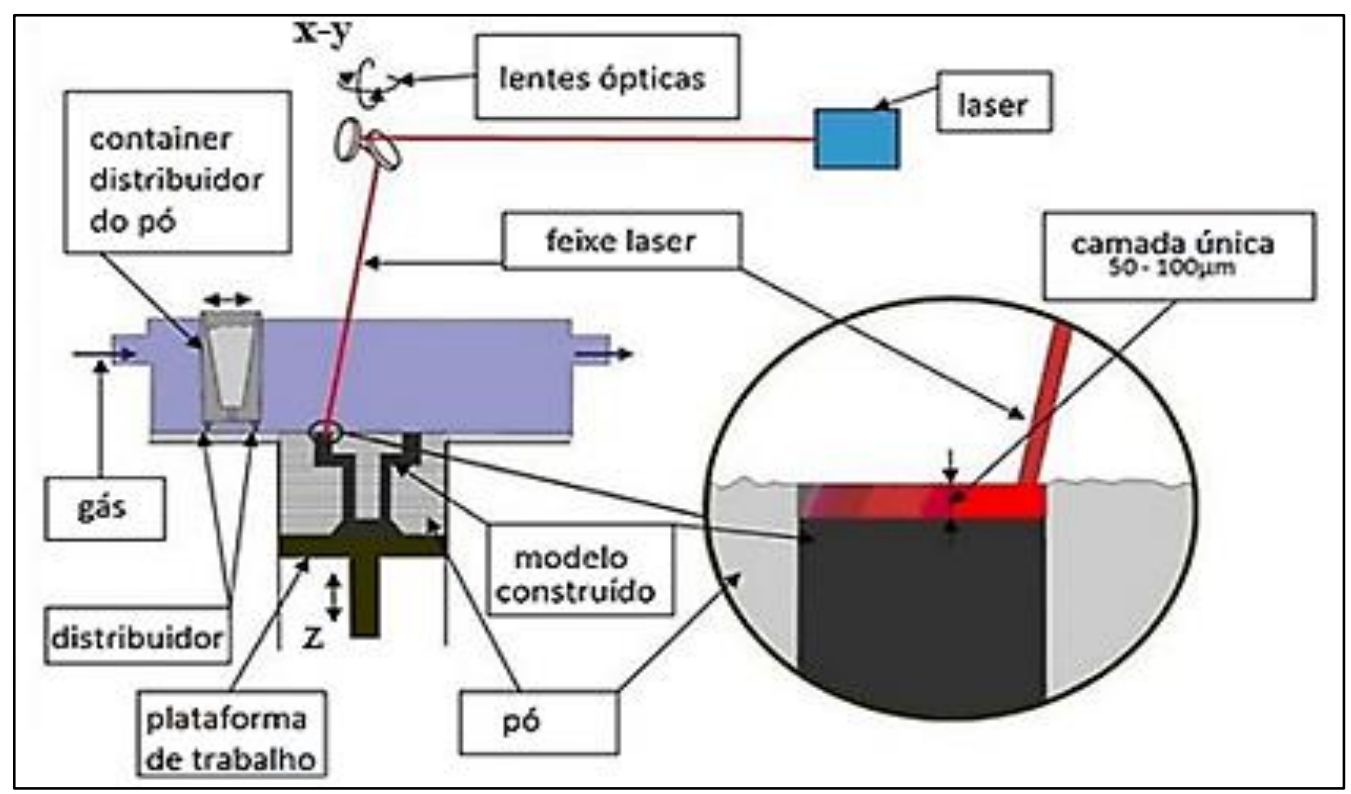

Figura 16 - Esquema básico dos componentes presentes em uma máquina de fusão seletiva a laser. Fonte: Adaptado de (KURZYNOWSKI et al., 2012).

O processo de consolidação do componente ocorre em uma câmara de consolidação, com ambiente interno sob proteção de atmosfera inerte (gases do tipo: argônio, nitrogênio, hélio ou misturas de argônio e nitrogênio) (OLAKANMI; COCHRANE; DALGARNO, 2015; KURZYNOWSKI et al., 2012). A atmosfera exerce 
importante influência nas propriedades mecânicas finais dos componentes nos diversos processos de fabricação (por exemplo, sinterização covencional e conformação) e pósprocessamentos (tratamentos térmicos). No processo SLM de ligas de alumínio, a utilização de atmosfera em operação é importante pois, limpa a câmara de consolidação (varre os produtos de reação prejudiciais), viabiliza reações (por exemplo, na formação de nitreto de alumínio que melhora a estabilidade dimensional de peças) e reduz a oxidação superfícial (OLAKANMI; COCHRANE; DALGARNO, 2015; SCHAFFER et al., 2005)

De acordo com o tipo de fabricante da máquina SLM pode haver mudanças construtivas no equipamento, como por exemplo na forma de deposição do pó (distribuído por meio de um rolo) e na fonte de energia térmica (fontes de fibra de laser de Neodymium Yttrium Aluminium Garnet (Nd:YAG) e Ytterbium Yttrium Aluminium Garnet (Yb:YAG)) (OLAKANMI; COCHRANE; DALGARNO, 2015).

A técnica SLM possui parâmetros de processo que podem ser agrupados em cinco famílias relacionadas ao: laser, escaneamento, material (pó), temperatura e câmara de consolidação (GU et al., 2012; MEINERS, 2012; GERMANOVIX, 2011).

1) Laser: potência " $P$ ”, diâmetro de foco “ $d f$ ”, duração do pulso, frequência do pulso;

2) Escaneamento: velocidade “ $v$ ", distância de hachura (hatch) " $H$ ”, padrão/ estratégia;

3) Pó (material): propriedades do material, tamanho de partícula, distribuição, densidade da cama de pó, espessura da camada " $e_{c}$ ";

4) Temperatura: camada de consolidação, alimentador de pó, uniformidade;

5) Câmara de consolidação: composição da atmosfera protetora.

Na Figura 17 podem ser observados de forma esquemática os principais parâmetros da técnica SLM indicados anteriormente. 


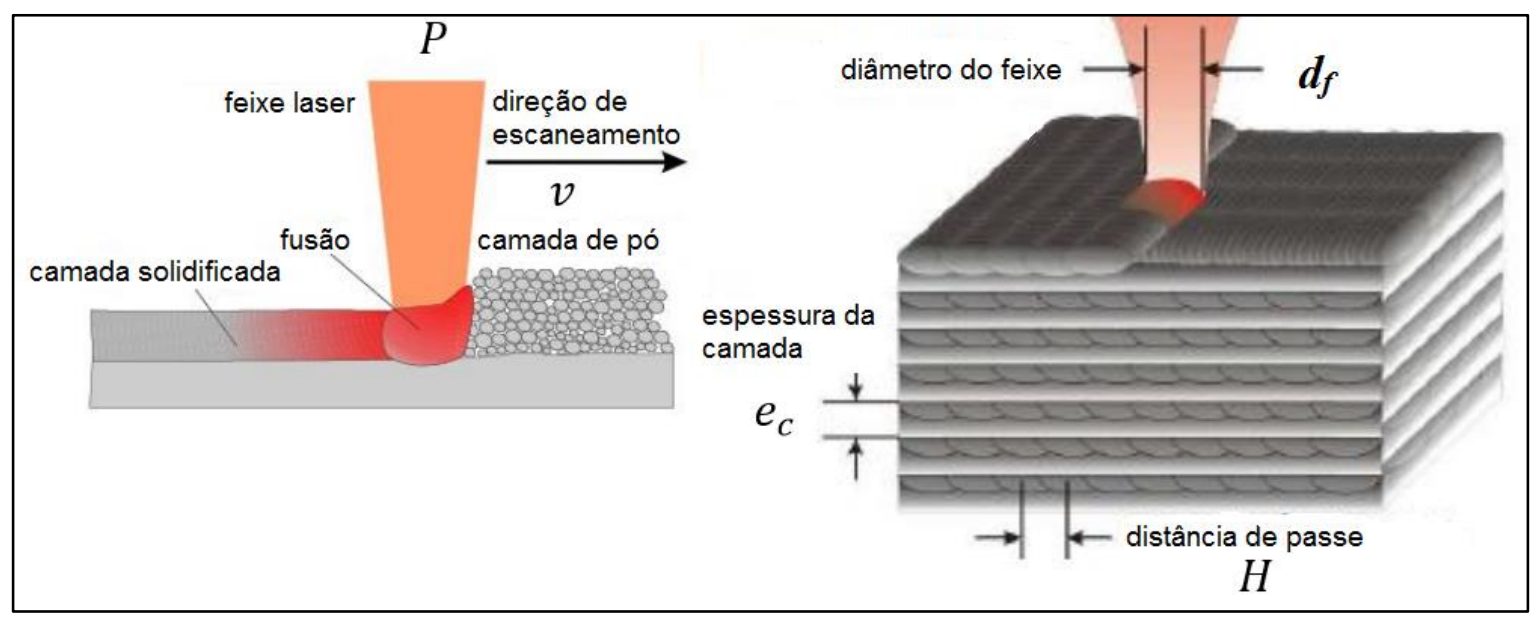

Figura 17 - Representação esquemática e variáveis do processo de consolidação da técnica SLM. Fonte: Adaptado de (MEINERS, 2012).

Conforme descrito, a matéria prima utilizada na técnica SLM é a variável principal, pois influência no processo de fusão da camada. A formação de uma camada uniforme de pó facilita a absorção do laser e na energia térmica transferida a camada de pó. Partículas mais finas proporcionam uma maior área de superfície e absorvem a energia do laser de forma mais eficiente do que em partículas de diâmetros maiores. Em pós de formato esférico, a fluidez é maior quando comparada a de pós irregulares (vide Figura 18). Para tanto, o pó necessita apresentar formato esférico e faixa granulométrica (usual) de 20 a $50 \mu \mathrm{m}$, características determinantes para o pó possuir correta escoabilidade e empacotamento (KURZYNOWSKI et al., 2012).

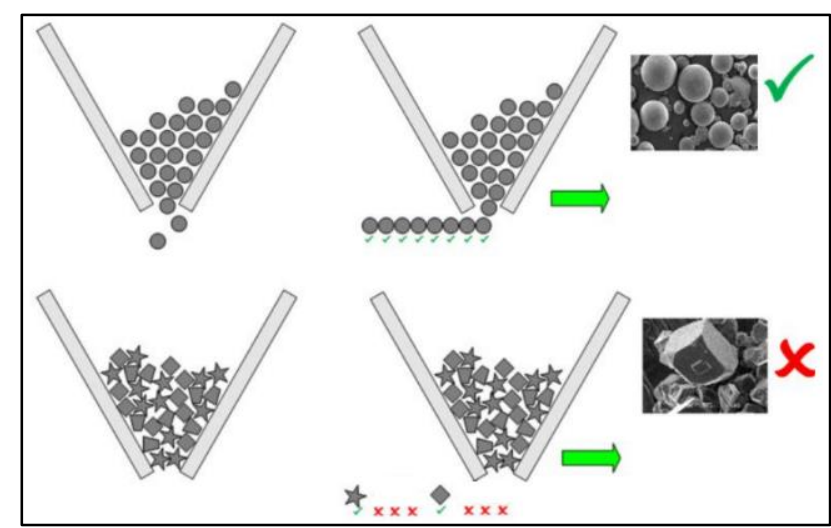

Figura 18 - Esquema de deposição de pós em formato esférico e formato irregular. Fonte: (KURZYNOWSKI et al., 2012).

Os parâmetros a serem ajustados no processo de SLM visando otimização da fabricação de componentes são: potência do laser, velocidade de escaneamento, distância de passe e espessura da camada. Diversos autores (GRZESIAK; KRAWCZYK, 2015; 
SALLICA-LEVA; JARDINI; FOGAGNOLO, 2013; SIMCHI; POHL, 2003) reportam que estes parâmetros afetam a densidade volumétrica de energia, determinante na fusão dos pós e que, por sua vez, influenciam nas propriedades mecânicas e na rugosidade da superfície das peças consolidadas. A combinação dessas variáveis pode gerar insuficiente ou excedente taxa de energia durante o processo de consolidação, que pode acarretar no fenômeno de "balling” entre as camadas (CALIGNANO et al., 2017; YAP et al., 2015).

No entanto, as estratégias de escaneamento também fazem referência ao gradiente de temperatura no processo de consolidação, como: sentido e orientação de escaneamento do feixe laser, ângulo de rotação entre as camadas e ao número de passe do feixe laser (repasse) por camada (LIVERANI et al., 2016; FAIDEL et al., 2015; LU et al., 2015; QIAN et al., 2015).

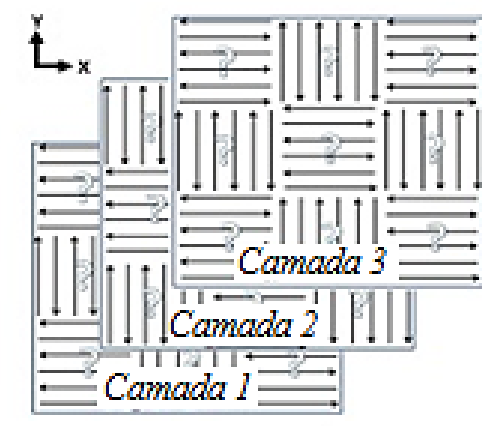

(a)

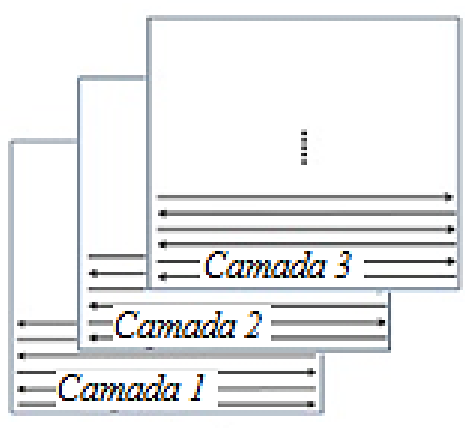

(b)

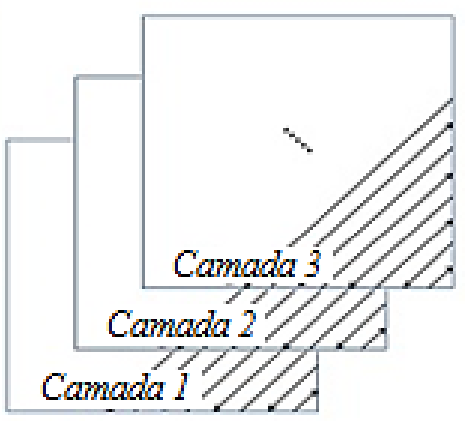

(c)

Figura 19 - Exemplos de diferentes estratégias de escaneamento para consolidação de amostras, escaneamento em: a) ilha, b) linha e c) linha a $45^{\circ}$. Fonte: Adaptado de (CHENG; SHRESTHA; CHOU, 2016).

As propriedades físicas dos componentes finais obtidos por SLM podem estar associadas a anisotropia de fabricação das amostras (vide Figura 20a) e não só relacionados aos diversos parâmetros de consolidação descritos anteriormente. Para tanto, a norma ASTM F2971 descreve uma padronização para reportar os resultados de testes ou a avaliação dos espécimes (por exemplo em relação as propriedades mecânicas) produzidos por MA nos diversos sentidos de escaneamento (vide Figura 20b). (ALSALLA; HAO; SMITH, 2016; GIRARDIN et al., 2016; KAJIMA et al., 2016; VRANCKEN et al., 2014). 


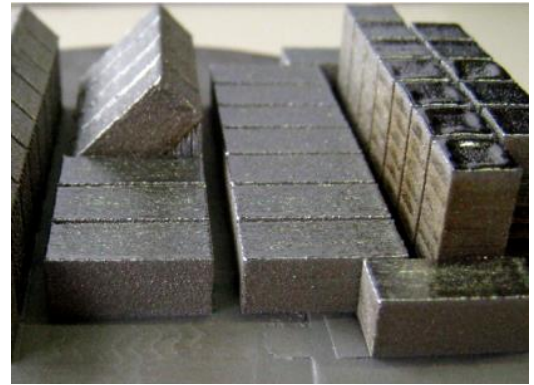

(a)

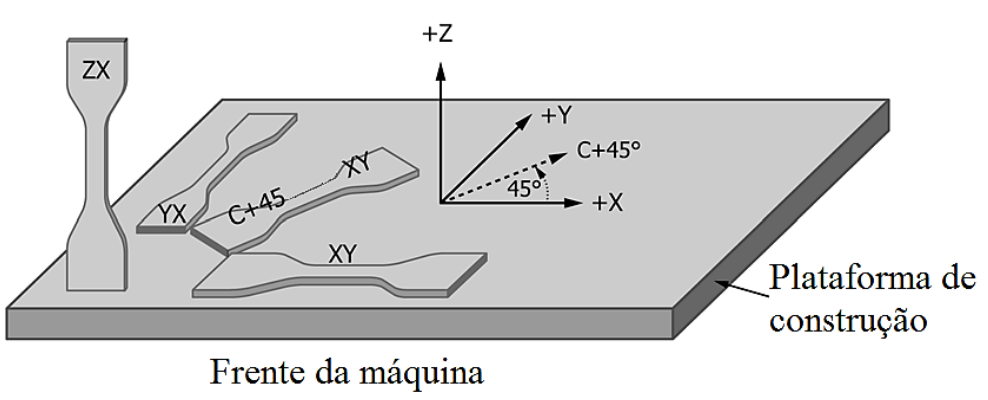

(b)

Figura 20 - a) Representação das amostras SLM orientadas em $0^{\circ}, 45^{\circ}$ e $90^{\circ}$ em relação a plataforma de consolidação e b) representação das orientações de consolidação de amostras por MA. Fonte: Adaptado respectivamente de DADBAKHSH et al., 2016 e ASTM F2971.

A elevada complexidade de avaliação dos parâmetros e variáveis envolvidos no processo SLM é de fundamental importância nos estudos que relacionam estes parâmetros com as características (qualidade superficial e das propriedades mecânicas) dos componentes finais produzidos para o desenvolvimento da tecnologia SLM (ALIAKBARI, 2012; GU et al., 2012; KRUTH et al., 2007).

O pós-processamento dos componentes produzidos por SLM, incluindo jateamento com areia, usinagem, ataque químico, eletro-polimento, pulverização de plasma e tratamentos térmicos são usados em casos específicos (componentes médicos, aeronáuticos e aeroespaciais por exemplo) (CALIGNANO et al., 2017; MANÇANARES, 2016; BREMEN; MEINERS; DIATLOV, 2012).

\subsubsection{Fusão seletiva a laser e fundição de precisão em ligas de $\mathrm{Co}-\mathrm{Cr}$}

Estudos realizados (BILGIN et al., 2016; HEDBERG et al., 2014; JABBARI et al., 2014; KAJIMA et al., 2016; KIM et al., 2016a, 2016b; ÖRTORP et al., 2011; REN; ZHU; CHU, 2016; SONG et al., 2015; TAKAICHI et al., 2013; XIN et al., 2012) têm abordado a técnica de fabricação convencional de fundição (fundição de precisão) comparativamente com a tecnologia de fusão seletiva a laser, em relação aos seguintes aspectos: propriedades mecânicas, microestrutura, corrosão, desgaste - biotribológico e entre outras características que atendam propriedades físicas e químicas, biológicas (biocompatibilidade) de componentes odontológicos.

$\mathrm{O}$ rendimento produtivo da liga de $\mathrm{Co}-\mathrm{Cr}$ atomizada a gás utilizada no equipamento de MA é elevado. Segundo a empresa EOS GmbH Electro Optical Systems (Krailling, Alemanha) que atua no setor industrial de impressão 3D, na área odontológica é possível a produção de 450 coroas customizadas a cada 24 horas. Nos laboratórios de 
próteses, que utilizam o método convencional de fabricação de fusão, usinagem e conformação, o rendimento de fabricação é de 25 coroas para o mesmo tempo de 24 horas. Desta forma esse resultado deve trazer uma diminuição de tempo nos laboratórios e redução dos custos ao usuário final da prótese, o que representa grande vantagem e benefícios econômicos (FOGGIATTO, 2006; TESSARE, 2006).

Na literatura (MORI; YAMANAKA; CHIBA, 2014; YAMANAKA; MORI; CHIBA, 2015, 2016) estudos investigam a relação entre a microestrutura e sua influência nas propriedades mecânicas em ligas de Co-Cr processadas por fundição, sob influência de tratamentos térmicos e adições de elementos de liga para aplicações odontológicas.

Kajima et al. (2016) investigaram a fadiga de amostras de Co-Cr-Mo (liga comercial MP1 da empresa EOS) fabricados por SLM para próteses removíveis dentárias (termo em inglês removable partial dentaures $-R P D$ ). Os resultados apresentaram valores significativos de limite de escoamento e tensão máxima para o grupo de amostras SLM, em relação as amostras fundidas. No entanto, a anisotropia associada a solicitação de fadiga nos espécimes SLM, evidenciaram que a consolidação a $90^{\circ}$ (em relação a plataforma de construção) é extremamente superior ao fundido, bem como nas amostras consolidadas a $0^{\circ}$ e $45^{\circ}$.

Hedberg et al. (2014) estudaram a reposta da biocompatibilidade in vitro de liga dentária de Co-Cr consolidada por diferentes parâmetros de consolidação utilizando a técnica SLM. A liga em pó $(5-40 \mu \mathrm{m})$ de Co-Cr-Mo (MP1 ${ }^{\mathrm{TM}}$ da empresa EOS®) foi utilizada para confecção de espécimes em três estratégias de escaneamento, e para comparação dos resultados foram fabricados espécimes processados por fundição. Os resultados obtidos do estudo evidenciaram que a perda total de metal foi menor para amostras SLM. Hedberg et al. (2014) apontam que estudos devem ser difundidos focando as estratégias e parâmetros de fabricação pela técnica SLM a fim de otimizar a resistência a corrosão e a perda de metais em meio biológico, mantendo as propriedades mecânicas requeridas.

Örtop et al. (2011), avaliaram e compararam a adaptação in vitro de próteses fixas dentárias da liga Co-Cr fabricadas por quatro diferentes métodos: método de cera perdida convencional, cera moída com o método de cera perdida, Co-Cr moído e SLM de metal direto. Os melhores resultados foram obtidos com o uso da técnica SLM.

Viswanathan e Han-Cheol (2009), compararam o comportamento eletroquímico das ligas de implantes dentários Co-Cr-Mo e Ni-Cr-Co por dois diferentes métodos de fabricação: fundição centrífuga e fundição de indução de alta frequência. Os 
resultados apontam que a resistência à corrosão na microestrutura das ligas é pouco significativa em relação ao método de fabricação, porém a liga de $\mathrm{Co}-\mathrm{Cr}$ apresenta melhores propriedades de resistência à corrosão do que a liga de $\mathrm{Ni}-\mathrm{Cr}$.

Foram realizados estudos (MERGULHÃO; PODESTÁ; NEVES, 2015a, 2015b; PODESTÁ; MERGULHÃO; NEVES, 2015) comparativos de espécimes consolidados por fundição de precisão e SLM, a partir de pós de $\mathrm{Co}-\mathrm{Cr}$ nos quais observaram-se uma elevada presença de poros nos espécimes fundidos e propriedades mecânicas inferiores, quando comparadas as obtidas nos espécimes SLM. Conforme as propriedades avaliadas de limite de escoamento e o alongamento nas amostras SLM, resultaram respectivamente $33 \%$ e $40 \%$, superior ao obtido em amostras fundidas.

Segundo Takaichi et al. (2013), as propriedades mecânicas obtidas em amostras fabricadas por fusão seletiva a laser e fundição de uma liga de Co-Cr-Mo (vide Tabela 5), apresentaram respectivamente propriedades de $\sigma_{\mathrm{LE}}=516 \pm 28 \mathrm{MPa}, \sigma_{\mathrm{LR}}=912 \pm$ $39 \mathrm{MPa}$ e $\mathrm{A}_{\mathrm{t}}=10,7 \pm 2,9 \%$ para amostra consolidada por SLM e $\sigma_{\mathrm{LE}}=296 \pm 25 \mathrm{MPa}, \sigma_{\mathrm{LR}}$ $=591 \pm 37 \mathrm{MPa}$ e $\mathrm{A}_{\mathrm{t}}=9,6 \pm 2,5 \%$ para a amostra consolidada por fundição.

Qian, et al. (2015) investigaram a microestrutura em escala macro e micro e as propriedades mecânicas utilizando por meio de amostras SLM, em comparação ao processo fundido de uma liga de Co-Cr-Mo comercial (CoCrMo - EOS®, vide Tabela 5). Os resultados do ensaio de tração para as amostras SLM foi de $\sigma_{\mathrm{LE}}=873 \pm 76 \mathrm{MPa}$ e $\sigma_{\mathrm{LR}}=$ $1303 \pm 73 \mathrm{MPa}$ e para a amostra fundida foi de $\sigma_{\mathrm{LE}}=610 \mathrm{MPa}$ e $\sigma_{\mathrm{LR}}=741 \mathrm{Mpa}$.

Kajima et al. (2016) investigaram a anisotropia mecânica, em ângulo de $0^{\circ}, 45^{\circ}$ e $90^{\circ}$, em amostras de Co-Cr-Mo (liga comercial MP1 da empresa EOS, vide Tabela 5) fabricados por SLM para próteses removíveis dentárias (removable partial dentures $R P D)$. Os espécimes fundidos (via cera perdida e resfriados à temperatura ambiente) foram produzidos com a finalidade de comparação dos resultados mecânicos. Os resultados apresentaram valores significativos de limite de escoamento e tensão máxima para o grupo de amostras SLM em relação as amostras fundidas por precisão. As amostras SLM para a mesma direção de consolidação do presente estudo obtiveram resultados de $\sigma_{\mathrm{LE}}=877 \pm 37$ $\mathrm{MPa}, \sigma_{\mathrm{LR}}=1170 \pm 29 \mathrm{Mpa}$ e $\mathrm{A}_{\mathrm{t}}=12,3 \pm 3 \%$. No caso, das amostras FP do estudo obtevese $\sigma_{\mathrm{LE}}=571 \pm 23 \mathrm{MPa}, \sigma_{\mathrm{LR}}=775 \pm 67 \mathrm{MPa}$ e $\mathrm{A}_{\mathrm{t}}=11,2 \pm 2 \%$.

Segundo Mengucci et al. (2016), amostras consolidadas por SLM em liga de Co-Cr-Mo (vide Tabela 5), após o tratamento de shoot-peened seguido de tratamento térmico para alívio de tensão (forno convencional sob atmosfera de argônio), obteve um resultado de resistência a ruptura transversal (TRS) igual a $2700 \pm 25 \mathrm{Mpa}$. 
De modo geral, as propriedades mecânicas obtidas em espécimes consolidados pela tecnologia SLM, resultam em valores superiores em relação à espécimes consolidados pelo método convencional de fundição de precisão (vide resultados da literatura na Tabela 5). O incremento das propriedades mecânicas é resultado da tecnologia SLM proporcionar uma microestrutura de grãos ultrafinos e de elevada homogeneidade química (QIAN et al., 2015; TAKAICHI et al., 2013). A presença de porosidade é reportada em diversos casos (HAAN et al., 2015; ZHOU et al., 2015), sendo a densidade das amostras superior a 98\% da densidade relativa.

Tabela 5 - Resultados das propriedades mecânicas obtidas de literatura em ligas de Co-CrMo consolidada por fundição (F) e SLM.

\begin{tabular}{|c|c|c|c|c|c|c|c|}
\hline \multicolumn{2}{|c|}{ Referência } & $\begin{array}{c}\text { Liga } \\
(\% \text { em peso })\end{array}$ & $\begin{array}{c}\sigma L E \\
(\mathrm{MPa})\end{array}$ & $\begin{array}{c}\mathbf{A}_{\mathrm{t}} \\
(\%)\end{array}$ & $\begin{array}{c}\sigma_{\mathrm{LR}} \\
(\mathbf{M P a})\end{array}$ & $\begin{array}{c}\text { TRS } \\
\text { (MPa) }\end{array}$ & $\begin{array}{c}\text { Dureza } \\
\text { (HV) }\end{array}$ \\
\hline \multirow{2}{*}{$\begin{array}{l}\text { Takaichi et al. } \\
\text { (2013) }\end{array}$} & $\mathbf{F}$ & \multirow{2}{*}{ Co- $28 \mathrm{Cr}-6 \mathrm{Mo}$} & $296 \pm 25$ & $9,6 \pm 2,5$ & $912 \pm 39$ & - & - \\
\hline & SLM & & $516 \pm 28$ & $10,7 \pm 2,9$ & $591 \pm 37$ & - & - \\
\hline \multirow{2}{*}{$\begin{array}{l}\text { Qian et al. } \\
\quad(2015)\end{array}$} & $\mathbf{F}$ & \multirow{2}{*}{$\begin{array}{l}\text { 60-65Co } 26-30 \mathrm{Cr} \\
5-7 \mathrm{Mo}\end{array}$} & 610 & - & 741 & - & - \\
\hline & SLM & & $873 \pm 76$ & - & $1303 \pm 73$ & - & - \\
\hline \multirow{2}{*}{$\begin{array}{l}\text { Kajima et al. } \\
\qquad(2016)\end{array}$} & $\mathbf{F}$ & $63 \mathrm{Co}-29 \mathrm{Cr}-6 \mathrm{Mo}$ & $571 \pm 23$ & $11,2 \pm 2$ & $775 \pm 67$ & - & - \\
\hline & SLM & $\begin{array}{c}\text { 60-65Co } 26-30 \mathrm{Cr} \\
5-7 \mathrm{Mo}\end{array}$ & $877 \pm 37$ & $12,3 \pm 3$ & $1170 \pm 29$ & - & - \\
\hline $\begin{array}{l}\text { Mengucci et al. } \\
\text { (2016) }\end{array}$ & SLM & $\begin{array}{c}63,8 \mathrm{Co}-24,7 \mathrm{Cr}- \\
5,1 \mathrm{Mo}-5,4 \mathrm{~W}\end{array}$ & - & - & $1340 \pm 20$ & $2700 \pm 25$ & $434 \pm 22$ \\
\hline \multirow{2}{*}{$\begin{array}{l}\text { Jabbari et al. } \\
\text { (2014) }\end{array}$} & $\mathbf{F}$ & $\begin{array}{c}61,6 \mathrm{Co}-30 \mathrm{Cr}- \\
6,5 \mathrm{Mo}\end{array}$ & - & - & - & - & $320 \pm 12$ \\
\hline & SLM & Co-29Cr-5,5Mo & - & - & - & - & $371 \pm 10$ \\
\hline $\begin{array}{c}\text { Liverani et al. } \\
(2016)\end{array}$ & SLM & Co $27-30 \mathrm{Cr} 5-7 \mathrm{Mo}$ & 677 & - & - & - & $361 \pm 31$ \\
\hline
\end{tabular}

Diversos autores (HAAN et al., 2015; MERGULHÃO; PODESTÁ; NEVES, 2015a, 2015b; PODESTÁ; MERGULHÃO; NEVES, 2015) apresentam a microestrutura de amostras consolidadas por fundição de precisão e SLM (vide Figura 21). Em amostras fundidas é descrito a formação de uma microestrutura dendrítica, estrutura bruta de fusão originada pela lenta solidificação do material (AHMED et al., 2014; JABBARI et al., 2014; KAISER et al., 2013; SONG et al., 2006; TAKAICHI et al., 2013). Amostras obtidas pelo processo SLM (vide Figura 21b) apresentam uma microestrutura com formato característico da fusão a laser, e sua configuração depende do tipo de estratégia de escaneamento utilizada no processo. Esta configuração típica do processo SLM é descrita por diversos autores (BARUCCA et al., 2015; GIRARDIN et al., 2016; RIVERA et al., 2011; STAWARCZYK et al., 2014; TAKAICHI et al., 2013; XIN et al., 2012). 

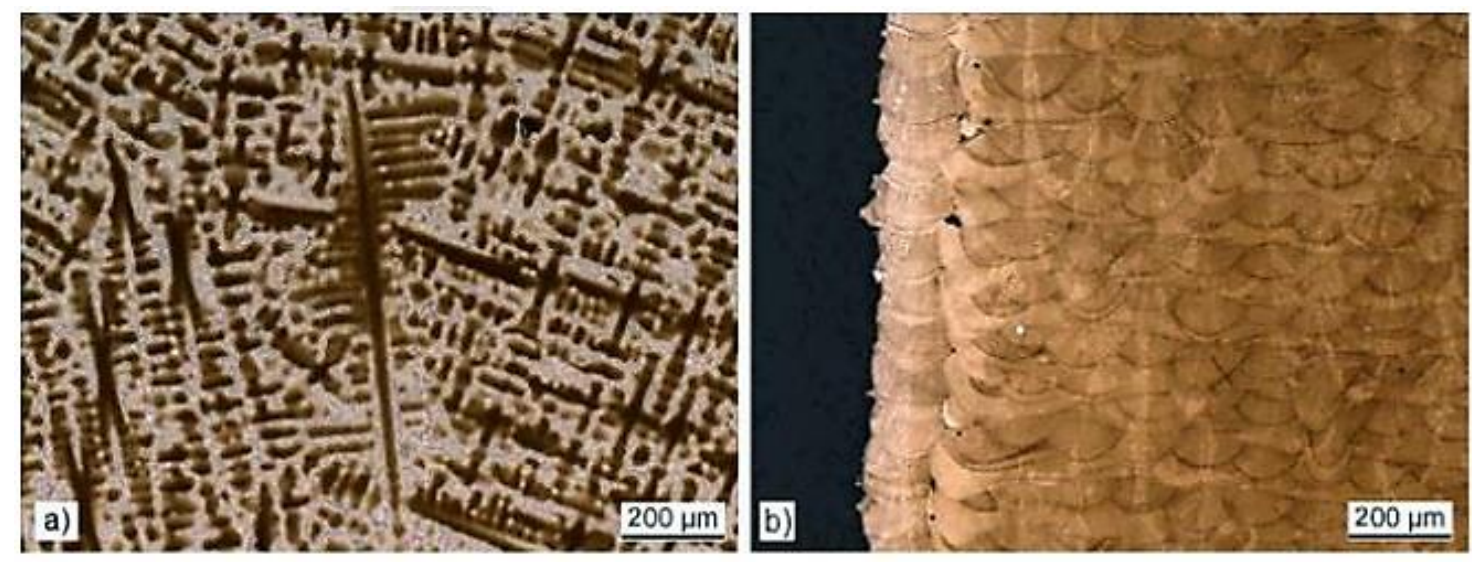

Figura 21 - Microestrutura típica de amostras fabricadas por fundição de precisão (a) e fusão seletiva a laser (b) de liga de Co-Cr após ataque químico. Fonte: Adaptado de (HAAN et al., 2015).

Os autores (JABBARI et al., 2014; YAMANAKA; MORI; CHIBA, 2015; ZANGENEH; LASHGARI; ROSHANI, 2012) estudaram a caracterização das fases presentes na liga de Co-Cr por MEV com EDS. As imagens formadas a partir de elétrons retroespalhados são obtidas por contraste de composição. Regiões da amostra que apresentam áreas mais escuras na imagem são formadas por elementos com menor número atômico "Z", e as áreas mais claras na imagem são formadas por elementos com maior número atômico "Z”. O contraste por composição é formado em razão a maior ou menor penetração dos elétrons na superfície da amostra, que responde com o retroespalhamento dos elétrons, originando o contraste claro ou escuro. Ao realizar imagens a partir de elétrons secundários é obtido uma imagem de topografia da superfície da amostra (VOORT, 1984). 


\section{MATERIAL E MÉTODOS}

\subsection{FLUXOGRAMA}

Nesta seção faz-se a utilização de fluxogramas para melhor visualização e compreensão da metodologia utilizada no presente trabalho.

O trabalho subdivide-se em três etapas: Etapa I - caracterização do material particulado (vide Figura 22); Etapa II - caracterização das amostras consolidadas (vide Figura 23) e Etapa III - caracterização mecânica e avaliação microestrutural das amostras consolidadas (vide Figura 24).

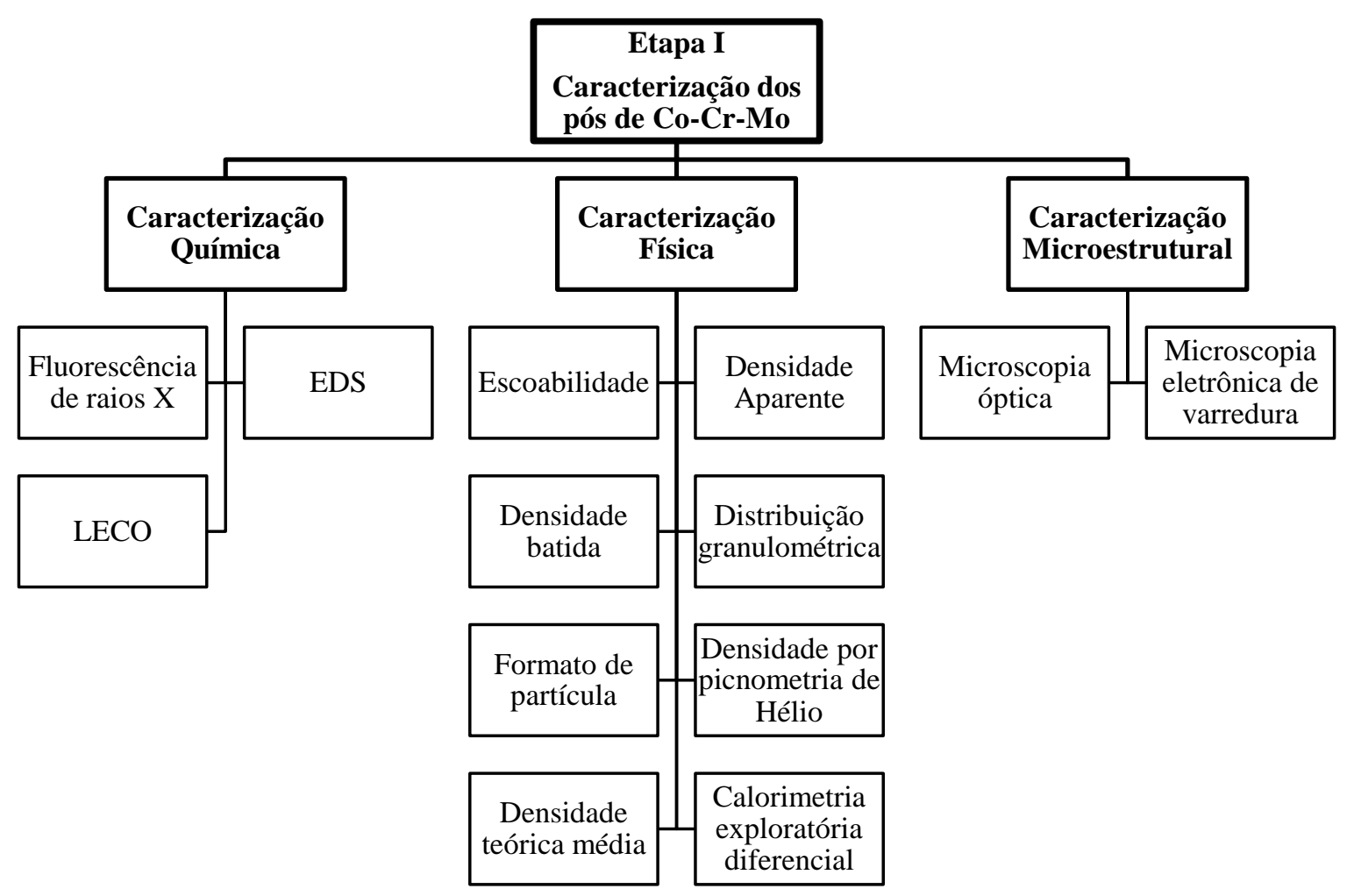

Figura 22 - Fluxograma da etapa I de caracterização química, física e microestrutural dos pós de Co-Cr-Mo. 


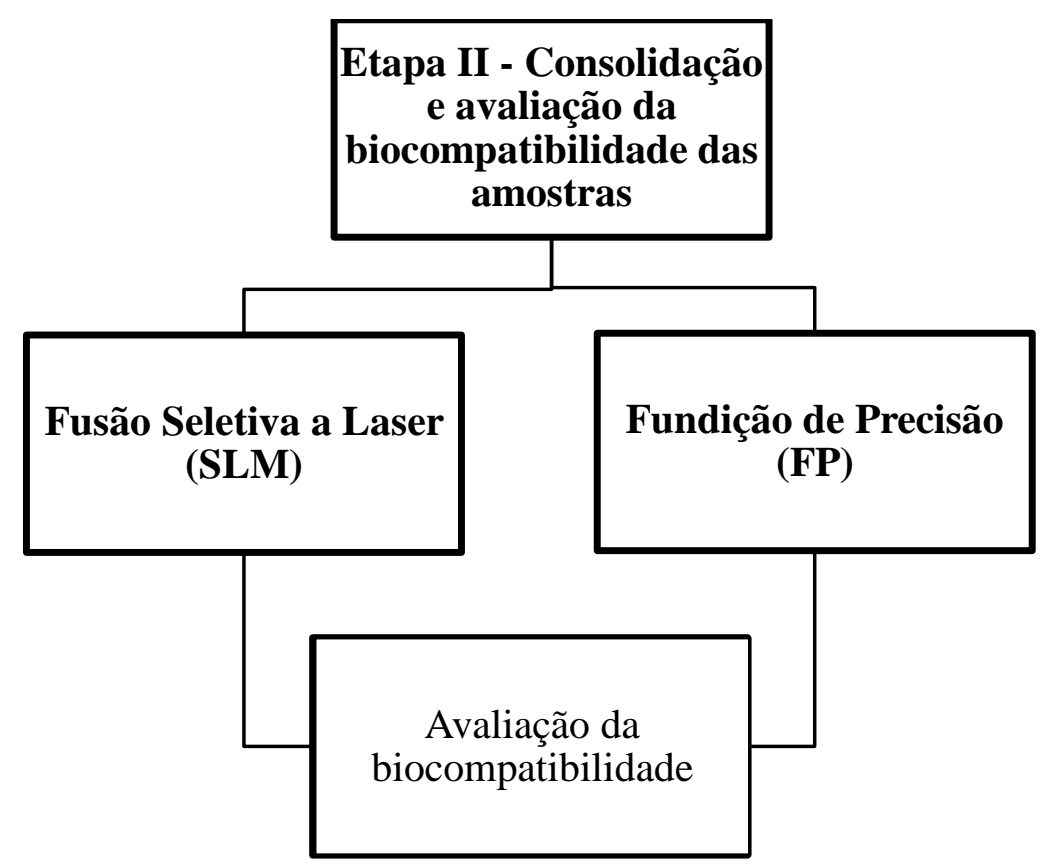

Figura 23 - Fluxograma da etapa II de consolidação das amostras por fusão seletiva a laser (SLM) e por fundição de precisão (FP).

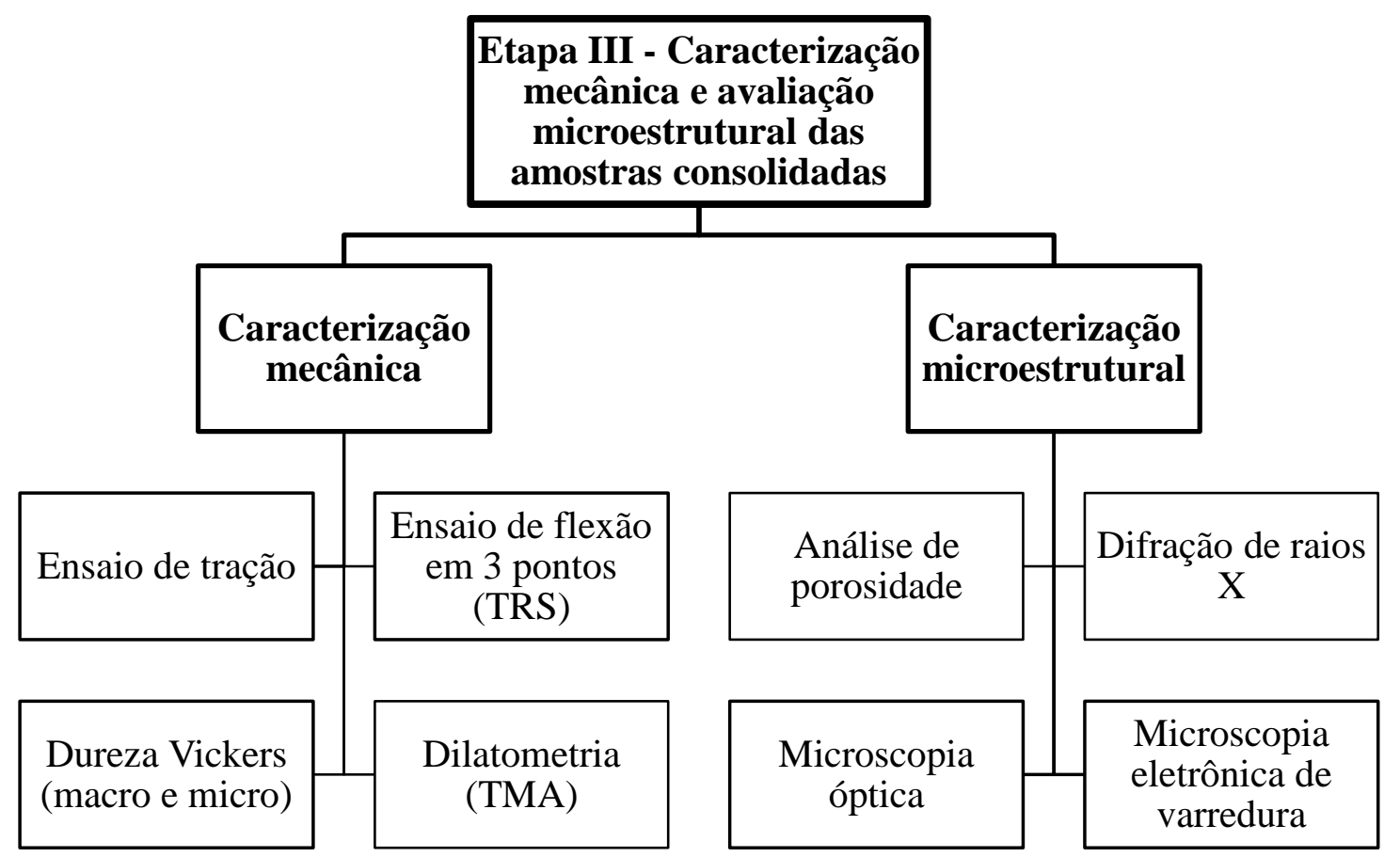

Figura 24 - Fluxograma da etapa III de caracterização mecânica e avaliação microestrutural das amostras consolidadas. 


\subsection{MATERIAL UTILIZADO}

A liga utilizada é constituída, basicamente, de Co-Cr-Mo e foi fornecida pela empresa HighBond® (Indaiatuba, Brasil), em três faixas granulométricas denominadas D1, D2 e D3 (conforme pode ser visto na Tabela 6). O material particulado (pó) foi obtido por atomização a gás realizada pela empresa H.C Starck® (Munique, Alemanha). A realização deste estudo baseou-se na liga fabricada por indústria nacional com certificação da Anvisa.

Tabela 6 - Caracterização dos pós de Co-Cr-Mo em relação a faixa granulométrica recebida.

\begin{tabular}{cc}
\hline Denominação dos pós & Faixa Granulométrica recebida $(\boldsymbol{\mu m})$ \\
\hline D1 & $<15$ \\
\hline D2 & 15 a 45 \\
\hline D3 & 76 a 106
\end{tabular}

A composição química das amostras de pós e da liga consolidada pelas técnicas de FP e por SLM foram determinadas por espectrômetro de fluorescência de raios X por energia dispersiva, utilizando o equipamento EDX-720 da marca Shimadzu, alocado no Centro de Ciência e Tecnologia de Materiais (CCTM) do IPEN. Foram realizadas três análises para cada tipo de amostra (em pó, FP e SLM). Ressalta-se que a técnica de fluorescência de raios $\mathrm{X}$ baseia-se em uma análise química semiquantitativa dos elementos presentes na amostra.

A análise dos elementos de $\mathrm{C}, \mathrm{S}$, e $\mathrm{O}$ foram obtidas por meio do método de adsorção na região do Infravermelho e a determinação de $\mathrm{N}$ por condutividade térmica utilizando o equipamento LECO®, localizado no Laboratório de Análises Químicas e Ambiental (LAQA) do Centro de Química e Meio Ambiente (CQMA) do IPEN.

\subsection{CARACTERIZAÇÃO FÍSICA E QUÍMICA DOS PÓS}

Foram determinadas propriedades físicas dos pós atomizados a gás, consideradas relevantes para este estudo como: distribuição granulométrica, escoabilidade, densidade teórica média, densidade aparente, densidade batida, densidade por picnometria de Hélio, formato das partículas, área de superfície específica e análise de calorimetria 
exploratória diferencial. Foi realizada a caracterização química dos pós por energia dispersiva de raios X (SEM-EDS). Nas seções seguintes são descritos os métodos para avaliação das propriedades físicas e químicas.

\subsubsection{Distribuição granulométrica dos pós}

As amostras dos pós atomizados a gás foram caracterizadas por meio da distribuição granulométrica utilizando um equipamento analisador de partículas por espalhamento (ou difração) de raios a laser, em um equipamento Cilas, modelo 1064

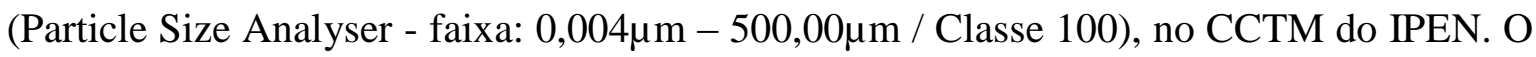
ensaio foi realizado em meio líquido de água destilada com adição de dispersante de Pirofosfato de Sódio, sob uso de ultrassom por 60 segundos.

$\mathrm{Na}$ análise da distribuição granulométrica obteve-se o valor do diâmetro cumulativo de 10\% (D10), 50\% (D50) e 90\% (D90). Os valores compreendidos de D10 e D90 são aproximações do menor e do maior diâmetro contido na amostra analisada. A análise é representada também por meio de duas curvas (primeira é a curva cumulativa "Q3" (em vermelho) representa a proporção do diâmetro da amostra e a segunda é a curva do histograma "q3" (em barras cinza) que representa a distribuição de tamanho para diferentes classes de tamanhos, no caso o histograma é a função derivada dos valores cumulativos). Portanto, a curva do histograma define o diâmetro médio em micrometros pela porcentagem da concentração da amostra passante.

\subsubsection{Formato das partículas}

O formato das partículas dos pós de Co-Cr-Mo, nas granulometrias recebidas, foi analisado no microscópio eletrônico de varredura - MEV Philips XL30. As amostras dos pós foram submetidas a análise sem preparação prévia, apenas utilizando uma fita adesiva de carbono, necessária para que a amostra se torne condutor e as partículas não sejam levadas pelo alto vácuo, presente na coluna do microscópio de varredura.

Com o objetivo de estudar a morfologia de solidificação dos pós formada pelo processo de atomização a gás, os mesmos foram submetidos à preparação metalográfica, para análise por meio de microscopia óptica e microscopia eletrônica de varredura.

As amostras dos pós de Co-Cr-Mo foram submetidas a análise química por meio do EDS acoplado ao MEV. Ressalta-se que a análise química por EDS é uma análise 
semiquantitativa, e trata-se de uma informação da composição dos elementos químicos presentes na amostra analisada e, portanto, não revela precisamente a quantidade dos elementos químicos presentes.

\subsubsection{Escoabilidade}

O ensaio de escoabilidade dos pós foi realizado de acordo com a norma ASTM B213 (2013a). A medida de escoabilidade foi obtida pela relação de tempo decorrido (segundos), em função do escoamento de 50 gramas do pó por meio do funil de Hall. A grandeza de escoabilidade é representada em segundos por 50 gramas (s/ 50g) (ASTM INTERNATIONAL, 2013a).

O resultado do ensaio foi calculado por meio do valor médio e desvio padrão de dez aferições para cada granulometria de pó. Para validar o resultado de escoabilidade dos pós verificou-se o desvio entre o maior e menor resultado de escoabilidade e chegou-se ao valor de no máximo de $0,4 \mathrm{~s} / 50 \mathrm{~g}$ de diferença.

\subsubsection{Densidade teórica média}

A densidade teórica média da liga de Co-Cr-Mo foi mensurada por meio dos cálculos de fração volumétrica (vide equação 1) e densidade média dos componentes presentes na liga (vide equação 2). As frações de massa dos elementos presentes foram obtidas por meio das análises de fluorescência de raios X.

As propriedades químicas dos componentes químicos presentes na liga de CoCr-Mo foram obtidas da tabela periódica da Merck (MERCK GROUP, 2016).

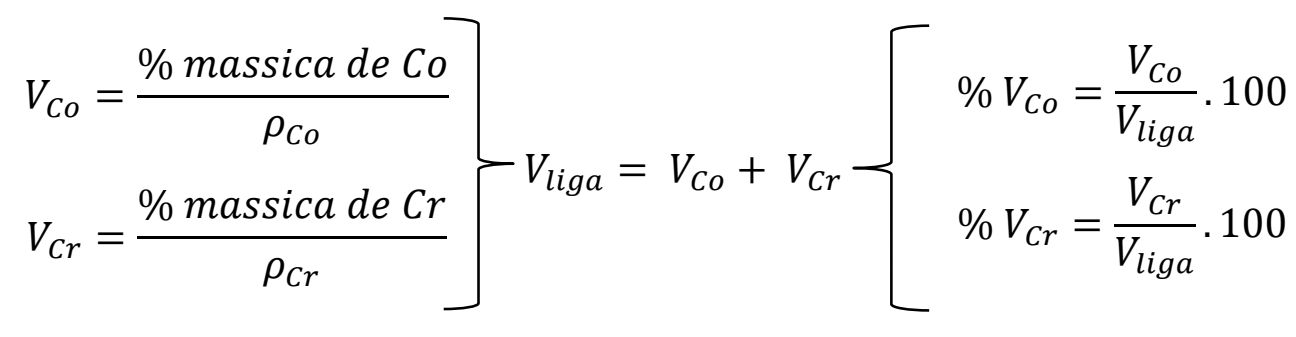

$$
\begin{aligned}
& \rho_{\text {liga }}=\frac{\% V_{C o}}{100} \cdot \rho_{C o}+\frac{\% V_{C r}}{100} \cdot \rho_{C r}
\end{aligned}
$$




\subsubsection{Densidade aparente}

Os ensaios de densidade aparente dos pós foram realizados segundo a norma ASTM B212 (2013b). A densidade aparente é obtida pelo escoamento do pó no funil de Hall (Figura 25a) até que o recipente de densidade (Figura 25b) com volume total de 25 $\mathrm{cm}^{3}$ seja preenchido. Para tanto, o recipiente é pesado e obtém-se a massa do pó contido no recipiente. O resultado do ensaio foi calculado por meio do valor médio e desvio padrão de dez aferições para cada granulometria de pó.

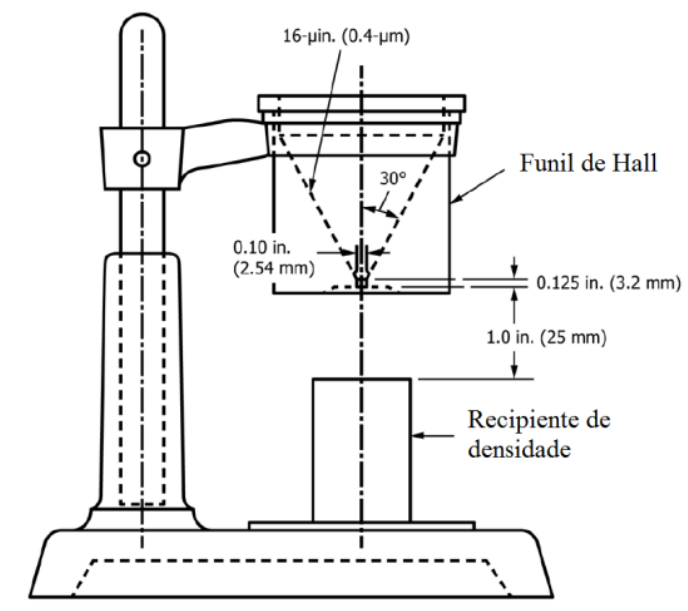

(a)

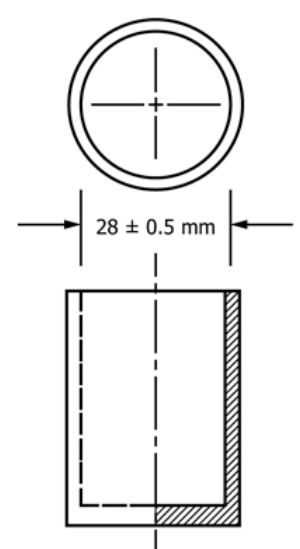

(b)

Figura 25 - a) Funil de Hall utilizado para medida de densidade aparente e b) recipiente de densidade. Fonte: Adaptado de (ASTM INTERNATIONAL, 2013b).

\subsubsection{Densidade batida}

Os ensaios da densidade batida dos pós foram realizados segundo a norma ASTM B527 (2014). Para realizar o ensaio de densidade batida em pós metálicos com densidade aparente maior do que $4,0.10^{-3} \mathrm{~kg} / \mathrm{m}^{3}$ é necessário o uso de um tubo graduado com escala de $0,2 \mathrm{~cm}^{3}\left(2.10^{-7} \mathrm{~m}^{3}\right)$ (vide Figura 26).

O ensaio foi realizado a partir da massa de 100 gramas de pó. O tubo de ensaio foi submetido à choques verticais até que não haja mais adensamento do pó. Com isso, aferiu-se o volume característico batido e calculou-se a densidade batida pela relação da massa do pó (dada em $\mathrm{kg}$ ), pelo volume batido (dado em $\mathrm{m}^{3}$ ) da amostra. O resultado do ensaio foi calculado por meio do valor médio e desvio padrão de dez aferições para cada granulometria de pó. 


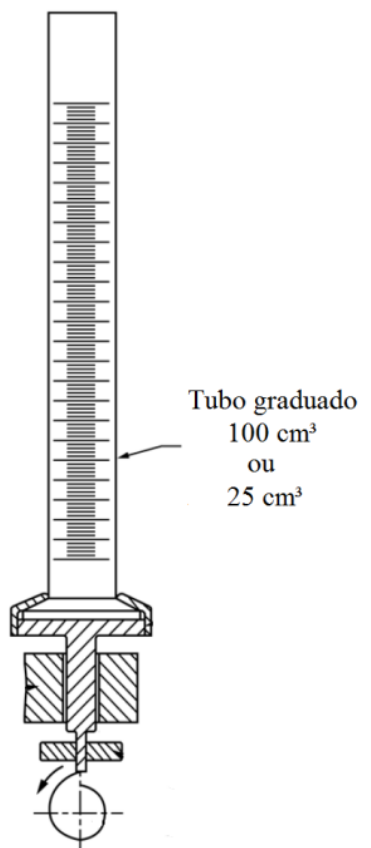

(a)

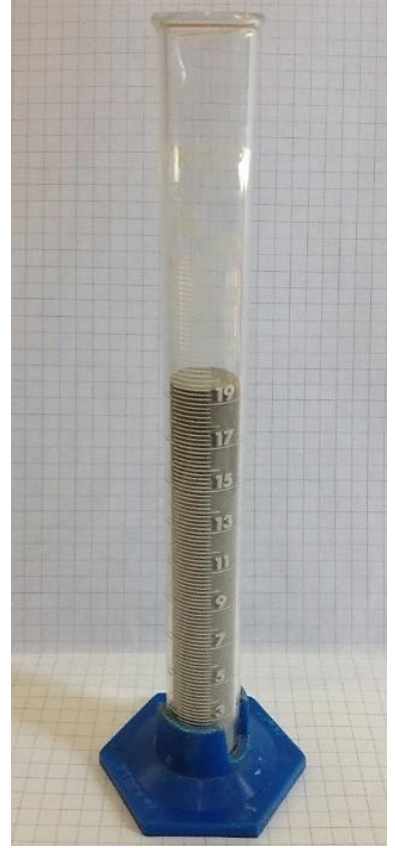

(b)

Figura 26 - a) Exemplo do equipamento de densidade batida e b) tubo graduado utilizado para realização da medida de densidade batida dos pós. Fonte: Adaptado de (ASTM

INTERNATIONAL, 2014).

\subsubsection{Densidade por picnometria de Hélio}

A análise de picnometria de Hélio (He) é uma técnica utilizada para a medição de volume real de um sólido, na qual o gás de He recobre a superfície da amostra, e penetra facilmente nos poros abertos que a amostra possa apresentar. Deste modo, a densidade mensurada pelo equipamento considera a porosidade interna (fechada), a qual não é possível ser analisada pelo equipamento.

A caracterização por picnometria de $\mathrm{He}$ foi realizada nos pós da liga $\mathrm{Co}-\mathrm{Cr}$ Mo. Pretende-se com esta técnica a comparação entre os resultados de densidades mensuradas a partir de outras técnicas, bem como quantificar a porosidade interna das amostras. O resultado do ensaio foi calculado por meio do valor médio e desvio padrão de trinta aferições em cada amostra de pó (granulometrias D1, D2 e D3). A densidade por picnometria de He foi obtida por meio do equipamento Micromeritics, modelo Accu Pyc 1330 Pycnometer, localizado no Centro de Combustível Nuclear (CCN) do IPEN.

\subsubsection{Análise de Calorimetria Exploratória Diferencial (DSC)}

A análise de calorimetria exploratória diferencial foi realizada na amostra de pó D1 (atomizada a gás) da liga de Co-Cr-Mo. Selecionou-se o menor tamanho de 
partícula, partindo-se da premissa que amostras com menor tamanho proporcionam maior sensibilidade dos eventos ocorridos. O equipamento utilizado foi o Setsys 16/18, da Setaram, utilizando a haste com termopar de $\mathrm{Pt} / \mathrm{Pt} \mathrm{Rh} 10 \%$, cuja temperatura máxima de análise é de $1600^{\circ} \mathrm{C}$, alocado no Laboratório de Metalografia do CCN-IPEN.

O resultado de DSC foi obtido por meio de três corridas (curvas de aquecimento e resfriamento) para a amostra de pó D1 de Co-Cr-Mo, em taxas de 10, 20 e $30^{\circ} \mathrm{C} / \mathrm{min}$. A atmosfera estática constituída em argônio $(99,999 \%)$ foi usada para evitar a possível oxidação das amostras. Os experimentos foram conduzidos utilizando cadinhos (porta amostra e referência - vazio durante todos os ensaios) constituídos de alumina $\left(\mathrm{Al}_{2} \mathrm{O}_{3}\right)$ e o volume da amostra de pó $\mathrm{D} 1$ foi de aproximadamente $100 \mu \mathrm{L}$. A rotina para esta análise de DSC consistiu-se de:

- Aquecimento da amostra da temperatura ambiente (fixada em $30^{\circ} \mathrm{C}$ ) até $1400^{\circ} \mathrm{C}$ (temperatura acima do ponto de fusão do material) de acordo com a sua respectiva taxa $\left(10,20,30^{\circ} \mathrm{C} / \mathrm{min}\right)$, e manutenção da temperatura máxima por 20 minutos.

- Início do resfriamento da amostra (depois de atingido o patamar da temperatura máxima) com taxas de aquecimento $\left(10,20,30^{\circ} \mathrm{C} / \mathrm{min}\right)$ até a temperatura ambiente.

\subsection{CONSOLIDAÇÃO DAS AMOSTRAS}

A consolidação do material de partida (pós atomizados a gás) da liga de Co-CrMo foi realizada pelas técnicas de fundição de precisão e SLM.

Os corpos de prova de tração foram fabricados em dimensões padronizadas segundo a norma ISO 22674 (2006). A norma ISO 22674 especifica as propriedades mecânicas mínimas para ligas metálicas utilizadas em próteses móveis e fixas, bem como estabelece uma classificação (do tipo 1 ao 5, sendo o tipo 5 a classe superior) de acordo com a propriedade mecânica adquirida.

Os corpos de prova de flexão em três pontos para determinação da tensão de resistência a ruptura (TRS) foram fabricados em dimensões padronizadas segundo norma ASTM B528 (2012a).

Nas seções seguintes são apresentados alguns detalhes dos processos de fabricação utilizados na confecção dos espécimes. 


\subsubsection{Consolidação por fundição via cera perdida}

A consolidação dos corpos de prova de tração e flexão em 3 pontos da liga CoCr-Mo foi realizada pela técnica convencional de fundição de precisão (via cera perdida), segundo a norma ASTM F75 (ASTM INTERNATIONAL, 2012b).

O processo de fabricação das amostras seguiu as seguintes etapas: usinagem de discos de cera nas dimensões padronizadas dos corpos de prova de tração e flexão em três pontos; montagem e revestimento dos cachos; e após desceragem foi realizada a fundição da liga de Co-Cr-Mo por meio de um forno de indução à temperatura de $1489^{\circ} \mathrm{C}$. $\mathrm{Na}$ Figura 27 verificam-se os corpos de prova fabricados pela empresa HighBond ${ }^{\circledR}$ (Indaiatuba, Brasil).

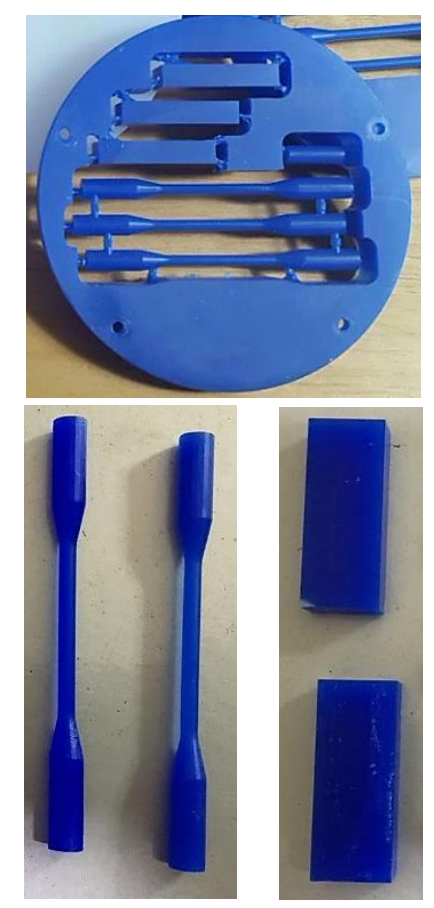

(a)

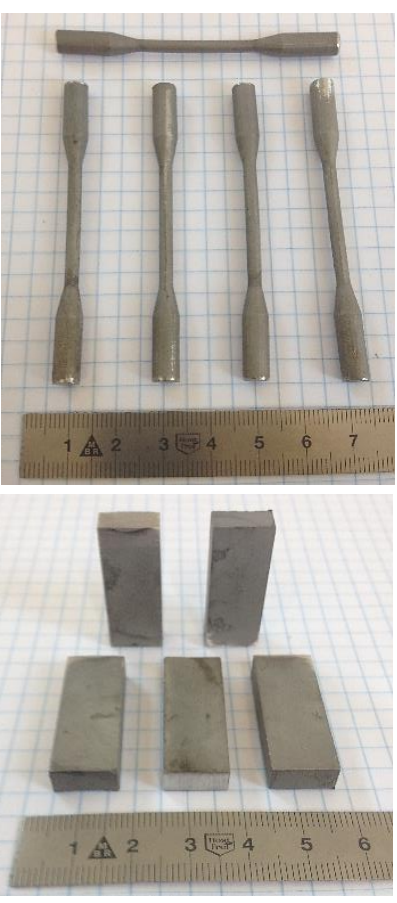

(b)

Figura 27 - a) Modelos em cera usinados nas dimensões padronizadas dos corpos de prova de tração e flexão e b) corpos de provas fabricados por FP da liga Co-Cr-Mo.

\subsubsection{Consolidação por SLM}

A consolidação pela técnica SLM dos corpos de prova de tração e de flexão em três pontos da liga Co-Cr-Mo foi realizada conforme as dimensões padronizadas da norma ISO 22674. A consolidação das amostras pela técnica de SLM foi realizada pela empresa SLM Solutions® (Lübeck, Alemanha) utilizando uma máquina de SLM (SLM ${ }^{\circledR} 280^{\mathrm{HL})}$. Os parâmetros utilizados para consolidação foram determinados pelo padrão de sistema de 
fabricação do equipamento. Na Tabela 7 verifica-se os parâmetros principais da máquina utilizada $\mathrm{SLM}^{\circledR} 280^{\mathrm{HL}}$.

Tabela 7 - Principais parâmetros do sistema de operação da máquina $\operatorname{SLM}^{\circledR} 280^{\mathrm{HL}}$ (SLM Solutions $\left.{ }^{\circledR}\right)$.

\begin{tabular}{|c|c|}
\hline \multicolumn{2}{|c|}{ Parâmetros do sistema da máquina SLM ${ }^{\circledR} 280^{\mathrm{HL}}$} \\
\hline Volume de fabricação & $280 \times 280 \times 365 \mathrm{~mm}^{3}$ \\
\hline Potência do laser (máxima) & $400 \mathrm{~W}-$ Laser de fibra de Yb \\
\hline Velocidade de construção & $>55 \mathrm{~cm}^{3} / \mathrm{h}$ \\
\hline Espessura de camada & $20 \mu \mathrm{m}-75 \mu \mathrm{m}$ \\
\hline Diâmetro do feixe laser (em operação) & $80-120 \mu \mathrm{m}$ \\
\hline Velocidade máxima de escaneamento & $10 \mathrm{~m} / \mathrm{s}$ \\
\hline Consumo de gás inerte (em operação) & $\mathrm{Ar} / \mathrm{N}_{2}, 2,5 \mathrm{~L} / \mathrm{min}-3,0 \mathrm{~L} / \mathrm{min}$ \\
\hline
\end{tabular}

A consolidação dos espécimes da liga de Co-Cr-Mo, segundo informações do fabricante, foram realizados sob os seguintes parâmetros:

- Potência do laser: $400 \mathrm{~W}$ (variável durante o processo);

- Espessura de camada: $30 \mu \mathrm{m}$;

- Diâmetro do feixe laser: $76 \mu \mathrm{m}$;

- Atmosfera de operação: Ar/ $\mathrm{N}_{2}$ com vazão de 3,0 L/min

A velocidade de escaneamento e a estratégia de escaneamento utilizada no processo de consolidação das amostras são desconhecidos em razão a proteção de tecnologia utilizada pela empresa SLM Solutions ${ }^{\circledR}$.

A orientação de consolidação das amostras de tração e flexão em três pontos foi realizada no eixo ZY, conforme pode ser observado na Figura 28a. Em sua totalidade foram produzidas 10 amostras de tração e 10 amostras de flexão em três pontos pela técnica de SLM, vide Figura 28 b e c. 


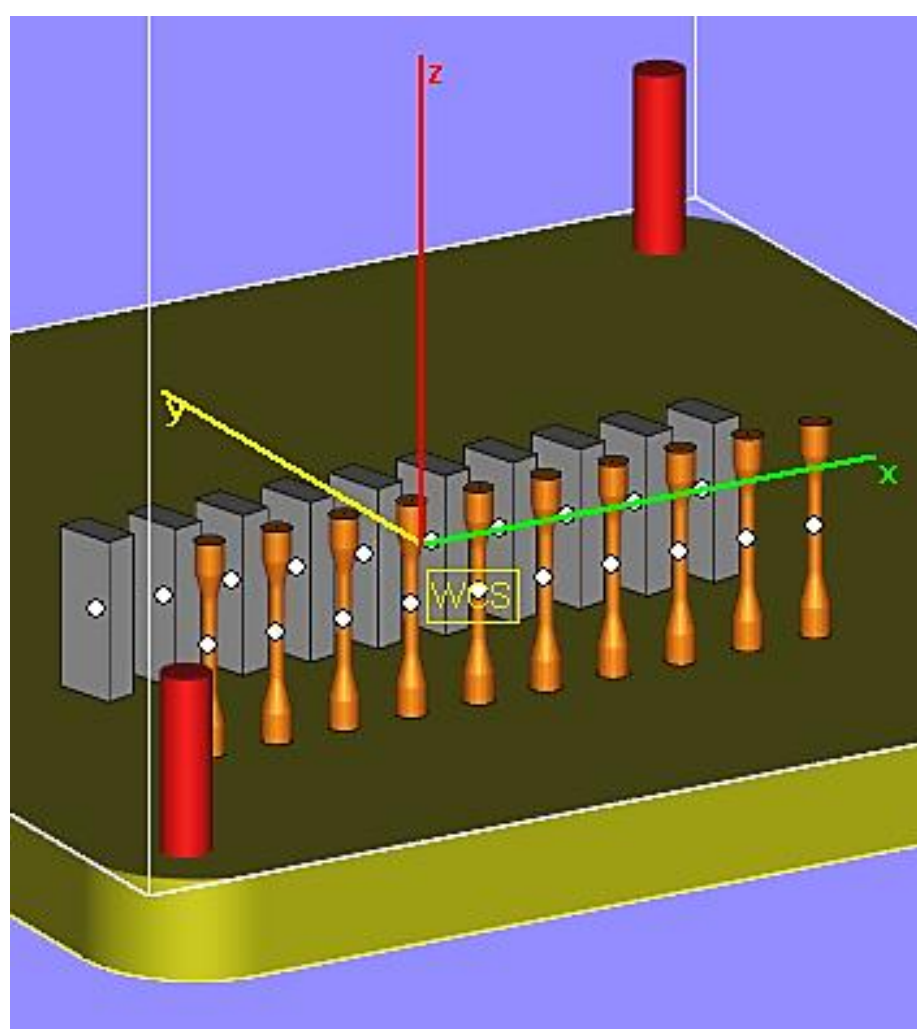

(a)

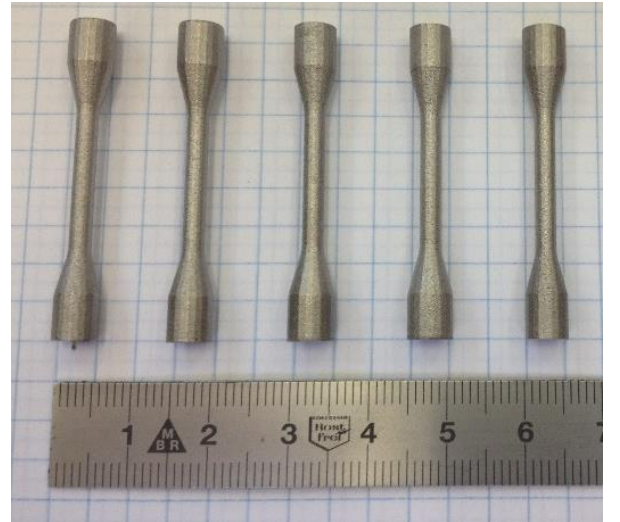

(b)

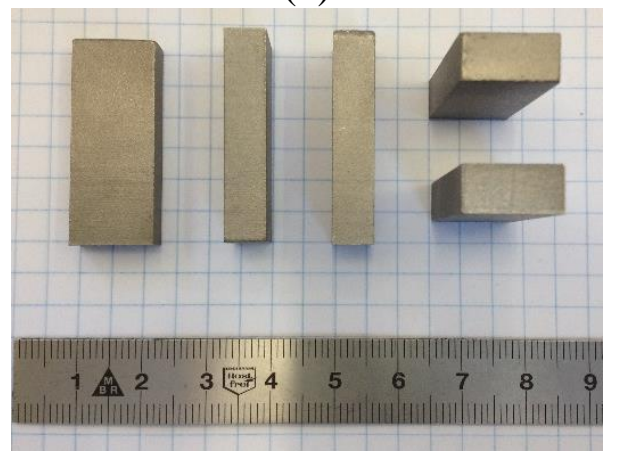

(c)

Figura 28 - a) Esquema de orientação da consolidação SLM das amostras, b) corpos de prova de tração e c) corpos de prova de flexão em três pontos.

\subsection{AVALIAÇÃO DA BIOCOMPATIBILIDADE}

A determinação da biocompatibilidade das amostras após consolidação pelas técnicas de fundição de precisão e fusão seletiva a laser foi realizada por meio da avaliação de citotoxicidade.

O objetivo da análise é avaliar a suscetibilidade ao crescimento celular na liga de Co-Cr-Mo após os processos de consolidação, segundo condições da norma ISO 109935 (1995). Este efeito tóxico é analisado por meio da medição quantitativa de morte celular, inibição de crescimento celular e entre outros efeitos causados nas células.

Inicialmente, as amostras foram esterilizadas por meio da radiação gama (Co 60) com uma dose 25 KGy no IPEN. Para o teste de citotoxicidade são utilizadas 5 placas de cultura de 96 poços. Cada poço recebe $100 \mu \mathrm{L}$ da suspensão de células de CHO-K1, resultando em uma concentração média final de 10000 células por poço. As placas devem ser mantidas na incubadora úmida por 24 horas à temperatura de $37^{\circ} \mathrm{C}$ e após retirá-las da incubadora e adicionar em cada poço $20 \mu \mathrm{L}$ de solução MTS (corante supervital de 
composto tetrazólico) e PMS (agente acoplador de elétrons) na razão de 20:1. As placas voltaram à incubadora por mais 2 horas para serem submetidas, na sequência, ao espectrofotômetro ELISA (para leitura de placas com 96 poços), equipado com filtro de $490 \mathrm{~nm}$, a fim de obter as densidades ópticas e verificar a viabilidade de crescimento celular.

Segundo a ISO10993-5 (2009), a análise da citotoxicidade é realizada em relação ao extrato puro, sem diluição, ou seja, apresenta apenas a viabilidade a $100 \%$. Por este motivo, desde 2010, as diluições do extrato $100 \%$ não são mais realizadas, apresentando deste modo, a viabilidade celular do extrato $100 \%$, contrastando com as respostas de controle positivo e controle negativo, comumente reportados por diluições de $25 \%$ em $25 \%$.

\subsection{CARACTERIZAÇÃO MECÂNICA}

A caracterização mecânica da liga de Co-Cr-Mo consolidada pelas técnicas de FP e SLM utilizou-se de uma abordagem técnica convencional. Para tanto, os métodos de obtenção das propriedades mecânicas foram conduzidos com base em teorias de resistência dos materiais completamente densos.

\subsubsection{Ensaios de Tração}

Os ensaios mecânicos de tração em amostras da liga de Co-Cr-Mo consolidadas por FP e SLM, conforme descrito na seção 4.4. Os ensaios foram conduzidos no Laboratório do Grupo Mecânica dos Sólidos e Impacto em Estruturas - GMSIE, da Escola Politécnica da Universidade de São Paulo.

Nos ensaios de tração das amostras consolidadas por FP e SLM foram medidas as propriedades mecânicas de: tensão limite de escoamento $\left(\sigma_{\mathrm{LE}}\right)$, tensão limite de resistência $\left(\sigma_{L R}\right)$, tensão de ruptura $\left(\sigma_{f}\right)$, alongamento percentual $\left(A_{t}\right)$ e módulo de elasticidade $(E)$. No total foram conduzidos de 5 testes de tração para cada técnica de consolidação da liga de Co-Cr-Mo.

Utilizou-se uma máquina de ensaios universais Instron, modelo 3369, célula de carga de $50 \mathrm{KN}$. Os ensaios de tração foram conduzidos a velocidade de $2,00 \mathrm{~mm} / \mathrm{min}$ a 
temperatura ambiente $\left(25^{\circ} \mathrm{C}\right)$, seguindo a norma ASTM E8/E8M (2015). Para determinação das curvas de tensão versus deformação de engenharia dos espécimes usouse a técnica óptica de correlação digital de imagem conhecida por DIC para a aquisição dos dados referente aos ensaios conduzidos nas amostras SLM. A aquisição de dados de deformação por DIC foi obtida por meio de fotos utilizando uma câmera fotográfica NIKON D90, com resolução de 12.2 MPixels na proporção de 4288 pixels por 2848 pixels, com 24 bits de profundidade de cor e tempo de exposição de 1/5 segundos no modo time lapse shooting. Utilizou-se um sistema especial de iluminação LED, da Visual Instrumentation Corporation com aproximadamente 12500 lúmens, vide o arranjo experimental na Figura 29.

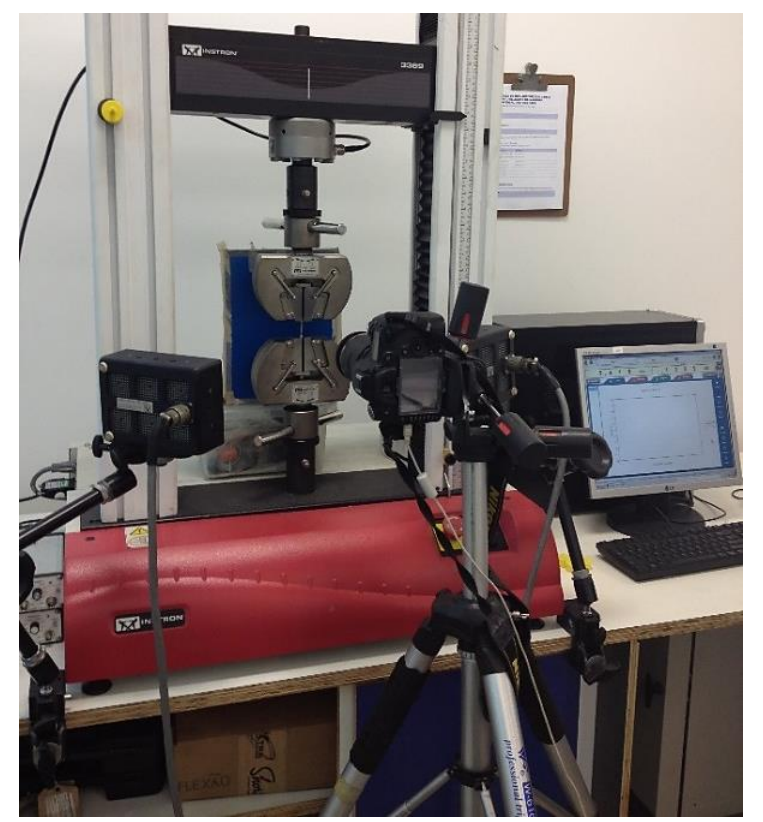

(a)

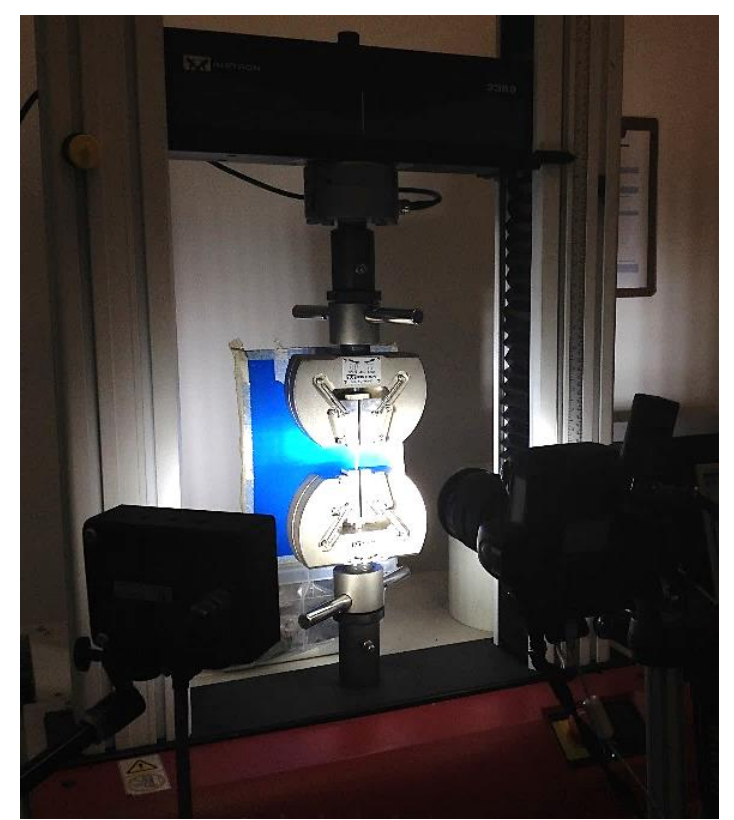

(b)

Figura 29 - a) e b) Arranjo experimental para ensaio de tração no laboratório GMSIE.

A partir de uma imagem digital é possível definir um "padrão de correlação" em um dado ponto, como a região dos pixels em torno do ponto. Ao correlacionar esta primeira imagem digital, com uma segunda imagem digital (cujo ponto de referência esta deslocado ou deformado) determina-se por diferença da comparação de padrões de correlação. Ou seja, por esta técnica pode-se mensurar o deslocamento, por meio da correlação da região de pixels entre imagens. Para realizar o processamento das imagens e obter o deslocamento do corpo de prova, utilizou-se o software ProAnalyst ${ }^{\circledR}$.

Nos ensaios iniciais realizados nas amostras SLM, constatou-se uma dificuldade na realização dos ensaios de tração, em razão as pequenas dimensões dos 
espécimes. As amostras consolidadas por fundição de precisão foram fabricadas com dimensões incrementadas, adequando-se aos dispositivos de fixação (garras mecânicas) e facilitando a aquisição de deformação dos corpos de prova por meio de extensômetro acoplado a máquina de ensaios. As dimensões otimizadas dos corpos de prova e o arranjo utilizado no ensaio de tração das amostras FP são apresentados na Figura 30.

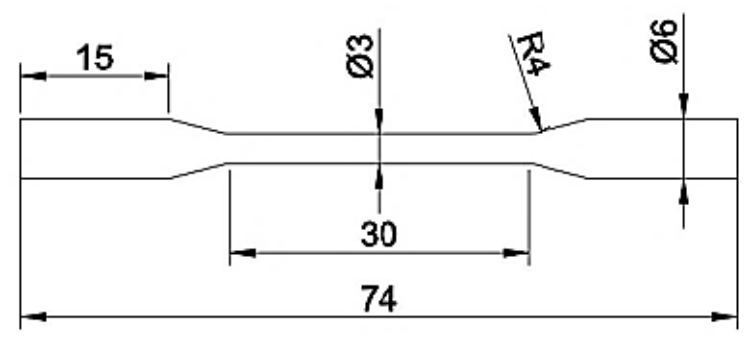

(a)

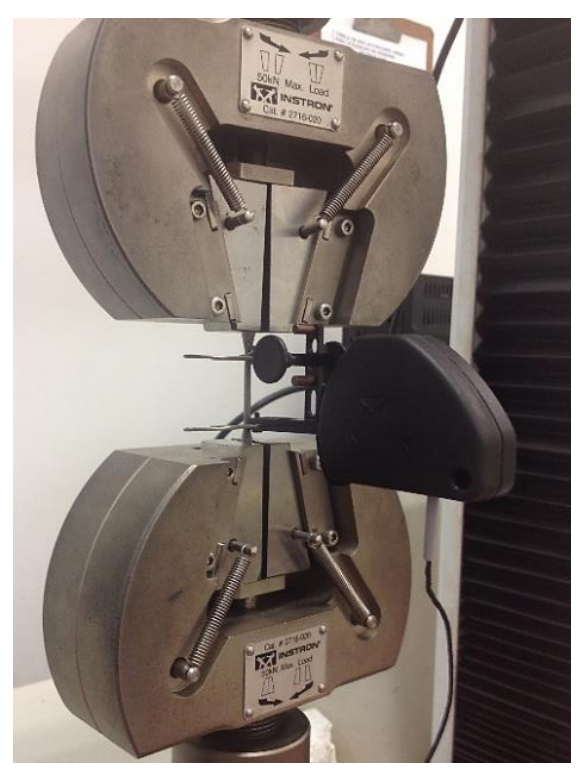

(b)

Figura 30 - a) Dimensões otimizadas (em milímetros) do corpo de prova de tração FP, com base na norma ISO 22674 (2006) e b) arranjo do ensaio de tração utilizando dispositivo extensômetro.

Os resultados das propriedades mecânicas obtidos são comparados segundo as normas ISO 22674 (2006) e norma ASTM F75 (2012b) - apresentados na Tabela 8.

Tabela 8 - Propriedades mecânicas mínimas requeridas para liga de Co-Cr-Mo consolidada por fundição e materiais metálicos utilizados em próteses odontológicas.

\begin{tabular}{|c|c|c|c|c|c|c|}
\hline NORMA & Tipo & $\sigma_{L E}(\mathrm{MPa})$ & $A_{t}(\%)$ & $E(\mathbf{G P a})$ & $R A(\%)$ & $\sigma_{\text {LR }}(\mathrm{MPa})$ \\
\hline \multirow{5}{*}{ ISO 22674} & 1 & 80 & 18 & \multirow{4}{*}{ - } & \multirow{5}{*}{-} & \multirow{5}{*}{ - } \\
\hline & 2 & 180 & 10 & & & \\
\hline & 3 & 270 & 5 & & & \\
\hline & 4 & 360 & 2 & & & \\
\hline & 5 & 500 & 2 & 150 & & \\
\hline ASTM F75 & & 450 & 8 & - & 8 & 655 \\
\hline
\end{tabular}

Fonte: Adaptado de (ASTM INTERNATIONAL, 2012b; ISO, 2006). 


\subsubsection{Ensaios de flexão em três pontos}

O ensaio de flexão em três pontos foi realizado para o cálculo da resistência a ruptura transversal (TRS) das amostras consolidadas por FP e SLM. A resistência a ruptura transversal foi determinada pela equação 3 , a qual relaciona a carga aplicada ( $\mathrm{P}$ em Newton) e a distância entre os apoios ( $\mathrm{L}$ em milímetros), sobre a área transversal da amostra (t igual a espessura e w igual a largura), medidas em milímetros.

$$
T R S=\frac{3 \cdot P \cdot L}{2 \cdot t^{2} \cdot w}
$$

Os ensaios mecânicos de flexão em três pontos nas amostras da liga de Co-CrMo consolidadas por FP e SLM foram conduzidos no laboratório GMSIE, da Escola Politécnica da Universidade de São Paulo. Utilizou-se uma máquina de ensaios universais Instron, modelo 3369, célula de carga de $50 \mathrm{KN}$. Os ensaios de TRS foram conduzidos a velocidade de $2,00 \mathrm{~mm} / \mathrm{min}$ a temperatura ambiente $\left(25^{\circ} \mathrm{C}\right)$, seguindo a norma ASTM B528 (2012a). Foram realizados três ensaios para cada técnica de consolidação.

Utilizou-se a técnica DIC (conforme o arranjo experimental na Figura 31) para determinação da deformação dos corpos de prova durante o ensaio de flexão em três pontos, assim como descrito nos ensaios de tração (vide seção 4.6.1).

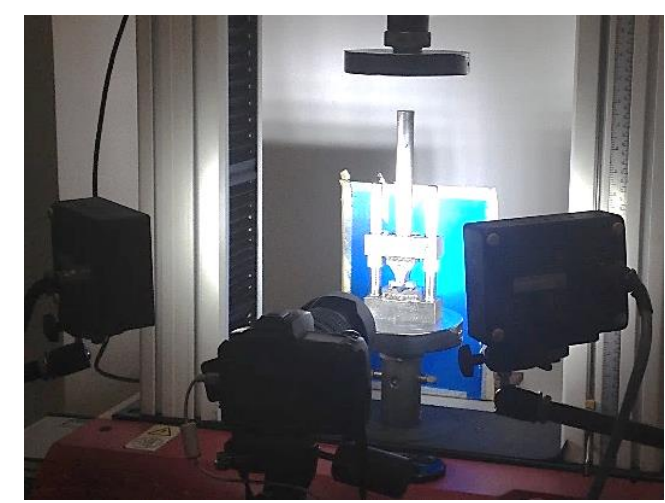

(a)

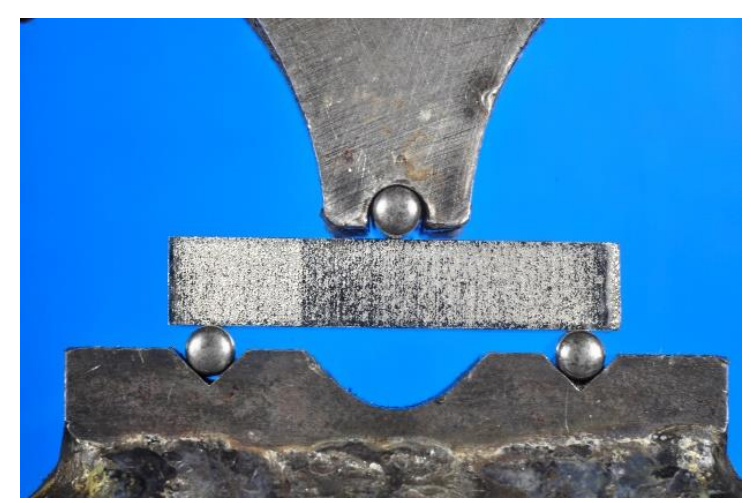

(b)

Figura 31 - a) Arranjo experimental para ensaios de flexão em três pontos no laboratório GMSIE e b) dispositivo de flexão em três pontos.

\subsubsection{Análise da dureza Vickers}

A dureza Vickers foi determinada nas amostras FP e SLM, bem como nas amostras dos pós de Co-Cr-Mo. Para realização das medidas de dureza, as amostras foram 
preparadas por metalografia até a etapa de polimento, conforme requisito dos padrões de medida de dureza. Os equipamentos utilizados para mensurar foram durômetro Buehler série 5100 e um microdurômetro Fischerscope HM2000 (vide Figura 32), respectivamente segundo as normas ASTM E384 (2012c) e ISO 14577-1 (2002). Segundo a norma ASTM F75 (2012b) a liga de Co-Cr-Mo na condição fundida deve apresentar uma dureza entre a faixa de 25 a 35 HRC (266 a 345 HV).

Utilizou-se o test t de Student (conhecido como testes t) para análise estatística dos resultados de dureza e sua relação entre as seções (horizontal e vertical) de medida. $\mathrm{O}$ teste $\mathrm{t}$ (por meio de conceitos estatísticos) consiste em rejeitar ou não uma hipótese nula. Rejeita-se a hipótese nula quando o resultado observado (probabilidade desse resultado descrita por "valor p" ou "p-valor") for menor que 0,05. Neste estudo, a hipótese nula refere-se à semelhança de dureza entre as seções (horizontal e vertical).

O teste de dureza Vickers realizado no Durômetro Buehler série 5100 utilizou uma escala de força de 500 gf (HV0.5) durante 15 segundos. Para determinar a dureza foram realizadas 17 medidas, sendo que, entre estas medidas, excluíram-se a de maior valor e a de menor valor. Segundo a norma ASTM E384, para testes de dureza Vickers realizados com forças variando de 1 a 1000 gf caracteriza-se microidentação. Já testes realizados com forças acima de $1 \mathrm{kgf}$ caracteriza-se macroidentação. Porém, deve-se evitar o termo microdureza quando for utilizado a microidentação, uma vez que a força e o tamanho da identação são pequenos (ASTM INTERNATIONAL, 2012c).

O teste de dureza Vickers realizado no microdurômetro Fischerscope HM2000 foi realizado a fim de se obter a dureza das fases presentes nas amostras, após o ataque da microestrutura. Com o intuito de relacionar a dureza dos pós com a faixa granulométrica, proveniente do processo de atomização a gás foram realizadas medidas de microdureza nas amostras de pós de Co-Cr-Mo. Os ensaios de microdureza foram conduzidos com uma carga de $100.000 \mathrm{mN}$ (micro Newton) durante 10 segundos, realizando o mesmo procedimento de medições da macrodureza Vickers. 


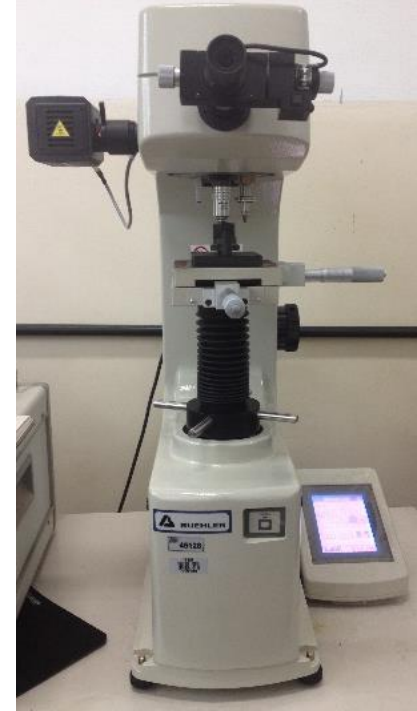

(a)

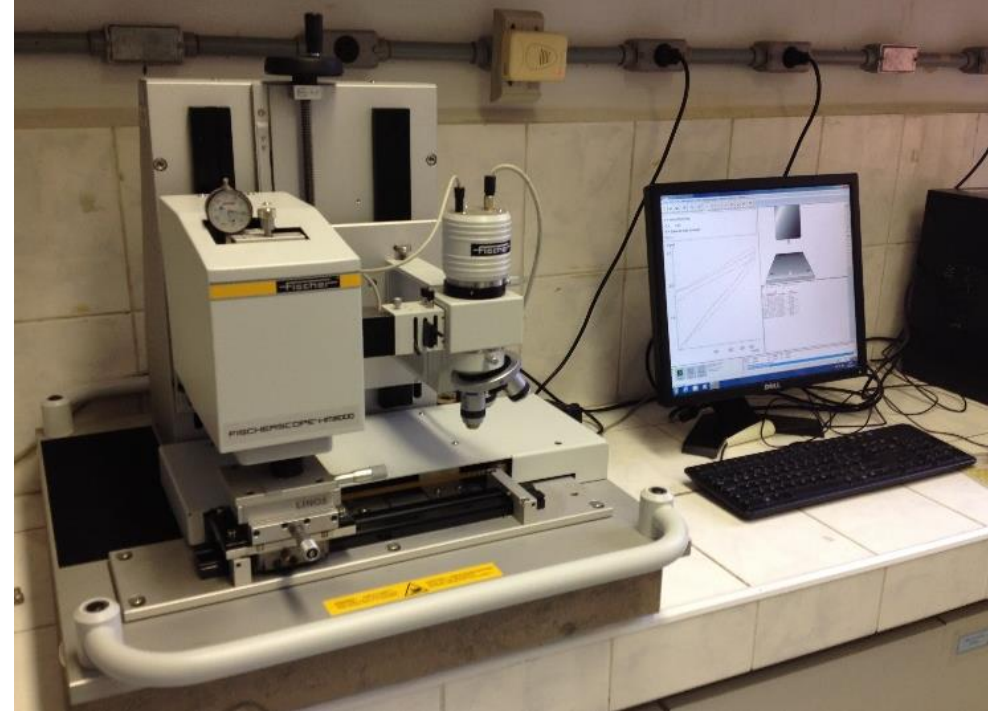

(b)

Figura 32 - Durômetros Vickers, a) Durômetro Buehler série 5100 e b) Microdurômetro Fischerscope HM2000.

\subsubsection{Análise termomecânica - dilatometria}

A análise termomecânica, conhecida como dilatometria, foi realizada em amostras de pequenas dimensões consolidadas por SLM e FP da liga de Co-Cr-Mo. A realização do ensaio teve o propósito de complementar os resultados térmicos da liga, obter o coeficiente de dilatação $\left(\alpha=10^{-6 \circ} \mathrm{C}^{-1}\right.$ ou coeficiente de expansão térmico - CET) e facilitar a compreensão dos eventos evidenciados pela análise de DSC.

O equipamento utilizado foi o Setsys 16/18, da Setaram, utilizando a haste com termopar de Pt/Pt Rh 10\% (Pt - Platina e Rh - Ródio), alocado no laboratório de metalografia do CCN. A rotina da análise de dilatometria foi similar a rotina realizada na análise de DSC. Utilizou-se uma taxa de aquecimento de $10^{\circ} \mathrm{C} / \mathrm{min}$ até a temperatura de $1300^{\circ} \mathrm{C}$ e a taxa de resfriamento foi mantida em $20 \%$ min.

Para realizar a análise nas amostras SLM, utilizou-se a amostra de flexão em três pontos seccionada em dois sentidos distintos: longitudinal (SLM 1 - sentido de consolidação da amostra) e vertical (SLM 2 - sentido transversal a consolidação da amostra), conforme pode ser observado no esquema da Figura 33. 


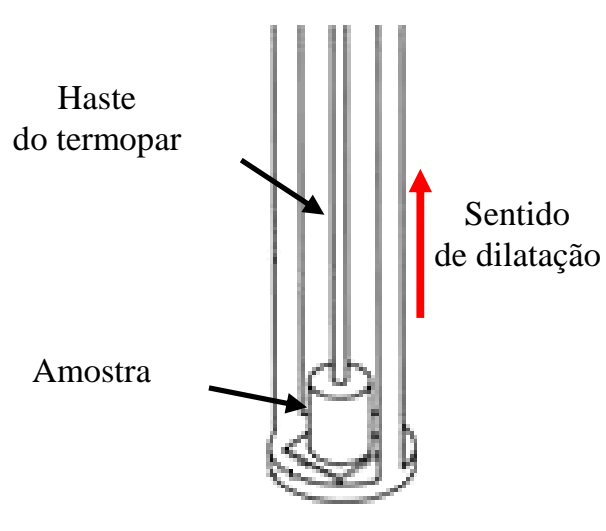

(a)

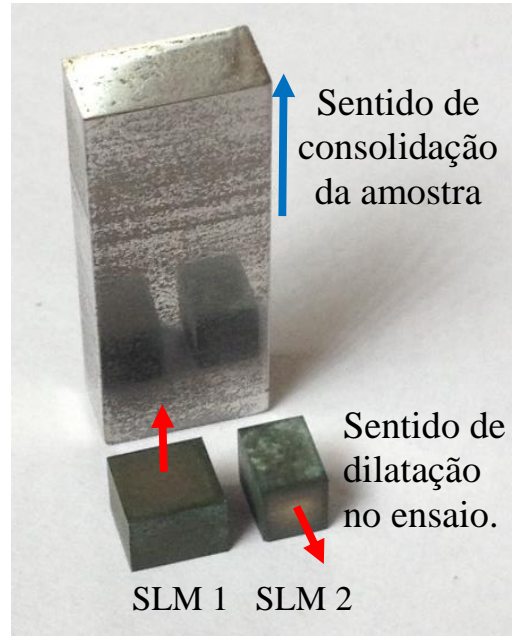

(b)

Figura 33 - a) Arranjo do sistema de análise de TMA e b) esquema de corte da amostra SLM para análise de TMA.

\subsection{CARACTERIZAÇÃO MICROESTRUTURAL}

\subsubsection{Análise de porosidade das amostras}

Com o intuito de avaliar a porosidade interna das amostras consolidadas foram utilizadas as técnicas de densidade: volumétrica, picnometria de He e teórica média da liga.

A densidade volumétrica considera em seu resultado a presença de porosidade aberta (porosidade superficial) e de porosidade interna (porosidade fechada). Para mensurar esta grandeza foram medidas as dimensões das amostras por meio de paquímetro convencional (tolerância de $0,01 \mathrm{~mm}$ ) e a massa das mesmas por meio de uma balança analítica convencional (tolerância de 0,0001 g). Cada grandeza (dimensões de largura, comprimento, altura e massa) foi mensurada cinco vezes em cada amostra e a densidade volumétrica de cada amostra calculada pela média das grandezas. A densidade volumétrica final foi obtida pela média e desvio padrão de 8 amostras de cada processo (FP e SLM). Esta densidade deve apresentar um resultado inferior ao da densidade por picnometria de $\mathrm{He}$, pois a grandeza (volume) medida considera a porosidade (aberta e fechada) como sendo um volume efetivo ocupado.

$\mathrm{Na}$ densidade por picnometria de $\mathrm{He}$, o gás de He penetra com maior facilidade na porosidade aberta, permitindo deste modo aferir com maior acurácia o volume real da amostra. Porém, a porosidade interna é considerada pelo método. Em contrapartida, o 
resultado da densidade por picnometria tende a ser maior que o resultado de densidade volumétrica. A densidade por picnometria de He de cada amostra foi obtida por meio de 20 aferições. A densidade picnométrica foi calculada pela média e desvio padrão de 8 amostras de cada processo (FP e SLM). Para tanto, utilizou-se o equipamento Micromeritics (Modelo Accu Pyc 1330 Pycnometer), localizado no Centro de Combustível Nuclear - CCN/IPEN.

A densidade teórica média foi mensurada conforme as equações (l 1 e 2 ) descritas na seção 4.3.4, a partir da análise química semiquatitativa de fluorescência de raios X das amostras consolidadas por FP e SLM.

\subsubsection{Difração de raios $X$}

A caracterização das amostras consolidadas foi realizada por meio de difração de raios X, no CCTM, para identificação das fases presentes. A análise foi obtida por meio do difratômetro Rigaku Rint 2000 , sob os parâmetros de: $30^{\circ} \leq 2 \Theta \leq 110^{\circ}, \Delta 2 \Theta=0,02^{\circ} \mathrm{e}$ $\Delta \mathrm{t} /$ passo $(2 \Theta)=2,0 \mathrm{~s}$ utilizado um tubo de Cromo. A caracterização dos picos de difração foi determinada utilizando as fichas catalográficas do programa Crystallographica SearchMatch®.

\subsubsection{Metodologia empregada para metalografia}

As amostras para preparação metalográfica da liga de Co-Cr-Mo consolidada por SLM e FP foram obtidas a partir dos corpos de prova de tração. Para tanto, as amostras foram seccionadas (na região não tracionada, evitando possíveis danos microestruturais) nas direções, transversal e na longitudinal, com o intuito de avaliar possíveis diferenças microestruturais nos diferentes planos de consolidação, conforme observa-se na Figura 34a. Nas Figura 34b e c são observadas as duas seções denominadas de "H" para seção horizontal (ou transversal) e "V" para seção vertical (ou longitudinal).

As amostras utilizadas para caracterização microestrutural foram preparadas por técnicas metalográficas, seguindo as etapas de: lixamento mecânico em lixas abrasivas de $\mathrm{SiC}$ até a granulometria de \#600, em água corrente; polimento em panos com solução de

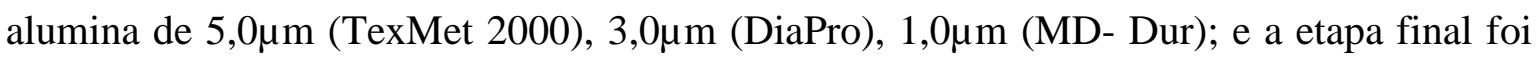
realizada por meio de um polimento químico mecânico com pano ChemoMet sob solução de sílica coloidal em suspensão de 0,02 $\mu \mathrm{m}(90 \%$ Sílica Coloidal $+10 \% \mathrm{HCl})$. Após cada 
etapa (lixamento e polimento), as amostras foram submetidas a limpeza por ultrassom em etanol para remoção de partículas indesejadas.

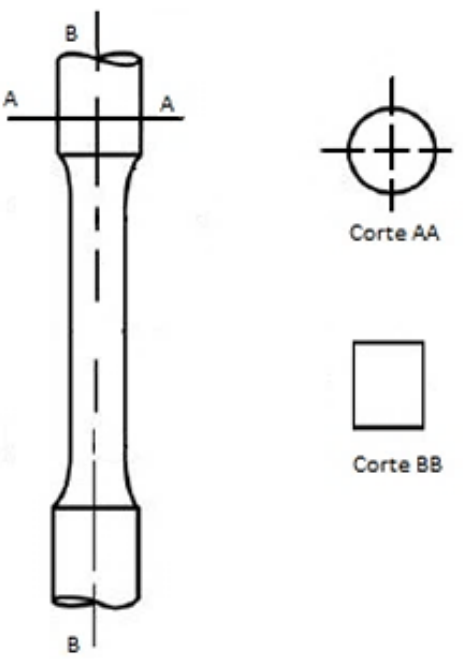

(a)

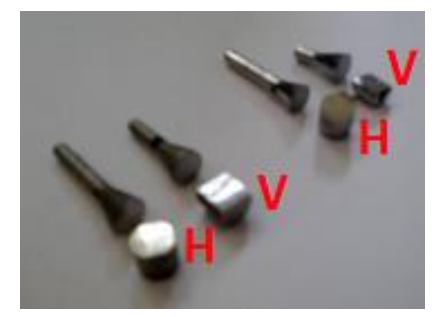

(b)

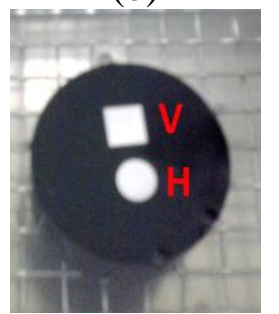

(c)

Figura 34 - a) Seções de corte da amostra de tração para preparação metalográfica, b) amostras SLM e FP seccionadas e c) amostra final de metalografia.

O ataque químico das amostras FP e SLM foi conduzido em meio a solução de $100 \mathrm{~mL}$ de ácido clorídrico $(\mathrm{HCl})$ e $2 \mathrm{~mL}$ peróxido de hidrogênio $\left(\mathrm{H}_{2} \mathrm{O}_{2}\right)$, pelo tempo de 60 a $240 \mathrm{~s}$ à temperatura ambiente. O pó D2 de Co-Cr-Mo foi atacado na temperatura entre 40 a $60^{\circ} \mathrm{C}$ controlada por meio de um termómetro convencional, aquecido por uma chapa.

\subsubsection{Microscopia Óptica}

As imagens das micrografias das amostras de Co-Cr-Mo analisadas (pós atomizados e amostras consolidadas por SLM e FP) foram obtidas por meio do microscópio óptico (MO) utilizando o equipamento Olympus, modelo BX51M, alocado no Laboratório de Metalografia do CCTM.

\subsubsection{Microscopia Eletrônica de Varredura}

As micrografias dos materiais analisados (pós atomizados e amostras consolidadas e fraturas) foram obtidas pela técnica de microscopia eletrônica de varredura (MEV).

Utilizou-se o MEV de bancada da marca Hitachi - TableTop TM3000 (imagens realizadas por elétrons retroespalhados) e um Philips XL30 com EDS acoplado. Fez-se o uso de um terceiro equipamento de MEV da marca JEOL, modelo JSM6701F, permitindo 
aumentos de magnitude superior aos MEV: TableTop TM3000 e Philips XL30. Os equipamentos utilizados estão localizados no CCTM.

A técnica de micrografia eletrônica permite a formação de imagens por meio de um feixe de elétrons, proveniente de elétrons retroespalhados (designado por "BSE" no MEV Philips XL30 e por "LEI" no MEV-FEG da marca JEOL) e elétrons secundários (designado por "SE" no MEV Philips XL30 e por "COMPO" no MEV-FEG da marca JEOL). 


\section{RESULTADOS E DISCUSSÃO}

\subsection{CARACTERIZAÇÃO DO MATERIAL}

As análises de composição química realizadas pelas técnicas de FRX e LECO $®$ dos pós e das amostras consolidadas da liga de Co-Cr-Mo são apresentadas respectivamente na Tabela 9 e Tabela 10. O resultado médio das análises química semiquantitativas foram comparados com os valores máximos, mínimos e tolerâncias dos elementos presentes na composição química estabelecida pela norma ASTM F75 para a liga de Co-Cr-Mo, como pode ser visto nas tabelas apresentadas. Com base nas composições químicas analisadas considerou-se a estequiometria da liga em pó na relação de 64Co-29Cr-7Mo (\% em peso).

Tabela 9 - Composição química (\% em peso) dos elementos de liga das amostras (pós, FP e SLM) da liga de Co-Cr-Mo por meio de FRX.

\begin{tabular}{ccccc}
\hline Elementos $(\%)$ & PÓS & FP & SLM & $\begin{array}{c}\text { NORMA } \\
\text { ASTM F75 }\end{array}$ \\
\hline Co & $63,93 \pm 0,16$ & $66,38 \pm 0,15$ & $65,38 \pm 0,32$ & Balanço \\
\hline Cr & $28,83 \pm 0,19$ & $26,76 \pm 0,21$ & $27,68 \pm 0,13$ & $\mathbf{2 7 , 0 0}-\mathbf{3 0 , 0 0} \pm \mathbf{0 , 3 0}$ \\
\hline Mo & $7,07 \pm 0,31$ & $6,68 \pm 0,03$ & $6,61 \pm 0,16$ & $\mathbf{5 , 0 0}-\mathbf{7 , 0 0} \pm \mathbf{0 , 1 5}$ \\
\hline Fe & $0,17 \pm 0,01$ & $0,18 \pm 0,08$ & $0,33 \pm 0,06$ & $\mathbf{0 , 7 5} \pm \mathbf{0 , 0 3}$ \\
\hline
\end{tabular}

Tabela 10 - Composição química (\% em peso) dos elementos residuais das amostras (pós, FP e SLM) da liga de Co-Cr-Mo por meio de LECO®.

\begin{tabular}{ccccc}
\hline Elementos (\%) & Pós & FP & SLM & $\begin{array}{c}\text { NORMA } \\
\text { ASTM F75 }\end{array}$ \\
\hline $\mathbf{C}$ & $0,03 \pm 0,01$ & $0,02 \pm 0,01$ & $0,03 \pm 0,01$ & $\mathbf{0 , 3 5 0} \pm \mathbf{0 , 0 2 0}$ \\
\hline $\mathbf{S}$ & $0,01 \pm 0,01$ & $0,01 \pm 0,01$ & $0,01 \pm 0,01$ & $\mathbf{0 , 0 1 0} \pm \mathbf{0 , 0 0 3}$ \\
\hline $\mathbf{N}_{2}^{(\mathbf{1})}$ & $0,0820 \pm 0,0011$ & $0,0416 \pm 0,0015$ & $0,1330 \pm 0,0015$ & $\mathbf{0 , 2 5 0} \pm \mathbf{0 , 0 2 0}$ \\
\hline $\mathbf{O}_{2}{ }^{(\mathbf{1})}$ & $0,0940 \pm 0,0015$ & $0,0187 \pm 0,0016$ & $0,0240 \pm 0,0010$ & $*$ \\
\hline
\end{tabular}

Nota: $*$ porcentagem de $\mathrm{O}_{2}$ não especificada pela norma ASTM F75.

(1) $=$ porcentagem transformada de $\mathrm{ppm}$.

Os resultados das análises químicas evidenciaram que os pós atomizados a gás e as amostras consolidadas por FP e SLM da liga se enquadram na composição química estabelecida pela norma ASTM F75. No entanto, para a amostras FP, ocorreu um ligeiro decréscimo do elemento $\mathrm{Cr}$, em relação à norma ASTM F75. Em razão da análise de 
fluorescência de raios $X$ realizar uma semiquantificação química, e por obter o resultado somente de uma fina camada superficial (aproximadamente 8 micras de penetração na análise) da composição química das amostras não há possibilidade de verificar a composição em volume. Deste modo, o fenômeno de segregação ${ }^{1}$ de elementos químicos na região superficial das amostras influencia na análise de composição química.

Analisa-se que o processo SLM propicia a fabricação de componentes de elevada pureza, sendo esta, proporcionada pela atmosfera de proteção (por gás inerte de argônio). Em razão da potência do laser ser elevada, a temperatura no foco do laser pode variar de 1500 a $1600^{\circ} \mathrm{C}$ (CHIVEL, 2013) existindo a possibilidade de ocorrer a volatilização de elementos químicos da liga. No entanto, esta verificação é imprecisa em razão as técnicas de caracterização química utilizadas.

No caso das amostras consolidadas houve um decréscimo elevado na porcentagem do elemento de $\mathrm{O}_{2}$, em relação ao pó atomizado. Verifica-se um valor superior de $\mathrm{N}_{2}$ na composição inicial dos pós de Co-Cr-Mo, em relação a amostra consolidada por SLM. Esta variação de $\mathrm{N}_{2}$ está associada a consolidação das amostras pelo processo SLM, o qual ocorreu sob atmosfera de mistura de gases de argônio e nitrogênio.

\subsection{CARACTERIZAÇÃO DOS PÓS}

\subsubsection{Distribuição granulométrica}

A distribuição granulométrica dos pós atomizados a gás determinada por difração a laser pode ser observada na Tabela 11. No entanto, para a amostra do pó D3 não foi possível realizar a análise da distribuição granulométrica pelo equipamento CILAS 1064, em razão do pó não se dispersar no líquido utilizado na análise. Este fato pode estar associado ao tamanho da partícula do pó, por ser de maior diâmetro a mesma aglomerou-se no líquido dispersante durante o funcionamento do equipamento, e consequentemente, impossibilitou a realização da análise. Com isso utilizou-se um analisador de imagens do microscópio óptico (Olympus - BX51M) para realizar a medida de diâmetro médio das partículas da amostra do pó D3.

${ }^{1}$ É um efeito associado a distribuição heterogênea de elementos químicos, comumente presente nos processos de fundição. A razão do mecanismo de formação deste defeito é complexa, no entanto, pode ser destacada a ocorrência do mesmo proveniente do processo de solidificação da amostra fora das condições de equilíbrio do diagrama de fases (ASM INTERNACIONAL, 2008). 
Tabela 11 - Resultado da distribuição granulométrica dos pós de Co-Cr-Mo por difração a laser.

\begin{tabular}{cccccc}
\hline & Faixa & \multicolumn{4}{c}{ Distribuição Granulométrica $(\boldsymbol{\mu m})$} \\
\cline { 3 - 6 } Pó & $\begin{array}{c}\text { Granulométrica } \\
\text { recebida }(\boldsymbol{\mu m})\end{array}$ & $\mathbf{D 1 0}$ & $\mathbf{D 5 0}$ & $\mathbf{D 9 0}$ & Dmédio \\
\hline D1 & $<\mathbf{1 5}$ & 5,67 & 12,73 & 19,64 & 12,76 \\
\hline D2 & $\mathbf{1 5}$ a 45 & 20,88 & 31,11 & 46,10 & 32,36 \\
\hline D3 & $\mathbf{7 6}$ a 106 & \multicolumn{4}{c}{-} \\
\hline
\end{tabular}

A distribuição granulométrica da amostra do pó D3 foi avaliada por um analisador de imagens do MO, a partir de imagens realizadas do pó D3 similares a Figura 35. Como observado nas imagens do pó D3 foi realizado as medições do tamanho médio dos diâmetros das partículas de pó. A partir das medições obteve-se uma distribuição dos valores do diâmetro médio das partículas de pó D3, conforme observa-se na Tabela 12.

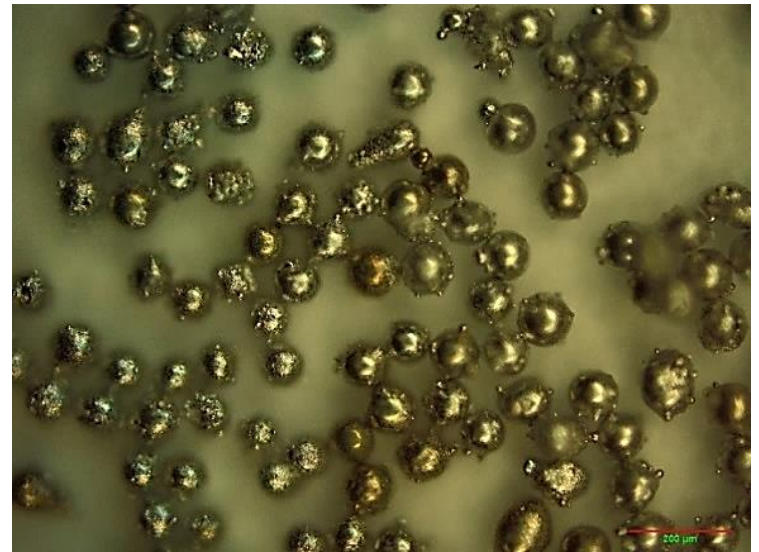

(a)

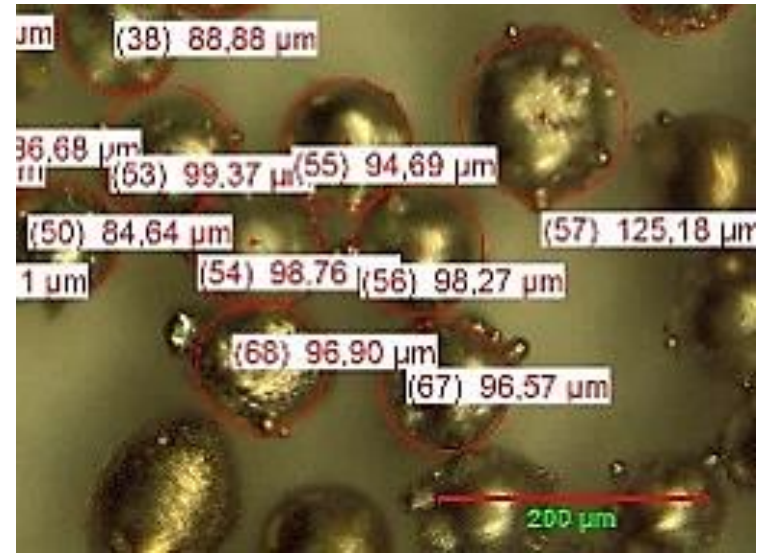

(b)

Figura 35 - Imagens de MO da análise de imagens realizadas no pó D3, em a) pó D3 e b) medições realizadas de diâmetro médio das partículas de pó. Aumentos de 200x.

Tabela 12 - Resultado das medições do diâmetro médio das partículas de pó D3 por imagens ópticas.

\begin{tabular}{cccc}
\hline $\mathbf{N}^{\mathbf{o}}$ de Contagens: 300 & Dmínimo $(\boldsymbol{\mu m})$ & Dmáximo $(\boldsymbol{\mu m})$ & Dmédio $(\boldsymbol{\mu m})$ \\
\hline Média e desvio $(\%)$ & $69,68 \pm 4,44$ & $118,74 \pm 6,78$ & $92,81 \pm 2,10$ \\
\hline
\end{tabular}

No histograma da amostra do pó D1 (Figura 36a) é apresentada uma faixa de diâmetros que varia entre $0,5 \mu \mathrm{m}$ e $30,0 \mu \mathrm{m}$ e um diâmetro médio de partícula de 12,76 $\mu \mathrm{m}$. Na amostra do pó D2 (Figura 36b) verifica-se que a faixa de diâmetros de partícula varia entre $15,0 \mu \mathrm{m}$ e $80,0 \mu \mathrm{m}$ e um diâmetro médio de partícula de $32,36 \mu \mathrm{m}$. 


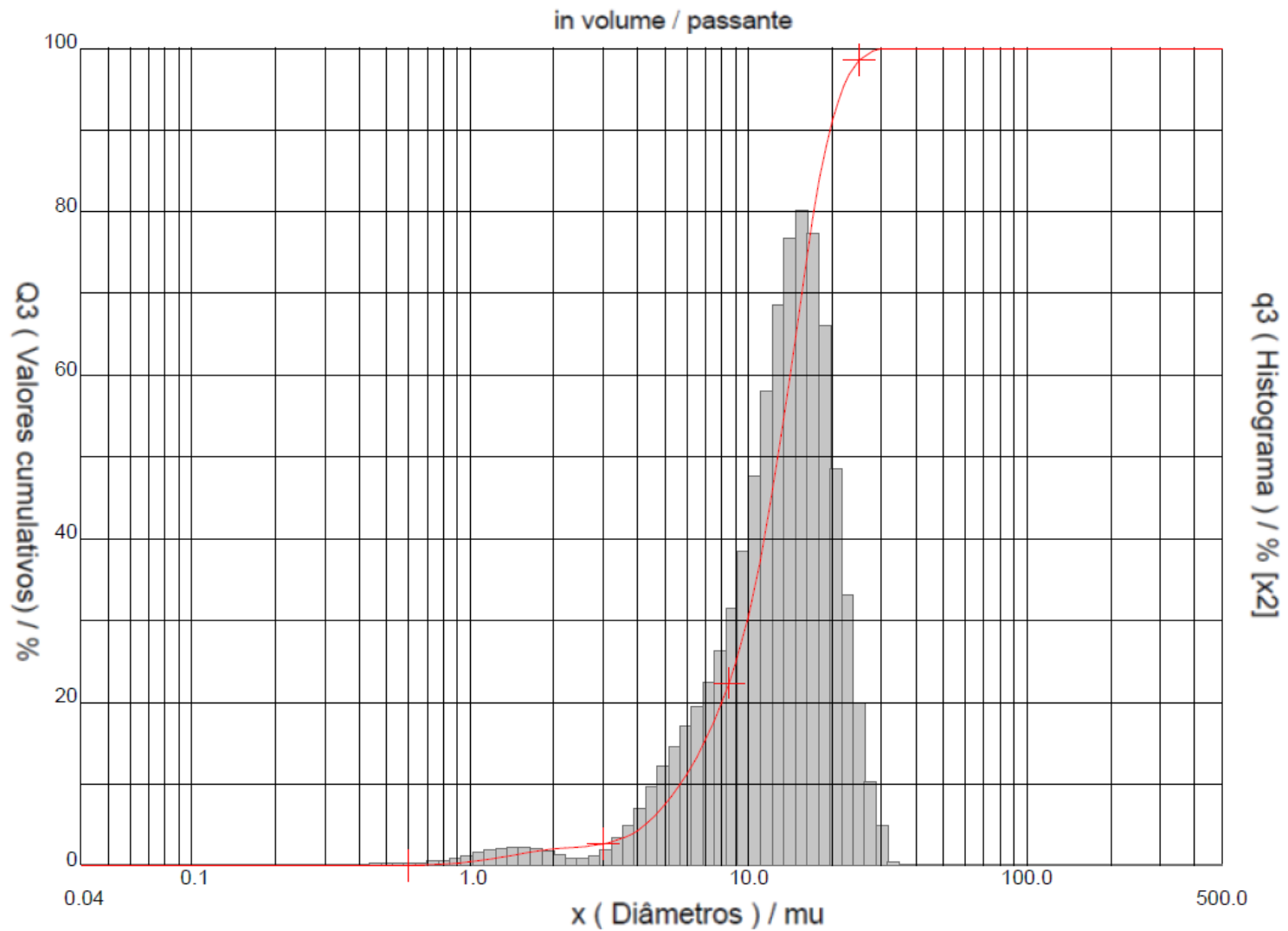

(a)

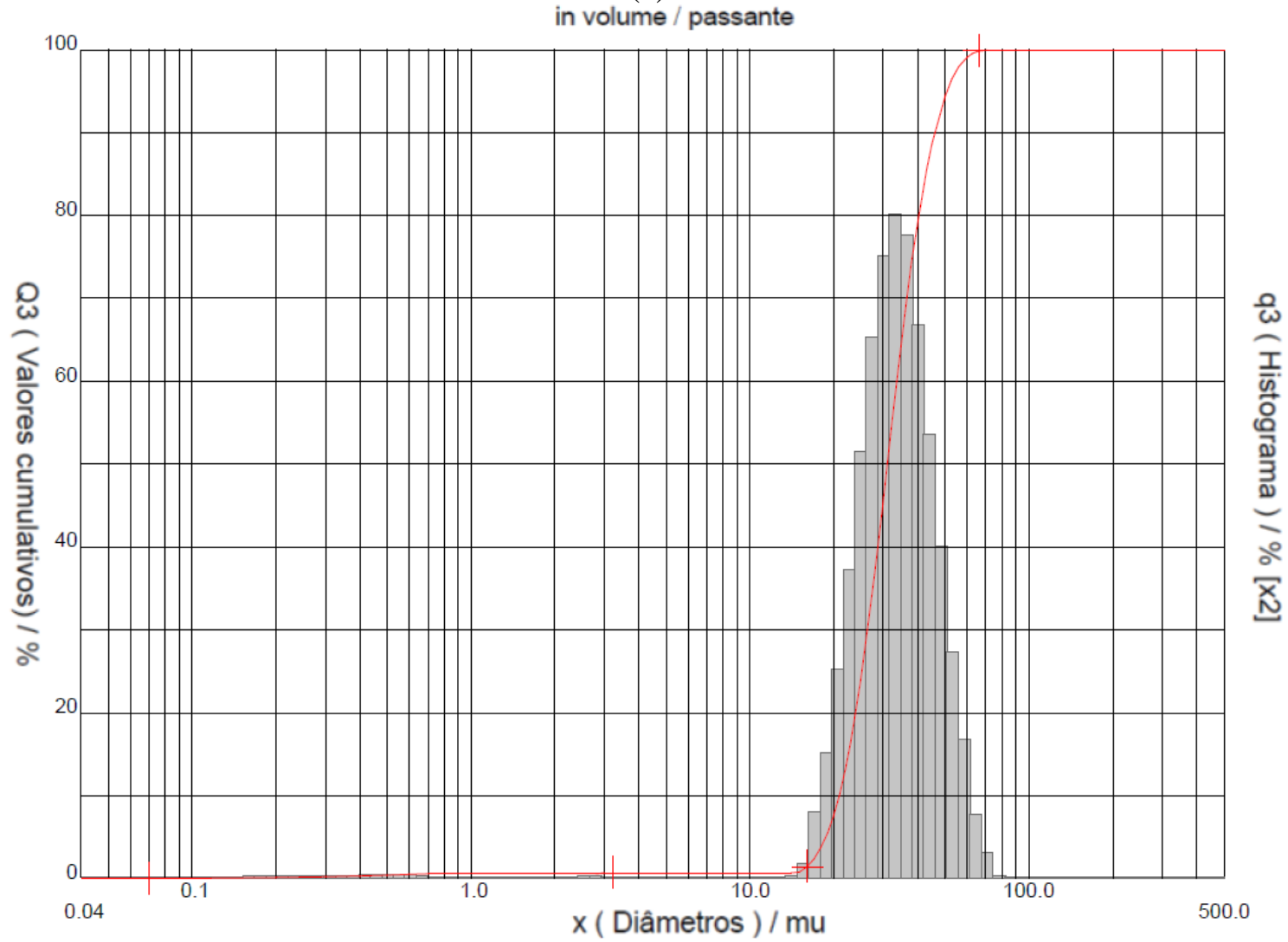

(b)

Figura 36 - Histogramas da distribuição granulométrica das amostras dos pós, em a) pó D1 (diâmetro médio de $12,76 \mu \mathrm{m}$ ) e b) pó D2 (diâmetro médio de 32,36 $\mu \mathrm{m}$ ). 


\subsubsection{Formato das partículas}

O formato das partículas dos pós de Co-Cr-Mo foi analisado por meio do MEV, como apresentado na Figura 37. Verifica-se o formato esférico, característico do processo de obtenção do pó, por meio da atomização a gás. Evidencia-se a presença de satélites nas imagens com aumentos superiores, apontados pelas setas em vermelho (vide Figura 37).

Estas protuberâncias na superfície são ocasionadas por colisões entre as partículas durante a atomização, e a incidência deste efeito aumenta com a diminuição do tamanho da partícula. Na superfície da partícula verificam-se detalhes da formação dendrítica na amostra do pó D3, resultado da taxa de resfriamento no processo de atomização (GERMAN, 1994; LAWLEY, 1992; YULE; DUNKLEY, 1994).

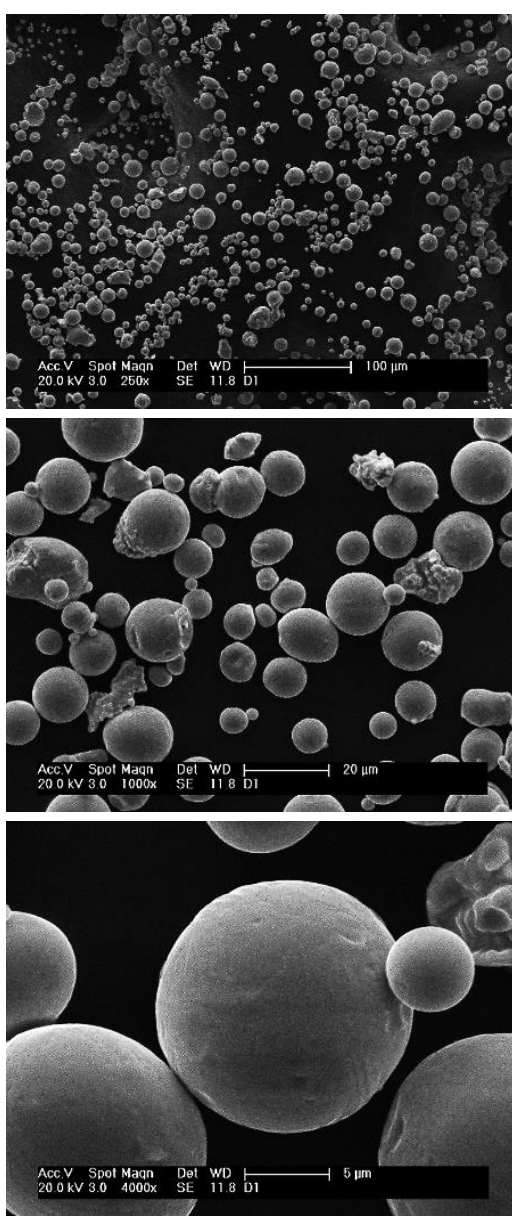

(a)
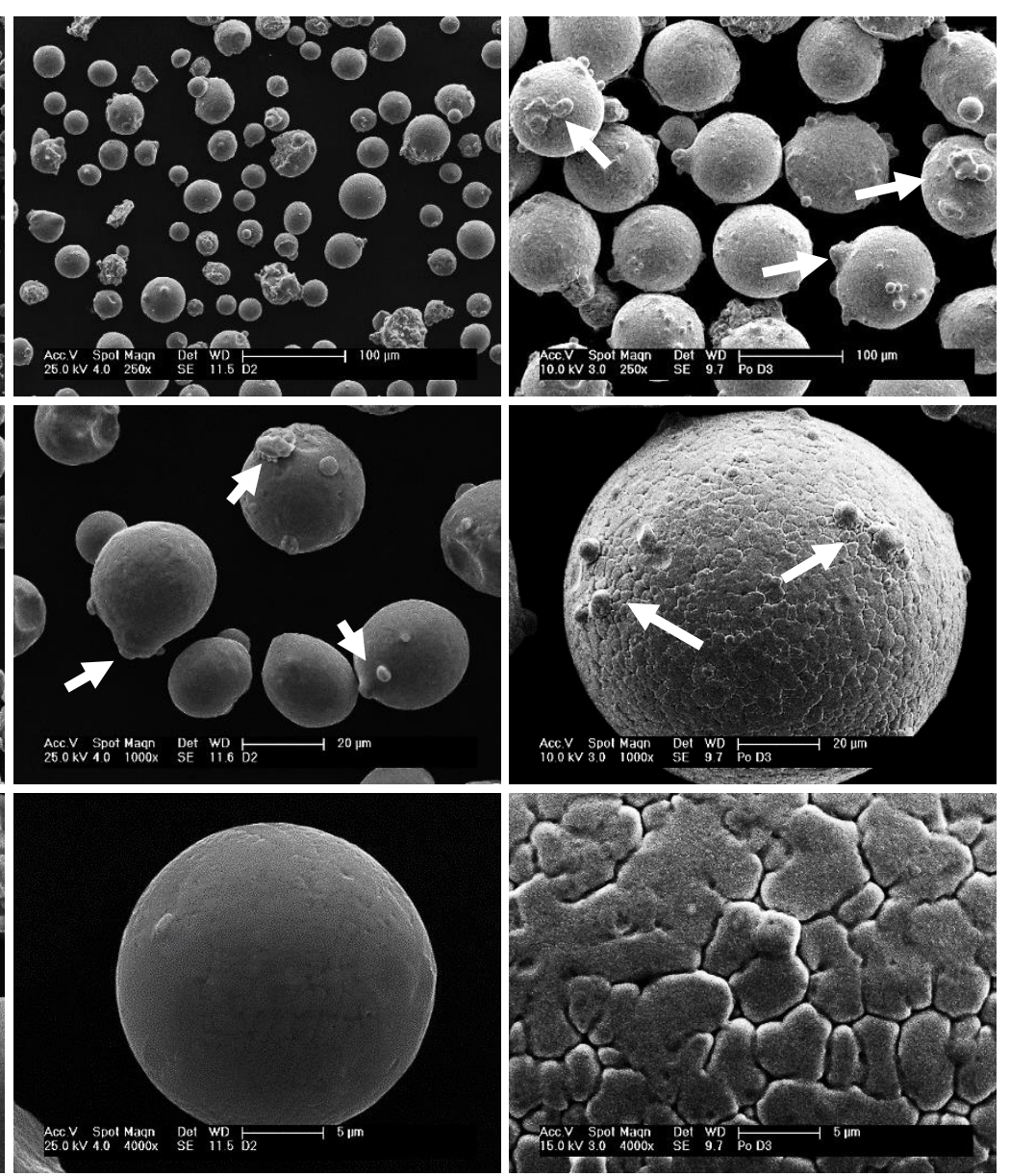

(b)

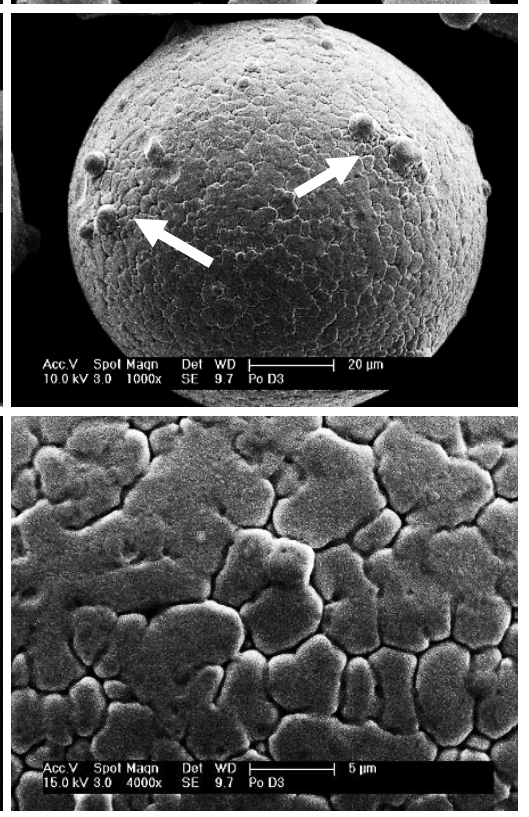

(c)

Figura 37 - Imagens de MEV dos pós de Co-Cr-Mo (setas destacam os satélites) em a) pó D1, b) pó D2, c) pó D3. Aumentos de: 250x, 1000x e 4000x. 
Ressalta-se que o formato da partícula influência nas propriedades de empacotamento, escoabilidade e de compressibilidade, como também é função do processo utilizado (GERMAN, 1998). No caso de processos envolvendo técnicas de impressão 3D, as partículas satélites influenciam nas propriedades físicas de escoabilidade e nas densidades. Consequentemente, interferem na distribuição do pó na plataforma de construção da peça, uma vez que, esta serve de suporte para as consecutivas camadas de pó.

Na Figura 38 apresenta-se a análise química por EDS e observa-se a presença dos elementos químicos de $\mathrm{Co}, \mathrm{Cr}$, Mo e Fe. As análises químicas por EDS comparadas à análise de fluorescência de raios $X$ (conforme apresentado na seção 5.1) evidencia-se a presença dos mesmos elementos químicos. É possível detectar a presença do elemento Si no material particulado. Este evento pode estar relacionado à presença pontual do elemento, detectada pela microanálise realizada por meio do EDS acoplado ao MEV. Na análise por fluorescência de raios $\mathrm{X}$ não foi detectada a presença de silício.

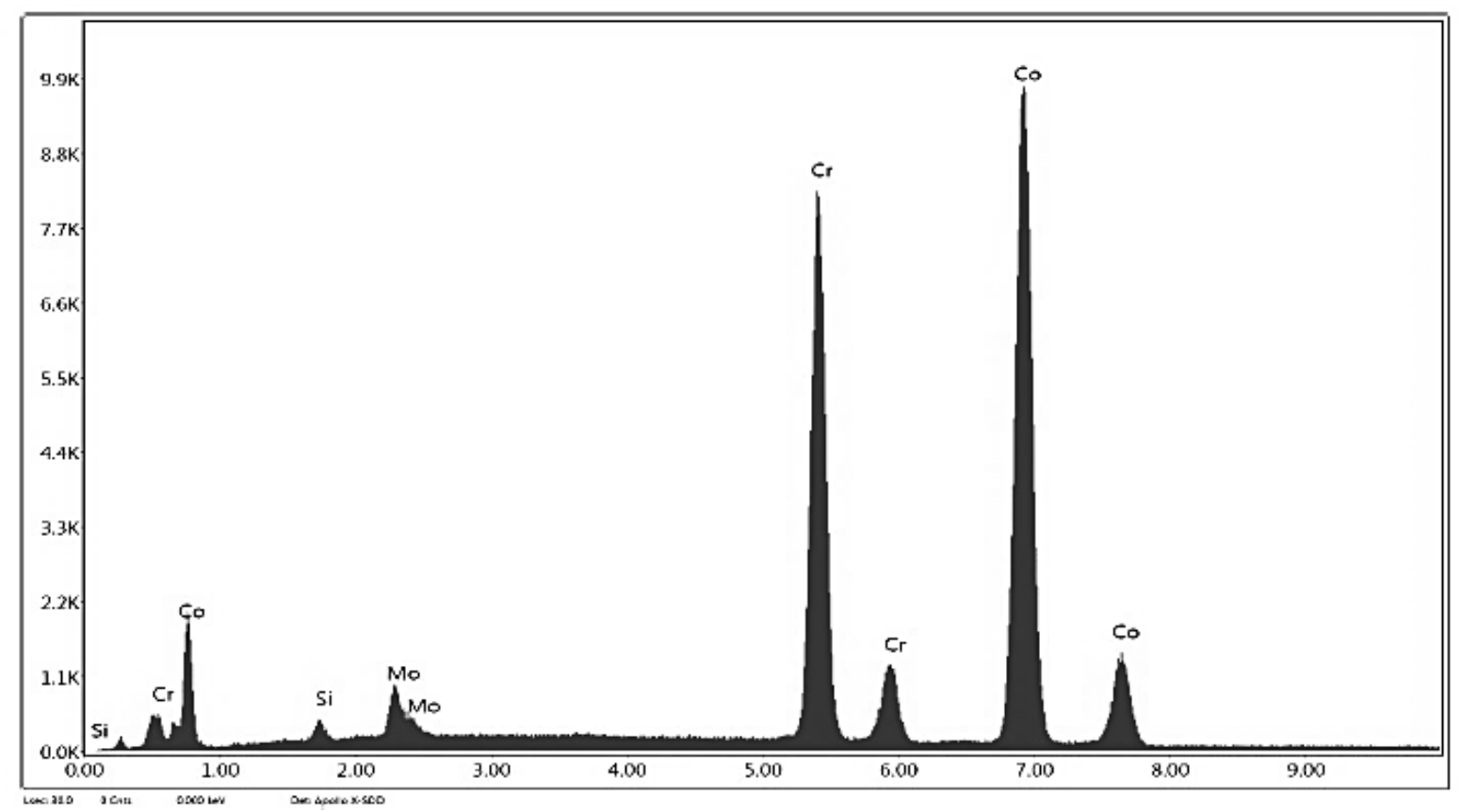

Figura 38 - Imagem do espectrograma por EDS dos pós da liga Co-Cr-Mo.

\subsubsection{Microestrutura das partículas}

Na Figura 39 observam-se as imagens por MEV dos pós da liga Co-Cr-Mo após o ataque químico com temperatura e verifica-se a formação da microestrutura dendrítica nas partículas de pó, configurado pelos braços e ramificações dendríticas 
presentes na microestrutura. A morfologia dendrítica dos pós é característica do processo de atomização a gás obtida pelo rápido resfriamento do material após colisão com o feixe de gás do atomizador. A morfologia dendrítica foi destacada também por diversos autores em estudo de pós atomizados a gás (AHMED et al., 2014; ASM INTERNACIONAL, 1998; GERMAN, 1998; SONG et al., 2006).

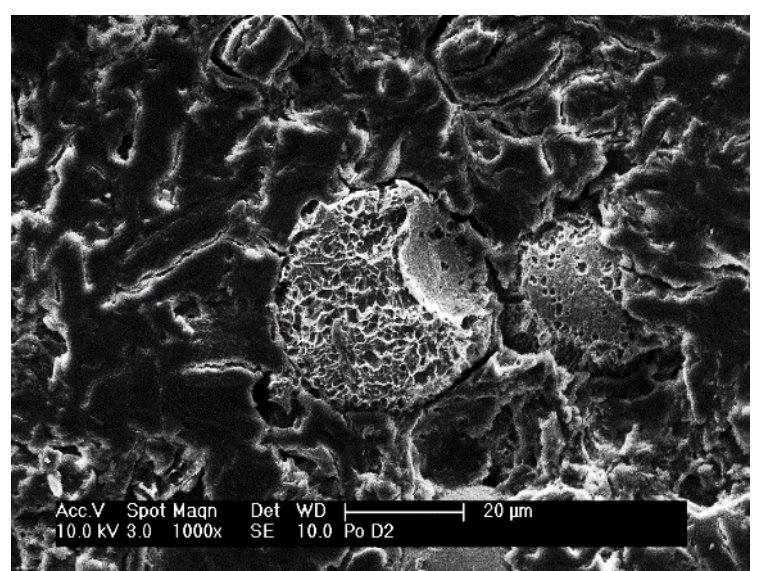

(a)

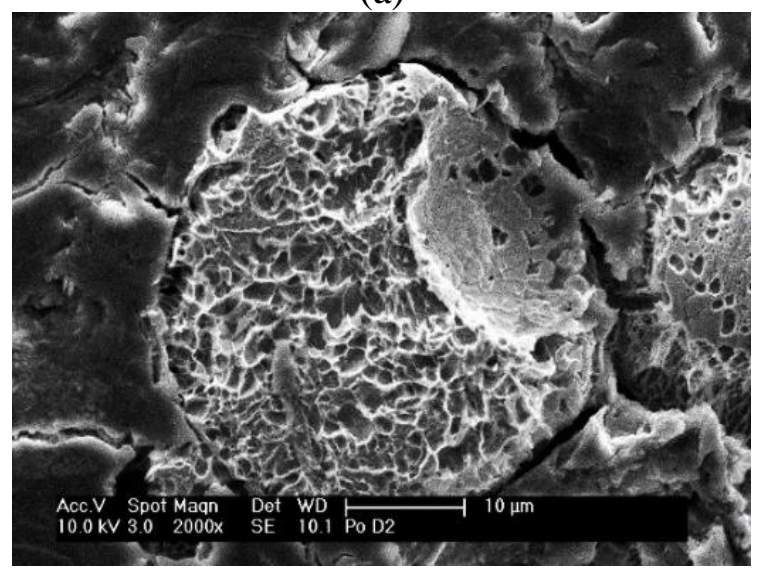

(c)

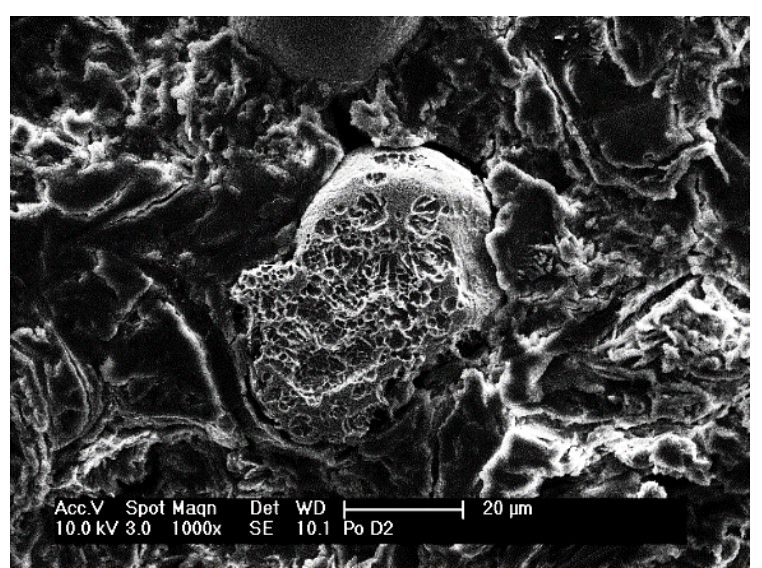

(b)

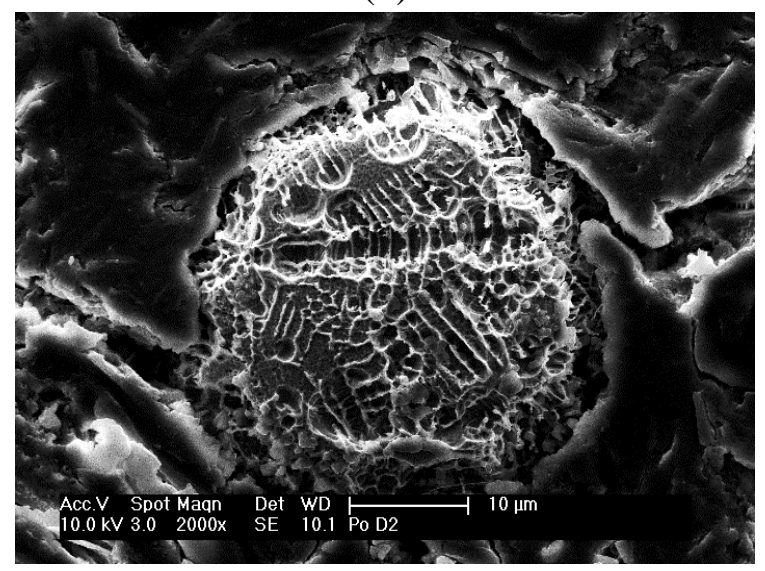

(d)

Figura 39 - Imagens obtidas por MEV das partículas de pó D2, em a) e b) aumento de

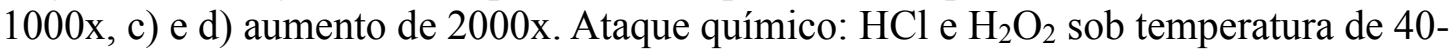
$60^{\circ} \mathrm{C}$.

\subsubsection{Escoabilidade}

Na Tabela 13 é apresentado o resultado obtido de escoabilidade para os pós de Co-Cr-Mo. A amostra do pó D1 em razão de ter uma granulometria muito fina não escoou pelo funil de Hall, portanto não foi possível mensurar a escoabilidade. De acordo com os dados da Tabela 13 verifica-se que o desvio entre o valor máximo e mínimo obtido $(\mathrm{D} 2=$ $0,29 \mathrm{~s} / 50 \mathrm{~g}$ e $\mathrm{D} 3=0,09 \mathrm{~s} / 50 \mathrm{~g}$ ) é inferior ao desvio de $0,4 \mathrm{~s} / 50 \mathrm{~g}$ considerado pela norma ASTM B213, portanto o resultado é confiável (ASTM INTERNATIONAL, 2013a). 
Tabela 13 - Resultado da escoabilidade dos pós de Co-Cr-Mo.

\begin{tabular}{cccc}
\hline \multicolumn{4}{c}{ Escoabilidade (s/50 g) } \\
\hline Pó & D1 & D2 & D3 \\
\hline Média e desvio padrão & - & $15,85 \pm 0,11$ & $22,88 \pm 0,03$ \\
\hline Desvio obtido & - & 0,29 & 0,09 \\
\hline
\end{tabular}

De acordo com Hann et al. (2015), a escoabilidade de pós de liga de Co-CrMo, apresentou resultados similares aos obtidos, respectivamente para pós com diâmetro D90 igual a $39 \mu \mathrm{m}$, a escoabilidade foi de $18,6 \mathrm{~s} / 50 \mathrm{~g}$.

\subsubsection{Densidade teórica média}

A densidade teórica média obtida pelas equações 1 e 2 para a liga de Co-Cr-Mo é apresentada na Tabela 14, bem como a representação das etapas dos cálculos realizados. O valor obtido de densidade média teórica foi de $8,38 \mathrm{~g} / \mathrm{cm}^{3}$.

Tabela 14 - Representação dos cálculos para obter a densidade teórica média da liga de Co-Cr-Mo com base na composição mássica.

\begin{tabular}{|c|c|c|c|c|c|}
\hline Elementos químicos & Co & $\mathbf{C r}$ & Mo & Fe & Total \\
\hline \% massa & 63,93 & 28,83 & 7,07 & 0,17 & 100,00 \\
\hline Densidade teórica $\left(10^{-3} \mathrm{~kg} / \mathrm{m}^{3}\right)$ & 8,89 & 7,14 & 10,28 & 7,87 & - \\
\hline Volume $(\mathrm{m} / \mathrm{\rho})$ & 7,19 & 4,04 & 0,69 & 0,02 & 11,94 \\
\hline$\% \mathrm{~V}(\mathrm{~V} / \mathrm{Vt})$ & $60,24 \%$ & $33,82 \%$ & $5,76 \%$ & $0,18 \%$ & $100 \%$ \\
\hline Densidade teórica média $\left(10^{-3} \mathrm{~kg} / \mathrm{m}^{3}\right)$ & 5,36 & 2,41 & 0,59 & 0,01 & $\mathbf{8 , 3 8}$ \\
\hline
\end{tabular}

\subsubsection{Densidade aparente}

$\mathrm{Na}$ Tabela 15 observam-se as medidas de densidade aparente dos pós. Os resultados indicando um valor aceitável em relação a norma ASTM B212, por apresentar um pequeno desvio padrão (ASTM INTERNATIONAL, 2013b).

Tabela 15 - Resultado da densidade aparente dos pós de Co-Cr-Mo.

\begin{tabular}{cccc}
\hline \multicolumn{4}{c}{ Densidade aparente $\left(\mathbf{1 0}^{-3} \mathbf{~ k g} / \mathbf{m}^{\mathbf{3}}\right)$} \\
\hline Pó & $\mathrm{D} 1$ & $\mathrm{D} 2$ & $\mathrm{D} 3$ \\
\hline Média e desvio & $4,12 \pm 0,01$ & $4,51 \pm 0,01$ & $4,55<0,01$ \\
\hline
\end{tabular}

Os resultados de densidade aparente dos pós evidenciaram que os valores obtidos estão diretamente relacionados com o tamanho da partícula. É possível observar pelos resultados dos pós D1, D2 e D3, respectivamente de 4,12, 4,51 e 4,55.10-3 kg/m que a densidade aumenta com o aumento da faixa granulométrica. O resultado obtido é 
confirmado segundo as referências de metalurgia do pó (ASM INTERNACIONAL, 1998; GERMAN, 1994; GESSINGER, 1984), em que é descrito que a densidade aparente decresce com o decréscimo do tamanho da partícula. Este fenômeno está associado a maior superfície específica em partículas de menor diâmetro, e consequentemente, dificultam a acomodação entre as partículas (ASM INTERNACIONAL, 1998; GERMAN, 1994).

De acordo com Hann et al. (2015), a densidade aparente obtida para pós de liga similar à de Co-Cr-Mo foi de 4,38 $.10^{-3} \mathrm{~kg} / \mathrm{m}^{3}$ (pó com D90 = $39 \mu \mathrm{m}$ ). No entanto, no estudo de Dourandish et al. (2008), a relação da densidade aparente para duas granulometrias distintas, de menor diâmetro $(\mathrm{D} 90=34 \mu \mathrm{m})$ e de maior diâmetro $(\mathrm{D} 90=84$ $\mu \mathrm{m})$, respectivamente obteve-se 4,4 e $4,1.10^{-3} \mathrm{~kg} / \mathrm{m}^{3}$. Neste caso, a densidade aparente do pó fino foi superior em relação ao pó de maior diâmetro.

Segundo as referências analisadas (ASM INTERNACIONAL, 1998; DOURANDISH et al., 2008; GERMAN, 1994; GESSINGER, 1984; HAAN et al., 2015) e os resultados obtidos neste estudo, a análise de densidade aparente de pós indicam resultados que podem ter tendências diferentes, em razão das diversas propriedades que influenciam no adensamento dos pós.

\subsubsection{Densidade batida}

$\mathrm{Na}$ Tabela 16 observam-se os resultados do volume característico batido ou densidade batida dos pós de Co-Cr-Mo. Os resultados obtidos de densidade batida foram respectivamente de: $5,00,5,26$ e $5,09.10^{-3} \mathrm{~kg} / \mathrm{m}^{3}$ para os pós D1, D2 e D3. A partir da comparação da medida de densidade aparente verifica-se o incremento da densidade (batida) em relação a faixa granulométrica. No entanto, não houve conformidade entre os resultados do pó D2 para o pó D3. Neste caso, o decréscimo da densidade batida do pó D3 associa-se a maior presença de satélites nas partículas de pó (vide Figura 37).

$\mathrm{O}$ resultado de densidade batida tende a ser superior ao resultado da densidade aparente. $\mathrm{O}$ incremento da razão entre a densidade batida e aparente é maior quanto menor for a densidade aparente. Em razão da acomodação das partículas há o decréscimo da quantidade de vazios entre as mesmas (ASM INTERNACIONAL, 1998).

Tabela 16 - Resultado da densidade batida dos pós de Co-Cr-Mo.

\begin{tabular}{cccc}
\hline \multicolumn{4}{c}{ Densidade batida $\left(\mathbf{1 0}^{-\mathbf{3}} \mathbf{~ k g} / \mathbf{m}^{\mathbf{3}}\right)$} \\
\hline Pó & $\mathrm{D} 1$ & $\mathrm{D} 2$ & $\mathrm{D} 3$ \\
\hline Média e desvio & $5,00 \pm 0,02$ & $5,26 \pm 0,05$ & $5,09 \pm 0,02$ \\
\hline
\end{tabular}


Segundo o estudo de Dourandish et al. (2008) a densidade batida obtida para duas faixas granulométricas, de menor diâmetro $(\mathrm{D} 90=34 \mu \mathrm{m})$ e de maior diâmetro (D90 $=84 \mu \mathrm{m})$, apresentou respectivamente o resultado de 5,0 e $4,5.10^{-3} \mathrm{~kg} / \mathrm{m}^{3}$. Portanto, conclui-se que assim como os resultados obtidos por Dourandish et al. de (2008), os resultados apresentados são pertinentes a densidade batida em pós de Co-Cr-Mo.

\subsubsection{Densidade por picnometria de Hélio}

Na Tabela 17 são apresentados os resultados de densidade por picnometria de He dos pós da liga Co-Cr-Mo. A partir da comparação entre a densidade teórica média e a densidade por picnometria de He evidencia-se a presença de porosidade fechada, que não é considerada na medida do volume de He, provocando redução da densidade por picnometria de He. A presença de porosidade interna calculada em relação as densidades (teórica e por picnometria) é de até $1,3 \%$.

Tabela 17 - Resultado da densidade por picnometria de He dos pós da liga Co-Cr-Mo.

\section{Pó \\ Densidade Téorica média Densidade por picnometria de $\mathrm{He}$}

$\left(10^{-3} \mathrm{~kg} / \mathrm{m}^{3}\right)$ $\left(10^{-3} \mathrm{~kg} / \mathrm{m}^{3}\right)$

\begin{tabular}{|c|c|c|}
\hline D1 & & $8,28 \pm 0,001$ \\
\hline D2 & 8,38 & $8,30 \pm 0,001$ \\
\hline D3 & & $8,27 \pm 0,001$ \\
\hline
\end{tabular}

Apresenta-se na Tabela 18 os resultados obtidos das propriedades físicas: distribuição granulométrica, escoabilidade, densidade (aparente, batida e teórica média, por picnometria de He) dos pós.

Nota-se na Tabela 18 a relação da distribuição granulométrica dos pós com as propriedades físicas de empacotamento (densidade aparente e densidade batida) e escoabilidade.

Conforme descrito na seção de densidade aparente (vide 5.2.6), a razão ao aumento da área superficial (aumento de atrito entre as partículas) está associada com o decréscimo do diâmetro da partícula. O elevado atrito entre as partículas dificulta a escoabilidade do pó, e consequentemente, na dispersão e acomodação das partículas. 
Tabela 18 - Resultado geral das propriedades físicas dos pós de Co-Cr-Mo obtidas.

\begin{tabular}{|c|c|c|c|}
\hline \multirow{2}{*}{ Propriedades Físicas } & \multicolumn{3}{|c|}{ Pós de Co-Cr-Mo } \\
\hline & D1 & D2 & D3 \\
\hline Distribuição granulométrica $(\mu \mathrm{m})$ & $5,67-19,64$ & $20,88-46,10$ & $69,68-118,74$ \\
\hline Escoabilidade (s/50g) & - & $15,85 \pm 0,11$ & $22,89 \pm 0,03$ \\
\hline Densidade aparente $\left(10^{-3} \mathrm{~kg} / \mathrm{m}^{3}\right)$ & $4,12 \pm 0,01$ & $4,51 \pm 0,01$ & $4,55 \pm 0,01$ \\
\hline Densidade batida $\left(10^{-3} \mathrm{~kg} / \mathrm{m}^{3}\right)$ & $5,00 \pm 0,02$ & $5,26 \pm 0,05$ & $5,09 \pm 0,02$ \\
\hline Densidade teórica média $\left(10^{-3} \mathrm{~kg} / \mathrm{m}^{3}\right)$ & & 8,38 & \\
\hline $\begin{array}{c}\text { Densidade por Picnometria } \\
\text { de } \mathrm{He}\left(10^{-3} \mathrm{~kg} / \mathrm{m}^{3}\right)\end{array}$ & $8,28 \pm 0,001$ & $8,30 \pm 0,001$ & $8,27 \pm 0,001$ \\
\hline
\end{tabular}

\subsubsection{Análise de dureza Vickers}

Medidas de dureza Vickers nos pós atomizados a gás de Co-Cr-Mo foram realizadas relacionando a dureza com a distribuição granulométrica. Em razão da granulometria muito fina do pó D1 (diâmetro médio de $12,76 \mu \mathrm{m}$ ) o teste de microdureza não evidenciou resultados significativos. Na Figura 40 e Tabela 19 apresenta-se as identações e resultados de microdureza Vickers para os pós de maior granulometria (pó D2 e pó D3).

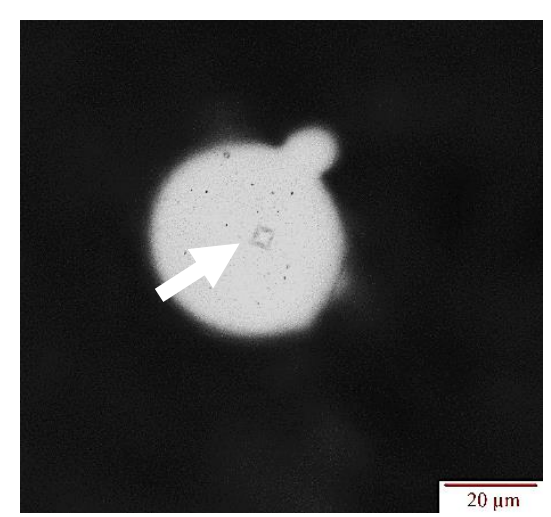

(a)

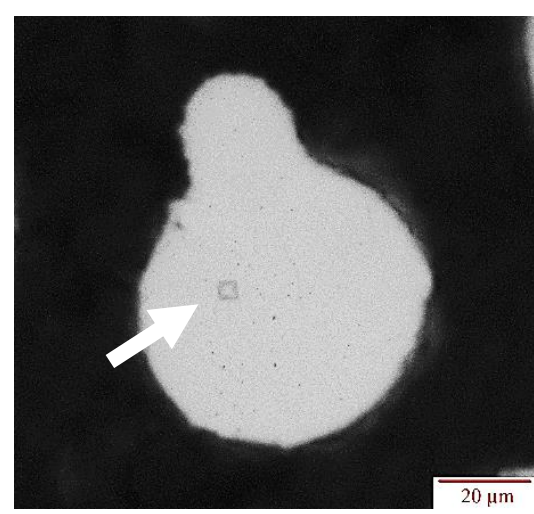

(b)

Figura 40 - Partículas dos pós de Co-Cr-Mo, respectivamente D2 e D3 com identação do penetrador Vickers (destacadas pelas setas em branco). Aumentos de 1000x.

Tabela 19 - Resultados de microdureza Vickers HV 0.1N/10s dos pós de Co-Cr-Mo após polimento de amostras embutidas.

\section{Microdureza Vickers HV 0.1N/10s}

\begin{tabular}{cccc}
\hline Pó & D1 & D2 & D3 \\
\hline Média e desvio padrão & - & $148,33 \pm 38,89$ & $390,35 \pm 40,73$ \\
\hline
\end{tabular}


O resultado da medida de microdureza Vickers do pó D3 é superior ao pó D2, respectivamente 390,35 HV0.1 e 148,33 HV0.1. O aumento da dureza em relação ao tamanho das partículas associa-se a taxa de resfriamento. A partícula de pó D3, por ser de maior granulometria, apresenta uma taxa de resfriamento maior, pelo fato destas partículas se formarem primeiro e transitarem de forma mais rápida (efeito da gravidade) pelas regiões de maior temperatura na coluna do atomizador (GESSINGER, 1984).

\subsubsection{Análise de calorimetria exploratória diferencial (DSC)}

As curvas de aquecimento da análise de DSC, obtidas utilizando o pó D1, são apresentadas na Figura 41. Nota-se nas curvas de aquecimento de DSC a presença de quatro eventos, sendo dois exotérmicos ( $1^{\circ}$ e $2^{\circ}$ evento), um endotérmico ( $3^{\circ}$ evento) e o evento final ( $4^{\circ}$ evento) correspondendo à fusão da liga de Co-Cr-Mo. Na Tabela 20 confere-se às temperaturas dos eventos presenciados e a variação de temperatura dos eventos entre as diferentes taxas de temperatura.

Segundo Mothé e Azevedo (2009), o início da análise térmica apresenta um evento ( $1^{\circ}$ evento) que se associa a presença de umidade da amostra, como, também, relaciona-se a diferença da capacidade calorífica entre o cadinho e a amostra. Este evento foi verificado na análise do pó D1 de Co-Cr-Mo, porém o mesmo é irrelevante para a análise térmica do material em estudo.

Em relação ao segundo evento (exotérmico), ocorrendo por volta de $582,81^{\circ} \mathrm{C}$, o mesmo relaciona-se a transformação de fase da liga (precisamente do Co), da fase cúbica de face centrada $(\alpha \mathrm{Co})$ para a fase hexagonal compacta $(\varepsilon \mathrm{Co})$. Em análise similar, Santos (2012) obteve um ligeiro pico a $600^{\circ} \mathrm{C}$ na análise térmica (DTA), no entanto, o ocorrido não é abordado pelo autor. Esta ocorrência é descrita por Facchini (2010) e ocorre a aproximadamente $650^{\circ} \mathrm{C}$. Porém, é descrito um pico endotérmico, divergindo da presente análise, a qual na curva de $20^{\circ} \mathrm{C} / \mathrm{min}$ ocorre em aproximadamente $600^{\circ} \mathrm{C}$ descrevendo um pico exotérmico. Levanta-se a hipótese de que esta divergência se associa a diferença de calibrações entre os equipamentos utilizados na análise.

O terceiro evento (endotérmico) ocorre por volta de $944,52^{\circ} \mathrm{C}$ e relaciona-se a transformação alotrópica do elemento Co, pela transição da fase de estrutura hexagonal compacta $(\varepsilon \mathrm{Co})$ para a fase de estrutura cúbica de face centrada $(\alpha \mathrm{Co})$. Esta transformação é confirmada no diagrama binário do Co-Cr (vide seção 3.2.2) ocorrendo por volta de $950^{\circ} \mathrm{C}$ (em relação a $29 \%$ de peso de $\mathrm{Cr}$ ). Esta ocorrência é similar à descrita por 
(FACCHINI, 2010; SANTOS, 2012), que obtêm picos endotérmicos respectivamente a $970^{\circ} \mathrm{C}$ e $1000^{\circ} \mathrm{C}$, em relação ao obtido no presente estudo de $944,52^{\circ} \mathrm{C}$. A esta diferença de temperatura associa-se a composição química da liga (64Co-29Cr-7Mo do presente estudo), as quais, representam ligas de acordo com a norma ASTM F75, cuja estequiometria é $66 \mathrm{Co}-28 \mathrm{Cr}-6 \mathrm{Mo}$, e portanto, há diferença de temperatura de 26 e $56^{\circ} \mathrm{C}$ em relação as referências citadas. Associa-se a calibrações distintas entre os equipamentos utilizados na análise.

Nas curvas de aquecimento de DSC verifica-se a temperatura de fusão $\left(4^{\circ}\right.$ evento) da liga de Co-Cr-Mo. Por meio do valor médio das três taxas de aquecimento, a temperatura de fusão é de $1354,5^{\circ} \mathrm{C}$, ocorrendo uma variação de $4^{\circ} \mathrm{C}$ entre as taxas. Estes resultados concordam com os valores observados na literatura (FACCHINI, 2010; SANTOS, 2012).

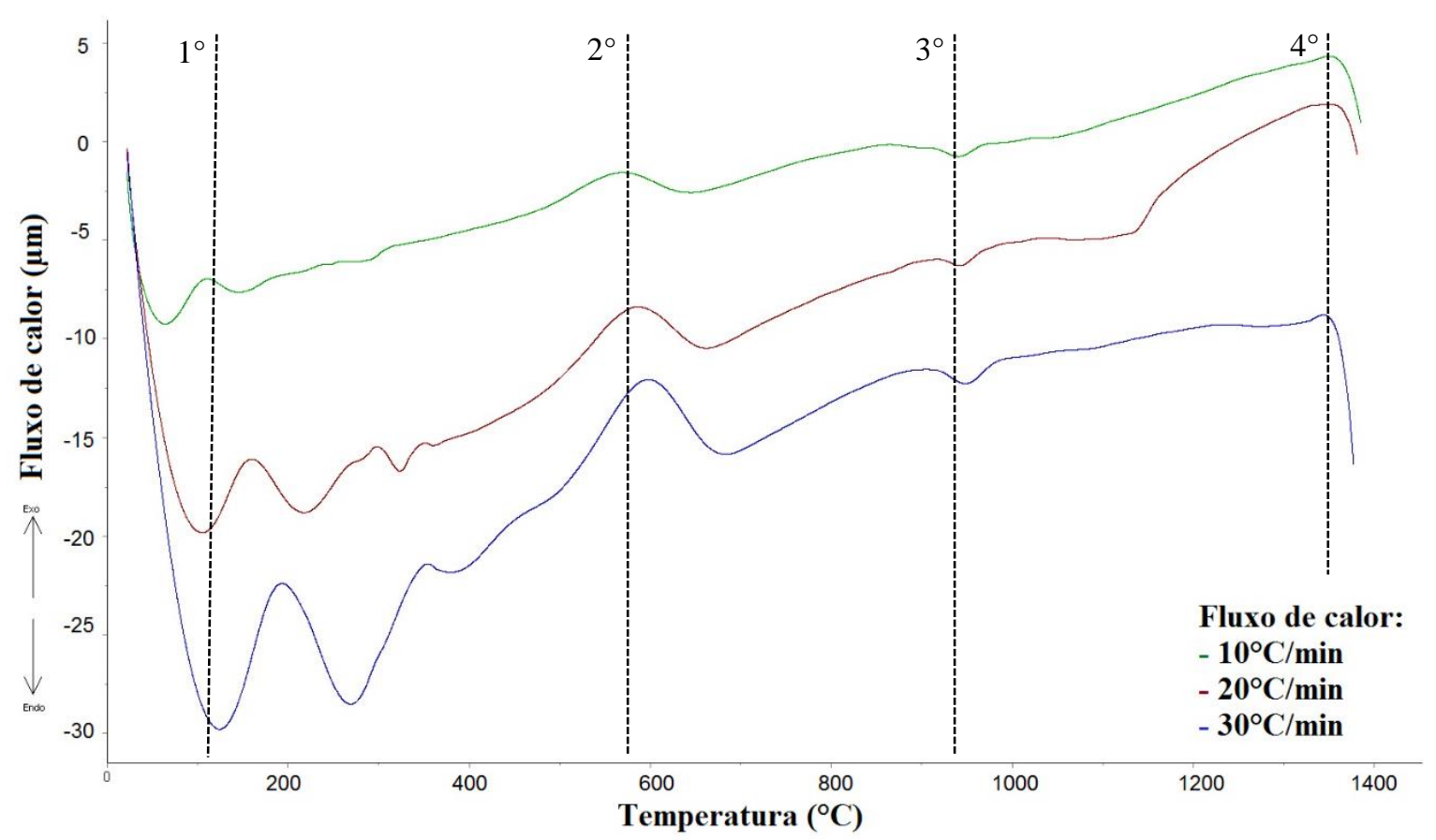

Figura 41 - Curvas de aquecimento da análise de DSC da amostra de pó D1 de Co-Cr-Mo (taxa de aquecimento: 10,20 e $30^{\circ} \mathrm{C} / \mathrm{min}$. Atmosfera: argônio).

Tabela 20 - Resultados das temperaturas correspondentes aos eventos ocorridos na curva de aquecimento durante a análise DSC para o pó D1 de Co-Cr-Mo.

\begin{tabular}{llcccc}
\multirow{2}{*}{ Evento } & \multicolumn{3}{c}{ Taxa $\left({ }^{\circ} \mathbf{C} / \mathbf{m i n}\right)$} & $\begin{array}{c}\text { Temperatura média e } \\
\text { desvio padrão }\left({ }^{\circ} \mathbf{C}\right)\end{array}$ \\
\cline { 3 - 5 } $\mathbf{1}^{\circ}$ & Exotérmico & 10 & 20 & 30 & 103,56 \\
\hline $\mathbf{2}^{\circ}$ & Exotérmico & 566,70 & 584,41 & 191,59 & $150,85 \pm 44,38$ \\
\hline $\mathbf{3}^{\circ}$ & Endotérmico & 941,88 & 942,67 & 949,74 & $582,81 \pm 15,55$ \\
\hline $4^{\circ}$ & Fusão & 1355,38 & 1358,52 & 1350,11 & $1354,67 \pm 4,25$
\end{tabular}


As curvas de resfriamento obtidas da análise de DSC para o pó D1 são apresentadas na Figura 42. Nas curvas de resfriamento obtêm-se a faixa de temperatura que ocorre a solidificação da liga de Co-Cr-Mo, a temperatura de 1300 a $1380^{\circ} \mathrm{C}$. Comparada com as literaturas abordadas pelos autores (KAISER et al., 2013; LIU et al., 2010; RAMÍREZ-VIDAURRI et al., 2009), a temperatura de solidificação ocorre respectivamente a $1355^{\circ} \mathrm{C}, 1387^{\circ} \mathrm{C}$ e $1390^{\circ} \mathrm{C}$.

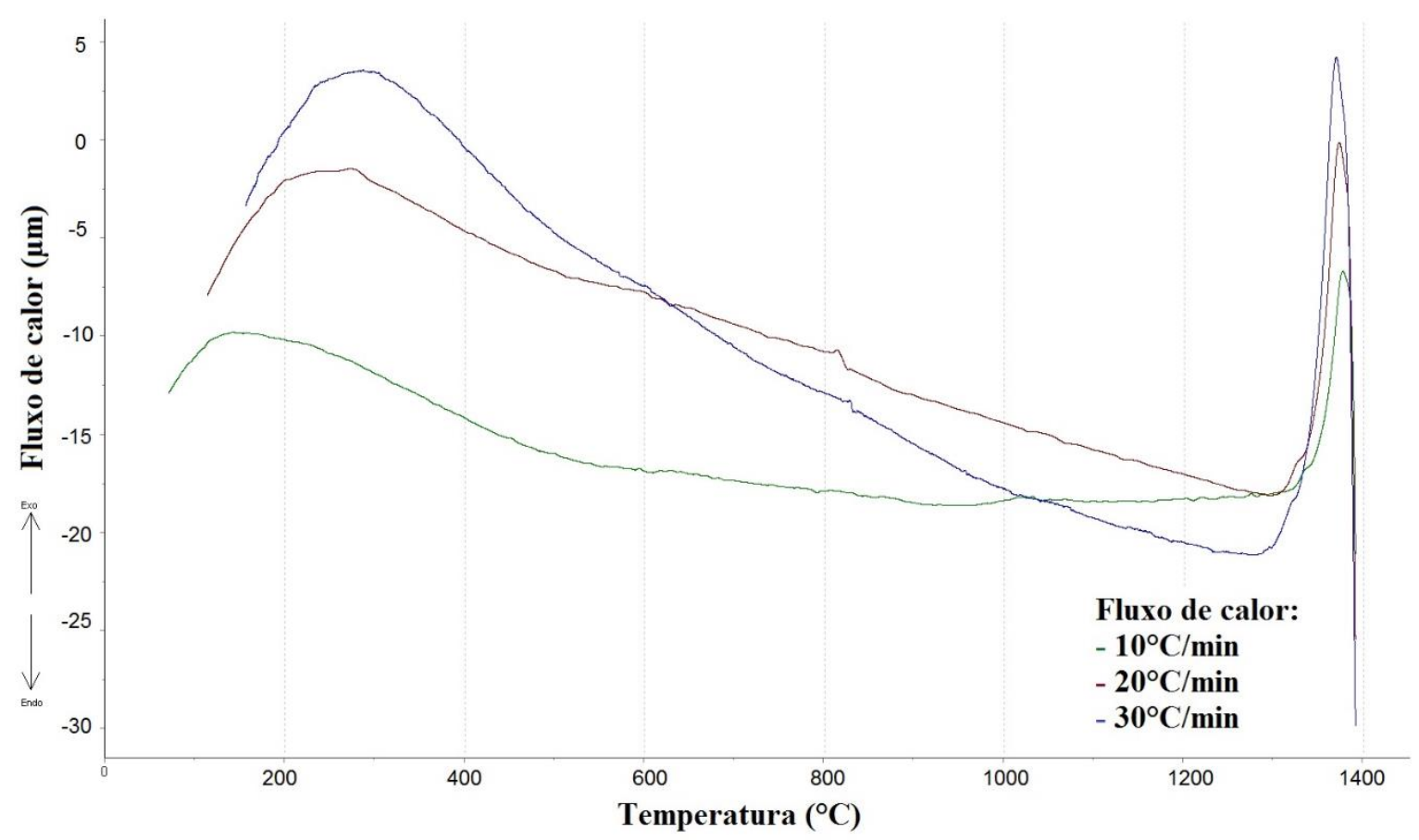

Figura 42 - Curvas de resfriamento da análise de DSC da amostra de pó D1 de Co-Cr-Mo (taxa de resfriamento: 10,20 e $30^{\circ} \mathrm{C} / \mathrm{min}$. Atmosfera: argônio).

As curvas de resfriamento possuem um comportamento de inflexão distinto das curvas de aquecimento, que se configuram de forma crescente e paralela. Visto que nas curvas de resfriamento há uma sobreposição das mesmas, sendo que a curva da taxa de $30^{\circ} \mathrm{C}$, sobrepõe-se as curvas de taxas de 10 e $20^{\circ} \mathrm{C}$. Esta observação associa-se ao fluxo de calor, representado pelo eixo das ordenadas (dado na unidade de Microvolts - $\mu \mathrm{V}$ ), o qual é incrementado de acordo com a taxa de aquecimento/ resfriamento. Portanto, devido ao fluxo de calor ocorrer de forma elevada, a curva da taxa de $30^{\circ} \mathrm{C}$ intercepta as curvas anteriores de resfriamento.

De acordo com Song et al. (2006), as curvas de resfriamento apresentam dois eventos. O primeiro associado com a transformação isotérmica martensítica e o segundo evento associado a reações de precipitação do carboneto, no entanto, as curvas de 
resfriamento não destacam os eventos descritos pela literatura (SANTOS, 2012; FACCHINI, 2010; SONG et al., 2006). Observa-se pela análise de DSC da amostra em pó D1 da liga de Co-Cr-Mo, que os resultados obtidos foram similares em relação às temperaturas de ocorrência dos eventos. No entanto, as divergências apresentadas em comparação aos estudos abordados (SANTOS, 2012; FACCHINI, 2010; SONG et al., 2006) se associam ao equipamento e metodologia utilizada nas análises que são desconhecidos.

Para melhor compreensão e investigação correta dos eventos, propõe-se realizar análise de dilatometria, assim como a realizada por (FACCHINI, 2010), possibilitando corresponder e associar os eventos de análise térmica.

\subsection{AVALIAÇÃO DA BIOCOMPATIBILIDADE}

\subsubsection{Ensaio de citotoxicidade}

A Figura 43 apresentada o resultado da análise de citotoxicidade para as amostras processadas.

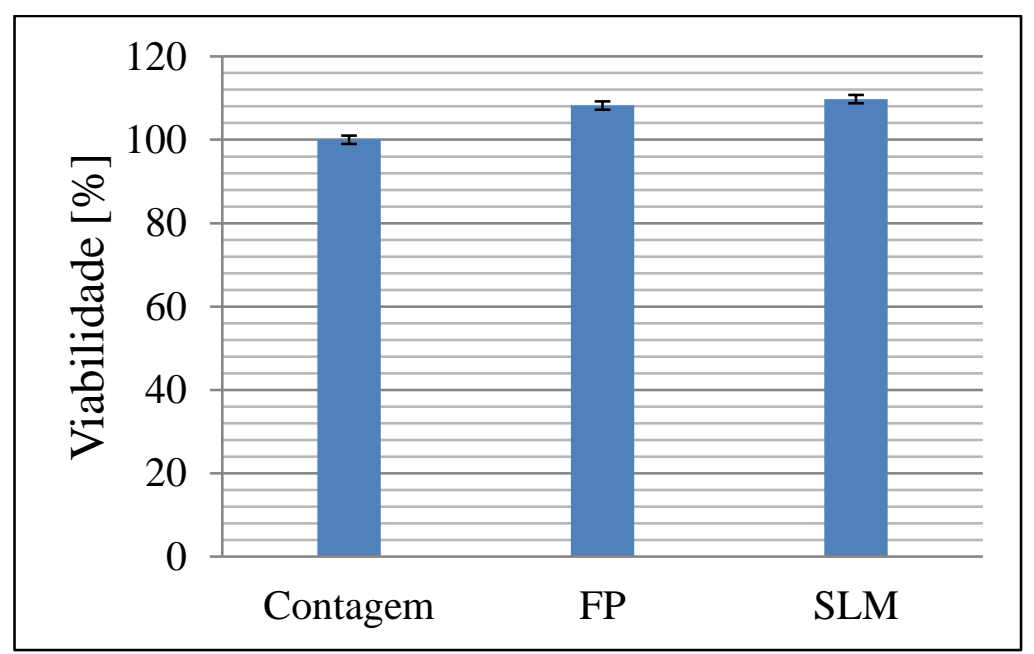

Figura 43 - Gráfico de viabilidade de crescimento celular das amostras consolidadas por FP e SLM da liga de Co-Cr-Mo.

De acordo com o ensaio da análise da citotoxicidade em relação ao extrato puro em 100\% (sem diluição) as amostras processadas por fundição de precisão e fusão seletiva a laser não apresentaram toxicidade. O resultado reforçou o esperado para a liga de 
Co-Cr-Mo, ou seja, na confecção de implantes ou próteses médicas e odontológicas estas ligas não apresentam toxicidade (IVANOVA; BAZAKA; CRAWFORD, 2014; WATAHA, 2000).

\subsection{PROPRIEDADES MECÂNICAS}

\subsubsection{Ensaio de tração}

As curvas de tensão versus deformação no ensaio de tração das amostras consolidadas por FP e SLM são apresentadas na Figura 44. Os resultados obtidos (média e desvio padrão das propriedades mecânicas) são apresentados na Tabela 21. Já os valores mínimos requeridos pelas normas são apresentados no gráfico da Figura 45.

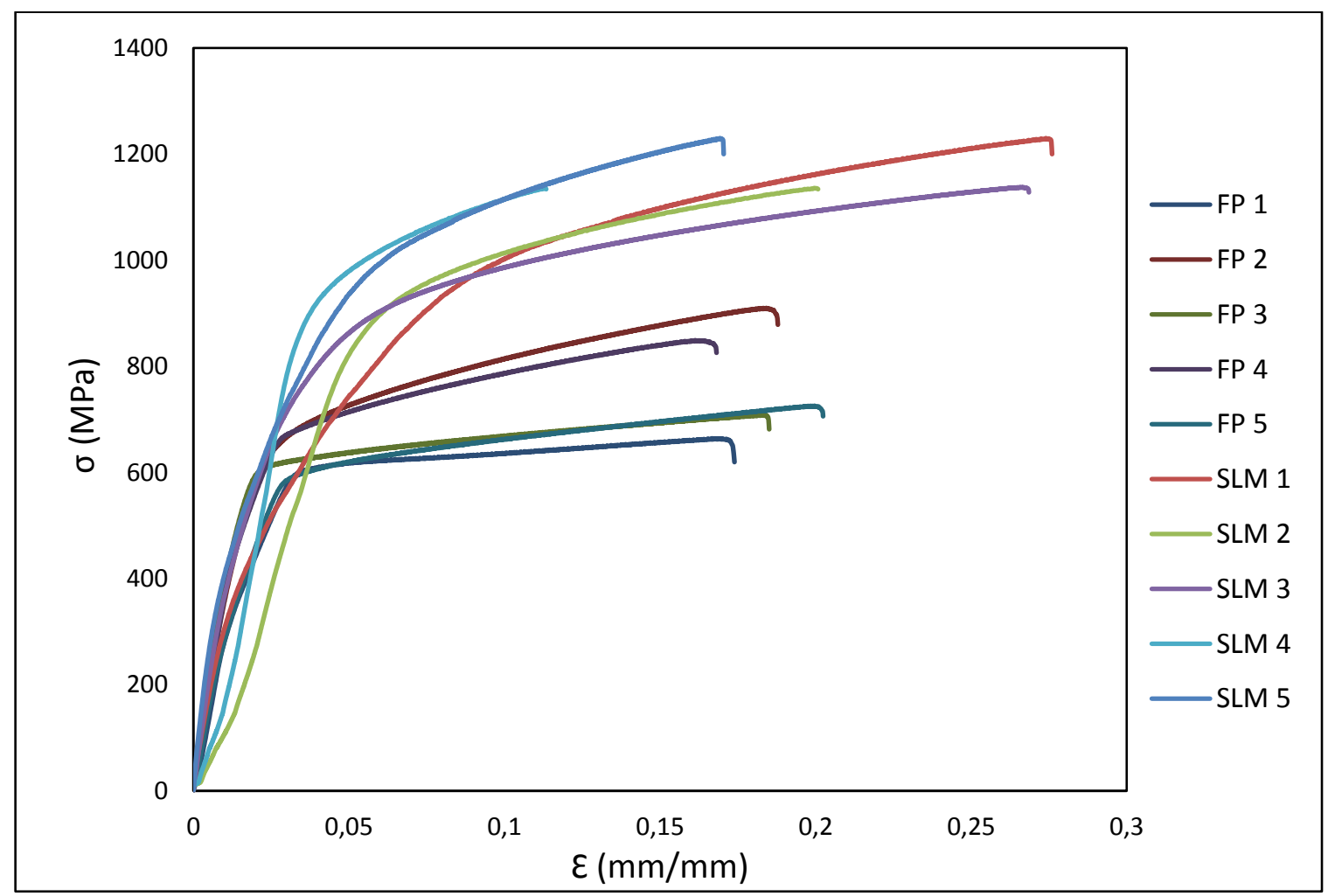

Figura 44 - Curvas de tensão versus deformação de engenharia da liga Co-Cr-Mo consolidada por SLM (Cp SLM) e por fundição de precisão (Cp FP). 
Tabela 21 - Resultados (valores médios e desvio padrão) das propriedades mecânicas obtidas nas amostras FP e SLM do pó D2 da liga de Co-Cr-Mo, em relação as propriedades mecânicas mínimas requeridas segundo as normas ISO 22674 e ASTM F75.

\begin{tabular}{ccccccc}
\hline \multicolumn{2}{c}{ REFERÊNCIA } & $\begin{array}{c}\boldsymbol{\sigma} \mathbf{L E} \\
(\mathbf{M P a})\end{array}$ & $\begin{array}{c}\mathbf{A}_{\mathbf{t}} \\
(\boldsymbol{\%})\end{array}$ & $\begin{array}{c}\boldsymbol{E} \\
(\mathbf{G P a})\end{array}$ & $\begin{array}{c}\boldsymbol{\sigma}_{\mathbf{L R}} \\
(\mathbf{M P a})\end{array}$ & $\begin{array}{c}\boldsymbol{\sigma}_{\mathbf{f}} \\
(\mathbf{M P a})\end{array}$ \\
\hline \multirow{2}{*}{ Co-Cr-Mo } & SLM & $731,50 \pm 40,31$ & $13,73 \pm 5,32$ & $225,18 \pm 14,40$ & $1136,95 \pm 0,92$ & $1127,91 \pm 0,15$ \\
\cline { 2 - 6 } & FP & $646,76 \pm 44,36$ & $14,20 \pm 2,76$ & $223,42 \pm 15,70$ & $771,70 \pm 103,32$ & $742,20 \pm 106,80$ \\
\hline ISO 22674 & Tipo “5” & 500 & 2 & 150 & - & \\
\cline { 1 - 5 } ASTM F75 & Fundição & 450 & 8 & - & 655 & \\
\hline
\end{tabular}

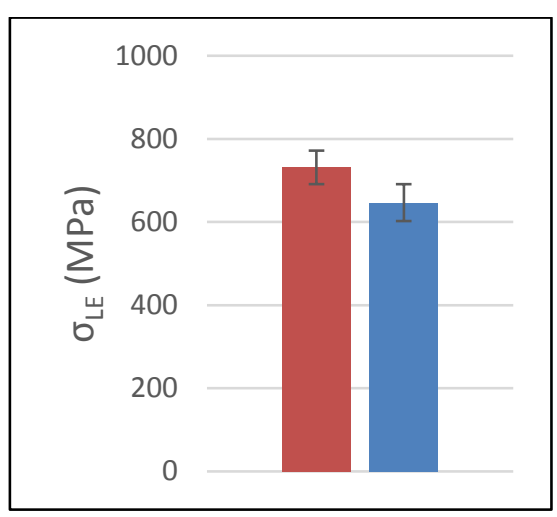

(a)

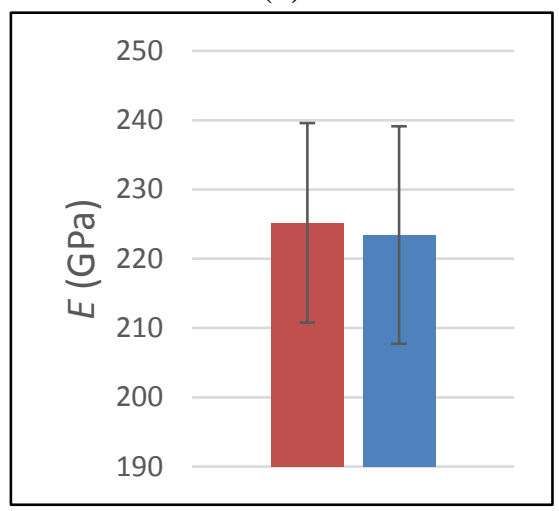

(c)

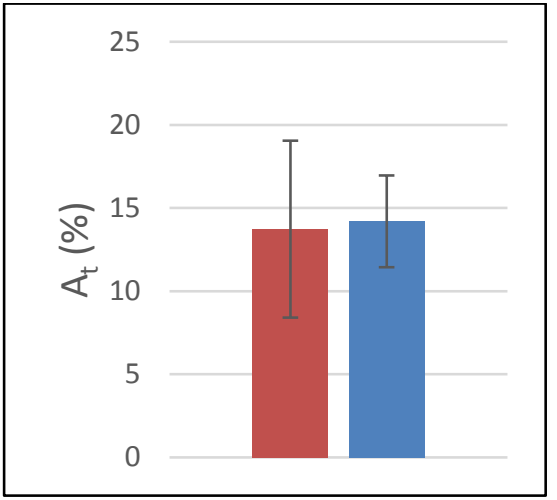

(b)

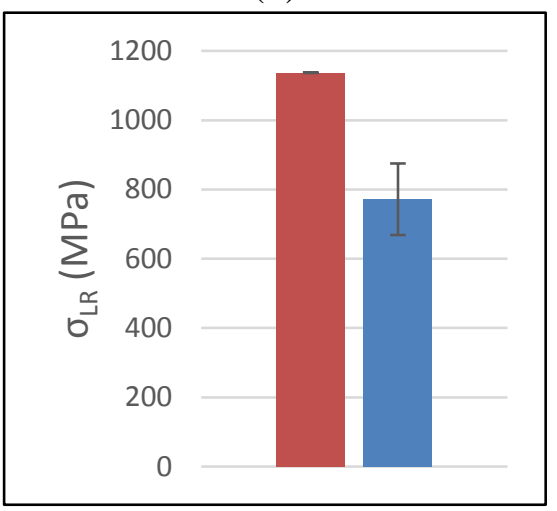

(e)

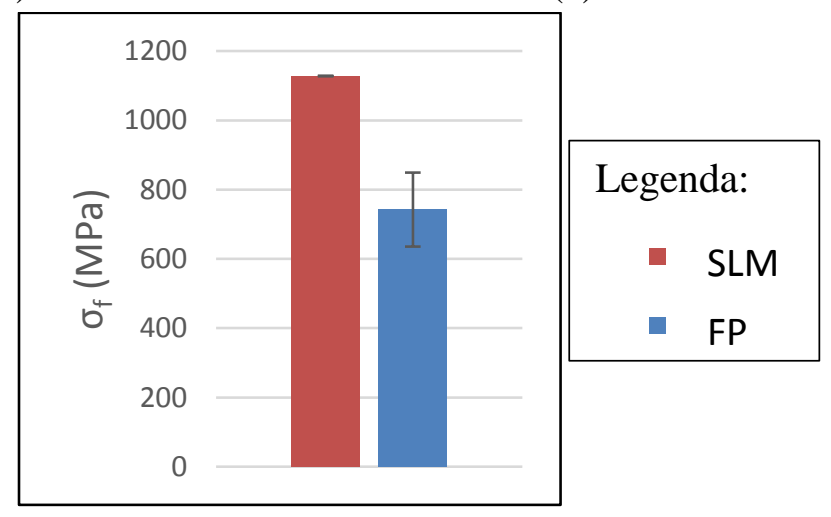

(f)

Figura 45 - Resultados das propriedades mecânicas da liga de Co-Cr-Mo consolidada por FP e SLM, em a) tensão de limite de escoamento, b) alongamento total, c) módulo de elasticidade, d) tensão limite de resistência e f) tensão limite de ruptura. 
Os resultados das propriedades mecânicas obtidas quando comparadas com as especificadas pelas normas referenciadas (vide Tabela 21) indica que a consolidação por SLM e FP da liga de Co-Cr-Mo se enquadram no tipo 5 da norma ISO 22674 (2006).

Em relação a norma ASTM F75 as amostras consolidadas por fundição de precisão atingem valores superiores ao estabelecido pela norma ASTM F75 (2012b). Ambos processos proporcionam a liga de Co-Cr-Mo propriedades mecânicas relevantes para a aplicação do mesmo na confecção de próteses dentárias fixas ou removíveis.

\subsubsection{Ensaios de flexão em três pontos}

A partir do ensaio de flexão em três pontos foram obtidos os resultados de resistência a ruptura transversal (TRS) dos corpos de prova consolidados por SLM e FP conforme apresentado na Figura 46.

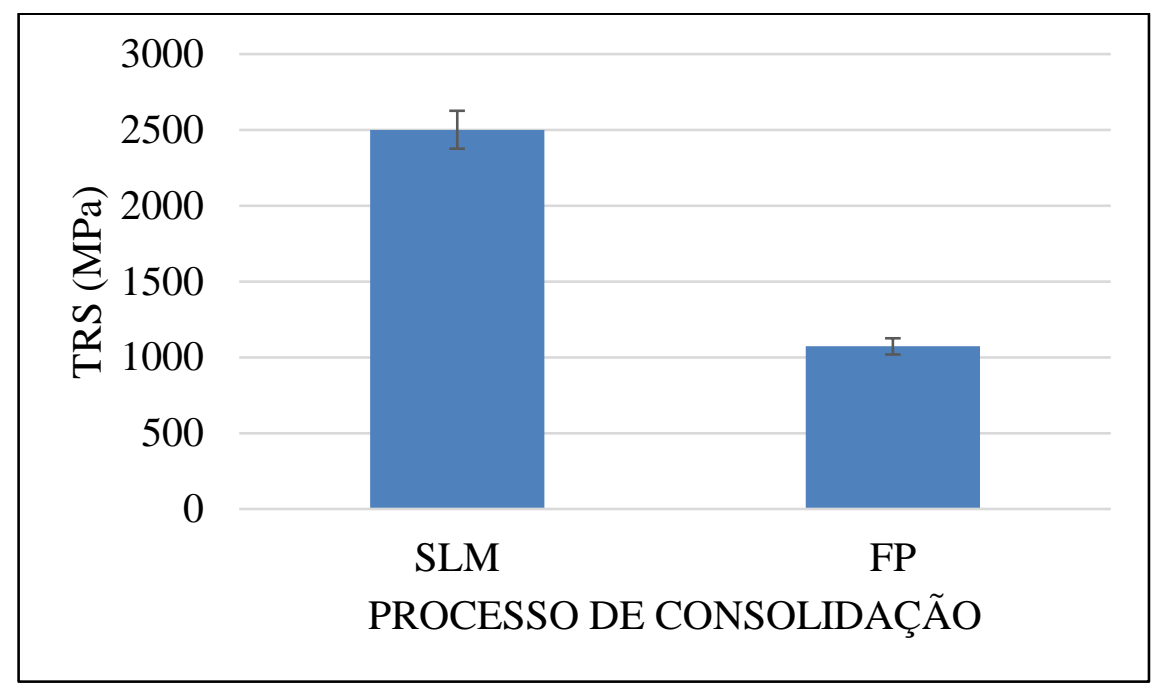

Figura 46 - Gráfico do resultado de TRS dos ensaios de flexão em três pontos da liga CoCr-Mo consolidada por SLM e FP.

O resultado de TRS obtido por meio da equação 3 (vide seção 4.6.2) das amostras SLM e FP é apresentado na Tabela 22. Verifica-se que o resultado é satisfatório para a amostra SLM do presente estudo (TRS = 2501,2 \pm 9,7 MPa) quando comparado ao resultado obtido no estudo de Mengucci et al. (2016) (resultado de TRS = $2700 \pm 25 \mathrm{Mpa}$ ). Como observado nos testes de tração as amostras SLM resultaram em uma elevada resistência a ruptura, sendo que o sentido de solicitação mecânica ocorreu no sentido de construção da amostra de tração. Em relação ao teste de TRS, o sentido de solicitação (em flexão) foi transversal ao sentido de construção da amostra, resultando no valor superior de 
resistência a ruptura da amostra. Em trabalhos futuros pretende-se avaliar a orientação dos grãos e correlacionar com a mecânica de fratura das amostras.

O resultado de TRS na amostra FP (TRS = 1072,3 \pm 4,6 MPa) evidenciou a ductilidade do processamento por fundição na liga de Co-Cr-Mo. A amostra FP demonstrou um comportamento de deformação mais plástico e que não levou a fratura da amostra. Caso o ensaio TRS não fosse interrompido, a ductilidade seria observada pela flecha superior em relação a da amostra SLM. Observa-se na Figura 47 que o ensaio de TRS para a amostra FP não foi conduzido até a ruptura do espécime. Em razão da deformação da amostra consolidada por FP ser alta, o espécime escorou no dispositivo (face inferior e face superior) impossibilitando a realização completa do ensaio, como demonstrado na Figura 47a (apontado pelas setas em vermelho) na qual são apresentados os corpos de prova após ensaio (vide Figura 47b). Já a amostra SLM atingiu a ruptura (sem escorar no dispositivo - vide Figura 47c).

Tabela 22 - Resultados do ensaio de flexão em três pontos das amostras consolidadas por SLM e FP de Co-Cr-Mo.

\begin{tabular}{cc}
\multicolumn{2}{c}{ Resistência a ruptura transversal - TRS (MPa) } \\
\hline Amostra & Média e desvio padrão \\
\hline SLM & $2501,2 \pm 9,7$ \\
\hline FP & $1072,3 \pm 4,6$ \\
\hline
\end{tabular}

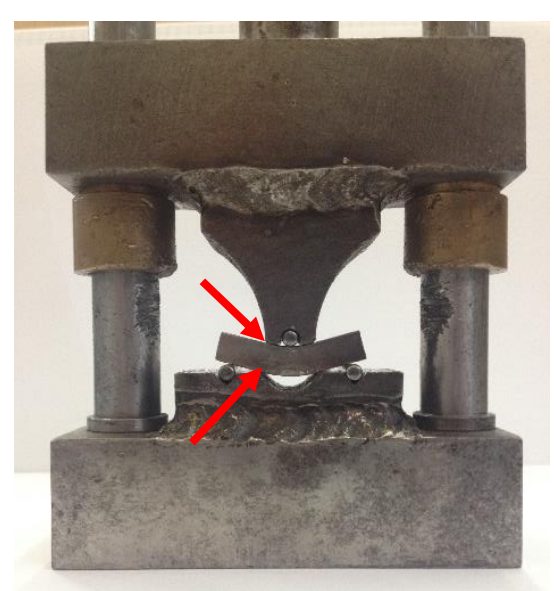

(a)

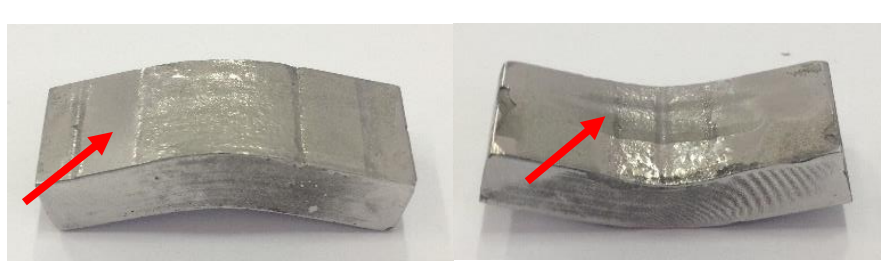

(b)

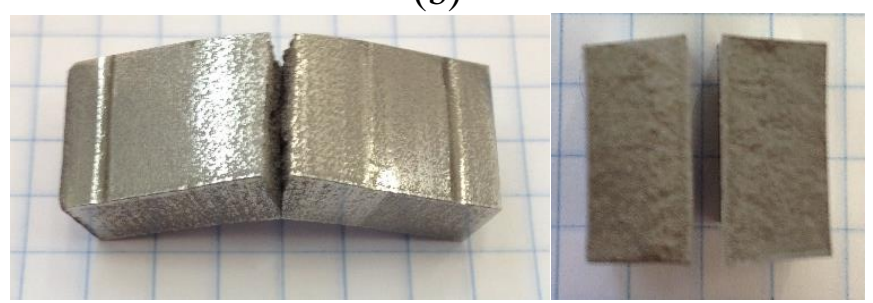

(c)

Figura 47 - a) Ensaio de flexão em três pontos da amostra FP interrompido devido a escora (apontado pelas setas em vermelho) da amostra com o dispositivo, b) corpo de prova FP após ensaio de TRS interrompido (marcas de escora destacadas pelas setas em vermelho) e c) corpo de prova SLM após fratura. 


\subsubsection{Análise da dureza Vickers}

Na Figura 48 observa-se a dureza em escala macro Vickers obtida após os processos de consolidação SLM e FP da liga de Co-Cr-Mo, em relação as seções (horizontal e vertical) de medida das amostras.

Verifica-se a faixa de dureza, destacada pelas linhas tracejadas no limite inferior e superior (266 a 345 HV), definida pela norma ASTM F75 (2012b). Na Tabela 23 apresenta-se os resultados de dureza e da análise estatística realizada pela execução do teste $\mathrm{t}$ em relação as médias de dureza obtida para as seções horizontal e vertical de cada processo.

Tabela 23 - Resultados de dureza Vickers das amostras SLM e FP.

\begin{tabular}{cccc}
\hline \multirow{2}{*}{$\begin{array}{c}\text { Dureza Vickers } \\
(\text { HV0.5) }\end{array}$} & \multicolumn{2}{c}{ Seção de medida } & \multirow{2}{*}{$\begin{array}{c}\text { Análise estatística } \\
\text { Teste } \mathbf{~}\end{array}$} \\
\cline { 2 - 3 } Amostra & \multicolumn{2}{c}{ Média e desvio padrão } & \\
\hline SLM & $358,1 \pm 9,8$ & $334,8 \pm 16,0$ & Valor de $\mathrm{p}$ \\
\hline FP & $256,7 \pm 12,9$ & $235,9 \pm 11,2$ & 0,001 \\
\hline
\end{tabular}

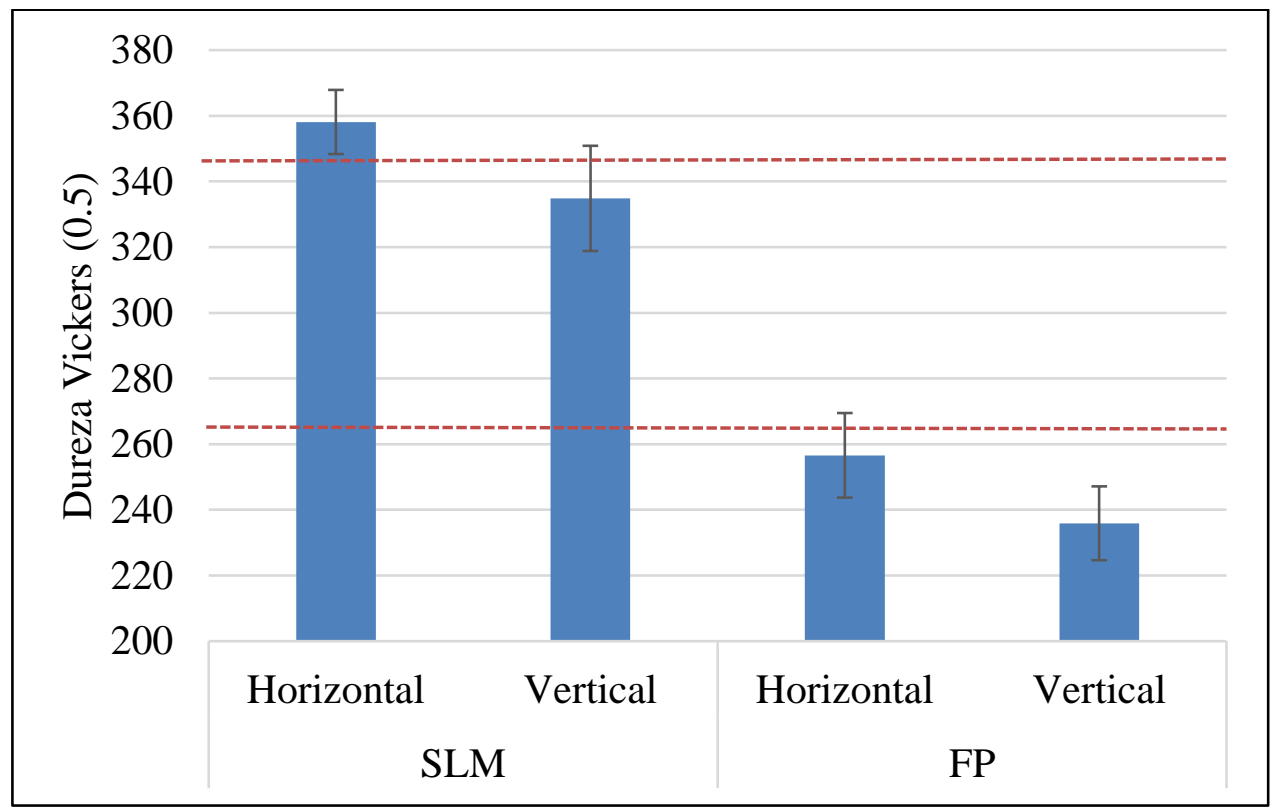

Figura 48 - Gráfico do resultado de dureza Vickers (HV0.5).

De acordo com os resultados obtidos verifica-se que as durezas para as amostras consolidadas por FP são inferiores as amostras SLM. Este resultado está diretamente ligado ao processo de solidificação das amostras, o qual nas amostras consolidadas por fundição deve ocorrer de modo mais lento, oposto ao processo de 
solidificação das amostras consolidadas por SLM que é rápido. De acordo com Kaiser et al. (2013) as propriedades mecânicas (no caso a dureza) do material são influenciadas pela taxa de resfriamento. Maiores taxas de resfriamentos provocam uma solidificação com microestrutura refinada e maior homogeneidade microestrutural, originando uma microestrutura favorável a propriedades mecânicas superiores.

Considerando-se a análise estatística em relação as seções de medida, constatase que o valor de p para as amostras SLM é de 0,001. No caso do valor de p ser menor que 0,05 é rejeitada a hipótese de semelhança de dureza entre as seções. Em outras palavras existe diferença da dureza macro na seção horizontal em relação a seção vertical na amostra SLM. Este resultado está diretamente relacionado a orientação de consolidação da amostra pelo processo de fusão seletiva a laser, conforme resultados da literatura (TAKAICHI et al., 2013). Para as amostras FP nota-se que o valor de p é igual a 0,243 (maior que 0,05). Conclui-se que não há diferença de dureza entre as seções (horizontal e vertical) na amostra processada por FP. Este ocorrido associa-se a baixa e homogênea taxa de resfriamento das amostras durante o processo de FP.

Segundo os resultados obtidos por Liverani et al. (2016), em amostras SLM de liga Co-Cr-Mo (vide Tabela 24), a dureza obtida foi de aproximadamente $361 \pm 31 \mathrm{HV}$. Em estudo realizado por Jabbari et al. (2014) amostras fabricadas por SLM de uma liga similar à de Co-Cr-Mo, obteve-se um resultado de dureza Vickers (HV10) igual a $371 \pm 10$ HV. No caso do incremento da dureza da amostra SLM em relação a FP associou-se à microestrutura de grãos refinados obtida pelo processo de fusão a laser. A alta dureza pode estar associada a possível presença de tensões residuais na amostra proveniente do processo de consolidação SLM (JABBARI et al., 2014; SHIOMI et al., 2004; SIMCHI; POHL, 2003).

A dureza obtida pelo processo FP é inferior ao processo SLM. Em relação as seções de análise (horizontal e vertical) a amostra FP evidencia uma diferença de dureza superior em relação ao obtido nas seções de análise (horizontal e vertical) da amostra SLM. A dureza para seção horizontal foi de 256,6 $\pm 12,9$ HV0.5 e para seção vertical de 235,9 \pm 11,2 HV0.5. De acordo com os autores (AHMED et al., 2014; JABBARI et al., 2014; HENRIQUES; SOARES; SILVA, 2012) a dureza obtida em amostras fundidas de composição similar a amostra FP apresentou resultados na faixa de 300 a $330 \mathrm{HV}$. Esta diferença se relaciona a dois fatores: as distintas velocidades de resfriamento nas regiões da amostra, que é verificada com maior influência na seção vertical (em razão da área de medição ser superior a seção horizontal) e as variações de composição química localizada. 
A partir dos resultados apresentados verifica-se que as durezas obtidas para as amostras consolidadas por FP são inferiores aos valores obtidos para as amostras consolidadas por SLM, em consequência a rápida solidificação.

Observa-se que as durezas (amostras FP e SLM) obtidas não se enquadram na faixa de dureza estabelecida pela norma ASTM F75 (2012b). No caso da amostra consolidada por FP a dureza está abaixo do limite inferior (266 HV) e para a amostra SLM está acima do limite superior (345 HV). Deve-se realizar tratamentos térmicos nas amostras (FP e SLM) para obter o valor requerido pela norma ASTM F75. Ressalta-se que não é estabelecido um padrão de dureza pela norma ISO 22674. Segundo os dados das propriedades mecânicas avaliadas verifica-se que a liga de Co-Cr-Mo do presente estudo consolidada pelas técnicas de SLM e FP atingem resultados de propriedades mecânicas similares aos apresentados na literatura (conforme Tabela 24).

Tabela 24 - Resultados das propriedades mecânicas obtidas da liga de Co-Cr-Mo consolidada por FP e SLM, em comparação com os resultados de literaturas.

\begin{tabular}{|c|c|c|c|c|c|c|c|}
\hline \multicolumn{2}{|c|}{ Referência } & $\begin{array}{c}\text { Liga } \\
(\% \text { em peso })\end{array}$ & $\begin{array}{c}\text { бLE } \\
(\mathbf{M P a})\end{array}$ & $\begin{array}{c}\mathbf{A t}_{\mathrm{t}} \\
(\%)\end{array}$ & $\begin{array}{c}\text { бLR } \\
(\mathbf{M P a})\end{array}$ & $\begin{array}{c}\text { TRS } \\
\text { (MPa) }\end{array}$ & $\begin{array}{c}\text { Dureza } \\
\text { (HV) }\end{array}$ \\
\hline \multirow{2}{*}{$\begin{array}{c}\text { Presente } \\
\text { trabalho } \\
\text { Co-Cr-Mo } \\
\end{array}$} & FP & \multirow{2}{*}{$64 \mathrm{Co}-29 \mathrm{Cr}-7 \mathrm{Mo}$} & $646,76 \pm 44,36$ & $14,20 \pm 2,76$ & $771,70 \pm 103,32$ & $1072,3 \pm 4,6$ & $256,7 \pm 12,9$ \\
\hline & SLM & & $731,50 \pm 40,31$ & $13,73 \pm 5,32$ & $1136,95 \pm 0,92$ & $2501,2 \pm 9,7$ & $358,1 \pm 9,8$ \\
\hline \multirow{2}{*}{$\begin{array}{l}\text { Takaichi et al. } \\
\qquad(2013)\end{array}$} & $\mathbf{F}$ & \multirow{2}{*}{ Co-28Cr-6Mo } & $296 \pm 25$ & $9,6 \pm 2,5$ & $912 \pm 39$ & - & - \\
\hline & SLM & & $516 \pm 28$ & $10,7 \pm 2,9$ & $591 \pm 37$ & - & - \\
\hline \multirow{2}{*}{$\begin{array}{l}\text { Qian et al. } \\
\text { (2015) }\end{array}$} & $\mathbf{F}$ & \multirow{2}{*}{$\begin{array}{c}60-65 \mathrm{Co} 26-30 \mathrm{Cr} \\
5-7 \mathrm{Mo}\end{array}$} & 610 & - & 741 & - & - \\
\hline & SLM & & $873 \pm 76$ & - & $1303 \pm 73$ & - & - \\
\hline \multirow{2}{*}{$\begin{array}{c}\text { Kajima et al. } \\
(2016)\end{array}$} & $\mathbf{F}$ & $63 \mathrm{Co}-29 \mathrm{Cr}-6 \mathrm{Mo}$ & $571 \pm 23$ & $11,2 \pm 2$ & $775 \pm 67$ & - & - \\
\hline & SLM & $\begin{array}{c}60-65 \mathrm{Co} 26-30 \mathrm{Cr} \\
5-7 \mathrm{Mo}\end{array}$ & $877 \pm 37$ & $12,3 \pm 3$ & $1170 \pm 29$ & - & - \\
\hline $\begin{array}{l}\text { Mengucci et al. } \\
\text { (2016) }\end{array}$ & SLM & $\begin{array}{c}\text { 63,8Co-24,7Cr- } \\
5,1 \mathrm{Mo}-5,4 \mathrm{~W}\end{array}$ & - & - & $1340 \pm 20$ & $2700 \pm 25$ & $434 \pm 22$ \\
\hline \multirow{2}{*}{$\begin{array}{l}\text { Jabbari et al. } \\
\quad(2014)\end{array}$} & $\mathbf{F}$ & $\begin{array}{c}61,6 \mathrm{Co}-30 \mathrm{Cr}- \\
6,5 \mathrm{Mo}\end{array}$ & - & - & - & - & $320 \pm 12$ \\
\hline & SLM & Co-29Cr-5,5Mo & - & - & - & - & $371 \pm 10$ \\
\hline $\begin{array}{c}\text { Liverani et al. } \\
\text { (2016) }\end{array}$ & SLM & Co $27-30 \mathrm{Cr} 5-7 \mathrm{Mo}$ & 677 & - & - & - & $361 \pm 31$ \\
\hline
\end{tabular}

A partir do processo de consolidação das amostras é possível associar variações microestruturais com análise de microdureza. Neste caso, ocorrerem variações nos resultados de microdureza dependendo da região de análise. Os ensaios de microdureza das amostras da liga Co-Cr-Mo são apresentados e relacionados a determinadas microestruturas na seção de avaliação microestrutural. 


\subsubsection{Análise Termomecânica (TMA) - Dilatometria}

As curvas de aquecimento de dilatometria representadas pelo coeficiente de dilatação (CET) versus temperatura das amostras consolidadas por SLM e FP são apresentadas na Figura 49. A relação do coeficiente de dilatação e dos picos dos eventos em relação à temperatura do ensaio das amostras é apresentada na Tabela 25.

O CET para as amostras consolidadas possui um comportamento distinto entre os processamentos da liga de Co-Cr-Mo. Verifica-se que o CET das amostras SLM 1, SLM 2 e $\mathrm{FP}$ à temperatura de $500^{\circ} \mathrm{C}$ é respectivamente de $15,0 / 19,5 / 22,0.10^{-6}{ }^{\circ} \mathrm{C}^{-1}$. $\mathrm{Na}$ temperatura de $600^{\circ} \mathrm{C}$ o valor do coeficiente decresce para os valores de 12,5/ 14,5/ $18,5.10^{-6}{ }^{\circ} \mathrm{C}^{-1}$. Segundo Santos (2012) em liga similar à de Co-Cr-Mo processada por forjamento o CET obtido foi de aproximadamente $13,0.10^{-6}{ }^{\circ} \mathrm{C}^{-1}$ à temperatura de $500^{\circ} \mathrm{C}$. Esta diferença é maior para a liga processada por FP (característica associada à microestrutura dendrítica formada). Já o processamento de forjamento é caracterizado por uma microestrutura de grãos finos e de maior empacotamento (SANTOS, 2012).

O coeficiente de expansão térmico é uma propriedade térmica da liga de grande interesse nos casos de aplicações em componentes dentários, que necessitem de recobrimento cerâmico (por exemplo, a coroa dentária). As referências (CRAIG, 2012; MCCABE; WALLS, 2008; SANTOS, 2012) evidenciam que para o correto processo de queima cerâmica, como revestimento do componente metálico as ligas de Co-Cr devem apresentar um valor de CET na faixa de 14,0 a $14,6.10^{-6}{ }^{\circ} \mathrm{C}^{-1}$ em temperaturas de 500 a $600^{\circ} \mathrm{C}$. O CET dos materiais cerâmicos para aplicações de revestimento em materiais metálicos devem ser próximos, em razão da contração e expansão durante o aquecimento, evitando assim a possibilidade de ocorrer vazios ou trincas durante o processo de queima (LEÃO et al., 2010; OYAGÜE et al., 2012).

Nas curvas de dilatometria observam-se diversos picos (destacados pelo asterisco (*) na cor representativa de cada amostra indicada na legenda) ocorrendo nas amostras, os quais estão associados a transições de fases. O comportamento da dilatometria das amostras SLM (SLM 1 e SLM 2) evidenciam curvas similares, apresentando picos em faixas de temperatura semelhantes.

A comparação entre as curvas das amostras SLM 1 e SLM 2, evidencia que a amostra analisada na direção (vertical) de consolidação (SLM 1) apresenta picos mais evidentes em relação a amostra analisada na direção transversal (SLM 2). Para a amostra FP o comportamento da curva apresenta picos similares em relação as amostras SLM, 
porém deslocados em faixas de temperatura superior. Estas divergências se associam a microestrutura obtida pelos processos de consolidação das amostras.

Tabela 25 - Relação do coeficiente de dilatação e dos picos dos eventos nas curvas de aquecimento de TMA das amostras consolidadas por SLM e fundição da liga de Co-CrMo.

\begin{tabular}{ccc|ccc}
\hline \multirow{2}{*}{ AMOSTRA } & \multicolumn{2}{c|}{$\begin{array}{c}\text { Coeficiente de dilatação } \\
\boldsymbol{\alpha}=\mathbf{1 0}^{-\mathbf{6}}{ }^{\circ} \mathbf{C}^{-\mathbf{1}}\end{array}$} & \multicolumn{3}{|c}{ Temperatura dos eventos } \\
& \multicolumn{2}{c}{$\left.{ }^{\circ} \mathbf{C}\right)$} \\
\hline SLM 1 & $500^{\circ} \mathrm{C}$ & $600^{\circ} \mathrm{C}$ & $1^{\circ}$ & $2^{\circ}$ & $3^{\circ}$ \\
\hline SLM 2 & 15,0 & 12,5 & 615,8 & 750,8 & 992,0 \\
\hline FP & 19,5 & 14,5 & 609,3 & 701,6 & 992,0 \\
\hline
\end{tabular}

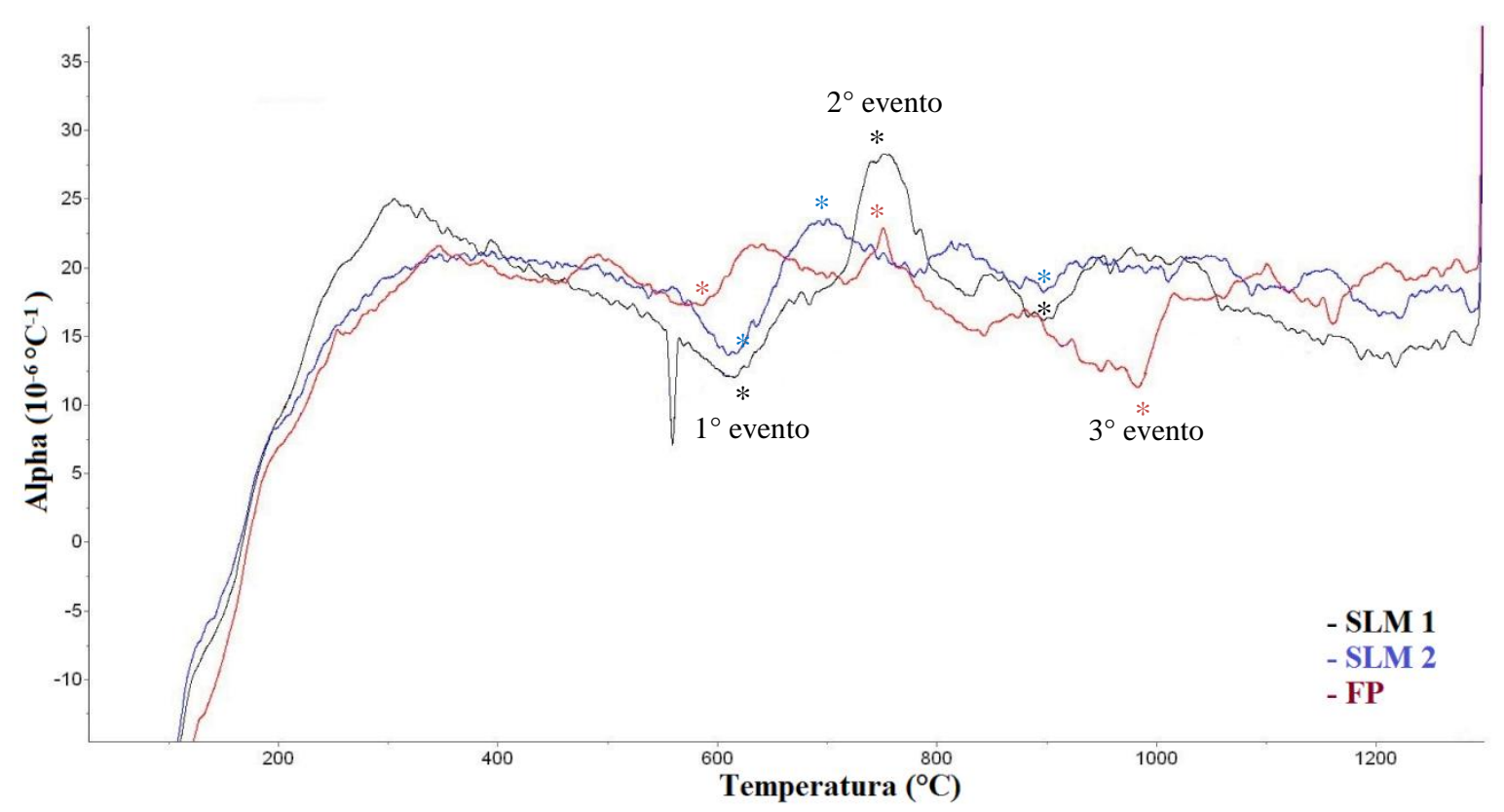

Figura 49 - Curvas de aquecimento da análise de TMA das amostras consolidadas por fusão seletiva a laser (SLM, em direções distintas de fabricação SLM 1 - na vertical e SLM 2 - na horizontal) e fundição de precisão (FP) (taxa de aquecimento: $10^{\circ} \mathrm{C} / \mathrm{min}$. Atmosfera: argônio).

As curvas de resfriamento (coeficiente de expansão térmico versus temperatura) obtidas para as amostras consolidadas por SLM e FP são apresentadas na Figura 50. A relação do coeficiente de dilatação e os picos evidenciados em relação a temperatura do ensaio das amostras são apresentados na Tabela 26. Observa-se nas curvas de resfriamento de TMA das amostras SLM (SLM 1 e SLM 2, curvas em preto e azul) um comportamento similar, originando o primeiro pico estabelecido em faixas de temperatura semelhantes, e o segundo pico ocorrendo apenas para a amostra SLM 1. 
Tabela 26 - Relação do coeficiente de dilatação e dos picos dos eventos nas curvas de resfriamento de TMA das amostras consolidadas por SLM e fundição da liga de Co-CrMo.

\begin{tabular}{ccc|cc}
\hline \multirow{2}{*}{ AMOSTRA } & \multicolumn{2}{c|}{$\begin{array}{c}\text { Coeficiente de dilatação } \\
\boldsymbol{\alpha}=\mathbf{1 0}^{-\mathbf{6}}{ }^{\circ} \mathbf{C}^{-\mathbf{1}}\end{array}$} & \multicolumn{2}{c}{ Temperatura dos eventos } \\
& $500^{\circ} \mathrm{C}$ & $600^{\circ} \mathrm{C}$ & $1^{\circ}$ & $2^{\circ}$ \\
\cline { 2 - 5 } & 8,7 & 9,3 & 731,4 & 467,6 \\
\hline SLM 1 & 9,7 & 11,9 & 670,0 & 481,4 \\
\hline SLM 2 & 8,7 & 9,4 & 750,0 & 450,0 \\
\hline FP & \multicolumn{2}{c}{} \\
\hline
\end{tabular}

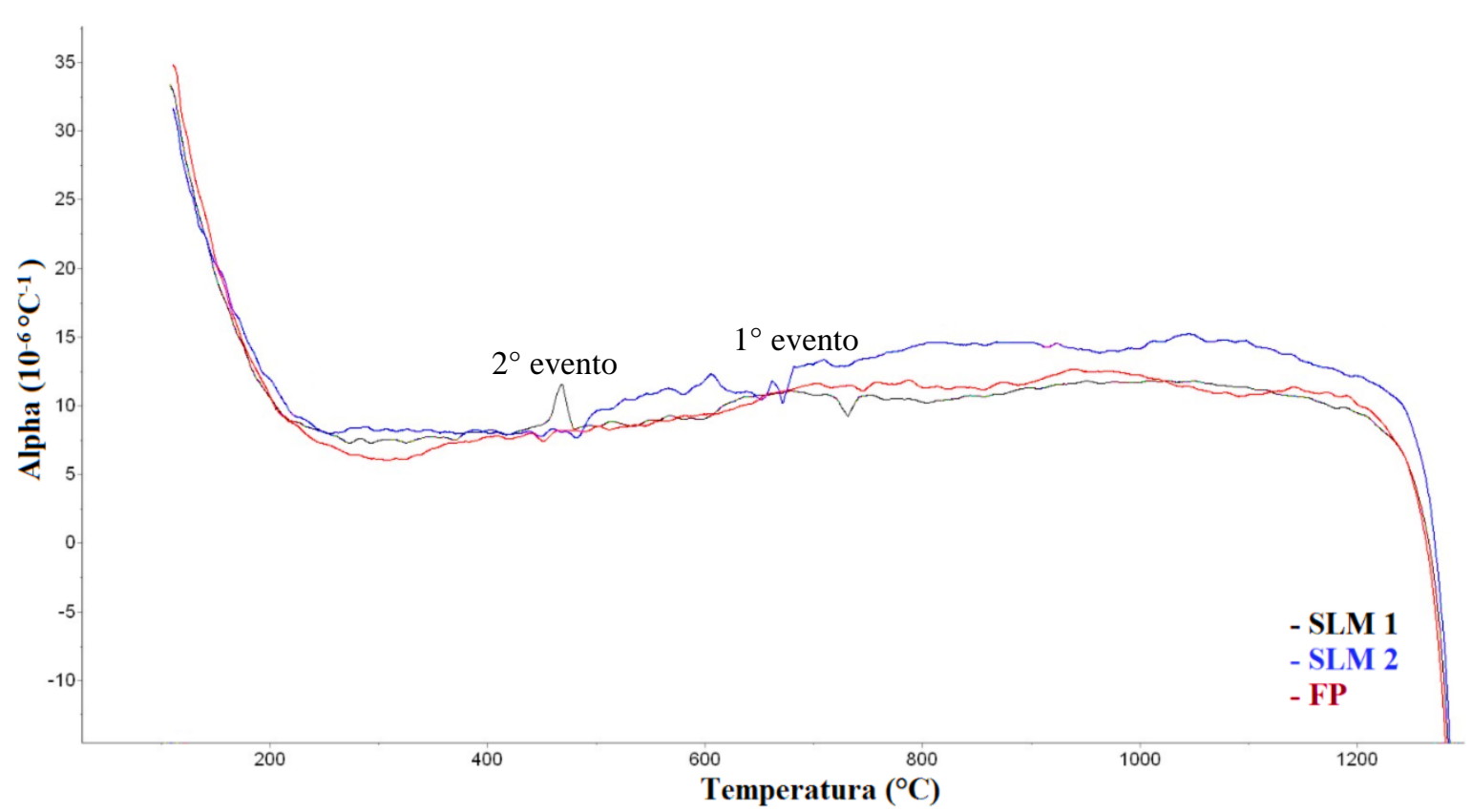

Figura 50 - Curva de resfriamento da análise de TMA das amostras consolidadas por fusão seletiva a laser (SLM, em direções distintas de fabricação SLM 1 - na vertical e SLM 2 na horizontal) e fundição de precisão (FP) (taxa de resfriamento: $20^{\circ} \mathrm{C} / \mathrm{min}$. Atmosfera: argônio).

Para a amostra FP o comportamento da curva é apresentado de forma mais linear e sem a presença de picos evidentes, em comparação ao observado nas amostras SLM. Estes eventos se associam com a transição de fases presentes na liga de Co-Cr-Mo e se relacionam com a microestrutura das amostras, visto que há similaridade nos eventos para as amostras consolidadas por SLM.

Para a compreensão dos eventos das análises de DSC e TMA, as curvas de aquecimento foram justapostas, como é apresentado na Figura 51. Ressalta-se que a curva de aquecimento da análise de DSC refere-se a análise do pó $\mathrm{D} 1$, a taxa de $10^{\circ} \mathrm{C} / \mathrm{min}$. Nas curvas há similaridade dos eventos obtidos entre as análises DSC e TMA em relação as faixas de temperatura e destacam-se dois eventos: o primeiro ocorre na faixa de 514 a $614^{\circ} \mathrm{C}$ e o segundo na faixa de 923 a $961^{\circ} \mathrm{C}$. 
No caso da amostra FP (ensaio de TMA) observa-se que a frequência dos eventos em relação as temperaturas é maior do que nas amostras processadas por SLM e esta associado a microestrutura das amostras. A amostra em pó (referente a análise de DSC) possui uma microestrutura dendrítica, idem a amostra fundida (referente a análise de TMA - amostra F). As curvas de TMA referentes às amostras SLM (SLM 1 e SLM 2) originam picos de formato mais agudo (em razão do processo de consolidação propiciar maior refinamento da microestrutura) e a transição destes eventos se estabelecem em temperaturas incrementadas em relação as amostras de microestrutura dendrítica (amostra FP).

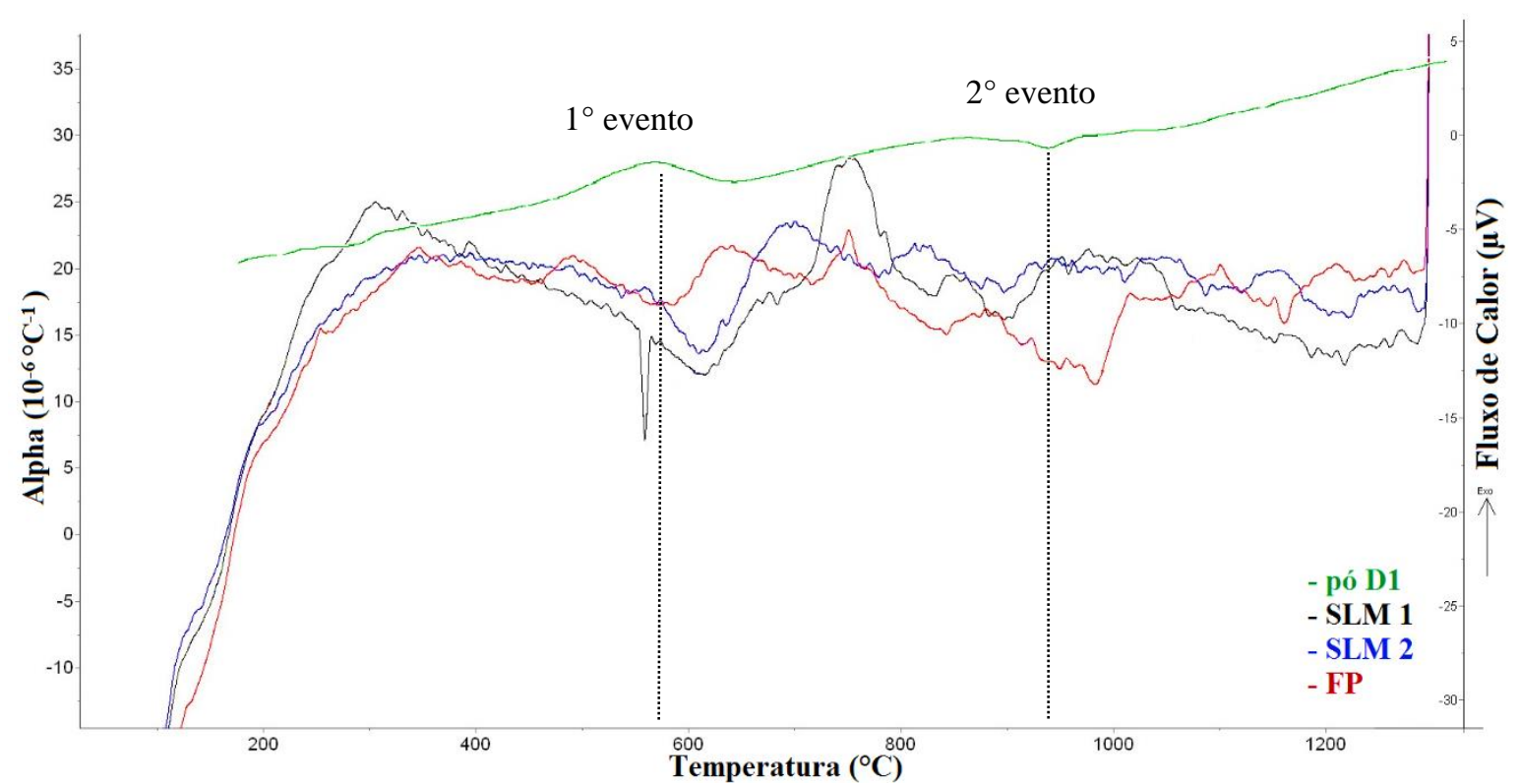

Figura 51 - Curvas de aquecimento das análises de DSC - amostra de pó D1 e TMA amostras SLM 1, SLM 2 e F (taxa de aquecimento: $10^{\circ} \mathrm{C} / \mathrm{min}$. Atmosfera: argônio).

Este estudo faz uma análise similar aos estudos de Facchini (2010), pontua-se que há um número limitado de referências sobre o assunto desta seção. No estudo de Facchini (2010) evidencia-se a curva da análise DSC e TMA (taxa de aquecimento de $20^{\circ} \mathrm{C} / \mathrm{min}$, vide Figura 8) realizada em uma liga de composição ASTM F75 (Co-28,5Cr$6 \mathrm{Mo}$ ) processada por fusão por feixe de elétrons (EBM). Ressalta-se que, nos estudos de Facchini (2010) as amostras foram processadas por EBM, já no presente estudo as amostras foram processadas por SLM. Contudo, as diferenças de processamento não interferem nas transições de fase pertinentes a liga (Co-Cr-Mo) e, consequentemente, no resultado final desta análise. Na Figura 52b observa-se o diagrama de fases para o sistema binário de Co-Cr associados aos eventos térmicos. Como descrito na análise de DSC (vide 
seção 5.2.10), o primeiro pico $\left(565-900^{\circ} \mathrm{C}\right)$ está associado a transição da fase $\mathrm{CFC}(\alpha \mathrm{Co})$ para a fase $\mathrm{HC}(\varepsilon \mathrm{Co})$, e o segundo pico $\left(900-1000^{\circ} \mathrm{C}\right)$ associado a redução da fase $\mathrm{HC}$ $(\varepsilon \mathrm{Co})$ e reaparecimento da fase CFC $(\alpha \mathrm{Co})$.

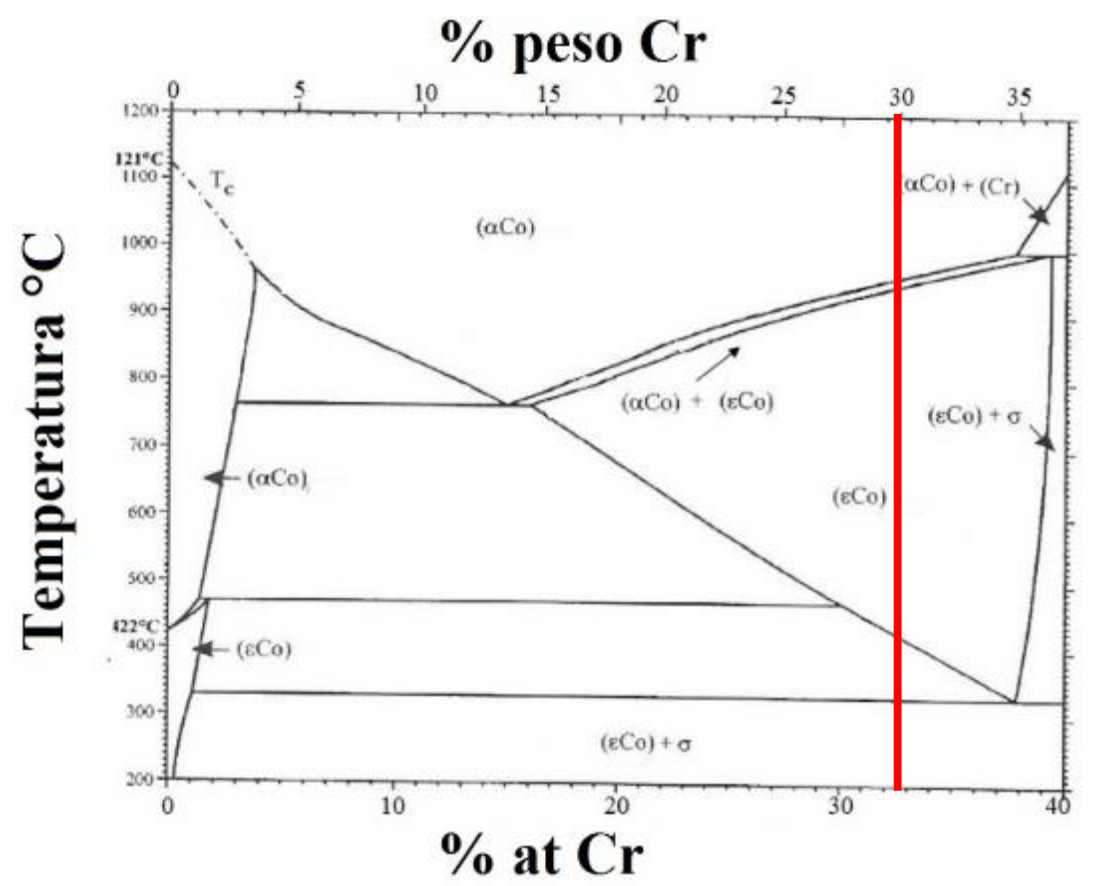

Figura 52 - Diagrama do sistema binário de Co-Cr. Fonte: Adaptado de (SANTOS, 2012).

No caso da região intermediária dos eventos observa-se nas curvas de TMA que o comportamento da dilatação sofre uma alteração e promove à transformação de fases. Ambas estruturas cristalográficas (CFC e HC) possuem um fator de empacotamento similar (fator de empacotamento FEA = 0,74). No entanto, os parâmetros de rede $(\mathrm{a}, \mathrm{c}$ ) são maiores para fase $\alpha \operatorname{Co}(\mathrm{a}=0,354 \mathrm{~nm})$, que para a fase $\varepsilon \operatorname{Co}(\mathrm{a}=0,250 \mathrm{~nm} \mathrm{e} \mathrm{c}=0,407 \mathrm{~nm})$ (ISHIDA; NISHIZAWA, 1990). Conforme exposto no diagrama de fases na Figura 52 a transição intermediária de fases $(\alpha \mathrm{Co}+\varepsilon \mathrm{Co})$ ocorre a aproximadamente $900^{\circ} \mathrm{C}$.

\subsection{CARACTERIZAÇÃO MICROESTRUTURAL}

\subsubsection{Relação de porosidade das amostras}

Na Tabela 27 são apresentados os resultados das densidades médias obtidas nas amostras consolidadas por FP e SLM. Para a determinação da porosidade das amostras foi 
estabelecida a comparação entre as densidades médias: teórica, volumétrica e picnometria de He.

Tabela 27 - Resultado da amostragem de densidades média teórica, por picnometria de He e volumétrica das amostras consolidadas por FP e SLM.

\begin{tabular}{cccc}
\hline \multirow{2}{*}{ Amostra } & \multicolumn{3}{c}{ Densidades médias $\left(\mathbf{1 0}^{-\mathbf{3}} \mathbf{~ k g} / \mathbf{m}^{\mathbf{3}}\right)$} \\
\cline { 2 - 4 } & Teórica & Picnometria de He & Volumétrica \\
\hline FP & 8,42 & $8,24 \pm 0,01$ & $8,22 \pm 0,10$ \\
\hline SLM & 8,39 & $8,24 \pm 0,01$ & $8,23 \pm 0,01$ \\
\hline
\end{tabular}

Analisando os resultados de densidade volumétrica identifica-se que as amostras FP apresentam um resultado inferior ao obtido nas amostras SLM e que a densidade por picnometria de He resulta em uma densidade de $8,24.10^{-3} \mathrm{~kg} / \mathrm{m}^{3}$ para ambos processos de consolidação. Ressalta-se que a medida da densidade volumétrica considera a porosidade aberta e fechada da amostra. Analisando a densidade volumétrica pela picnometria de He verifica-se que o processo FP resulta em maior porosidade aberta que a tecnologia SLM. A porosidade aberta resulta em $0,24 \%$ da densidade na amostra FP e $0,12 \%$ na amostra SLM e a diferença entre os processos (FP e SLM) a porosidade aberta é de $0,12 \%$.

A relação da densidade por picnometria de He e densidade teórica (sólido sem presença de porosidade), resulta na porosidade interna, que é de 2,14\% e 1,80\% para o processo FP e SLM, respectivamente. Conclui-se que o processo de consolidação SLM possibilita fabricar amostras com menor porosidade interna, obtendo componentes com densidades em torno de $98,20 \%$ da teórica, em contrapartida ao processo FP que obtém componentes com densidade de $97,86 \%$ da teórica.

Observa-se, por meio das análises de densidade, que a tecnologia SLM viabiliza a consolidação de espécimes com menor presença de porosidade aberta e interna. A presença de maior porosidade em amostras sob solicitações mecânicas influencia nos resultados das propriedades mecânicas de modo negativo. Visto que as propriedades mecânicas são avaliadas pelo método de resistência mecânica convencional (corpos completamente densos, sem presença de vazios ou poros).

\subsubsection{Difração de raios $X$}

Os difratogramas de raios X das amostras consolidadas por FP e SLM são 
apresentados na Figura 53 e correspondem as fichas catalográficas da estrutura cúbica de face centrada (cobalto - CFC, código de referência PCPDF 01-089-4307) e da estrutura hexagonal compacta (cobalto - HC, código de referência PCPDF 01-089-4308). Os difratogramas apresentam picos ocorrendo em posições angulares ( $2 \theta$ - theta) semelhantes. No entanto, com intensidades distintas, com picos de $40,74^{\circ}, 43,56^{\circ}, 46,49^{\circ}$ e $64,90^{\circ}$. Na amostra SLM distingue-se 2 picos (respectivamente na posição $2 \theta: 38,11^{\circ}$ e $96,14^{\circ}$ ), que não ocorrem no difratograma da amostra FP. Segundo Hedberg et al. (2014), os picos evidenciados em amostra consolidada por SLM (utilizando parâmetros de: potência do laser de $200 \mathrm{~W}$ e espaçamento entre escaneamento de $0,1 \mathrm{~mm}$ ) são similares aos obtidos para a amostras SLM deste estudo.

O resultado evidenciado pelo difratograma da amostra SLM é apresentado por diversos autores (GIRARDIN et al., 2016; KAJIMA et al., 2016; HEDBERG et al., 2014; JABBARI et al., 2014) indicando a presença de duas fases referentes aos picos de maior intensidade, representando as fases de $\gamma-\mathrm{Co}, \mathrm{Cr}(\mathrm{CFC})$ e $\varepsilon-\mathrm{Co}_{3} \mathrm{Mo}(\mathrm{HC})$.

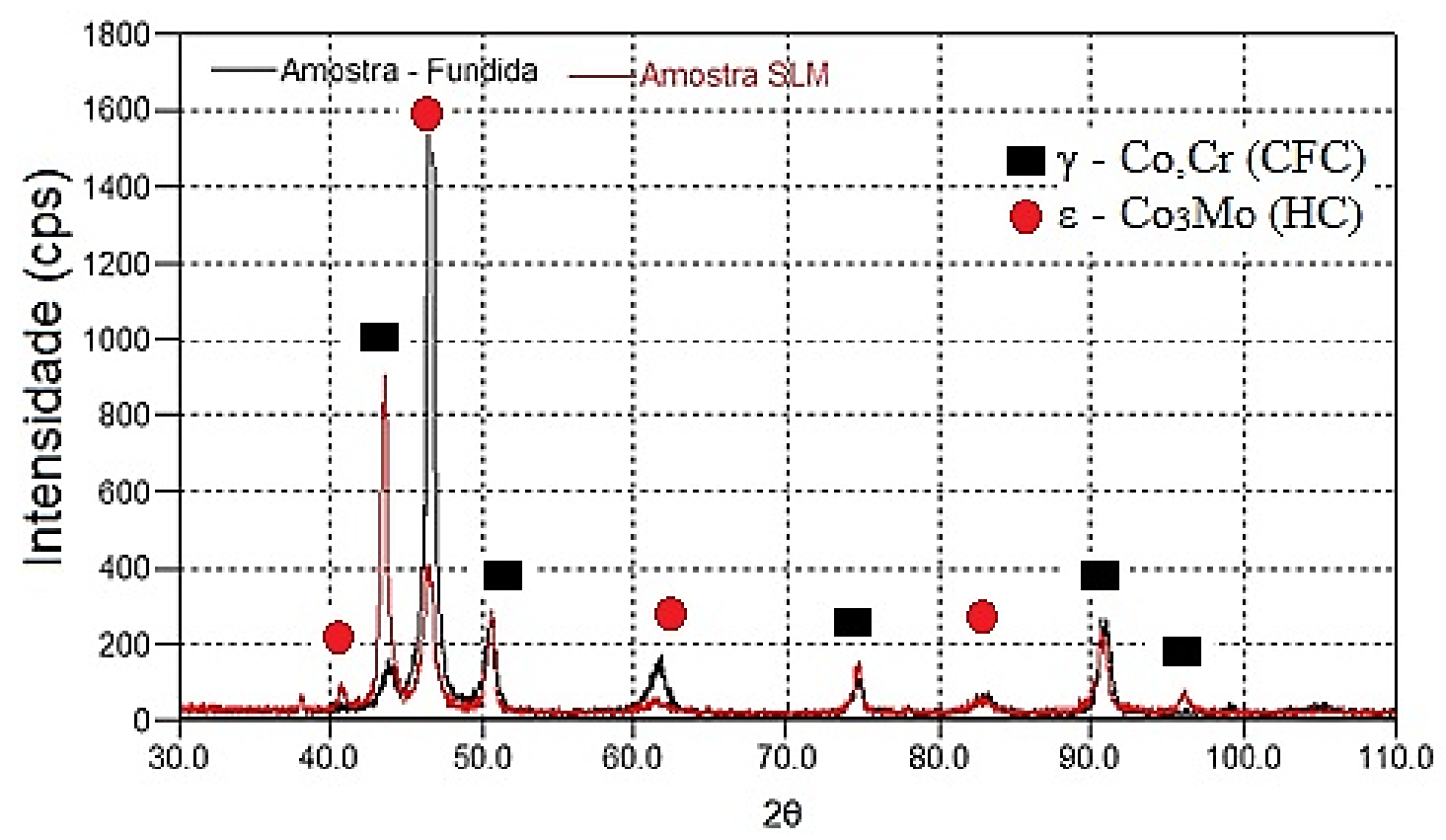

Figura 53 - Difratogramas de raios X das amostras consolidadas por fundição de precisão e fusão seletiva a laser (SLM).

Como abordado por Barucca et al. (2015), o difratograma característico da amostra SLM apresentou picos atribuídos a carbonetos (em destaque na Figura 54b), comumente descritos por $\mathrm{M}_{23} \mathrm{C}_{6}$ apontados na revisão bibliográfica e descritos como carbonetos de estrutura cúbica de $\mathrm{Cr}_{23} \mathrm{C}_{6}$. Segundo Ramírez et al. (2002), carbonetos 
$\mathrm{M}_{23} \mathrm{C}_{6}$ são reportados em ligas tratadas termicamente em temperaturas por volta de $1220^{\circ} \mathrm{C}$, desenvolvendo-se em temperaturas abaixo de $1150^{\circ} \mathrm{C}$ durante o resfriamento do processo de solidificação.

A formação do carboneto (modificadores das propriedades mecânicas) é promovida pelo decréscimo da temperatura e descrita pela reação global entre a fase $\sigma$ (representando a composição $\mathrm{Cr}_{8} \mathrm{Co}_{7}$ ) e o elemento de carbono e pode ocorrer durante o processo de fabricação de amostras e até mesmo em ligas com baixa porcentagem de carbono (ASM INTERNATIONAL, 2000; BARUCCA et al., 2015; JABBARI et al., 2014; RAMÍREZ et al., 2002)

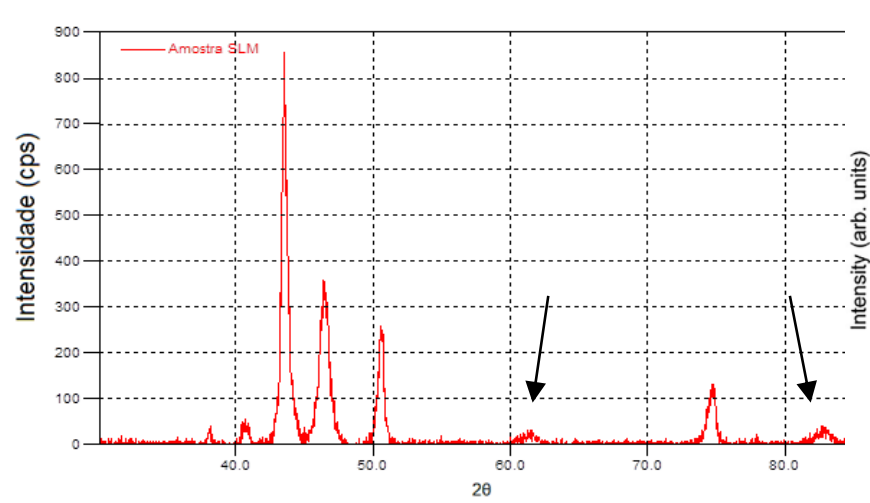

(a)

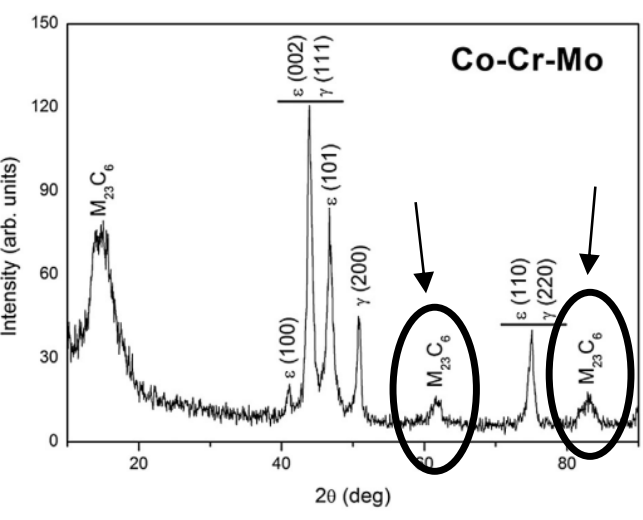

(b)

Figura 54 - a) Difratograma de raios X da amostra SLM (setas apontam os possíveis picos característicos de carbonetos) e b) difratograma obtido por (BARUCCA et al., 2015), em composição química similar à de estudo (com adição de 4\% tungstênio).

Os resultados obtidos na análise de DRX das amostras consolidadas por FP e SLM, divergem, ligeiramente em relação a identificação dos carbonetos (em ambas condições). A identificação de fases e constituintes pertinentes é apresentada nas seções seguintes de caracterização microestrutural das amostras fabricadas por PF e SLM.

\subsubsection{Caracterização das amostras FP por MO}

Na Figura 55 observa-se a caracterização microestrutural das amostras consolidadas por FP. Nas micrografias realizadas antes do ataque químico identifica-se a estrutura dendrítica na amostra, apresentando orientações diferentes de solidificação. Observa-se a presença de micro porosidade (pequenos pontos pretos) em toda a região das amostras em ambas seções de corte. A formação da microestrutura observada nas imagens de MO são similares à microestrutura descrita na literatura de ligas de Co-Cr-Mo 
(AHMED et al., 2014; JABBARI et al., 2014; KAISER et al., 2013; SONG et al., 2006;

TAKAICHI et al., 2013).

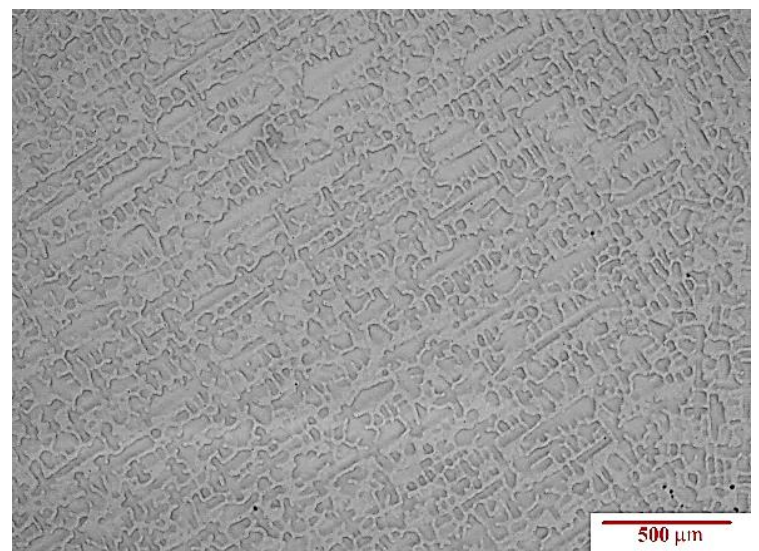

(a)

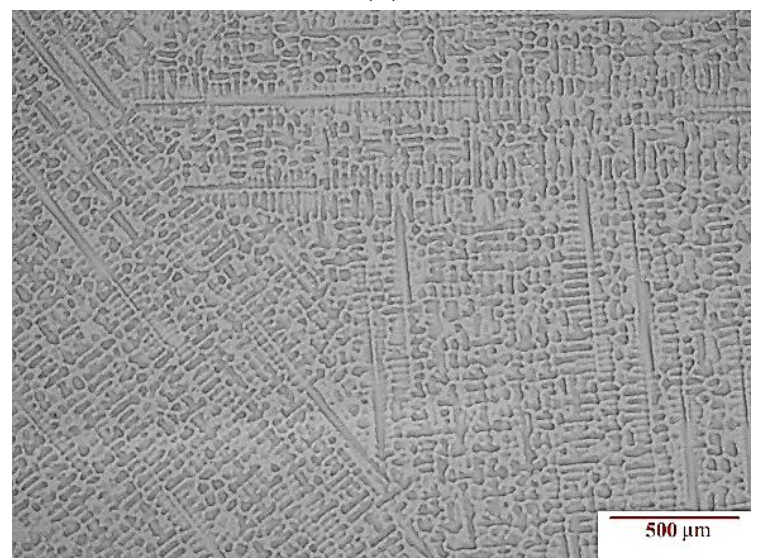

(c)

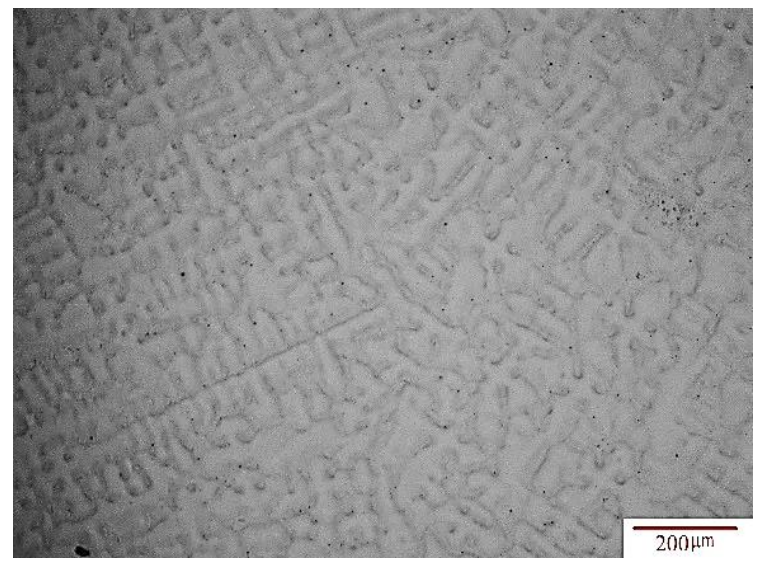

(b)

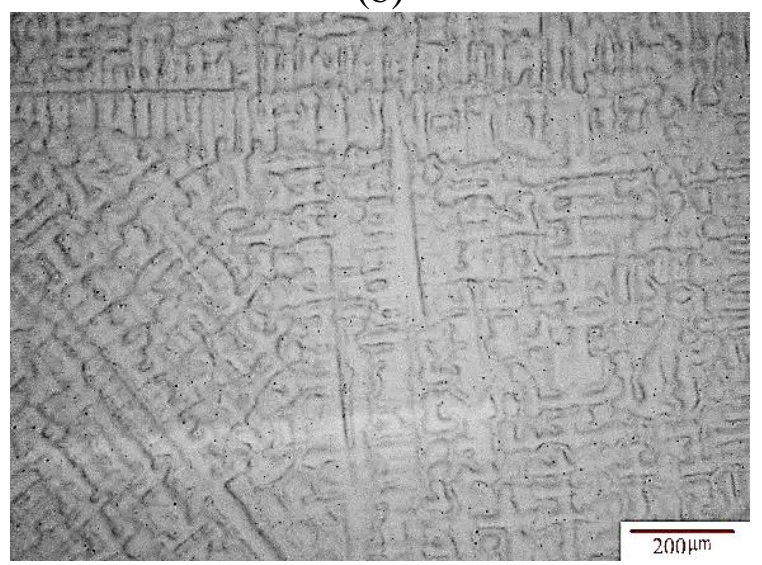

(d)

Figura 55 - Imagens de MO da amostra fundida após polimento químico final, a) e b) seção horizontal da amostra, c) e d) seção vertical da amostra. Polimento químico final: 90\% sílica coloidal e 10\% $\mathrm{HCl}$. Aumentos de respectivamente: 50x e 100x.

Nas micrografias realizadas após o ataque químico (Figura 56) identificam-se com maior nitidez as estruturas dendríticas nas amostras. A morfologia de solidificação depende do gradiente de temperatura, velocidade de avanço da interface sólido-líquido e da composição do líquido (CHALMERS, 1964). 


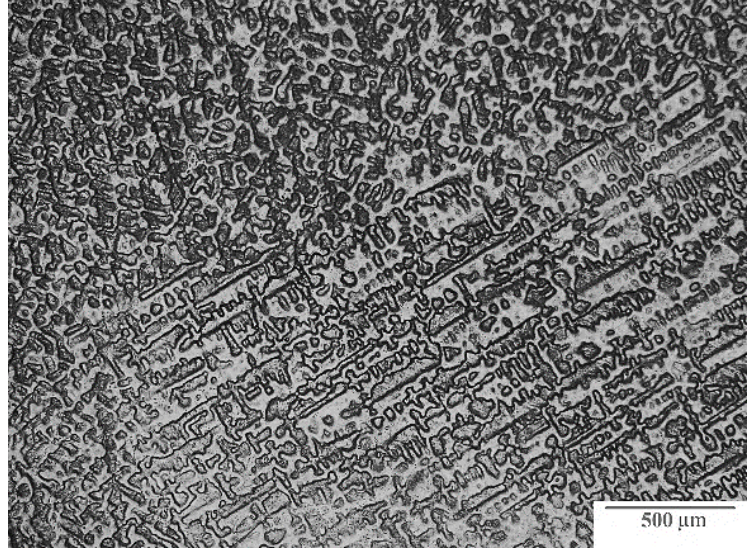

(a)

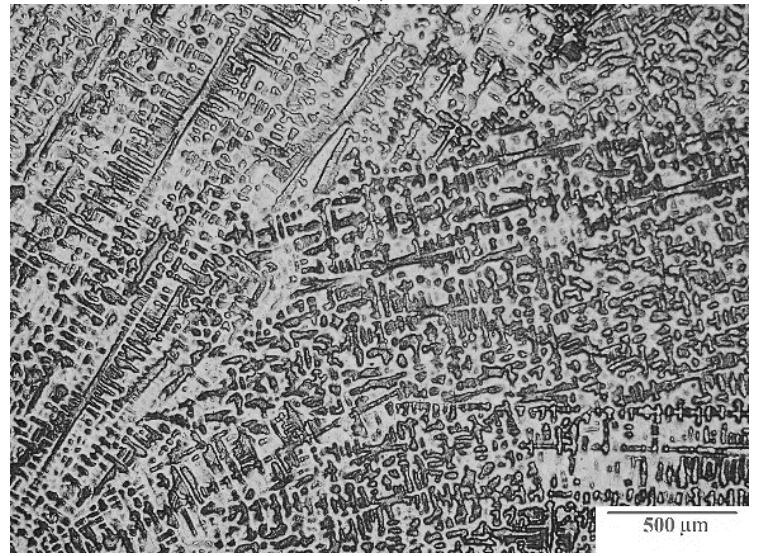

(c)

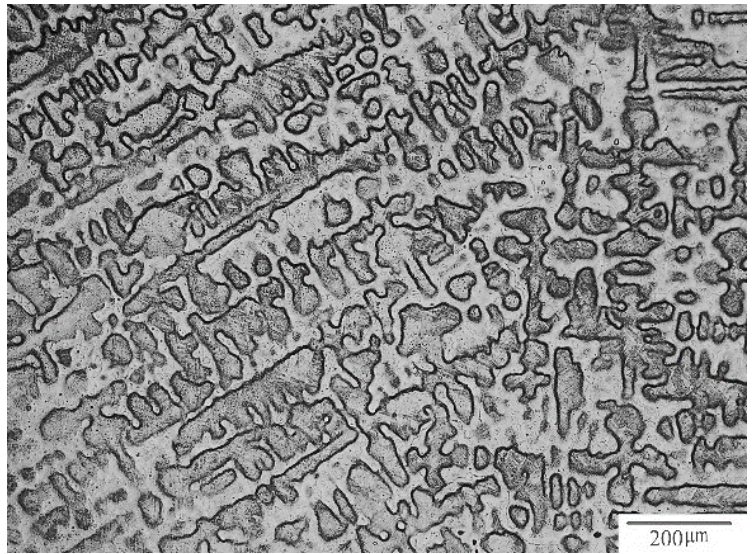

(b)

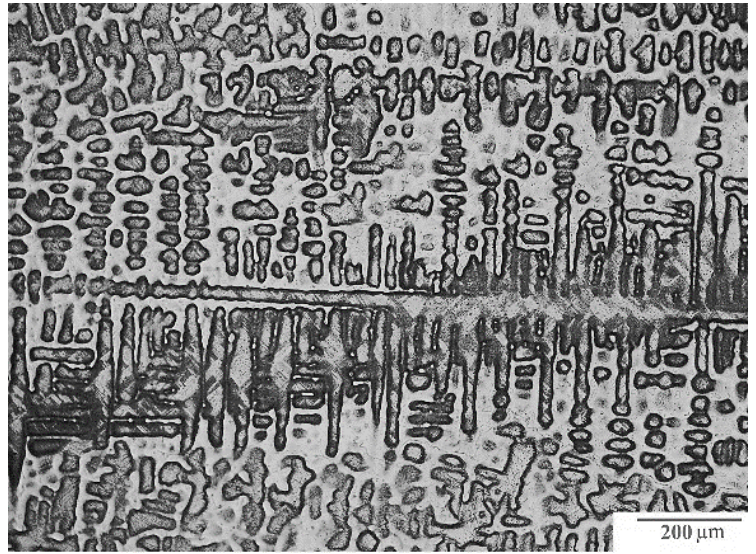

(d)

Figura 56 - Imagens de MO da amostra fundida após ataque químico, a) e b) seção horizontal da amostra, c) e d) seção vertical da amostra. Aumentos de respectivamente: 50x e 100x. Ataque químico: $\mathrm{HCl}$ e $\mathrm{H}_{2} \mathrm{O}_{2}$.

Nas imagens com aumentos maiores das seções (horizontal e vertical) da amostra verificam-se três fases distintas. Na Figura 57a representasse uma formação de relevo. Em outras palavras, percebe-se a presença de uma fase alta (Figura 57b), e uma fase baixa (Figura 57c). Portanto, a amostra FP apresenta duas fases distintas e uma fase intermediária.

Os autores (JABBARI et al., 2014; YAMANAKA; MORI; CHIBA, 2015; ZANGENEH; LASHGARI; ROSHANI, 2012) descrevem que em ligas de Co-Cr consolidadas pelo processo de fundição, há formações de carbonetos com os metais de adição da liga (como por exemplo $\mathrm{Mo}, \mathrm{W}$ e $\mathrm{Nb}$ ), estes carbonetos são descritos na literatura, como carbonetos $\mathrm{M}_{23} \mathrm{C}_{6}$. Segundo autores (GIACCHI et al., 2011; GIACCHI; FORNARO; PALACIO, 2012) a caracterização dos carbonetos $\mathrm{M}_{23} \mathrm{C}_{6}$ por meio de análises semiquantitativas utilizando MEV-EDS é rica em Cr. 


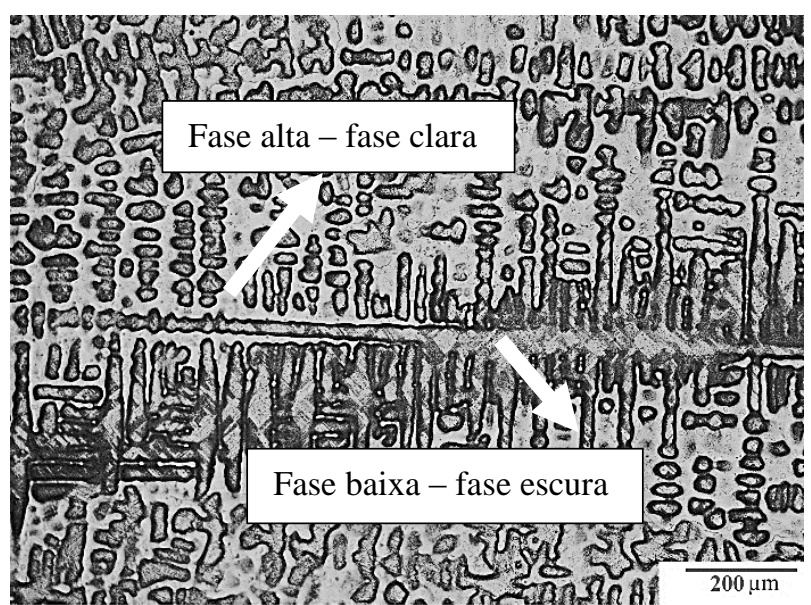

(a)

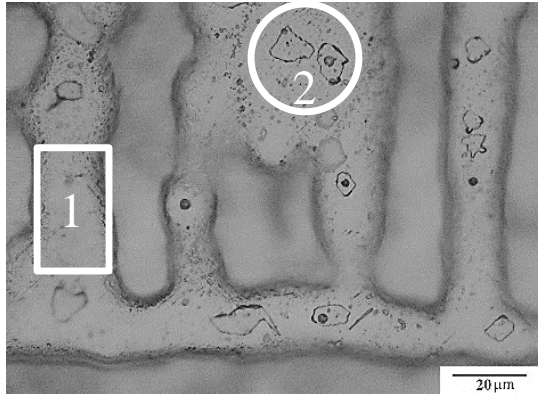

(b)

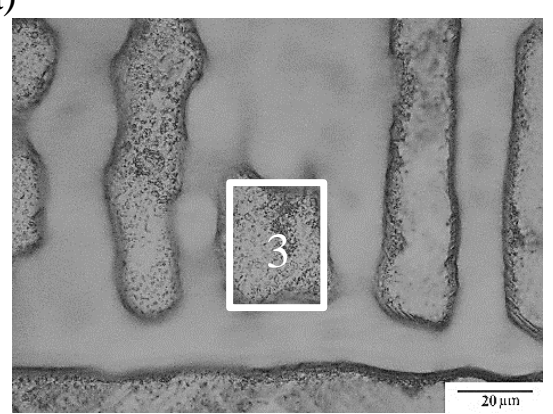

(c)

Figura 57 - Imagens de MO da amostra fundida após ataque químico, a) evidenciando a fase clara e fase escura (aumento de 100x), b) evidenciado em branco as regiões de fases intermediárias e c) evidenciando em branco a região da fase escura (aumentos de 1000x). Ataque químico: $\mathrm{HCl}$ e $\mathrm{H}_{2} \mathrm{O}_{2}$.

Com a finalidade de caracterizar as fases presentes nas amostras fundidas e sua influência nas propriedades mecânicas, apresenta-se nas seções seguintes: a caracterização por MEV acoplado ao EDS e análises de microdureza Vickers das fases.

\subsubsection{Caracterização das amostras FP por MEV}

As imagens obtidas por MEV das amostras FP foram comparadas antes (vide Figura 58a e b) e após (vide Figura 58c e d) o ataque químico. Antes do ataque químico observa-se, com maior destaque, a presença de porosidade (destacada pelas setas) e verifica-se a presença de três fases com contrastes de cinza distintos (destacados pelos retângulos). Após o ataque químico evidenciou-se duas regiões de contraste: uma mais clara, fase interdendrítica (representando um carboneto) e uma mais escura, representando a matriz da microestrutura. Observa-se a presença de porosidade maior pelo alargamento dos poros e uma possível formação de pitting (destacado pelo círculo) em consequência do ataque químico. 


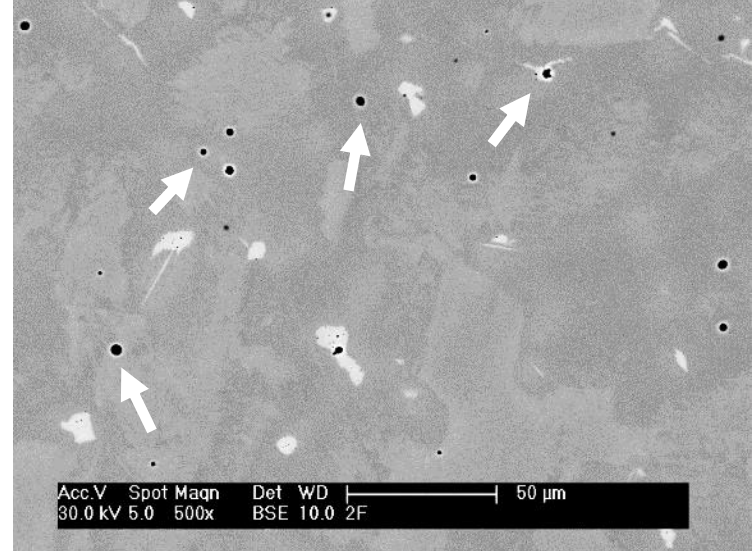

(a)

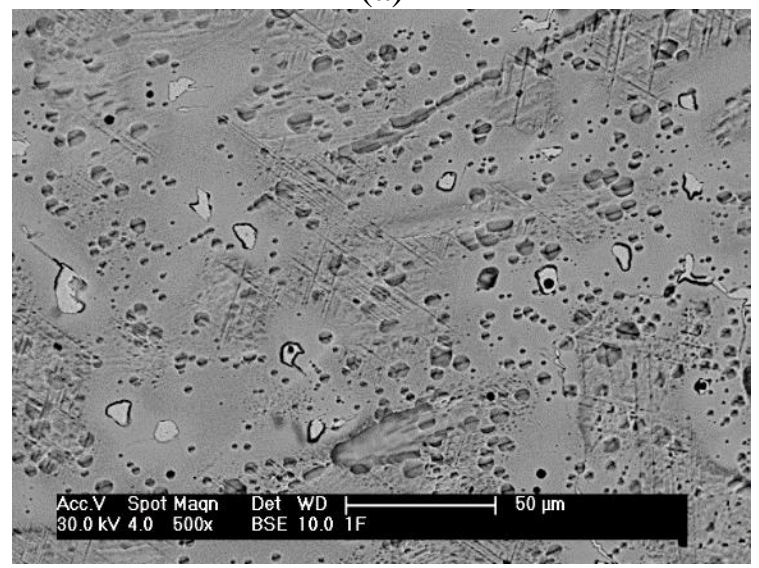

(c)

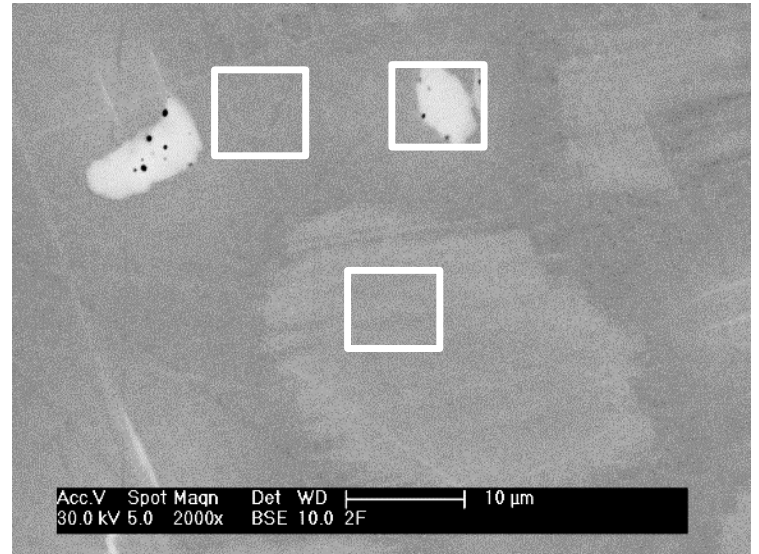

(b)

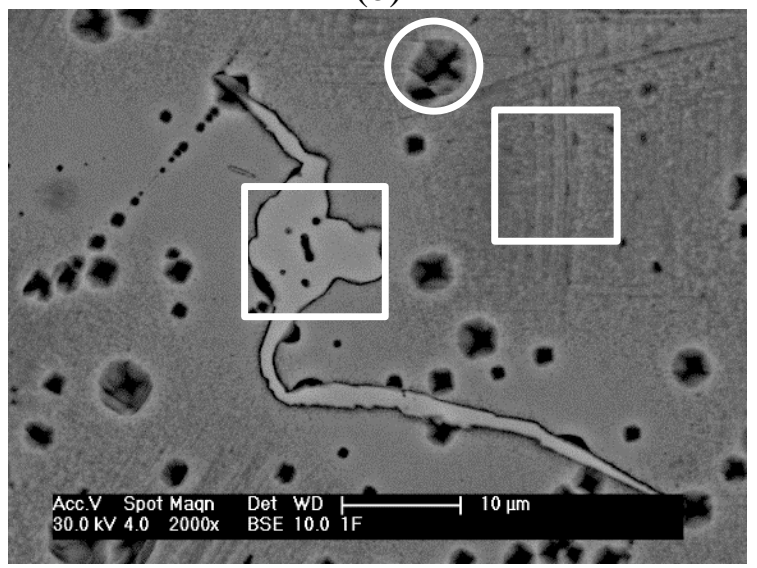

(d)

Figura 58 - Imagens de MEV por elétrons retroespalhados da amostra fundida: a) espécime sem ataque químico (setas indicam porosidade), b) espécime sem ataque químico (retângulos indicam a presença de fases distintas), c) e d) espécime com ataque químico (o círculo indica a formação de pitting e os retângulos indicam a presença de fases distintas carboneto e matriz). Ataque químico: $\mathrm{HCl}$ e $\mathrm{H}_{2} \mathrm{O}_{2}$.

Na Figura 59 observa-se a análise semiquantitativa química dos elementos presentes nas amostras obtida por EDS acoplado ao MEV. A distinção das fases presentes nas amostras foi obtida a partir da imagem formada por elétrons retroespalhados (BSE backscattering electron).

Verifica-se, em ambos os espectrogramas, (antes do ataque químico - Figura 59a e após ataque químico - Figura 59b) que a fase mais clara (fase interdendrítica) representa um carboneto $\mathrm{M}_{23} \mathrm{C}_{6}$ rico em $\mathrm{Cr}$ e Mo. A fase que correspondente a matriz da microestrutura é constituída de forma majoritária dos elementos de Co e Cr. 


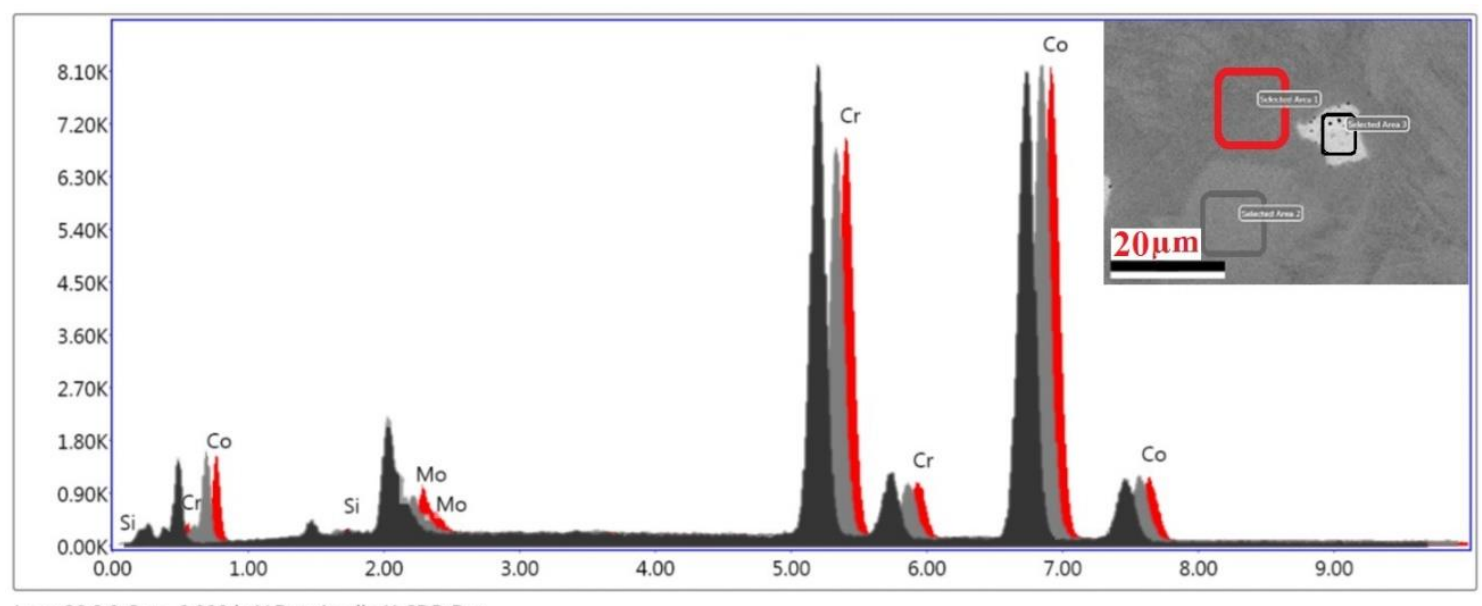

(a)

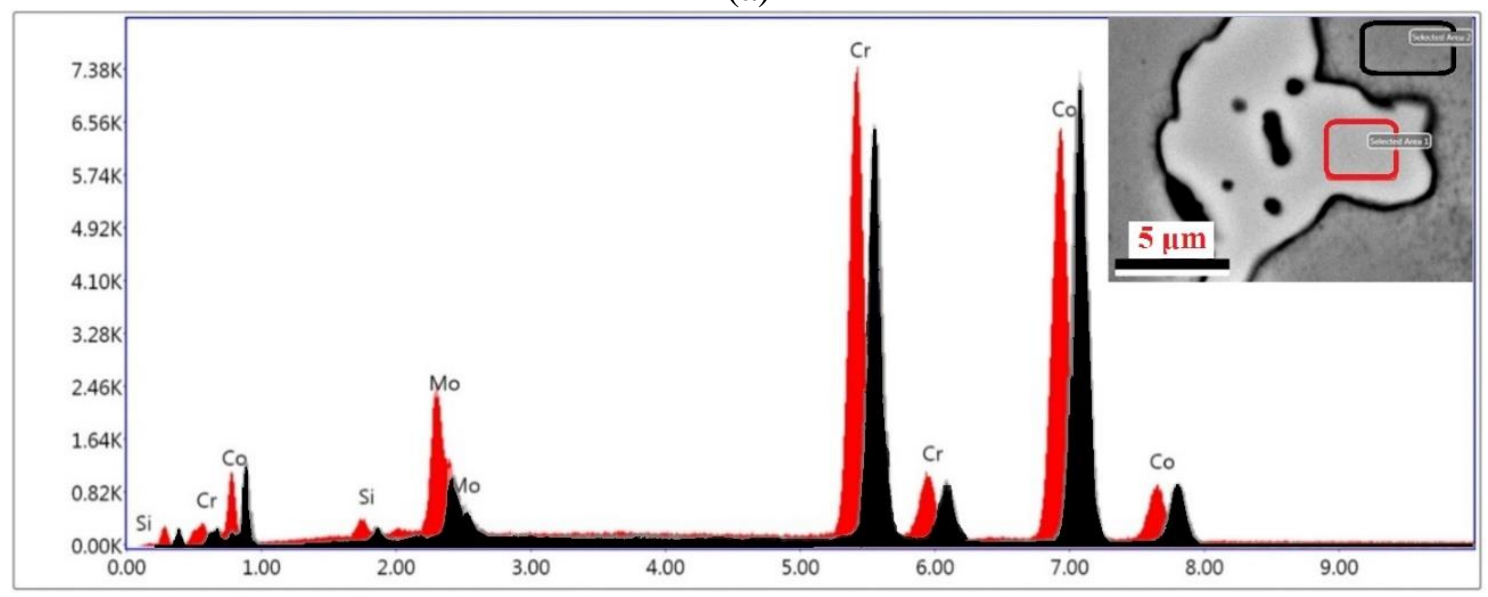

Lsec: 30.00 Cnts $0.000 \mathrm{keV}$ Det: Apollo X-SDD Det

(b)

Figura 59 - Espectrogramas da amostra fundida das regiões selecionadas (as cores representam as áreas de análise) em a) espécime sem ataque químico (aumento de 1000x) e b) espécime com ataque químico (aumento de 1000x).

\subsubsection{Microscopia versus microdureza Vickers da amostra FP}

Na Tabela 28 apresenta-se os resultados obtidos de microdureza com relação a microestrutura (apresentada em destaque na Figura 60).

A partir destes resultados conclui-se que há diferença significativa de dureza entre as fases. A média e desvio padrão entre as seções analisadas é de: 343,20 \pm 6,17 para fase clara, 372,54 \pm 5,75 para fase escura e 693,70 \pm 8,36 para fase intermediária. Desta forma, observa-se a presença de um carboneto $\mathrm{M}_{23} \mathrm{C}_{6}$, cuja dureza é superior em relação às outras fases. Ressalta-se que o incremento de dureza do carboneto entre as fases é de $50,5 \%$ em relação a fase clara e $46,3 \%$ em relação a fase escura.

Em relação às seções (horizontal e vertical) analisadas houve uma diferença no resultado (valor médio) da microdureza de: $2,6 \%$ da fase clara, 1,7\% da fase intermediária 
e 2,2\% da fase escura. Observa-se que não houve interação entre os dados de microdureza Vickers nas seções de medição das amostras FP, sendo que a medição da microdureza foi obtida em diversas regiões das amostras e o resultado permaneceu dentro do desvio padrão obtido (vide Figura 61).

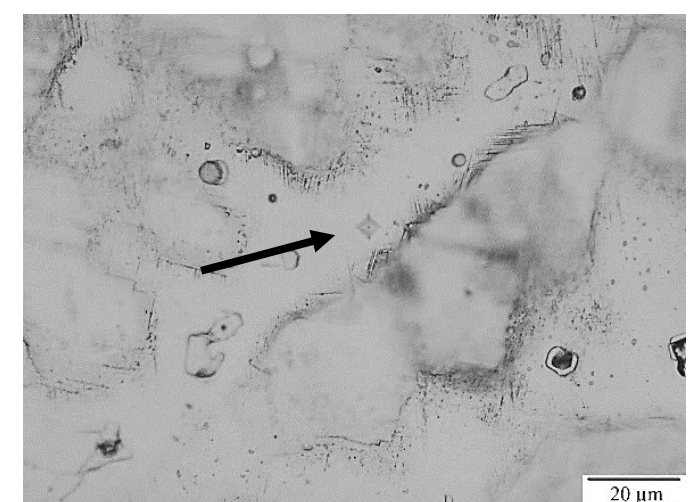

(a)

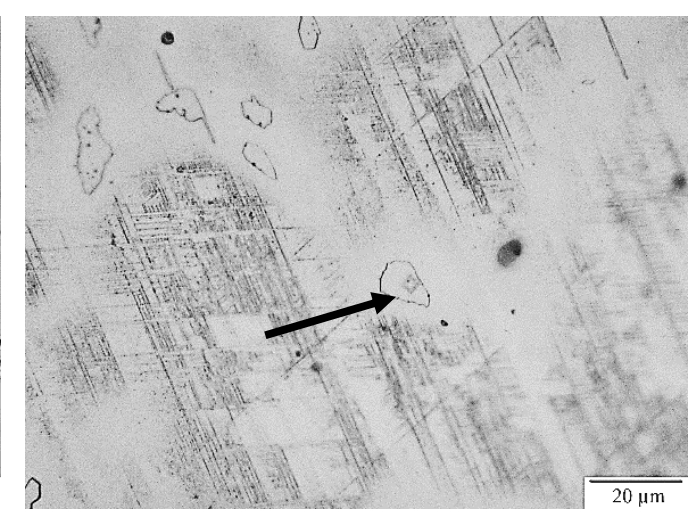

(b)

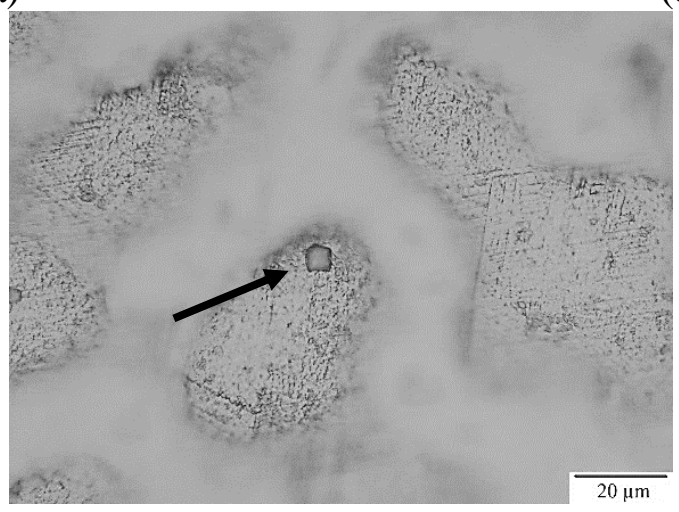

(c)

Figura 60 - Imagem das identações de microdureza na amostra FP (seção horizontal), respectivamente nas regiões a) fase clara, b) fase intermediária - carboneto e c) fase escura. Aumentos de 1000x. Ataque químico: $\mathrm{HCl}$ e $\mathrm{H}_{2} \mathrm{O}_{2}$.

Tabela 28 - Resultados da microdureza Vickers $100 \mathrm{mN} / 10 \mathrm{~s}$ (HV 0.1N/10s) nas fases presentes na amostra fundida.

\begin{tabular}{c|cc}
\hline \multicolumn{1}{c}{ Seção } & Região & Média \\
\hline \multirow{3}{*}{ Horizontal } & Fase Clara & $338,83 \pm 14,18$ \\
\cline { 2 - 3 } & Fase intermediária - carboneto & $699,61 \pm 131,10$ \\
\cline { 2 - 3 } Vertical & Fase Escura & $368,48 \pm 45,76$ \\
\cline { 2 - 3 } & Fase Clara & $347,56 \pm 10,06$ \\
\cline { 2 - 3 } & Fase intermediária - carboneto & $687,79 \pm 184,54$ \\
\cline { 2 - 3 } & Fase Escura & $376,61 \pm 51,41$ \\
\hline
\end{tabular}




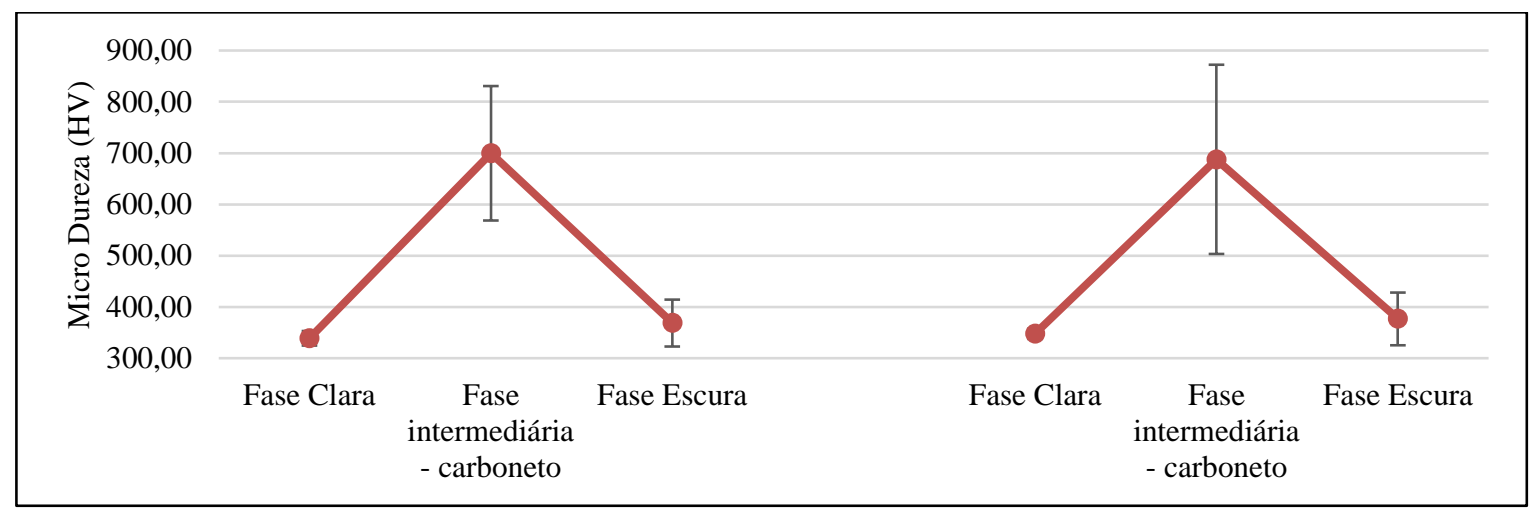

Figura 61 - Representação da microdureza média das regiões da amostra FP.

A ampla variação da medida de microdureza do carboneto apresenta um desvio padrão de 131,10 HV para seção horizontal e de 184,54 HV para seção vertical. Esta variação também é observada na literatura (KADLEC; ONDERKA, 2013; KAISER et al., 2013) e pode ser associada com a profundidade da medida de dureza, podendo exceder o carboneto e resultar em valores inferiores. Para confirmação dos resultados foram realizadas por MEV-EDS nas regiões das medidas de microdureza.

Verifica-se que a fase clara em relação a fase escura da amostra, apresenta picos mais significativos para os elementos químicos de $\mathrm{Cr}$ e Mo. Observa-se que, a média de microdureza da fase clara (para face horizontal de 338,34 HV0.1 e para face vertical 347,56 HV0.1) é ligeiramente inferior que a média de microdureza da fase escura (para face horizontal de 368,48 HV0.1 e para face vertical 376,61 HV0.1). Este fato deve-se a presença de elementos químicos, como o Cr e Mo (materiais de maior dureza). Confirmase, pelos espectrogramas (pontual - Figura 63a e em linha - Figura 63b) o aumento de Mo no carboneto em relação ao espectrograma da fase clara (Figura 63a) e fase escura (Figura 63b).

Portanto, a partir da análise semiquantitativa realizada por meio de MEV-EDS nos pontos de medição de microdureza, conclui-se que a amostra consolidada por FP apresenta regiões de elevada dureza em relação a matriz da liga e a microestrutura do fundido apresenta propriedades mecânicas mais heterogêneas (vide resultados de propriedades mecânicas na Figura 44 e Tabela 23). 

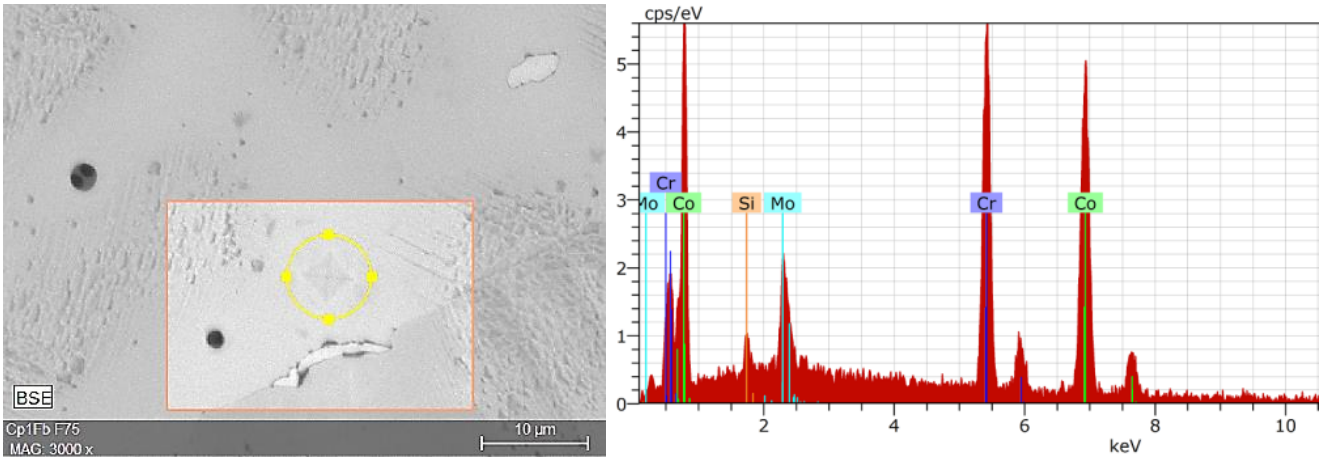

(a)
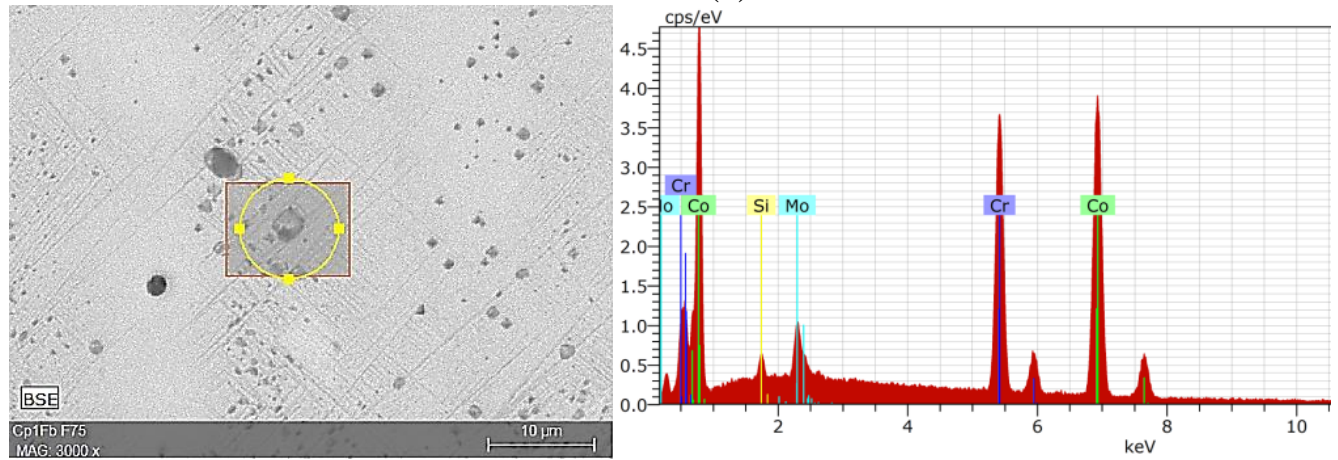

(b)

Figura 62 - Imagens de MEV por BSE e respectivos espectrogramas, em a) análise da região da fase 1 - fase clara e b) análise da região da fase 3 - fase escura. Aumentos de 3000x. Ataque químico: $\mathrm{HCl} \mathrm{e} \mathrm{H}_{2} \mathrm{O}_{2}$.
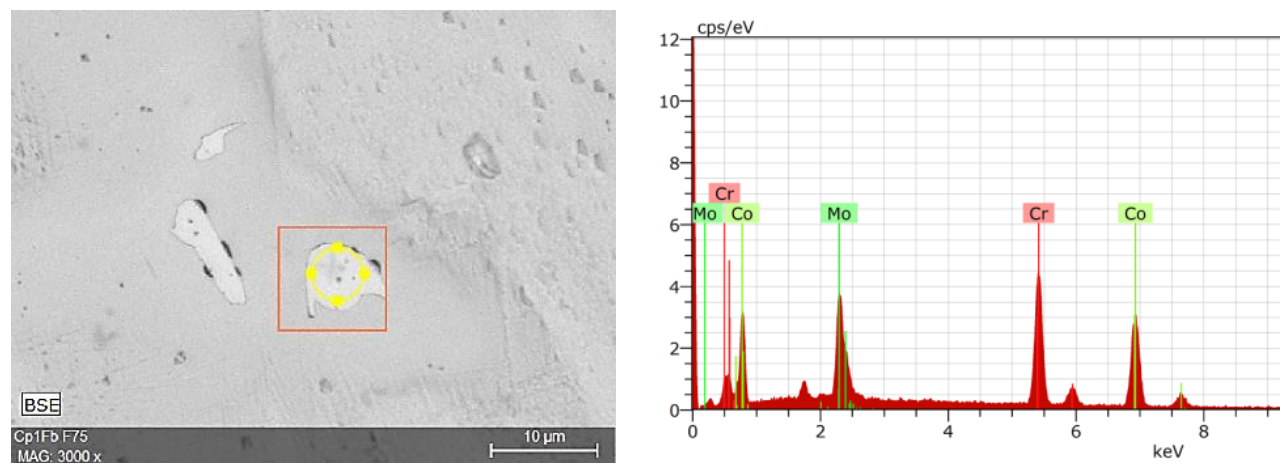

(a)
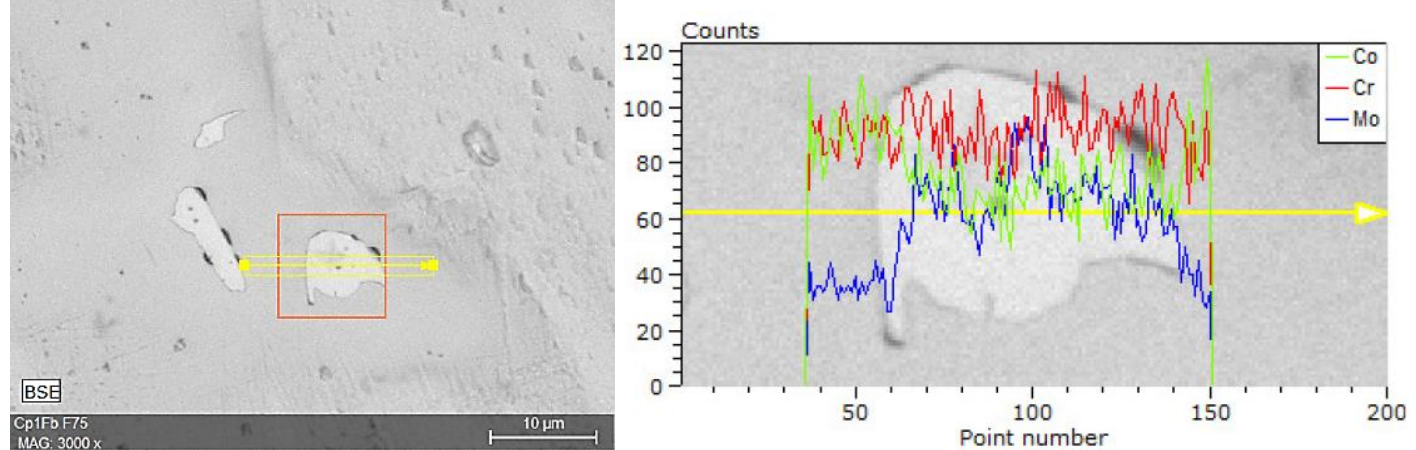

(b)

Figura 63 - Imagens de MEV por BSE das análises realizadas na região da fase 2 - fase intermediária e respectivos espectrogramas, a) análise pontual e b) análise em linha. Aumentos de 3000x. Ataque químico: $\mathrm{HCl} \mathrm{e} \mathrm{H}_{2} \mathrm{O}_{2}$. 


\subsubsection{Caracterização das amostras SLM por MO}

$\mathrm{Na}$ Figura 64 observa-se a caracterização microestrutural das amostras consolidadas por SLM. Nas micrografias realizadas antes do ataque químico verifica-se a presença de poros nas amostras em ambas seções. Na microestrutura originada do processo de FP observou-se a formação de uma segunda fase que não foi observada na microestrutura do processo SLM.

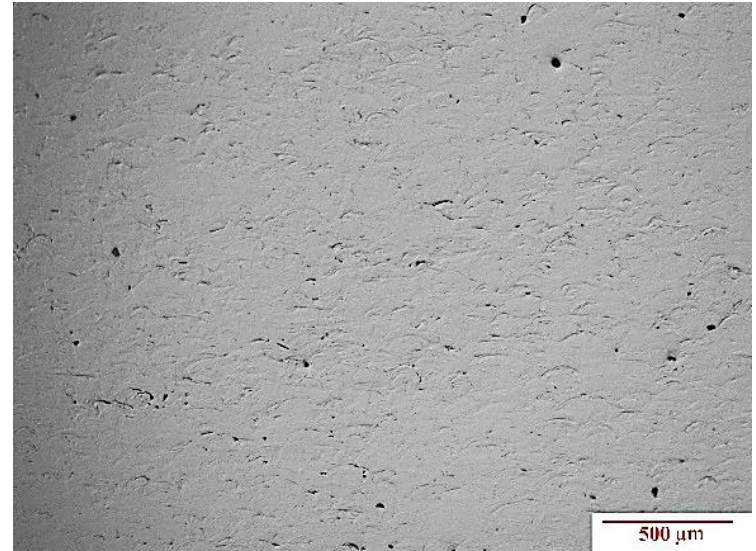

(a)

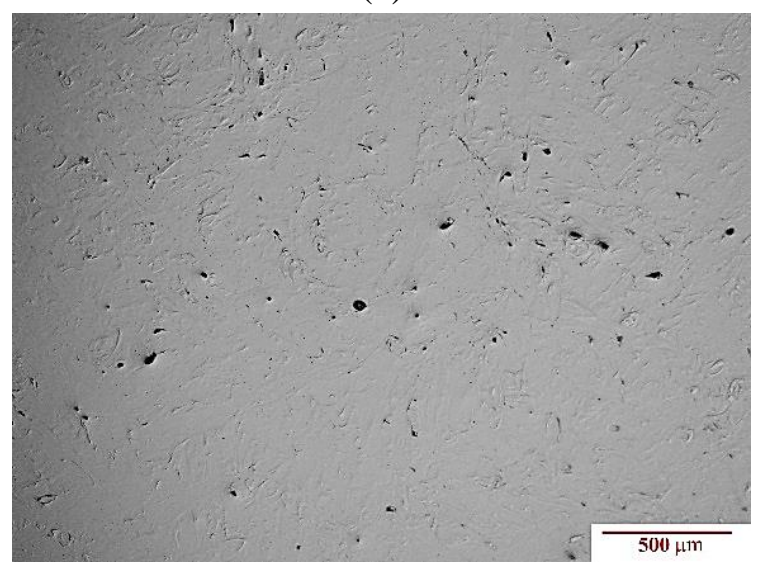

(c)

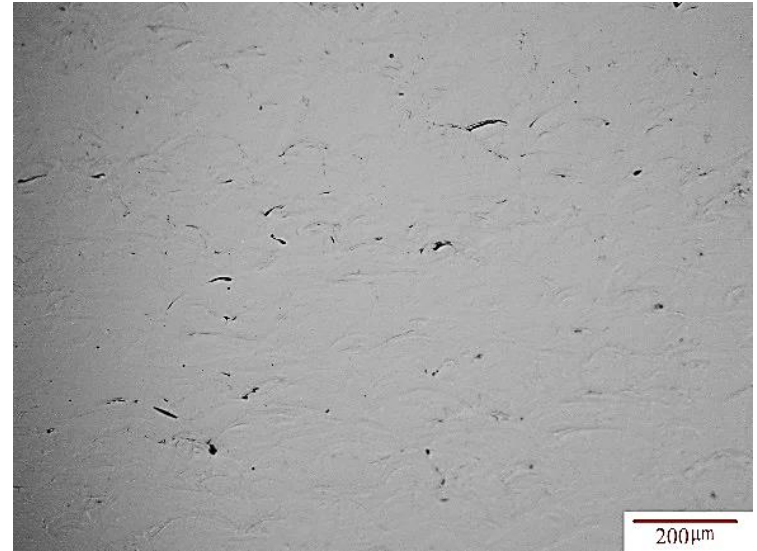

(b)

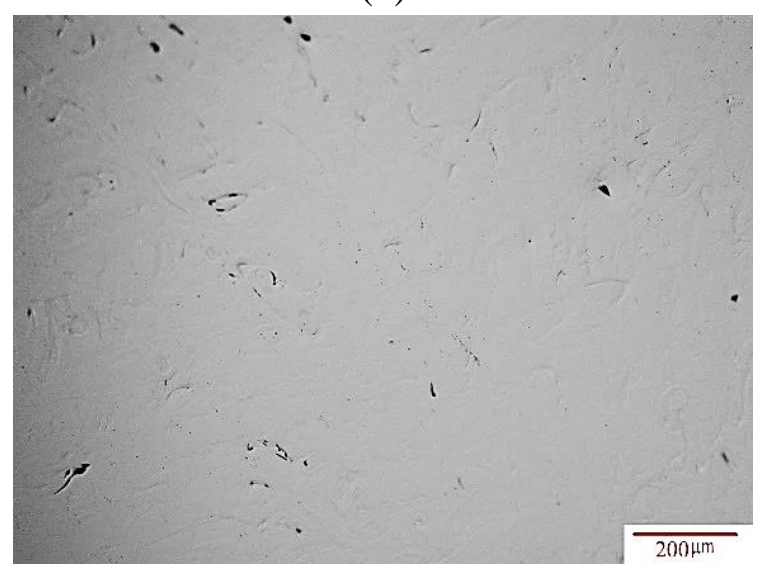

(d)

Figura 64 - Imagens de MO da amostra SLM após polimento químico final, a) e b) seção horizontal da amostra (aumentos de respectivamente 50x e 100x), c) e d) seção vertical da amostra (aumentos de respectivamente 50x e 100x). Polimento químico final: 90\% sílica coloidal e $10 \% \mathrm{HCl}$.

Na Figura 65 observa-se uma microestrutura homogênea e característica do processo de consolidação por SLM, representado pelo formato típico do processo de fusão pelo feixe laser, representado por uma morfologia ligeiramente elíptica. A microestrutura observada nas amostras está de acordo com a descrita por autores na literatura (HAAN et al., 2015; RIVERA et al., 2011; XIN et al., 2012). 
A relação entre as microestruturas de cada seção de corte indica a estratégia de escaneamento utilizado na consolidação da amostra (seção horizontal) e a sobreposição das camadas de consolidação da amostra (destacada pela seta preta - seção vertical). Na seção horizontal (Figura 65a e b) tem-se a visão de topo da fusão seletiva a laser. Verifica-se que a estratégia de escaneamento utilizada na consolidação das amostras, a cada camada, alterna o sentido de escaneamento e há uma distância entre as linhas de escaneamento (hachuras). Observa-se que não há sopreposição de escaneamento entre as linhas. Na seção vertical (Figura 65c e d) evidencia-se a formação de camada a camada pela ação do feixe laser e verifica-se a penetração da fusão entre as camadas.

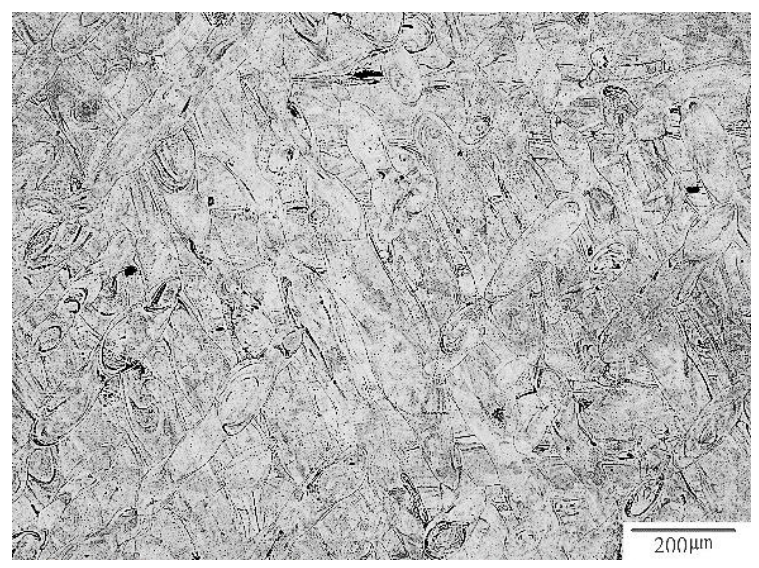

(a)

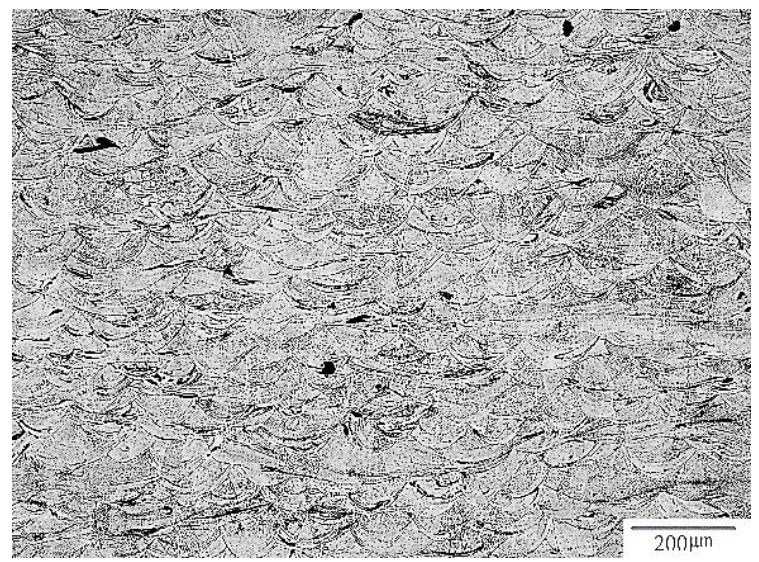

(c)

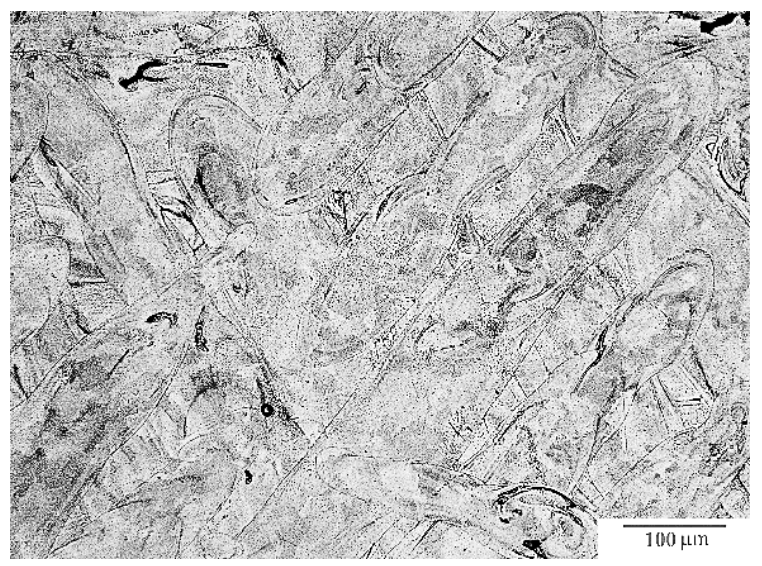

(b)

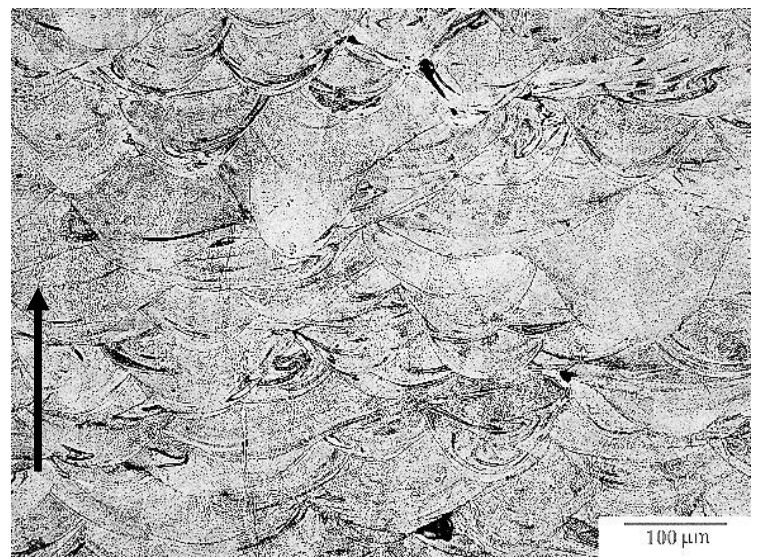

(d)

Figura 65 - Imagens de MO da amostra SLM após ataque químico, a) e b) seção horizontal (aumentos de respectivamente 100x e 200x), c) e d) seção vertical - sentido de consolidação destacado pela seta preta (aumentos de respectivamente 100x e 200x). Ataque químico: $\mathrm{HCl}$ e $\mathrm{H}_{2} \mathrm{O}_{2}$.

Na Figura 66 observa-se a análise de medição da microestrutura originária do processo SLM. Conforme descrito anteriormente, na seção transversal verifica-se o diâmetro da fusão proveniente do diâmetro do feixe laser que se estabelece em uma faixa 
de aproximadamente 80 a $120 \mu \mathrm{m}$ (vide Figura 66a). Na Figura 66b verifica-se que a espessura de penetração do feixe em relação a camada é de aproximadamente 50 a $70 \mu \mathrm{m}$.

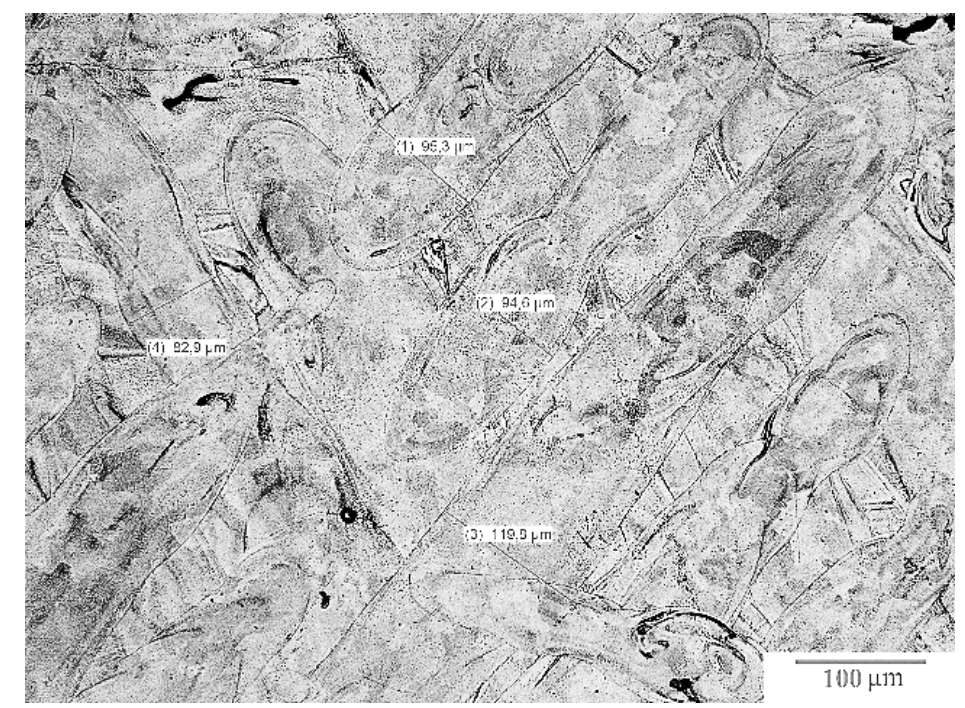

(a)

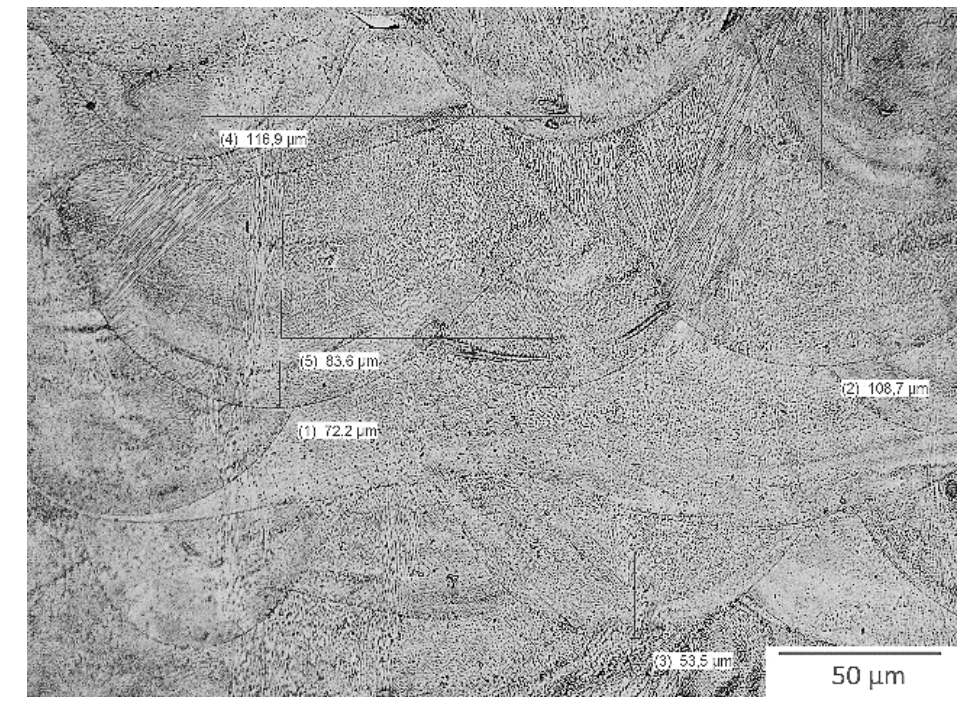

(b)

Figura 66 - Análise das imagens de MO da amostra SLM, em a) seção horizontal e b)

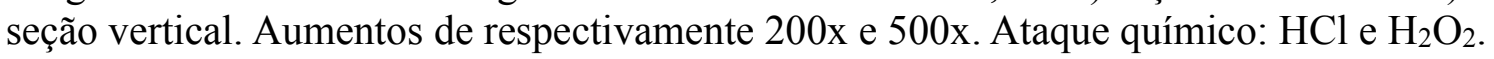

\subsubsection{Caracterização das amostras SLM por MEV}

Na Figura 67 observam-se as amostras consolidadas por SLM analisadas por MEV-EDS. Como analisado na microscopia óptica, a incidência do feixe laser resulta na estrutura de geometria elipsoide (destacado pelas setas nas imagens). Esta configuração típica do feixe laser é descrita por diversos autores (BARUCCA et al., 2015; GIRARDIN et al., 2016; STAWARCZYK et al., 2014; TAKAICHI et al., 2013). Em aumentos superiores observa-se que a microestrutura do SLM é homogênea e não há presença de 
fases segregadas, como observado nas amostras FP. A técnica de SLM proporciona a formação de uma microestrutura de grãos ultrafinos no interior de cada geometria elipsoide, formada pela fusão do material particulado (provocada pela ação do feixe laser).

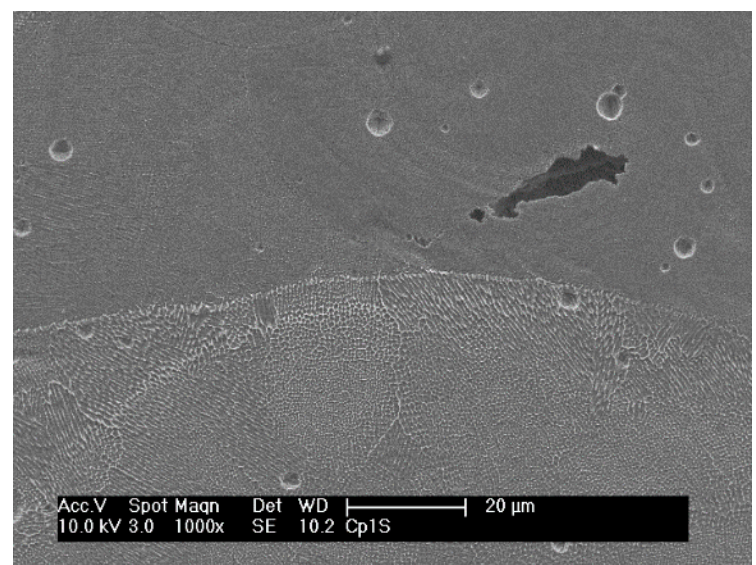

(a)

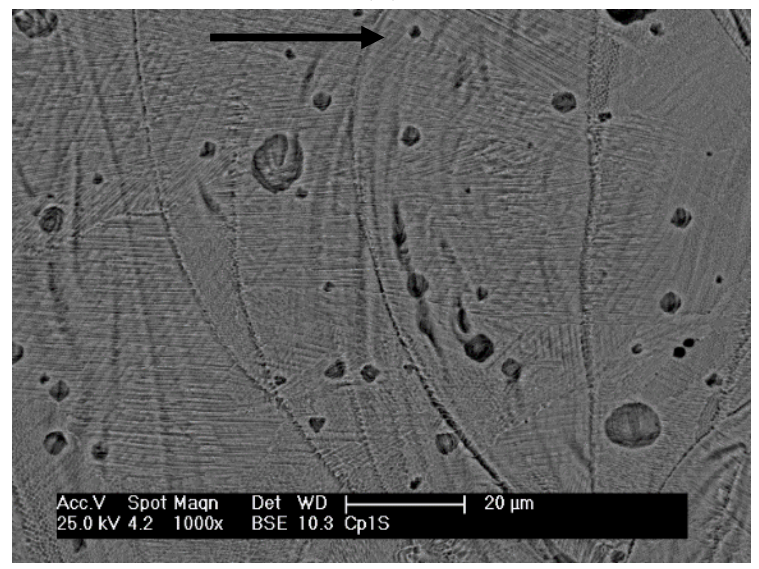

(c)

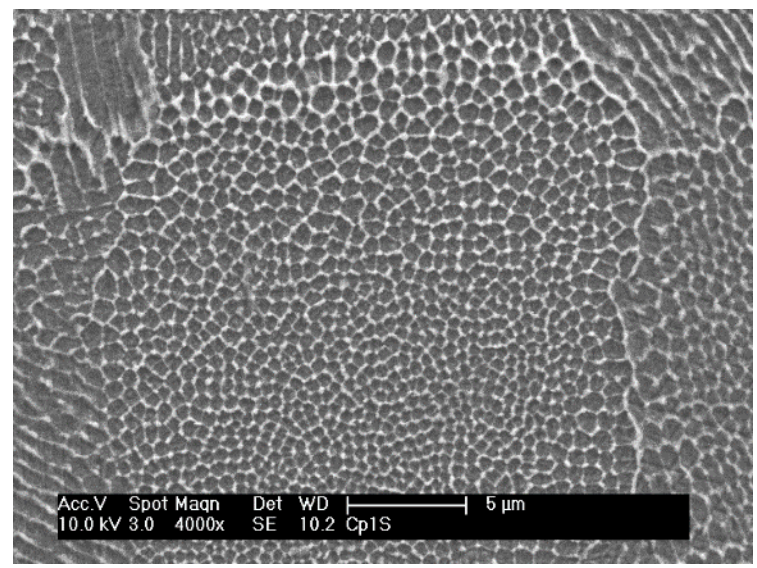

(b)

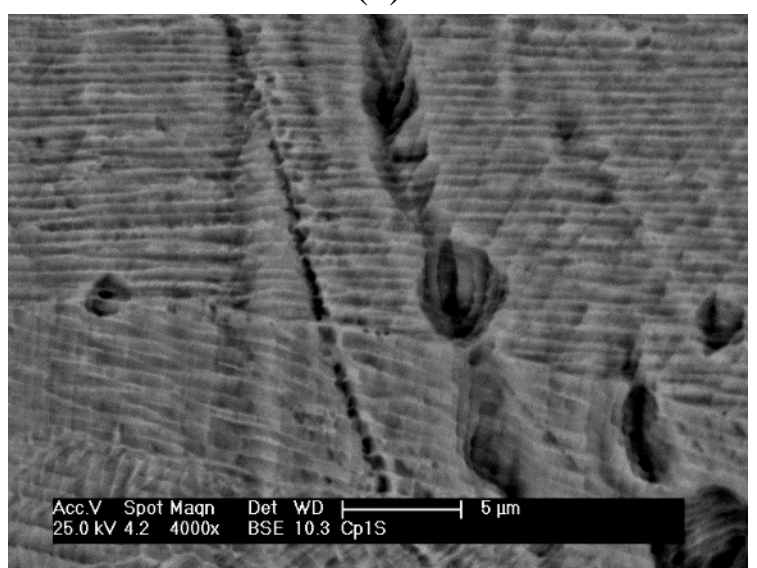

(d)

Figura 67 - Imagens de MEV da amostra SLM após ataque químico, a) e b) imagens por elétrons secundários (SE) da seção horizontal (aumentos de respectivamente 1000x e 4000x), c) e d) imagens por elétrons retroespalhados (BSE) da seção vertical - seta preta no sentido de consolidação (aumentos de respectivamente 1000x e 4000x). Ataque químico:

$\mathrm{HCl}$ e $\mathrm{H}_{2} \mathrm{O}_{2}$.

Para avaliar a composição química na estrutura apresentada, realizou-se uma análise química (resultado semiquantitativo, por meio do EDS), como se observa na Figura 68. Por meio dos pontos 1 (Figura 68a) e 2 (Figura 68b) avaliou-se o espectrograma da região clara e escura da estrutura de grãos ultrafinos. Não houve diferença significativa das composições química nas regiões analisadas e verifica-se que a fusão a laser auxilia na formação de regiões com elevada homogeneidade química. Como, também propicia a formação de uma matriz com contornos de grãos mais finos. A microestrutura homogênea formada na amostra SLM está relacionada com o aumento de resistência mecânica. 


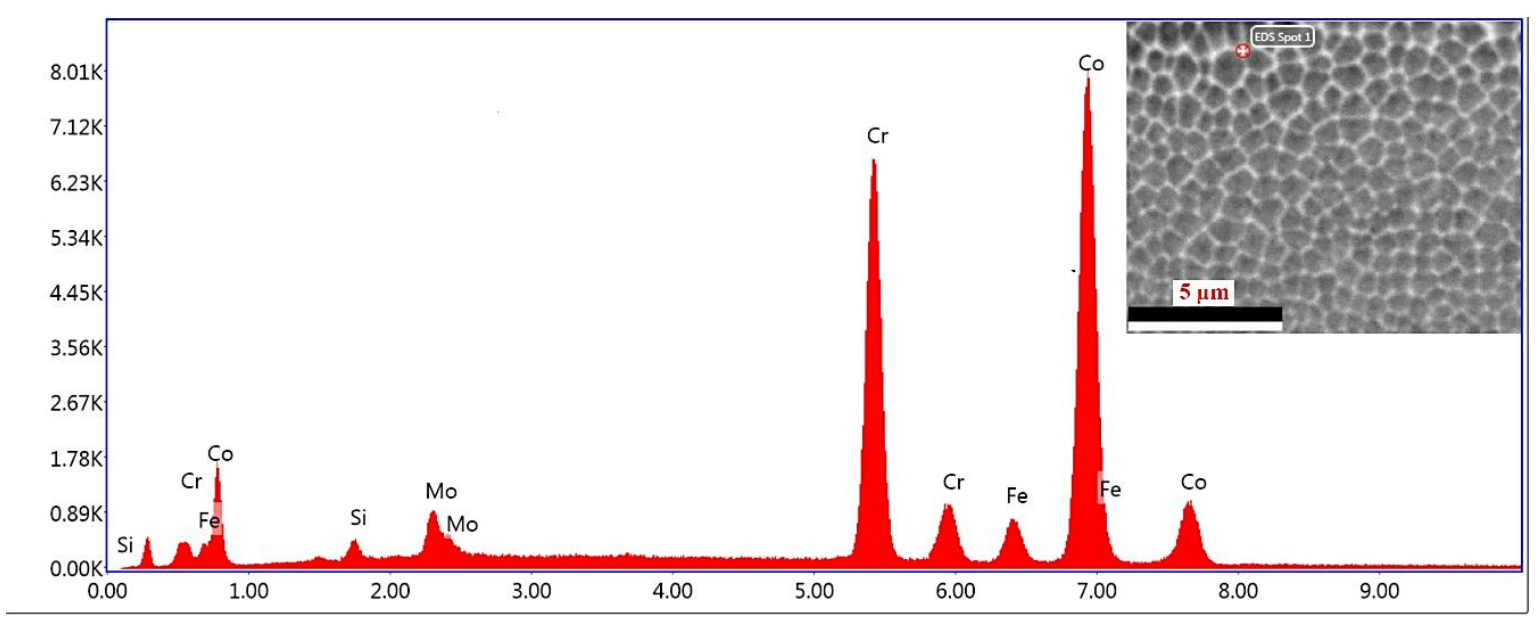

Lsec: 30.00 Cnts $0.000 \mathrm{keV}$ Det: Apollo X-SDD Det

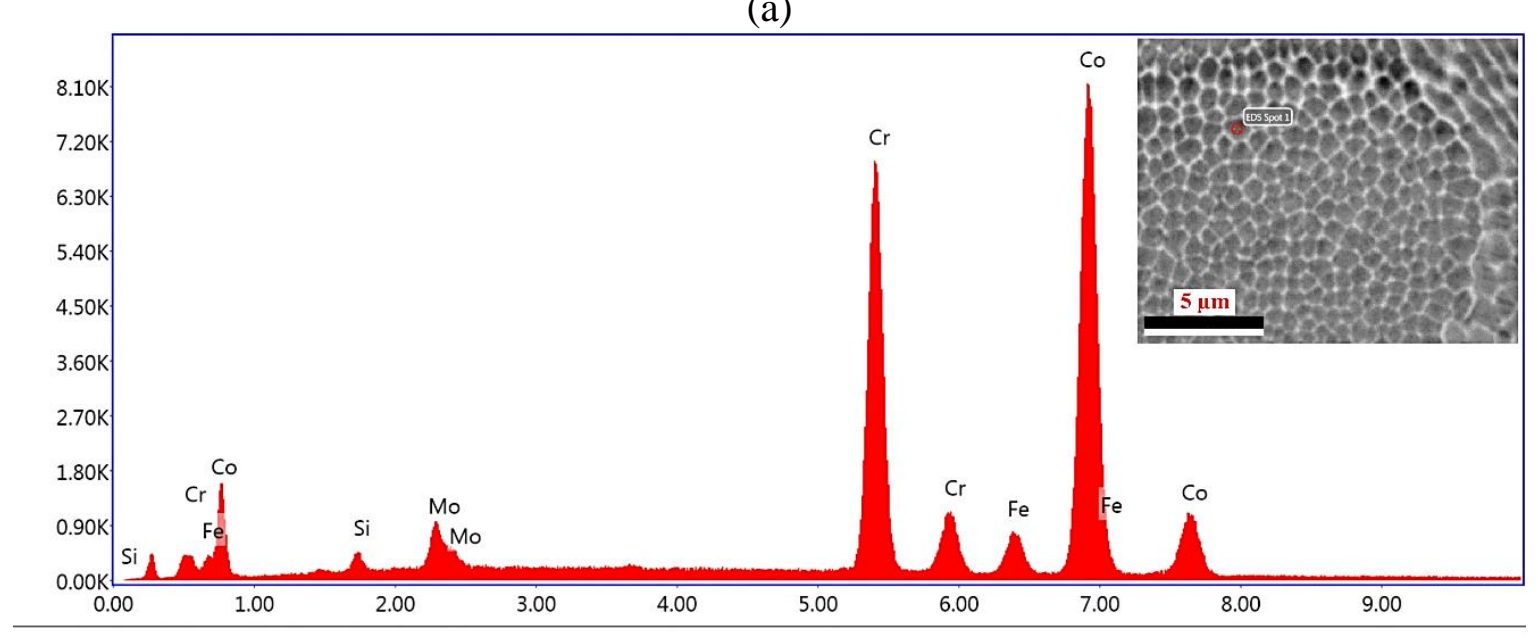

Lsec: 30.00 Cnts $0.000 \mathrm{keV}$ Det: Apollo X-SDD Det

(b)

Figura 68 - Espectrogramas da amostra SLM em a) ponto claro e b) ponto escuro.

Segundo Takaichi et al. (2013), análises por meio de EDS foram realizadas nas regiões: contornos de grãos, centro dos grãos e em possíveis regiões que poderiam conter precipitados (alocados nos contornos de grãos). Os resultados apontaram que a presença de Cr e Mo é superior no contorno, em relação ao centro de grão. E o precipitado apresentou índices mais elevados de $\mathrm{Cr}$ e Mo em relação ao contorno de grão, correspondendo a precipitados.

De acordo com Qian et al. (2015), por meio de microscopia eletrônica de transmissão (MET acoplado com EDS), os contornos de grãos apresentaram elementos de Cr e Mo (em maior porcentagem que a composição interna do grão), porém não apresentou carbonetos ou precipitado nos contornos de grãos.

Devido à magnitude da microestrutura formada nas amostras consolidadas por SLM, foram obtidas imagens por meio de MEV-FEG (proporcionando análise microestrutural com maiores aumentos - vide Figura 69). Como nas imagens obtidas por 
MO (vide Figura 65) e MEV (vide Figura 67), a análise microestrutural por meio do FEG, evidenciou a homogeneidade da microestrutura sem a presença de fases segregadas e com a presença de grãos ultrafinos (em ambas seções de análise). Esta é característica da rápida solidificação do processo SLM. Observa-se na Figura 69c (seção transversal - por elétrons secundários - COMPO) e na Figura 69e (seção longitudinal - por elétrons retroespalhados LEI), os contornos de grão em diferentes magnitudes. O tamanho dos grãos é influenciado pela consecutiva fusão a laser em cada camada consolidada. Conforme abordado na revisão bibliográfica (CHIVEL, 2013) a temperatura elevada do feixe laser e a rápida solidificação do processo configuram a microestrutura do consolidado.

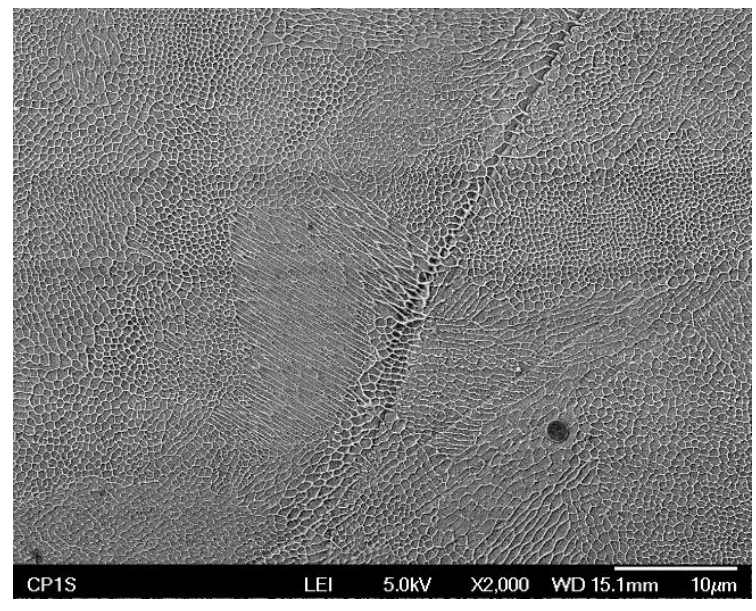

(a)

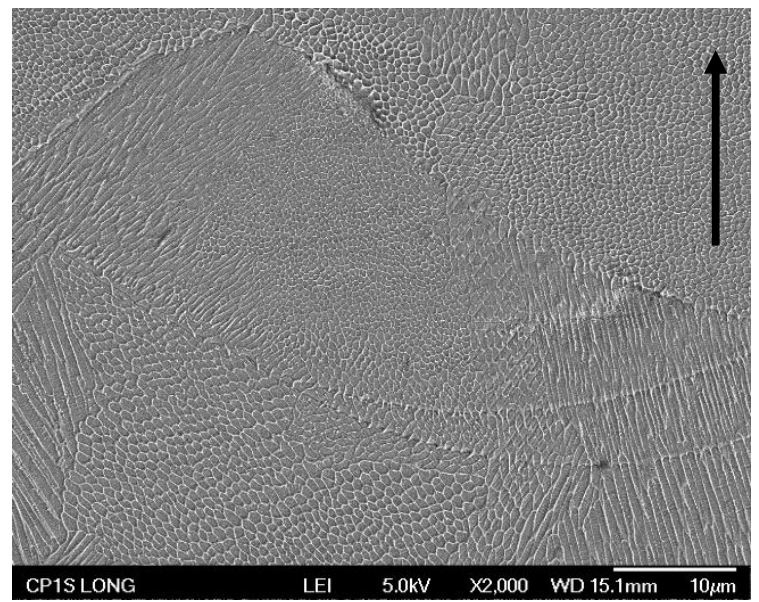

(c)

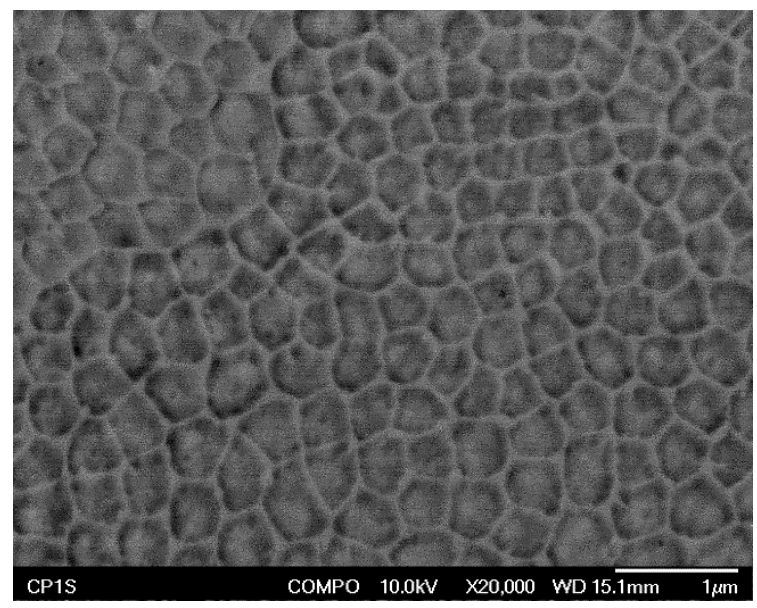

(b)

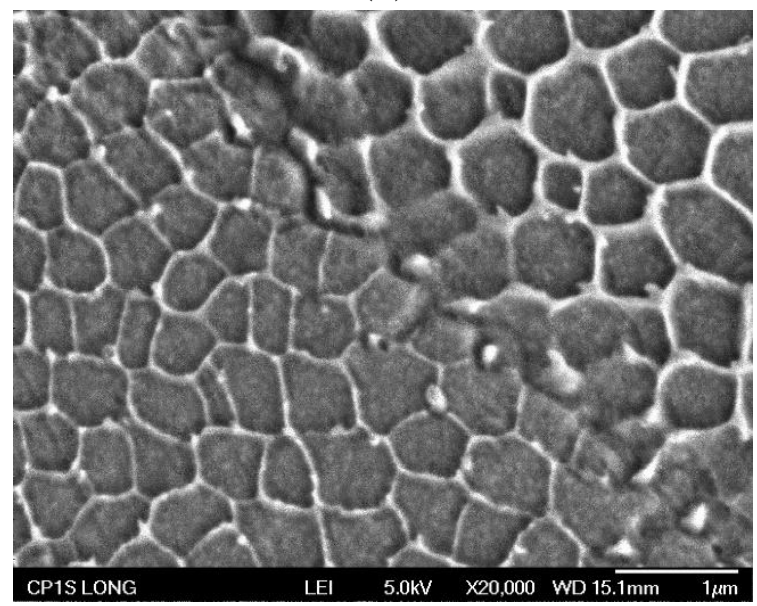

(d)

Figura 69 - Imagens obtidas por meio do MEV-FEG das amostras SLM, em a) seção horizontal a partir de elétrons retroespalhados e b) a partir de elétrons secundários, c) e d) seção vertical a partir de elétrons retroespalhados (seta preta indica o sentido de consolidação). Ataque químico: $\mathrm{HCl}$ e $\mathrm{H}_{2} \mathrm{O}_{2}$.

A proposta de obter resultados de análise química semiquantitativa com maior precisão (por meio do EDS acoplado ao MEV-FEG) em relação a análise anterior (vide 
Figura 68) não foi alcançada. Para tanto em trabalhos futuros pretende-se realizar outras técnicas de análise (microscopia de transmissão eletrônica e microssonda - WDS) para obter uma semiquantificação precisa dos pontos de interesse.

\subsubsection{Análise de fratura}

As fraturas das amostras (FP e SLM) de tração são apresentadas na Figura 70. O estudo inicial do modo de fratura é verificado pelo formato de separação (ruptura) da amostra após a fratura. Neste caso, tem-se a formação ou não da estricção (conhecido por taça-cone) dependendo da resistência adquirida do material, caracterizando uma fratura frágil ou dúctil, respectivamente. Verifica-se que as amostras apresentam uma característica de fratura frágil, ocorrendo transversal ao eixo da tensão de tração.

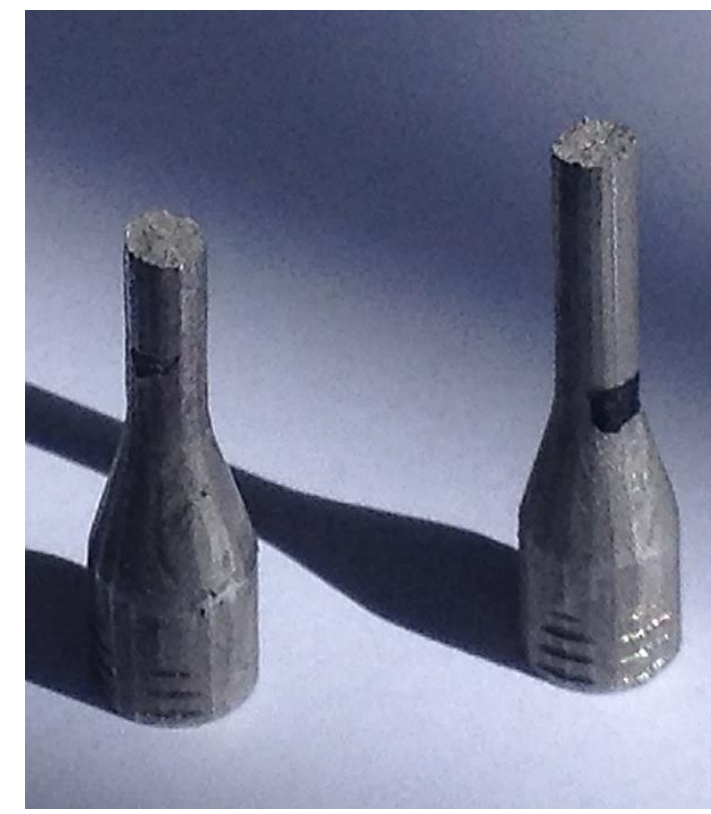

(a)

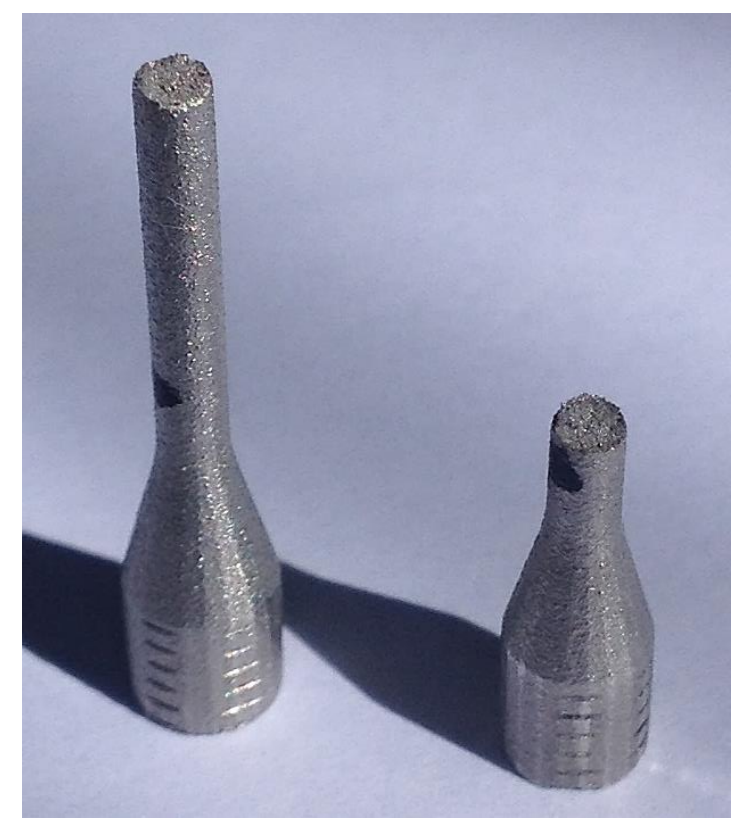

(b)

Figura 70 - Representação da fratura das amostras consolidadas, em a) amostra FP e b) amostra SLM.

Nas imagens obtidas por meio do MEV (vide Figura 71) são reveladas a formação de fratura frágil ocorrendo em um plano perpendicular em ambas amostras (FP Figura 71a e b e SLM - Figura 71c e d). Verifica-se que a fratura da amostra FP indica maior formação de uma fratura por clivagem, em relação a amostra SLM. Segundo Le et al. (2011), o processo de clivagem em uma liga de Co-Cr-Mo-N se desenvolve entre os contornos de grão e é induzido pela tensão e formação de martensita $(\varepsilon-\mathrm{HC})$. 


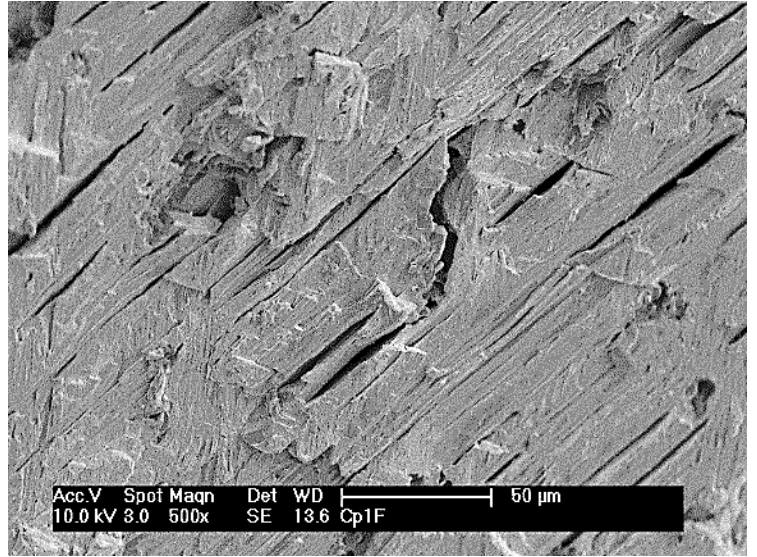

(a)

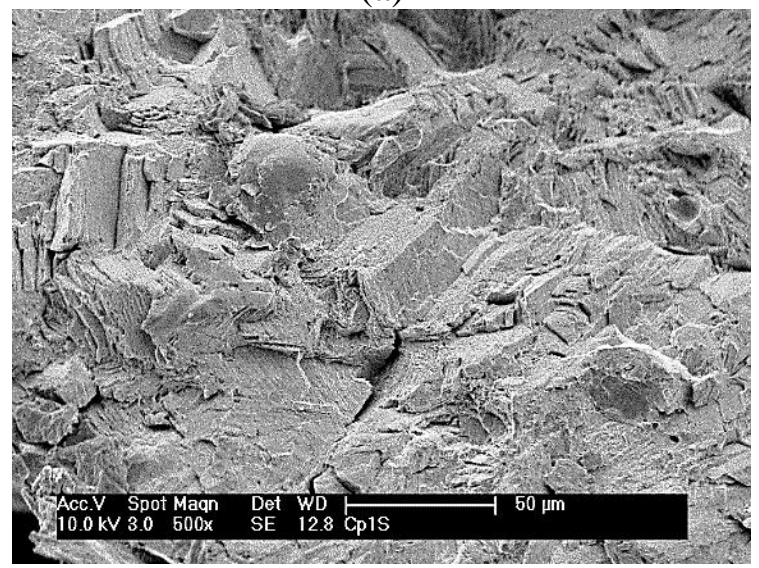

(c)

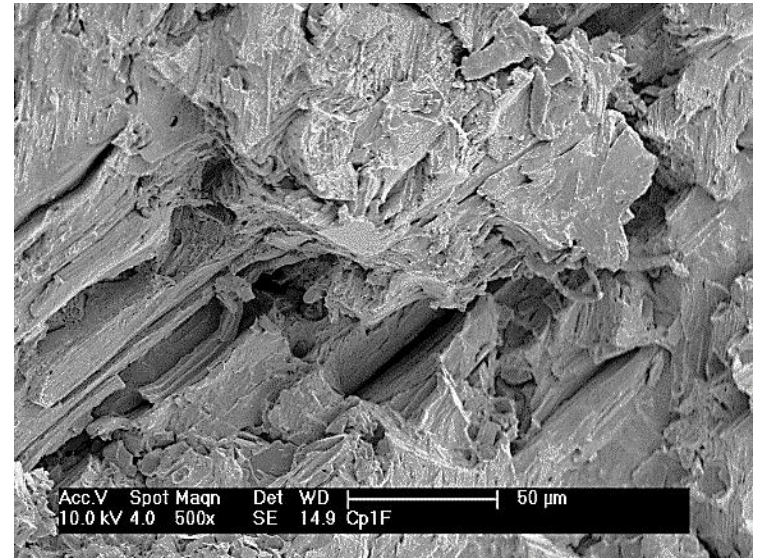

(b)

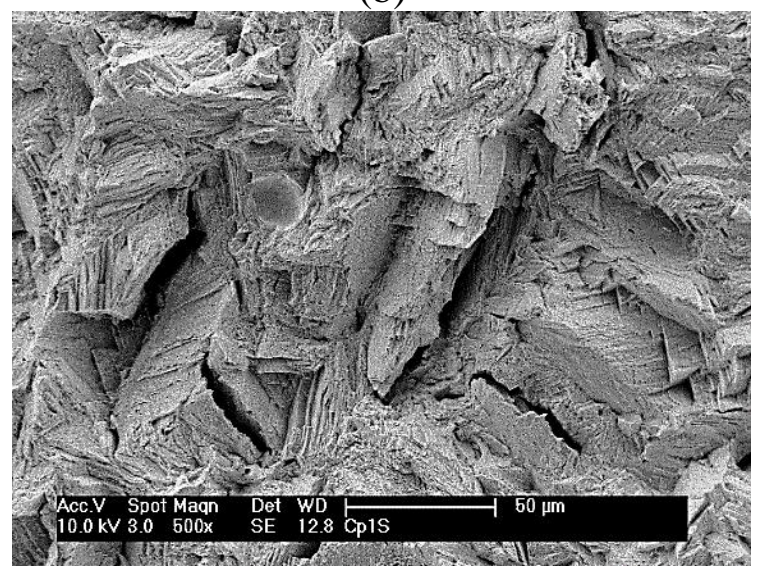

(d)

Figura 71 - Imagens de MEV das fraturas dos corpos de prova de tração, em a) e b) regiões da fratura da amostra FP, c) e d) regiões da fratura da amostra SLM. Aumentos de 500x.

Na Figura 72 analisam-se as fraturas em maior magnitude e percebe-se a formação de "dimples" (morfologia de alvéolos). A presença de dimples representa uma região de maior ductilidade e tenacidade. Na amostra SLM é visível que a formação de dimples se estende completamente pelos planos da fratura e que estes são menores (mais finos) e homogeneamente distribuídos na microestrutura de fratura, quando comparados à fratura da amostra FP. Em oposição a amostra FP evidencia-se regiões de fratura geometricamente maiores e observa-se a presença de regiões planares lisas (indicadas pelas setas brancas), caracterizando estes planos como clivagem.

A formação de dimples, mais finos, é característica de uma fratura mais dúctil e, por consequência, apresenta propriedades mecânicas e tenacidade mais elevada, assim como na amostra SLM (conforme os resultados apresentados, vide Figura 44 e Tabela 21). Segundo Takaichi et al. (2013), o tipo de fratura observado nas amostras é descrito pela formação de dimples ao longo da superfície de fratura e apresenta fissuras do tipo cunha. Esta observação é analisada na Figura 72a e c, na qual se aponta uma possível formação de fratura por clivagem ao longo de famílias de planos favoráveis. 


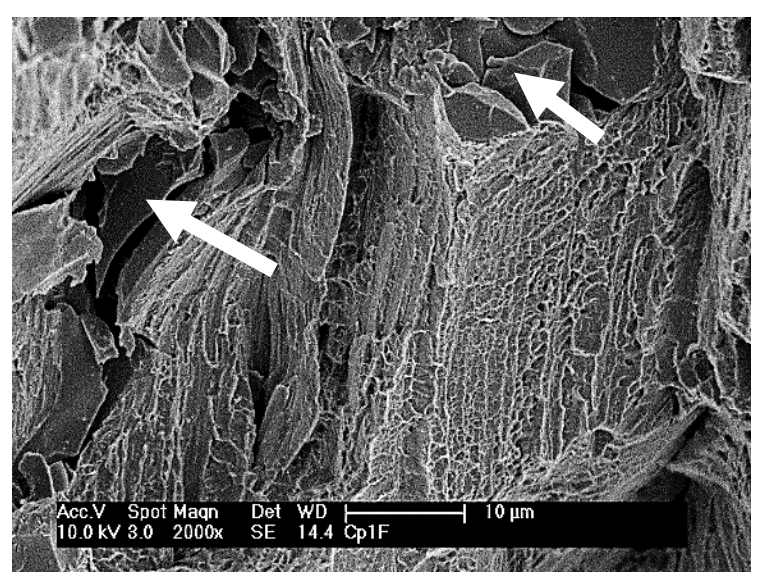

(a)

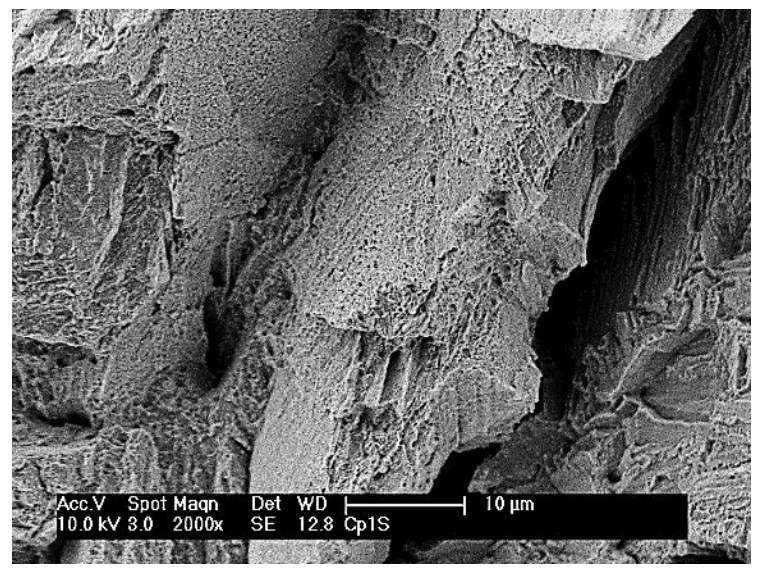

(c)

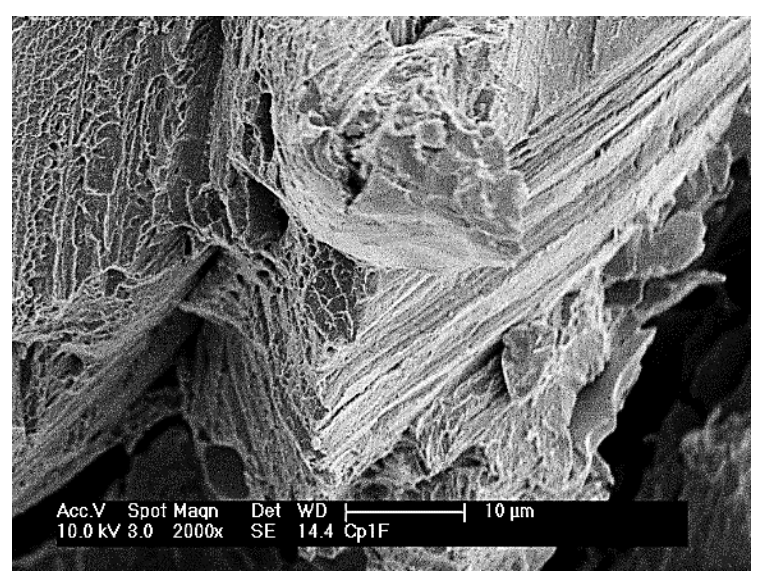

(b)

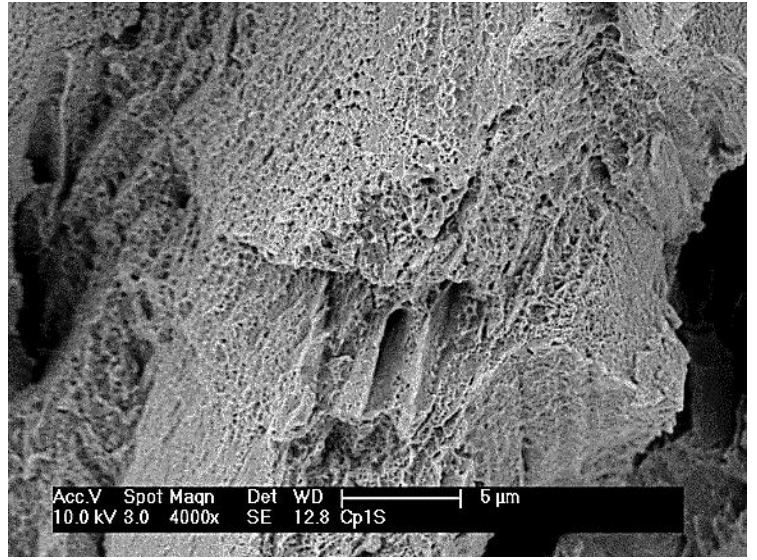

(d)

Figura 72 - Imagens de MEV das fraturas dos corpos de prova de tração, em a) e b) regiões da fratura da amostra FP (aumentos de 2000x), c) e d) regiões da fratura da amostra SLM (aumentos de respectivamente 2000x e 4000x).

Evidencia-se que o processo de consolidação das amostras influência o modo de fratura da liga de Co-Cr-Mo. Esta análise é confirmada pela correlação da microestrutura obtida com os processos de fabricação. Esta premissa pode ser comprovada por apresentar porosidade, segregação de fases com durezas distintas nas amostras processadas por FP em relação à SLM. A microestrutura de grãos ultrafinos (adquirida pela rápida solidificação do processo SLM) proporcionou a restrição da propagação de fissuras, trincas e movimentação dos planos atômicos da liga que incrementaram as propriedades mecânicas. Recorda-se que, o resultado das propriedades mecânicas obtido nos ensaios de tração das amostras evidenciou uma elevada tensão máxima ( $\sigma \mathrm{LR})$ para a amostra SLM em relação a amostra FP, respectivamente de 1136,95 \pm 0,92 $\mathrm{MPa}$ e de 771,70 \pm 103,32 $\mathrm{MPa}$. No entanto, ambos os processamentos, evidenciaram que a liga de Co-Cr-Mo obteve um comportamento dúctil pelo alongamento obtido $(E l=13,73 \pm 5,32 \%$ para a amostra SLM e $E l=14,20 \pm 2,76 \%$ para a amostra FP). 


\section{CONCLUSÕES}

As conclusões obtidas deste trabalho são:

- Verificou-se que o pó D2, na faixa granulométrica de 20 a 50 micras, obteve os melhores resultados de escoabilidade e empacotamento. Tomando-se por base os dados da literatura afirma-se que a utilização da faixa granulométrica unimodal se estabelece entre 15 a 60 micras.

- O processo de atomização a gás produz partículas com incidência de satélites e porosidade interna (neste estudo em até 1,3\% de porosidade), o que pode acarretar em porosidade interna em componentes customizados comprometendo o processo de manufatura aditiva.

- O estudo comparativo das densidades (teórica, volumétrica e por picnometria He) entre as amostras consolidadas, evidenciaram maior quantidade de poros nas amostras FP. O processo de SLM propiciou a consolidação de componentes com densificação superior ao processo convencional de FP, 98,20\% e 97,86\% de densidade, respectivamente.

- O ensaio de citotoxicidade realizado nos consolidados (amostras FP e SLM) de Co-Cr-Mo não comprometeram a biocompatibilidade.

- A técnica de SLM propiciou a obtenção de propriedades mecânicas superiores à técnica de FP. Neste caso, os limites de: escoamento, resistência e fratura nas amostras SLM foram superiores aos obtidos nas amostras FP (11,6\%, 32,0\% e 34,0\% respectivamente). Em relação ao alongamento e ao módulo de elasticidade os resultados foram similares.

- O valor de macrodureza Vickers foi 20,2\% superior no processo de SLM quando comparado as amostras consolidadas por FP. Em relação as seções de corte (horizontal e vertical) das amostras SLM e FP o resultado foi superior em 6,5\% e $8,0 \%$ respectivamente.

- Na caracterização microestrutural das amostras SLM observou-se a obtenção de uma microestrutura de maior homogeneidade química e a formação de grãos ultrafinos. A microestrutura obtida pelo processo de FP evidenciou uma estrutura bruta de fusão e estruturas de solidificações dendríticas (com segregações de fases 
interdendríticas apresentando carbonetos $\mathrm{M}_{23} \mathrm{C}_{6}$, ricos em $\mathrm{Cr}$ e Mo). Nos testes de microdureza Vickers os carbonetos apresentaram uma dureza 50\% superior que a matriz.

- A análise térmica de DSC e TMA evidenciou os picos dos fenômenos das transições de fases da liga de Co-Cr-Mo. Conforme resultado dos difratogramas de DRX das amostras consolidadas, correlacionam-se as fases presentes com a caracterização microestrutural.

De modo geral, o processamento usando a SLM mostrou-se uma técnica de processamento superior à FP. Os fatores determinantes para tal foram: propriedades mecânicas requeridas pelas normas ASTM F75 e ISO 22674 atingidas pelo processamento SLM; obtenção de um desvio padrão inferior ao processamento convencional de FP; as caracterizações microestruturais evidenciaram uma homogeneidade química, sem presença de segregações de fases para o processamento SLM, diferentemente do processo FP. Desta forma, a tecnologia de SLM é um processo da área de MA que se destaca na fabricação de próteses odontológicas. 


\section{TRABALHOS FUTUROS}

Propõe-se realizar trabalhos futuros envolvendo a realização de testes e análises complementares, como:

- Análise, determinação de porosidade e de tamanho de poros por meio da técnica de microtomografia computadorizada (MicroCT);

- Análises composicionais, quantitativas e qualitativas por dispersão de energia (EDS) e de comprimento de onda (WDS) das amostras consolidadas pela técnica SLM por meio de um equipamento de microssonda eletrônica e a caracterização microestrutural por meio de microscopia eletrônica de transmissão (MET);

- Análise da orientação e crescimento dos grãos no processo de consolidação SLM e a correlação com a mecânica de fratura dos espécimes.

- Avaliação microestrutural e mecânica de amostras consolidadas por SLM após tratamentos térmicos. 


\section{REFERÊNCIAS BIBLIOGRÁFICAS}

AHMED, R. et al. Structure-property relationships in a CoCrMo alloy at micro and nano-scales. Tribology International, v. 80, p. 98-114, 2014.

ALIAKBARI, M. Additive Manufacturing: State-of-the-Art, Capabilities, and Sample Applications with Cost Analysis. Dissertação (Mestrado) - School of Industrial Engineering and Management (ITM), 2012 .

ASM INTERNACIONAL. Powder Metal Technologies and Applications. In: ASM Handbook. 9th. ed. ASM Internacional, v. 7, 1998.

ASM INTERNACIONAL. Casting. In: ASM Handbook. 9th. ed. ASM Internacional, v. 15, 2008.

ASM INTERNACIONAL. ASM Specialty Handbook: Nickel, Cobalt, and Their Alloys. 1st. ed. ASM Internacional, 2000.

ASSIS, G. M. DE et al. Auxílio da prototipagem na reconstrução mandibular: caso clínico. Revista de Cirurgia e Traumatologia Buco-maxilo-facial, v. 10, n. 3, p. 013-018, 2010.

AMERICAN SOCIETY FOR TESTING AND MATERIALS (ASTM). Standard Test Method for Transverse Rupture Strength of Powder Metallurgy (PM) Specimens. Pensilvânia: ASTM, 2012a. (ASTM B528).

AMERICAN SOCIETY FOR TESTING AND MATERIALS (ASTM). Standard Specification for Cobalt28 Chromium-6 Molybdenum Alloy Castings and Casting Alloy for Surgical Implants. Pensilvânia: ASTM, 2012b. (ASTM F75).

AMERICAN SOCIETY FOR TESTING AND MATERIALS (ASTM).ASTM INTERNATIONAL. Standard Test Method for Knoop and Vickers Hardness of Materials. Pensilvânia: ASTM, 2012c. (ASTM E384).

AMERICAN SOCIETY FOR TESTING AND MATERIALS (ASTM).ASTM INTERNATIONAL. Standard Test Methods for Flow Rate of Metal Powders Using the Hall Flowmeter Funnel. Pensilvânia: ASTM, 2013a. (ASTM B213).

AMERICAN SOCIETY FOR TESTING AND MATERIALS (ASTM).ASTM INTERNATIONAL. Standard Test Method for Apparent Density of Free-Flowing Metal Powders Using the Hall Flowmeter Funnel. Pensilvânia: ASTM, 2013b. (ASTM B212).

AMERICAN SOCIETY FOR TESTING AND MATERIALS (ASTM).ASTM INTERNATIONAL. Standard Test Method for Determination of Tap Density of Metal Powders and Compounds. Pensilvânia: ASTM, 2014. (ASTM B527).

AMERICAN SOCIETY FOR TESTING AND MATERIALS (ASTM). Standard Test Methods for Tension Testing of Metallic Materials. Pensilvânia: ASTM, 2015. (ASTM E8/E8M).

BAMMANI, S. S. A.; BIRAJDARB, P. R.; METANC, S. S. Dental Crown Manufacturing using Stereolithography Method. Proc. of Int. Conf. on Advances in Industrial and Production Engineering. p. 7-10, 2012.

BARTOLO, P. et al. Biomedical production of implants by additive electro-chemical and physical processes. CIRP Annals - Manufacturing Technology, v. 61, n. 2, p. 635-655, 2012.

BARUCCA, G. et al. Structural characterization of biomedical Co-Cr-Mo components produced by direct metal laser sintering. Materials Science and Engineering: C, v. 48, p. 263-269, 2015. 
BILGIN, M. S. et al. Comparison of fracture resistance between cast, CAD/CAM milling, and direct metal laser sintering metal post systems. Journal of Prosthodontic Research, v. 60, n. 1, p. 23-28, 2016.

BORELLI, V. Pesquisa e desenvolvimento de biomateriais: estudo das inter-relações científicas, tecnológicas e normativas. Dissertação (Mestrado) - São Paulo: Instituto de Pesquisas Energéticas e Nucleares, 2011.

BREMEN, S.; MEINERS, W.; DIATLOV, A. Selective Laser Melting: A manufacturing technology for the future? Laser Technik Journal, v. 9, n. 2, p. 33-38, 2012.

CALIGNANO, F. et al. Overview on Additive Manufacturing Technologies. Proceedings of the IEEE, p. 120, 2017.

CALLISTER, W. D.; RETHWISCH, D. G. Materials Science and Engineering - An Introduction. 8. ed. [s.l.] John Wiley \& Sons Inc., 2010.

CANCIGLIERI, O. J.; SELHORST, A. J.; IAROZINSKI, A. N. Análise comparativa entre os processos de prototipagem rápida por deposição ou remoção de material na concepção de novos produtos. In: XXVII ENCONTRO NACIONAL DE ENGENHARIA DE PRODUÇÃO. Foz do Iguaçu: 2007. Disponível em: <http://www.abepro.org.br/biblioteca/ENEGEP2007_TR610459_0570.pdf>. Acesso em: 4 jan. 2014.

CHALMERS, B. Principles of Solidification. New York: John Willey Co., 1964.

CHEN, Q.; THOUAS, G. A. Metallic implant biomaterials. Materials Science and Engineering: R: Reports, v. 87, p. 1-57, 2015.

CHENG, B.; SHRESTHA, S.; CHOU, K. Stress and deformation evaluations of scanning strategy effect in selective laser melting. Additive Manufacturing, v. 12, p 240-251, 2016.

CHIAVERINI, V. Metalurgia do Pó. São Paulo: Associação Brasileira de Metalurgia e Materiais, 2001.

CHIVEL, Y. Optical In-Process Temperature Monitoring of Selective Laser Melting. Physics Procedia, v. 41, p. 904-910, 2013.

CRAIG, R. G. Craig's Restorative Dental Materials. 13. ed. [s.1.] Elsevier/ Mosby, 2012.

DADBAKHSH, S. et al. Texture and anisotropy in selective laser melting of NiTi alloy. Materials Science and Engineering: A, v. 650, p. 225-232, 2016.

DONI, Z. et al. Dry sliding and tribocorrosion behaviour of hot pressed CoCrMo biomedical alloy as compared with the cast CoCrMo and Ti6Al4V alloys. Materials \& Design, v. 52, p. 47-57, 2013.

DOURANDISH, M. et al. Sintering of biocompatible P/M Co-Cr-Mo alloy (F-75) for fabrication of porosity-graded composite structures. Materials Science and Engineering: A, v. 472, n. 1-2, p. 338-346, 2008.

EOS GMBH. BEGO USA Decides for EOS Technology to Bite Big into Changing U.S. Dental Restoration Market. Disponível em: <https://www.eos.info/press/customer_case_studies/bego>. Acesso em: 4 jan. 2014.

FACCHINI, L. Microstructure and mechanical properties of biomedical alloys produced by Rapid Manufacturing techniques. Tese (Doutorado) - Italy: University of Trento, 2010.

FAIDEL, D. et al. Investigation of the selective laser melting process with molybdenum powder. Additive Manufacturing, v. 8, p. 88-94, 2015.

FAZIRA, M. F. et al. Low Strain Rate Upset Forging of Preformed CoCrMo Powder Alloy for Load Bearing Application: A Review. Procedia Engineering, v. 68, p. 405-410, 2013. 
Foggiatto, J. A. Tecnologia \& Humanismo. O Uso Da Prototipagem Rápida Na Área MédicoOdontológica, v. 1, p. 60-68, 2006.

GAYTAN, S. M. et al. Advanced metal powder based manufacturing of complex components by electron beam melting. Materials Technology, v. 24, n. 3, p. 180-190, 2009.

GEDDES, B.; LEON, H.; HUANG, X. Superalloys: Alloying and Performance. 1. ed. [s.1.] ASM Internacional, 2010.

GERMAN, R. M. Powder Metallurgy Science. 2. ed. Princeton: Metal Powder Industry Federation, 1994.

GERMAN, R. M. Powder Metallurgy of Iron and Steel. 1. ed. New York: John Wiley \& Sons Inc., 1998.

GERMANOVIX, A. A. Establishing a benchmark part to analyze the capabilities of selective laser melting systems. Trabalho de Conclusão de Curso (TCC) - Santa Catarina: Universidade Federal de Santa Catarina, 2011.

GESSINGER, G. H. Powder Metallurgy of Superalloys. Baden, Switzerland: Butterworth \& Co., 1984.

GIACCHI, J. V. et al. Microstructural characterization of as-cast biocompatible Co-Cr-Mo alloys. Materials Characterization, v. 62, n. 1, p. 53-61, 2011.

GIACCHI, J. V.; FORNARO, O.; PALACIO, H. Microstructural evolution during solution treatment of CoCr-Mo-C biocompatible alloys. Materials Characterization, v. 68, p. 49-57, 2012.

GIBSON, I. Advanced Manufacturing Technology for Medical Applications: Reverse Engineering, Software Conversion and Rapid Prototyping. [s.1.] Wiley, 2005.

GIRARDIN, E. et al. Biomedical Co-Cr-Mo Components Produced by Direct Metal Laser Sintering1. Materials Today: Proceedings, v. 3, n. 3, p. 889-897, 2016.

GOUVEIA, M. F. Aplicação da Prototipagem Rápida no Planejamento de Cirurgias Craniofaciais. Tese (Doutorado) - Campinas: Universidade Estadual de Campinas (UNICAMP), 2009.

GRZESIAK, D.; KRAWCZYK, M. Effects of the Selective Laser Melting Process Parameters on the Functional Properties of the $\mathrm{Co}-\mathrm{Cr}$ Alloy. International Journal of Recent Contributions from Engineering, Science \& IT (iJES), v. 3, n. 1, p. 39-42, 2015.

GU, D. D. et al. Laser additive manufacturing of metallic components: materials, processes and mechanisms. International Materials Reviews, v. 57, n. 3, p. 133-164, 2012.

GUPTA, K. P. The Co-Cr-Mo (Cobalt-Chromium-Molybdenum) System. Journal of Phase Equilibria and Diffusion, v. 26, n. 1, p. 87-92, 2005.

HAAN, J. et al. Effect of subsequent Hot Isostatic Pressing on mechanical properties of ASTM F75 alloy produced by Selective Laser Melting. Powder Metallurgy, v. 58, n. 3, p. 161-165, 2015.

HARRIS, I. D. Additive Manufacturing: A Transformational Advanced Manufacturing Technology. Advanced Materials \& Processes (ASM INTERNATIONAL, 2000), v. 170, n. 5, p. 25-29, 2012.

HEDBERG, Y. S. et al. In vitro biocompatibility of CoCrMo dental alloys fabricated by selective laser melting. Dental Materials, v. 30, n. 5, p. 525-534, 2014.

HENRIQUES, B.; SOARES, D.; SILVA, F. S. Microstructure, hardness, corrosion resistance and porcelain shear bond strength comparison between cast and hot pressed CoCrMo alloy for metal-ceramic dental restorations. Journal of the Mechanical Behavior of Biomedical Materials, v. 12, p. 83-92, 2012.

ISHIDA, K.; NISHIZAWA, T. The Co-Cr (Cobalt-Chromium) system. Bulletin of Alloy Phase Diagrams, v. 11, n. 4, p. 357-370, 1990. 
INTERNATIONAL ORGANIZATION FOR STANDARDIZATION (ISO). Biological Evaluation of Medical Devices - Part 5: Tests for Cytotoxicity: in vitro methods. Geneva: ISO, 2010. (ISO 10933-5).

INTERNATIONAL ORGANIZATION FOR STANDARDIZATION (ISO). Metallic materials Instrumented indentation test for hardness and materials parameters - Part 1: Test method. Geneva: ISO, 2002. (ISO 14577-1).

INTERNATIONAL ORGANIZATION FOR STANDARDIZATION (ISO). Dentistry - Metallic materials for fixed and removable restorations and appliances. Geneva: ISO, 2006. (ISO 22674).

INTERNATIONAL ORGANIZATION FOR STANDARDIZATION (ISO). Standard Terminology for Additive Manufacturing - General Principles - Terminology. Geneva: ISO, 2015. (ISO/ ASTM 52900).

IVANOVA, E. P.; BAZAKA, K.; CRAWFORD, R. J. Cytotoxicity and biocompatibility of metallic biomaterials. In: New Functional Biomaterials for Medicine and Healthcare. [s.1.] Elsevier, 2014. p. 148172 .

JABBARI, Y. S. A. et al. Metallurgical and interfacial characterization of PFM Co-Cr dental alloys fabricated via casting, milling or selective laser melting. Dental Materials, v. 30, n. 4, p. 79-88, 2014.

KADLEC, J.; ONDERKA, F. Microstructural characterization, chemical composition and hardness of as-cast biocompatible CoCrMo alloy. Littera Scripta, v. 6, n. 2, 2013.

KAISER, R. et al. The influence of cooling conditions on grain size, secondary phase precipitates and mechanical properties of biomedical alloy specimens produced by investment casting. Journal of the Mechanical Behavior of Biomedical Materials, v. 24, p. 53-63, 2013.

KAJIMA, Y. et al. Fatigue strength of $\mathrm{Co}-\mathrm{Cr}-\mathrm{Mo}$ alloy clasps prepared by selective laser melting. Journal of the Mechanical Behavior of Biomedical Materials, v. 59, p. 446-458, 2016.

KALE, P. J.; METKAR, R. M.; HIWASE, S. D. Development and Optimization of Dental Crown Using Rapid Prototyping Integrated with CAD. In: WIMPENNY, D. I.; PANDEY, P. M.; KUMAR, L. J. (Eds.). Advances in 3D Printing \& Additive Manufacturing Technologies. Singapore: Springer, 2017. p. 169182.

KANE, L. M. et al. Marginal and internal adaptation of milled cobalt-chromium copings. The Journal of Prosthetic Dentistry, v. 114, n. 5, p. 680-685, 2015.

KIM, E.-H. et al. A microcomputed tomography evaluation of the marginal fit of cobalt-chromium alloy copings fabricated by new manufacturing techniques and alloy systems. The Journal of Prosthetic Dentistry, v. 117 (3), p. 393-399, 2016 a.

KIM, H. R. et al. Comparison of in vitro biocompatibility of a Co-Cr dental alloy produced by new milling/post-sintering or traditional casting technique. Materials Letters, v. 178, p. 300-303, 2016 b.

KRUTH, J.-P. et al. Consolidation phenomena in laser and powder-bed based layered manufacturing. Annals of the CIRP, v. 56 (2), p. 730-759, 2007.

KURTZ, S. Projections of Primary and Revision Hip and Knee Arthroplasty in the United States from 2005 to 2030. The Journal of Bone and Joint Surgery (American), v. 89, n. 4, p. 780, 2007.

KURZYNOWSKI, T. et al. Parameters in selective laser melting for processing metallic powders. Advances in Slow and Fast Light V, v. 8239, 2012

LAWley, A. Atomization The Production of Metal Powders. Princeton: Metal Powder Industry Federation, v. 1, 1992.

LEÃO, S. M. et al. Análise comparativa da desadaptação marginal de prótese parcial fixa sobre implantes com liga de Co-Cr e titânio já unidos por soldagem a laser, antes e após aplicação de porcelana. Innov Implant J, v. 5, n. 2, p. 9-13, 2010. 
LEE, B. S.; MATSUMOTO, H.; CHIBA, A. Fractures in tensile deformation of biomedical Co-Cr-Mo-N alloys. Materials Letters, v. 65, n. 5, p. 843-846, 2011.

LIU, R. et al. Investigation of solidification behavior and associate microstructures of $\mathrm{Co}-\mathrm{Cr}-\mathrm{W}$ and $\mathrm{Co}-\mathrm{Cr}-$ Mo alloy systems using DSC technique. Journal of Materials Science, v. 45, n. 22, p. 6225-6234, 2010.

LIVERANI, E. et al. Fabrication of Co-Cr-Mo endoprosthetic ankle devices by means of Selective Laser Melting (SLM). Materials \& Design, v. 106, p. 60-68, 2016.

LU, Y. et al. Investigation on the microstructure, mechanical property and corrosion behavior of the selective laser melted CoCrW alloy for dental application. Materials Science and Engineering: C, v. 49, p. 517-525, 2015.

LUCCHETTI, M. C. et al. Cobalt-chromium alloys in dentistry: An evaluation of metal ion release. Journal of Prosthetic Dentistry, v. 114, n. 4, p. 602-608, 2015.

MANÇANARES, C. G. Modelo de processo de avaliação para adoção de manufatura aditiva na indústria de alto valor agregado. Dissertação (Mestrado) - São Paulo: Universidade de São Paulo, 2016.

MARTÍNEZ, R. et al. In vitro bioactivity and biocompatibility of a Co-Cr-Mo alloy after heat treatment in contact with different bioactive systems. Ceramics International, v. 39, n. 2, p. 2003-2011, 2013.

MAS-AYU, H. et al. Influence of Carbon Concentrations in Reducing Co and Cr Ions Release in Cobalt Based Implant: A Preliminary Report. Advanced Materials Research, v. 845, p. 462-466, 2013.

MASSALSKI, T. B. et al. Binary Alloy Phase Diagrams. 2. ed. [s.1.] ASM Internacional, 1990.

MCCABE, J. F.; WALLS, A. W. G. Applied Dental Materials. 9. ed. [s.1.] Blackwell Publishing Ltd., 2008.

MEINERS, W. Selective Laser Melting: Generative Fertigung fur die Produktion der Zukunft. Optische Technologien in der Produktionstechnik, 2012.

MELCHELS, F. P. W.; FEIJEN, J.; GRIJPMA, D. W. A review on stereolithography and its applications in biomedical engineering. Biomaterials, v. 31, n. 24, p. 6121-6130, 2010.

MENGUCCI, P. et al. Effects of thermal treatments on microstructure and mechanical properties of a Co$\mathrm{Cr}-\mathrm{Mo}-\mathrm{W}$ biomedical alloy produced by laser sintering. Journal of the Mechanical Behavior of Biomedical Materials, v. 60, p. 106-117, 2016.

MERCK GROUP. Merck KGaA. Disponível em: <http://pse.merck.de/merck.php>. Acesso em: 3 ago. 2015.

MERGulhão, M. V.; PODESTÁ, C. E.; NEVES, M. D. M. DAS. Mechanical Properties and Microstructural Characterization of Cobalt-Chromium $(\mathrm{CoCr})$ Sintered Obtained by Casting and Selective Laser Sintering (SLS). . In: PTECH 2015 - TENTH INTERNATIONAL LATIN AMERICAN CONFERENCE ON POWDER TECHNOLOGY. Mangaratiba - RJ: 2015a

MERGUlhão, M. V.; PODESTÁ, C. E.; NEVES, M. D. M. DAS. Evaluation of Mechanical Properties and Microstructural Characterization of ASTM F75 CoCrMoFe Alloy Obtained by Selective Laser Sintering (SLS) and Casting Techniques. . In: PTECH 2015 - TENTH INTERNATIONAL LATIN AMERICAN CONFERENCE ON POWDER TECHNOLOGY. Mangaratiba - RJ: 2015b

MINISTÉRIO DA SAÚDE. SB Brasil 2015: Pesquisa Estadual de Saúde Bucal: Relatório Final / Ministério da Saúde. Secretaria de Atenção à Saúde. Secretaria de Vigilância em Saúde. Brasília: Ministério da Saúde, 2016.

MISCH, C. E. Dental implant prothetics. 2. ed. [s.1.] Elsevier, 2015. 
MORI, M.; YAMANAKA, K.; CHIBA, A. Phase decomposition in biomedical Co-29Cr-6Mo-0.2N alloy during isothermal heat treatment at 1073 K. Journal of Alloys and Compounds, v. 590, p. 411-416, 2014.

MOTHÉ, C. G.; AZEVEDO, A. D. D. Análise Térmica de materiais. São Paulo: Artliber, 2009.

NARUSHIMA, T. et al. Precipitates in Biomedical Co-Cr alloys. Precipitates in Biomedical Co-Cr alloys, v. 65, n. 4, p. 489-504, 2013.

NEUPE UFPR. Anatomia dos dentes. Disponível em: <http://www.nuepe.ufpr.br/blog/?page_id=4524>. Acesso em: 7 nov. 2016.

NEVES, M. D. M. DAS. Sinterização de Misturas de Pós de Ligas de Ferro para Aplicações Automotivas. Tese (Doutorado) - São Paulo: Instituto de Pesquisas Energéticas e Nucleares, 2005.

NIINOMI, M.; NARUSHIMA, T.; NAKAI, M. (EDS.). Advances in Metallic Biomaterials. Berlin, Heidelberg: Springer Berlin Heidelberg, 2015. v. 3

NISHIZAWA, T.; ISHIDA, K. The Co (Cobalt) System. Bulletin of Alloy Phase Diagrams, v. 4, n. 4, p. 387-390, 1983.

OLAKANMI, E. O.; COCHRANE, R. F.; DALGARNO, K. W. A review on selective laser sintering/melting (SLS/SLM) of aluminium alloy powders: Processing, microstructure, and properties. Progress in Materials Science, v. 74, p. 401-477, 2015.

ORÉFICE, R. L.; PEREIRA, M. D. M.; MANSUR, H. S. Biomateriais: Fundamentos \& Aplicações. Rio de Janeiro: Cultura Médica, 2006.

ÖRTORP, A. et al. The fit of cobalt-chromium three-unit fixed dental prostheses fabricated with four different techniques: A comparative in vitro study. Dental Materials, v. 27, n. 4, p. 356-363, 2011.

OYAGÜE, R. C. et al. Evaluation of fit of cement-retained implant-supported 3-unit structures fabricated with direct metal laser sintering and vacuum casting techniques. Odontology, v. 100, n. 2, p. 249-253, 2012.

ÖZCAN, M.; HÄMMERLE, C. Titanium as a Reconstruction and Implant Material in Dentistry: Advantages and Pitfalls. Materials, v. 5, n. 12, p. 1528-1545, 2012.

PODESTÁ, C. E.; MERGulhão, M. V.; NEVES, M. D. M. DAS. Comparative Study of Mechanical Properties Between Casting and Selective Laser Sintering (SLS) in Cobalt-Chromium Alloys. . In: POWDERMET2015, THE INTERNATIONAL CONFERENCE ON POWDER METALLURGY \& PARTICULATE MATERIALS. San Diego: 2015

QIAN, B. et al. Defects-tolerant Co-Cr-Mo dental alloys prepared by selective laser melting. Dental Materials, v. 31, n. 12, p. 1435-1444, 2015.

QIN, L. et al. Influence of surface wettability on the tribological properties of laser textured Co-Cr-Mo alloy in aqueous bovine serum albumin solution. Applied Surface Science, v. 268, p. 79-86, 2013.

RAMÍREZ, L. . et al. Precipitation path of secondary phases during solidification of the $\mathrm{Co}-25.5 \% \mathrm{Cr}-$ 5.5\% Mo-0.26\% C alloy. Scripta Materialia, v. 47, n. 12, p. 811-816, 2002.

RAMÍREZ-VIDAURRI, L. E. et al. Cooling rate and carbon content effect on the fraction of secondary phases precipitate in as-cast microstructure of ASTM F75 alloy. Journal of Materials Processing Technology, v. 209, n. 4, p. 1681-1687, 2009.

RATNER, B. D. et al. Biomaterials Science: An Introduction to Materials in Medicine. 2nd. ed. [s.1.] Academic Press, 2004. 
REN, F.; ZHU, W.; CHU, K. Fabrication, tribological and corrosion behaviors of ultra-fine grained Co28Cr-6Mo alloy for biomedical applications. Journal of the Mechanical Behavior of Biomedical Materials, v. 60, p. 139-147, 2016.

REN, L. et al. A novel coping metal material $\mathrm{CoCrCu}$ alloy fabricated by selective laser melting with antimicrobial and antibiofilm properties. Materials Science and Engineering: C, v. 67, p. 461-467, 2016.

RIVERA, S. et al. Development of dense and cellular solids in CrCoMo alloy for orthopaedic applications. Procedia Engineering, v. 10, p. 2979-2987, 2011.

ROACH, M. Base Metal Alloys Used for Dental Restorations and Implants. Dental Clinics of North America, Dental Materials. v. 51, n. 3, p. 603-627, jul. 2007.

SALLICA-LEVA, E.; JARDINI, A. L.; FOGAGNOLO, J. B. Microstructure and mechanical behavior of porous $\mathrm{Ti}-6 \mathrm{Al}-4 \mathrm{~V}$ parts obtained by selective laser melting. Journal of the Mechanical Behavior of Biomedical Materials, v. 26, p. 98-108, 2013.

SANTOS, L. A. Processamento e caracterização da liga 66Co-28Cr-6Mo (\% peso) para implantes. Dissertação (Mestrado). Escola de Engenharia de Lorena: Universidade de São Paulo, 2012.

SCHAFFER, G. et al. The effect of the atmosphere and the role of pore filling on the sintering of aluminium. Acta Materialia, v. 54 (1), p. 131-138, 2005.

SHAH, P.; RACASAN, R.; BILLS, P. Comparison of different additive manufacturing methods using computed tomography. Case Studies in Nondestructive Testing and Evaluation, v. 6, p. 69-78, 2016.

SHIOMI, M. et al. Residual Stress within Metallic Model Made by Selective Laser Melting Process. CIRP Annals - Manufacturing Technology, v. 53, n. 1, p. 195-198, 2004.

SIMCHI, A.; POHL, H. Effects of laser sintering processing parameters on the microstructure and densification of iron powder. Materials Science and Engineering: A, v. 359, n. 1-2, p. 119-128, 2003.

SINGH, S.; RAMAKRISHNA, S.; SINGH, R. Material issues in additive manufacturing: A review. Journal of Manufacturing Processes, v. 25, p. 185-200, 2017.

SLOTWINSKI, J. A. et al. Characterization of Metal Powders Used for Additive Manufacturing. Journal of Research of the National Institute of Standards and Technology, v. 119, p. 460, 2014.

SONG, B. et al. Differences in microstructure and properties between selective laser melting and traditional manufacturing for fabrication of metal parts: A review. Frontiers of Mechanical Engineering, v. 10, n. 2, p. $111-125,2015$.

SONG, C. et al. Development of athermal and isothermale-martensite in atomized Co-Cr-Mo-C implant alloy powders. Metallurgical and Materials Transactions A, v. 37, n. 11, p. 3197-3204, 2006.

STAWARCZYK, B. et al. A Novel CAD/CAM Base Metal Compared to Conventional CoCrMo Alloys: An in-vitro Study of the Long-term Metal-ceramic Bond Strength. Oral Health and Dental Management, v. 13, n. 2, p. 446-452, 2014.

SUN, J.; YANG, Y.; WANG, D. Mechanical properties of a Ti6Al4V porous structure produced by selective laser melting. Materials \& Design, v. 49, p. 545-552, 2013.

TAKAICHI, A. et al. Microstructures and mechanical properties of Co-29Cr-6Mo alloy fabricated by selective laser melting process for dental applications. Journal of the Mechanical Behavior of Biomedical Materials, v. 21, p. 67-76, 2013.

TANG, H. P. et al. Effect of Powder Reuse Times on Additive Manufacturing of Ti-6Al-4V by Selective Electron Beam Melting. JOM, v. 67, n. 3, p. 555-563, 2015. 
TESSARE, J. R. Prototipagem rápida no planejamento e redução do tempo de cirurgia de implantes com carga imediata: relato de caso clínico. RBP: Rev. Bras. Implantod. Prót. s/ Impl, 2006.

THEMES, U. F. O. Esthetics and Implant Prosthetics | Pocket Dentistry, 2017. Disponível em: <http://pocketdentistry.com/esthetics-and-implant-prosthetics/>. Acesso em: 5 jan. 2017

UTELA, B. et al. A review of process development steps for new material systems in three dimensional printing (3DP). Journal of Manufacturing Processes, v. 10, n. 2, p. 96-104, 2008.

VAN NOORT, R. The future of dental devices is digital. Dental Materials: Official Publication of the Academy of Dental Materials, v. 28, n. 1, p. 3-12, 2012.

VISWANATHAN, S. S.; HAN-CHEOL, C. Electrochemical behavior of $\mathrm{Co}-\mathrm{Cr}$ and $\mathrm{Ni}-\mathrm{Cr}$ dental cast alloys. Trans. Nonferrous Met. Soc. China, v. 19, p. 785-790, 2009.

VOLPATO, N. Prototipagem Rápida: Tecnologias e Aplicações. Brasil: Blucher, 2007.

VOORT, G. F. V. Metallography, Principles and Practice. [s.1.] ASM INTERNATIONAL 2000, 1984.

WATAHA, J. C. Biocompatibility of dental casting alloys: A review. Journal of Prosthetic Dentistry, v. 83 , n. 2, p. 223-234, 2000.

WILLIAMS, D. F. On the mechanisms of biocompatibility. Biomaterials, v. 29, n. 20, p. 2941-2953, 2008.

XIN, X. Z. et al. In vitro biocompatibility of $\mathrm{Co}-\mathrm{Cr}$ alloy fabricated by selective laser melting or traditional casting techniques. Materials Letters, v. 88, p. 101-103, 2012.

YAMANAKA, K.; MORI, M.; CHIBA, A. Assessment of precipitation behavior in dental castings of a CoCr-Mo alloy. Journal of the Mechanical Behavior of Biomedical Materials, v. 50, p. 268-276, 2015.

YAMANAKA, K.; MORI, M.; CHIBA, A. Developing high strength and ductility in biomedical Co-Cr cast alloys by simultaneous doping with nitrogen and carbon. Acta Biomaterialia, v. 31, p. 435-447, 2016.

YAN, Y. et al. Tribocorrosion in implants-assessing high carbon and low carbon $\mathrm{Co}-\mathrm{Cr}-\mathrm{Mo}$ alloys by in situ electrochemical measurements. Tribology International, v. 39, n. 12, p. 1509-1517, 2006.

YAP, C. Y. et al. Review of selective laser melting: Materials and applications. Applied Physics Reviews, v. 2 (4), p. 01-21, 2015.

YOSHINARI, M.; UZAWA, S.; KOMIYAMA, Y. Hybrid framework with cobalt-chromium alloy and gold cylinder for implant superstructure: Bond strength and corrosion resistance. Journal of Prosthodontic Research, v. 60 (4), p. 274-281, 2016.

YULE, A. J.; DUNKLEY, J. J. Atomization of Melts. Oxford: Claredon Press, 1994.

ZANGENEH, S.; LASHGARI, H. R.; ROSHANI, A. Microstructure and tribological characteristics of aged Co-28Cr-5Mo-0.3C alloy. Materials \& Design, v. 37, p. 292-303, 2012.

ZHOU, X. et al. 3D-imaging of selective laser melting defects in a Co-Cr-Mo alloy by synchrotron radiation micro-CT. Acta Materialia, v. 98, p. 1-16, 2015. 